\title{
Activation of diboron reagents: The development of mild conditions for the synthesis of unique organoboron compounds
}

\author{
Steven Brandon Thorpe \\ Dissertation submitted to the faculty of the Virginia Polytechnic Institute and State \\ University in partial fulfillment of the requirements for the degree of
}

Doctor of Philosophy

In Chemistry

Webster L. Santos, Chairman

Paul R. Carlier

David G. I. Kingston

James M. Tanko

March 23, 2012

Blacksburg, Virginia

Keywords: borylation, diboron reagent, boronic ester, conjugate addition, copper catalysis

(C) 2012 by Steven B. Thorpe 


\title{
Activation of diboron reagents: The development of mild conditions for the synthesis of unique organoboron compounds
}

\author{
Steven Brandon Thorpe
}

\begin{abstract}
The first successful synthesis and isolation of a boronic acid was reported in 1860 by Frankland in the pursuit of novel organometallic compounds. For more than a century, further studies of boronic acids were sparsely published. Suzuki and Miyaura jumpstarted the field in 1979 with an innovative carbon-carbon bond forming reaction employing an organoboronic acid and a carbon halide under palladium catalysis. Indeed, the Nobel Prize in Chemistry was awarded to Professor Akira Suzuki, along with Professors Richard Heck and Ei-ichi Negishi, in 2010 for their important contributions in palladium-catalyzed cross-coupling chemistry. Over the last 30 years, reports on organoboron compounds have increased exponentially. This dissertation describes the author's contributions to the development of preparative methods for organoboronic acid derivatives using transition metal-catalyzed reactions of diboron reagents.

A unique "mixed" diboron reagent was developed (PDIPA diboron) that contains $s p^{2}$ and $s p^{3}$-hybridized boron atoms, unambiguously confirmed by X-ray crystallography. PDIPA diboron is sufficiently activated internally through a dative-bonding amine to selectively transfer the $s p^{2}$-hybridized boron regioselectively, in the presence of copper, to electron deficient alkenes including $\alpha, \beta$-unsaturated ketones, esters, amides, aldehydes, and nitriles to provide the corresponding boratohomoenolates. A unique $\beta, \beta$-diboration of an $\alpha, \beta$-acetylenic ketone was also discovered.
\end{abstract}


The scope of PDIPA diboron reactions was then expanded to a set of substrates with a more complex structural backbone. Allenoates are $\alpha, \beta, \gamma$-unsaturated esters with orthogonal pi systems, which pose several possible difficulties with the regioselectivity of addition, not to mention known isomerizations catalyzed by copper. However, we successfully installed the boron moiety regioselectively on the $\beta$-carbon of a variety of allenoates, providing a vinyl boronic ester, and also observed exclusive formation of the $(Z)$-isomer from racemic starting materials. The resulting vinyl boronic ester was then shown to be an excellent Suzuki-Miyaura cross-coupling partner, affording a diastereopure, trisubstituted alkene in quantitative yield.

Commercially available bis(pinacolato)diboron has shown remarkable stability towards hydrolysis and autoxidation. Using this reagent, we developed a copper- and amine-catalyzed boration protocol performed entirely in water and open to air. Using only $1 \mathrm{~mol} \%$ copper, extraordinary activity was observed. UV-Vis, ${ }^{11} \mathrm{~B}$ NMR, and solvent kinetic isotope experiments were employed to gain insight into the mechanism, which showed the possibility of autocatalysis. Attempts to control stereoselectivity were not successful, although these results were rationalized by a dynamic catalyst structure. 


\section{Acknowledgements}

First and foremost, I would like to express my sincere gratitude to my advisor, Professor

Webster L. Santos. He has taken a true personal interest in my development into a successful Ph.D. Chemist. Behind the relentless phrase, "so where's my compound?" is a man who has always provided an inspiring environment for me to cultivate a stand-alone method of solving tough chemical problems, while also challenging me to develop and mature into a better person overall. He taught me how to set seemingly unachievable goals for myself and then how to manage my time, resources, and priorities to accomplish them. It is almost impossible to put into words what I have gained the past 5 years, but I know that I could not have achieved any of this without Dr. Santos by my side as both my leader, and my friend.

I would also like to thank my advisory committee; Dr. Paul Carlier, Dr. David Kingston, and Dr. Jim Tanko. You have all made exceptional efforts to ensure that my fundamental techniques are flawless and that my learning is unhindered; teaching me how to understand, embrace and even implement alternative approaches to answering chemical problems. I am very grateful for your patience while I struggled through learning concepts that I am sure seemed elementary to you. Additionally, I would like to thank Dr. Paul Deck for always being eager to advise me on anything I needed. Somehow, he has the answer to every question.

To my friends and colleagues, I would like to say thank you for the vital role you have played in my graduate career. From my first days here, when I was subjected to the rigorous training program of my mentor, Ken Knott, not a day has passed that I have not learned something new. I owe this primarily to the senior members of the Santos group; Ken Knott, Mithun Raje, David Bryson, Jason Crumpton, Mike Perfetti, Dr. Phileppe Bissel and Dr. Ming Gao, who have somehow simultaneously served as my role models, scientific advisors and 
friends. I would also like to recognize two individuals whom I had the pleasure of mentoring and befriending; Xi Guo and Joe Calderone.

Finally, I would like to thank all of my friends and family outside of the lab. You have all been vital in maintaining my sanity throughout grad school by supporting me and encouraging my success. To my parents, Steve and Debbie Thorpe, and grandparents, Chuck and Georgianne Kennedy, I would never have made it this far without you. To my brother, Justin Thorpe and uncle, David Kennedy, you have both been dynamic in my development and some of my fondest memories are with you. To my roommates over the years, thank you for distracting me from work at every opportunity and being the best friends I could ask for. Lastly, I would like to thank Cathy Minichino, who has been my unwavering support through the toughest of times. I look forward to many happy years with you. I love you all. 


\section{Dedication}

To my parents and grandparents.

You have been the most influential people in my life, and I love you. 


\section{Table of contents}

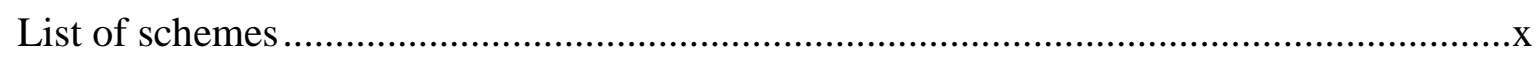

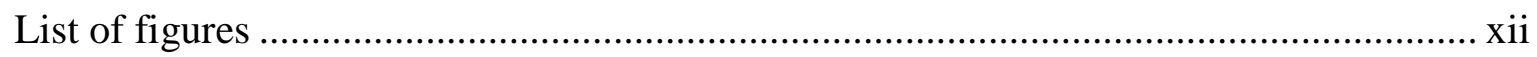

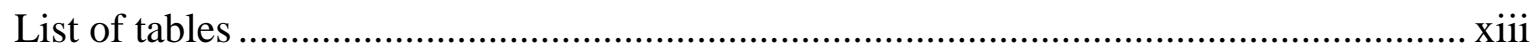

\section{Chapter 1 Boronic acids and their derivatives ..........................................................1}

1.1 Structure and properties of boronic acids and their derivatives .................................1

1.2 Pharmaceutical applications of organoboron compounds ...........................................

1.3 Synthetic intermediates - transforming the C-B bond ..............................................

1.4 Preparation of organoboron compounds ………………….................................16

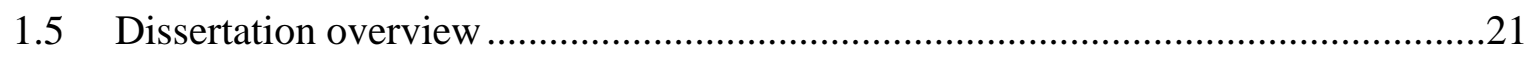

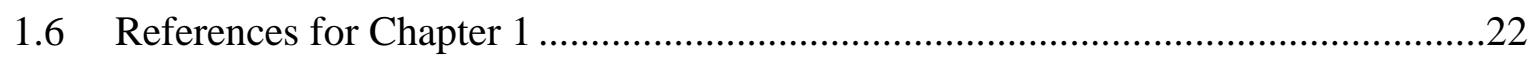

\section{Chapter 2 Structure and reactivity of a preactivated sp2-sp3 diboron} reagent: catalytic regioselective boration of $\alpha, \beta$-unsaturated conjugated compounds ....................................................................... 32

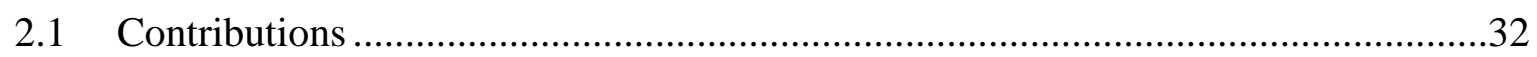

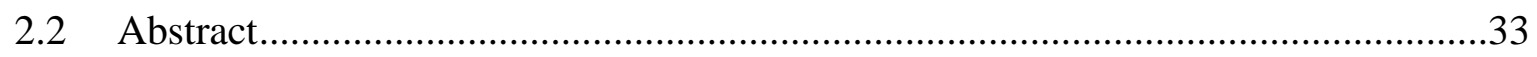

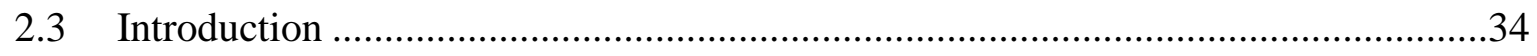

2.4 Design and synthesis of a novel "mixed" diboron reagent.........................................38

2.5 Reactivity of PDIPA diboron towards copper-catalyzed $\beta$-boration..........................39

$2.6 \quad$ Further development - introduction ......................................................................

2.7 Synthesis and characterization of $(R, R)$-PDIPA diboron .........................................43

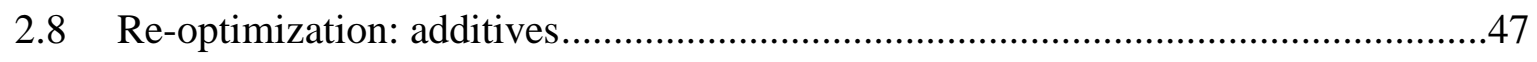

2.9 Re-optimization: stoichiometry and other reaction conditions ................................51

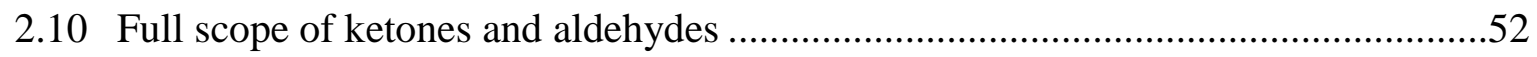




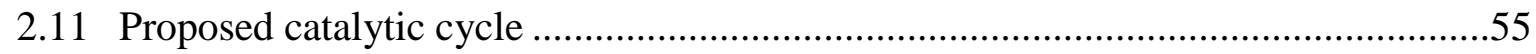

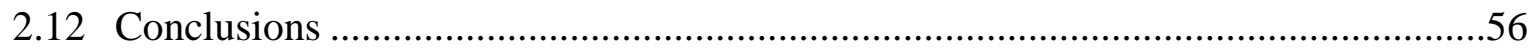

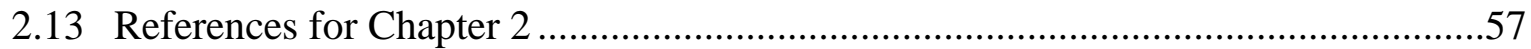

\section{Chapter 3 Regio- and stereoselective copper-catalyzed $\beta$-borylation of} allenoates by a preactivated diboron................................................ 68

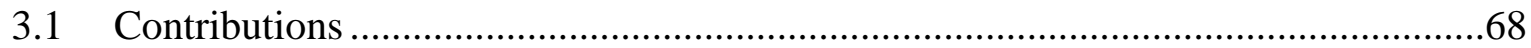

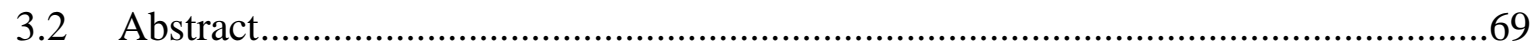

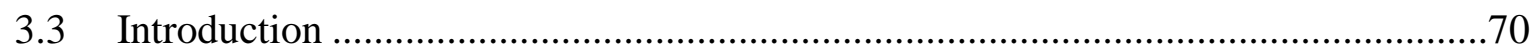

3.4 Optimization and substrate scope of the $\beta$-boration of allenoates.............................73

3.5 Rationale for diastereoselectivity, proposed mechanism, and product utility............78

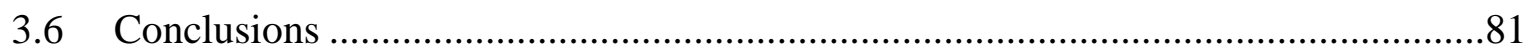

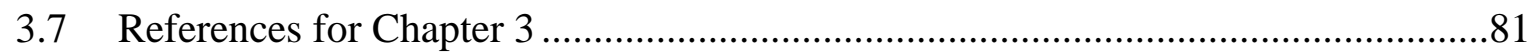

\section{Chapter 4 Unexpected copper(II) catalysis: catalytic amine base promoted $\beta$-borylation of $\alpha, \beta$-unsaturated carbonyl compounds in water ................................................................. 85}

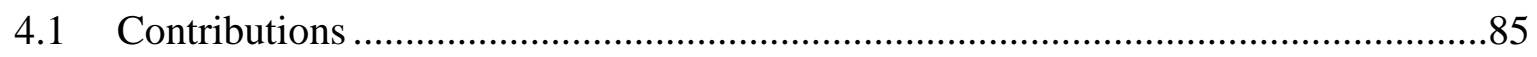

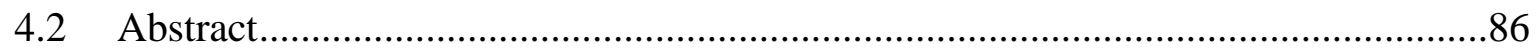

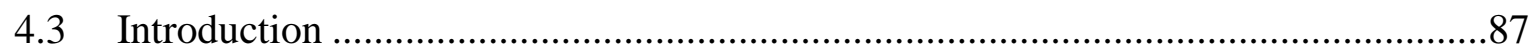

4.4 Optimization of the $\beta$-boration of 2-cyclohexen-1-one.............................................90

4.5 Substrate scope of copper(II) catalyzed $\beta$-boration in water...................................94

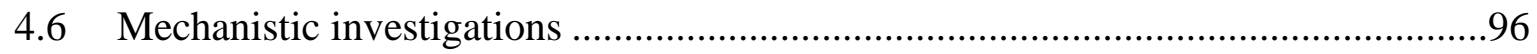

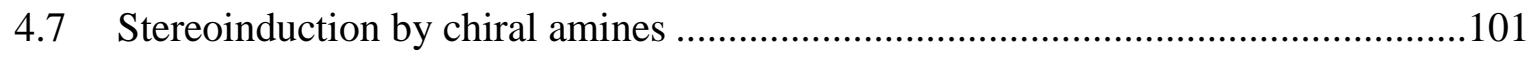

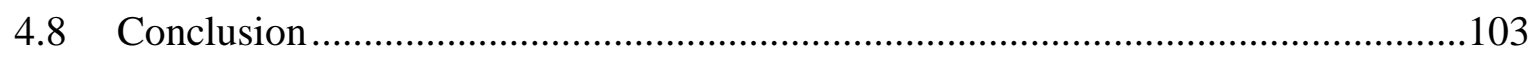

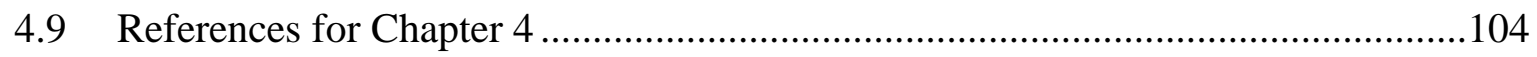


Chapter 5 Experimental........................................................................ 109

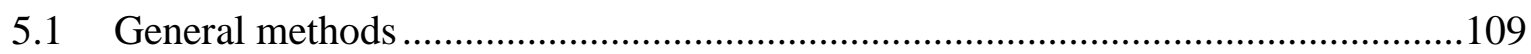

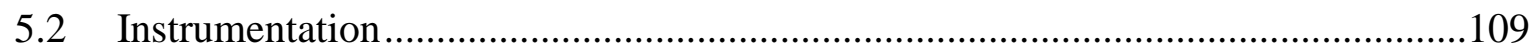

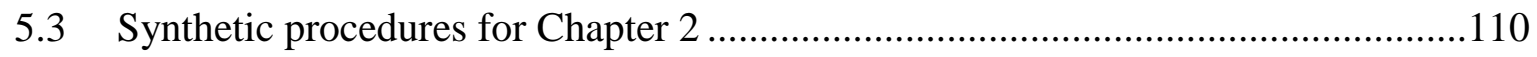

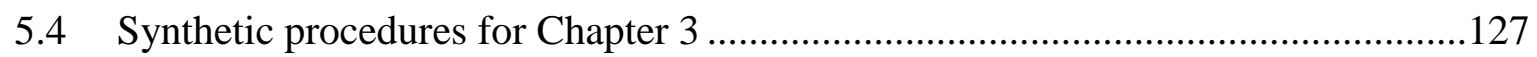

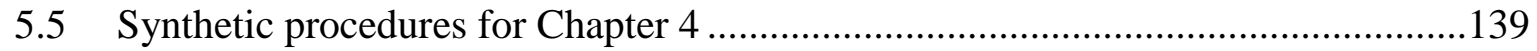

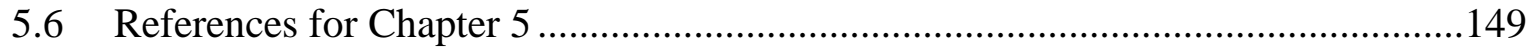




\section{List of schemes}

Scheme 1.1 Model of equilibrium between a nucleophile and boronic acid/ester ...............3

Scheme 1.2 Oxidation of a borane intermediate.........................................................6

Scheme 1.3 Transformations of $s p^{2}$-hybridized organoboron compounds..........................

Scheme $1.4 \quad$ Overall conditions for kinetic studies .................................................... 11

Scheme 1.5 Possible halide displacement routes to hydroxo $\mu_{2}$-bridged transition state....12

Scheme 1.6 Stoichiometric reactions of possible active intermediates ...........................13

Scheme 1.7 Suzuki-Miyaura catalytic cycle...........................................................13

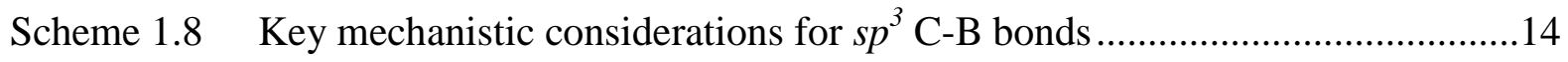

Scheme 1.9 Transformations of $s p^{3}$-hybridized organoboron compounds........................15

Scheme 1.10 Electrophilic trapping of trialkylborates .................................................. 17

Scheme 1.11 Divergent organoboron synthesis with bis(pinacolato)diboron .....................17

Scheme 1.12 Synthesis of boron-containing amino acid analogues...................................19

Scheme $1.13 \quad \beta$-Boration with platinum, rhodium, nickel, and palladium catalysts .............20

Scheme 2.1 Iterative SMC with MIDA boronates and on-pot hydroboration and

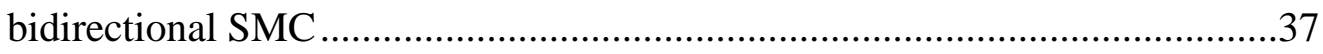

Scheme 2.2 Synthesis of racemic PDIPA diboron .................................................. 38

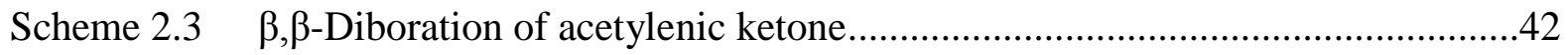

Scheme 2.4 Synthesis of enantiomerically pure PDIPA diboron ..................................44

Scheme 2.5 Rearrangement of $\mathbf{2 . 1 3}$ to $\mathbf{2 . 2 0}$ with potassium tert-butoxide ......................49

Scheme 2.6 Copper-catalyzed $\beta$-boration of other $\alpha, \beta$-unsaturated conjugated

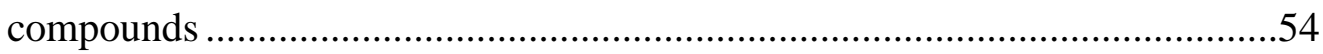

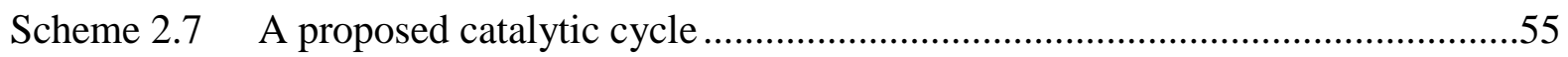

Scheme 3.1 Three component coupling, conjugate addition, and $\gamma$-addition reactions with allenoates .70 
Scheme 3.2 Divergent pathways in the presence of copper halides

Scheme 3.3 Examples of silaboration, cyanoboration, and diboration of allenes ................72

Scheme 3.4 General preparation of substituted allenoates …………………………….........76

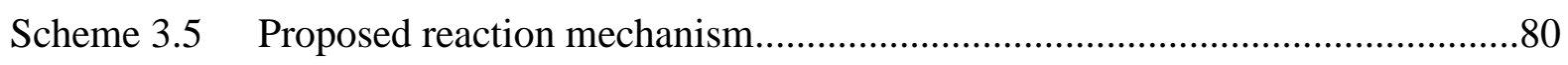

Scheme 3.6 Coupling of $\beta$-boronic ester with iodobenzene ................................................ 81

Scheme 4.1 Metal-catalyzed conjugate borylation approaches ...........................................87

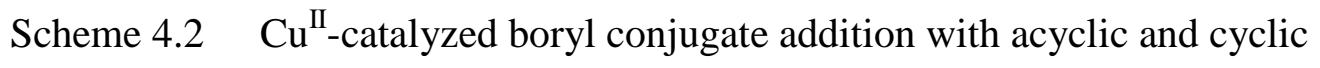

$\alpha, \beta$-unsaturated ketones and esters...............................................................94

Scheme 4.3 Tetra(hydroxyl)diborane as the boron source ………………….....................95

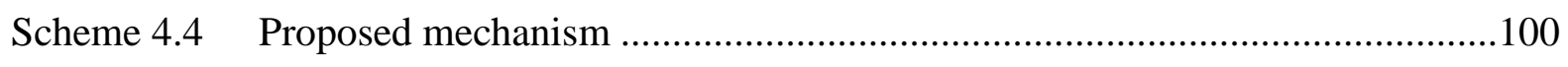

Scheme 4.5 Screening of chiral amines for the enantioselective $\beta$-boration of chalcone .102 


\section{List of figures}

Figure $1.1 \quad$ Structures of boronic acid derivatives.................................................

Figure 1.2 Structure and binding affinities of Velcade and peptidyl aldehyde .................4

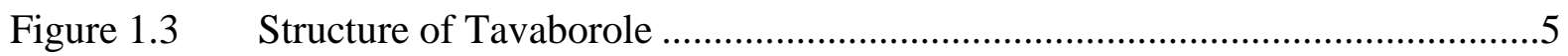

Figure 1.4 Spiro complex of AN2690 and leucycl tRNA synthetase .............................5

Figure 1.5 Structures of alkyl-9-BBN and alkyl-OBBD ......................................... 10

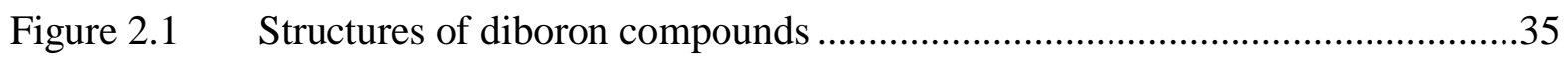

Figure 2.2 Structure and hydrolysis of MIDA and dan moieties .................................36

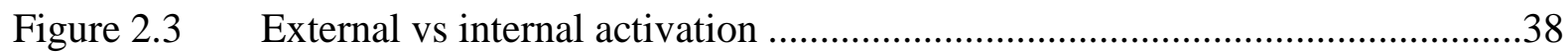

Figure 2.4 $\quad{ }^{11} \mathrm{~B}$ NMR spectra of $\mathbf{2 . 3}$ and 2.13 in $\mathrm{CD}_{3} \mathrm{CN}$ at room temperature.................39

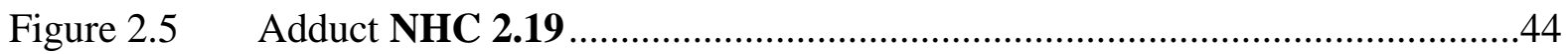

Figure 2.6 Anisotropic displacement ellipsoid drawings of $(R, R)-\mathbf{2 . 1 3}$ and $\mathbf{2 . 1 3} \ldots \ldots \ldots . . .45$

Figure 2.7 Boration of 2-cyclohexenone in the presence of various additives ................48

Figure 2.8 Perspective view of one formula unit of $\mathbf{2 . 2 0}$ and a view of the potassium-

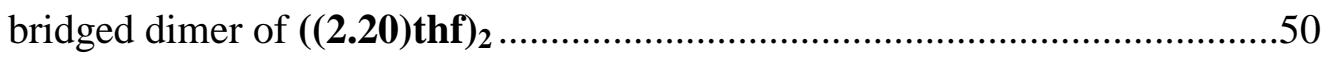

Figure 3.1 Steric interactions lead to exclusive formation of the $(Z)$-isomer..................79

Figure 4.1 National VOC emissions in 2008, by source ..........................................89

Figure 4.2 ${ }^{11} \mathrm{~B}$ NMR spectra of $\mathrm{B}_{2} \mathrm{pin}_{2}$ in 4-picoline, water, and water with 4-picoline...96

Figure 4.3 UV-Vis spectra of $\mathrm{CuSO}_{4}$ with increasing equivalents of 4-picoline .............97

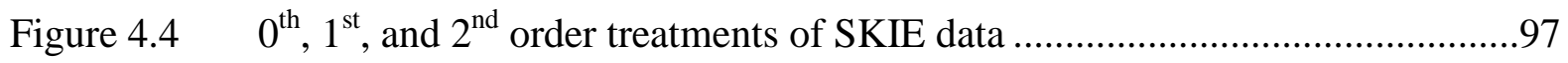

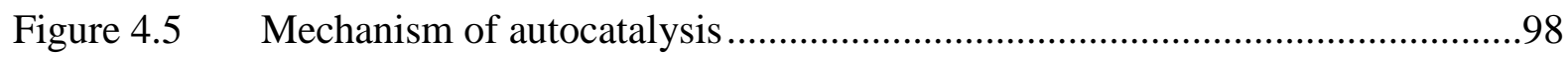

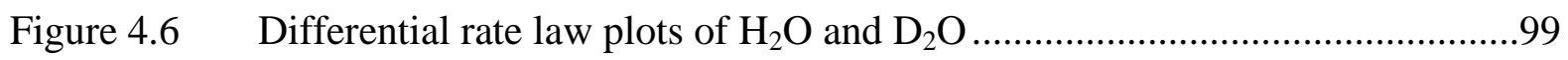

Figure 4.7 Proposed chelation and Lewis basicity of $\mathbf{L 1 0}$......................................103 


\section{List of tables}

Table 2.1 Cu-Catalyzed addition of mixed diboron $\mathbf{2 . 1 3}$ to benzyl acrylate under various conditions .40

Table 2.2 Copper-catalyzed $\beta$-boration of various unsaturated conjugated compounds .42

Table 2.3 B-B distances in selected diboron compounds ........................................46

Table 2.4 Addition of 2.13 to 2-cyclohexenone under various conditions ......................51

Table $2.5 \quad$ Copper-catalyzed $\beta$-boration of $\alpha, \beta$-unsaturated ketones .............................53

Table $3.1 \quad$ Optimization of reaction conditions...................................................... 74

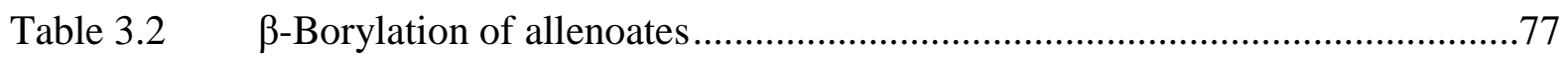

Table 4.1 Screening of additives and reaction conditions ......................................91

Table $4.2 \quad$ Screening of copper sources and stoichiometry....................................93

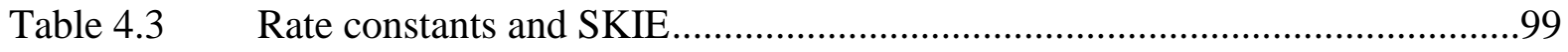




\section{Chapter 1 Boronic acids and their derivatives}

\subsection{Structure and properties of boronic acids and their derivatives}

Boronic acids are defined as organometallic compounds containing a trivalent boron atom that is covalently attached to one carbon substituent and two hydroxyl groups. ${ }^{1}$ The ground state boron atom is $s p^{2}$-hybridized, with a trigonal planar geometry and only six valence electrons, which gives the atom Lewis acidic properties due to the two electron deficiency and associated empty p orbital. The moderate stability of boronic acids can be attributed to short BO bonds (typically $1.35-1.38 \AA$ ) that are significantly stronger than C-O bonds (130 kcal/mol vs $92 \mathrm{kcal} / \mathrm{mol})^{2}$ due to donation of lone pair electrons on oxygen to the empty $\mathrm{p}$ orbital on boron, giving rise to partial double bond character. Conversely, the B-C bond is slightly weaker than a typical C-C bond $(77 \mathrm{kcal} / \mathrm{mol} \text { vs } 85 \mathrm{kcal} / \mathrm{mol})^{2}$ and is typically $1.55-1.59 \AA$.

A variety of boronic acid derivatives have been synthesized to address difficulties ranging from stability and reactivity to ease of purification. Notable and relevant examples are illustrated in Figure 1.1. Boronic acid 1.1 can be converted to pinacol boronic ester 1.2, which is typically less reactive than $\mathbf{1 . 1}$ but offers the benefits of facile purification and increased stability for long-term storage. ${ }^{3}$ Chiral variants exist also, such as (+)-pinanediolato boronic ester 1.3, however, they are up to 20 times more expensive to prepare and other efficient methods of

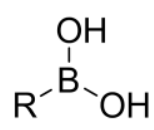

1.1

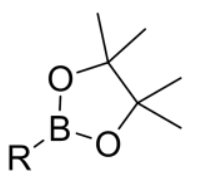

1.2

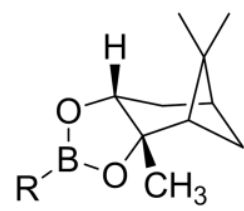

1.3

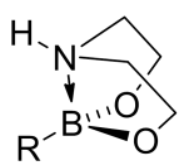

1.4
$\mathrm{R}^{-\mathrm{BF}_{3} \mathrm{~K}}$

1.5

Figure 1.1. Structures of boronic acid derivatives. 
chiral induction are currently available. ${ }^{4}$

Alternatives to $s p^{2}$-hybridized organoboron compounds have been extensively studied as well, for example, diethanolamine adduct $\mathbf{1 . 4}$ and potassium trifluoroboronate salt $\mathbf{1 . 5}$. Upon coordination of an additional bonding heteroatom, $\mathbf{1 . 4}$ adapts a distorted tetrahedral structure when boron's octet is filled by a dative bonding lone pair of electrons and the boron atom rehybridizes to a $s p^{3}$ center. $^{5}$ As a result of the increased electron density at the boron center, the B-C bond in $\mathbf{1 . 4}$ is elongated to approximately $1.61 \AA(0.04$ higher than 1.1) and the B-O bonds are lengthened significantly to $1.46-1.48 \AA(0.10$ higher than 1.1). The formation of a tetrahedral adduct was estimated to destabilize the $\mathrm{B}-\mathrm{O}$ bond by up to $12 \mathrm{kcal} / \mathrm{mol}$ compared to a trigonal planar boronic acid. ${ }^{6}$ Typically, diethanolamine derivatives like $\mathbf{1 . 4}$ are white powders that are easily purified by precipitation and filtration. Potassium trifluoroborate $\mathbf{1 . 5}$ is a unique variant that has proven to be exceptionally air stable and highly reactive in a diverse set of crosscoupling and addition reactions. ${ }^{7}$ This is not surprising when the difference in bond energies is considered; B-F bonds are almost $30 \mathrm{kcal} / \mathrm{mol}$ stronger than $\mathrm{B}-\mathrm{O}$ bonds. ${ }^{2}$ Like adduct $\mathbf{1 . 4}$, organotrifluoroborate $\mathbf{1 . 5}$ assumes a tetrahedral geometry and $s p^{3}$-hybridization on boron. ${ }^{8}$

The successful synthesis of boronic acid derivatives, and further reactions of organoboron compounds, originates from a fundamental theory of reactivity. Most similar to a carboxylate carbon, reactions usually proceed stepwise through a tetrahedral intermediate and return to a trigonal planar geometry, with a few exceptions as previously described. The balance of the resulting equilibrium is ultimately controlled by thermodynamic stability, however, the rate of exchange is highly dependent on the electrophilicity of the boron atom, Lewis basicity of the nucleophile, and steric interactions (Scheme 1.1). ${ }^{1}$ In fact, formation of stable $s p^{3}$-hybridized boron adducts like potassium organotrifluoroborates provides an exceptional resistance to 
Scheme 1.1. Model of equilibrium between a nucleophile, $Y$, and boronic acid/ester.

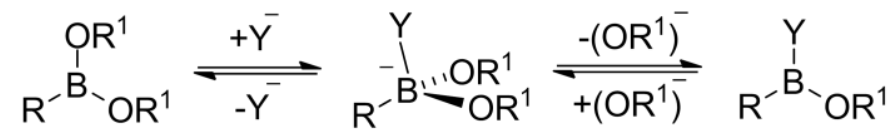

autoxidation, which is a highly favorable process as a result of the $53 \mathrm{kcal} / \mathrm{mol}$ greater bond strength of B-O bonds in comparison to B-C bonds. ${ }^{9}$ Through careful consideration of these properties, we can predict and exploit the reactivity of an element that has largely been underutilized in both medicinal and synthetic chemistry.

\subsection{Pharmaceutical applications of organoboron compounds}

Medicinal chemists are rapidly acclimating to the idea of boronic acid derivatives as therapeutics for their interesting physiochemical characteristics. The ability of boronic acids to form covalent bonds provides the opportunity to design inhibitors with much higher affinities (and consequently, slower dissociation rates) towards a physiological target than typical pharmaceuticals, which often rely on weaker forces such as hydrophobic interactions, hydrogen bonding and electrostatic attractions. Additionally, organoboron compounds differ from suicide inhibitors because the formation of the covalent bond through dative donation of lone pair electrons is reversible. Strong boron-oxygen bonds $(130 \mathrm{kcal} / \mathrm{mol})$ contribute to the selectivity of boronic drug candidates towards the alcohol functionalities found on serine and threonine residues over other nucleophilic side chains, such as thiols and amines. This interaction was effectively demonstrated on a simple model by introducing boric acid into trypsin, a serine protease. ${ }^{10,11}$ Characterization of the resulting adduct involved the comparison of chemical shifts in solution state ${ }^{1} \mathrm{H}$ and ${ }^{11} \mathrm{~B}$ NMR spectra under various conditions, kinetic results from spectrophotometric assays at different concentrations of a competitive inhibitor, and ultimately, successful acquisition of the crystal structure by X-ray crystallography. Although excellent 
candidacy as inhibitors has been demonstrated for serine proteases (such as thrombin, ${ }^{12}$ elastase, ${ }^{13}$ dipeptidyl IV ${ }^{14}$ hepatitis $\mathrm{C}$ virus protease, ${ }^{15} \beta$-lactamase ${ }^{16}$, and $\mathrm{ClpXP}{ }^{17}$ ) and threonine hydrolases ( $\gamma$-glutamyl transpeptidase ${ }^{18}$ and autotaxin $\left.{ }^{19}\right)$ these properties introduce inherent limitations because they are less likely to be effective on other targets, such as cysteine proteases. Although rare, examples of binding alternative structures have been reported, such as manganese-dependent $\operatorname{arginase}^{20}$ and tRNA (vide infra). Driven by a few key preliminary successes in the clinic, investigations of organoboron-based therapeutics are proliferating and traditional concerns of toxicity and poor stability are waning. ${ }^{21}$

The best example to date is Velcade (bortezomib), ${ }^{22}$ which is a boronic acid-containing dipeptide (1.6; Figure 1.2). Velcade was approved by the FDA in 2003 for the treatment of multiple myeloma and relapsed mantle cell lymphoma and represents both the first boroncontaining drug, and the first proteasome inhibitor of any type to be approved by the FDA. The dipeptide interacts specifically with threonine residues in the active sites of various $\beta$-subunits of the $20 \mathrm{~S}$ proteasome as shown by crystallographic studies, ${ }^{23}$ however the exact interaction responsible for the desired phenotype response has not yet been determined. ${ }^{24}$ Velcade exemplifies the primary mechanism of action expected for boronic acids in which the electronic and geometric properties mirror that of a carbonyl, with one distinct difference: the stability of<smiles>[R]O[R6]#[W]</smiles><smiles>[Y][R6]([Y])([3H])O[Na]</smiles>

Figure 1.2. Structure and binding affinities of Velcade $\mathbf{1 . 6}$ and peptidyl aldehyde $\mathbf{1 . 7}$. 
the tetrahedral intermediate. A comparison of binding affinities towards the proteasome with the corresponding peptidyl aldehyde 1.7 clearly validates this concept (Figure 1.2). ${ }^{22}$

Another prime example was reported in 2006 by Anacor Pharmaceuticals. The drug candidate Tavaborole (AN2690), which contains a benzoxaborole functionality (Figure 1.3), was shown to be an effective anti-fungal agent in the treatment of onychomycosis $^{25}$ and is currently in Phase 3 clinical trials. Interestingly, Tavaborole exhibits a different mechanism of action than previously described and actually targets a completely different class of macromolecules (vide supra). Inhibition of leucyl tRNA<smiles>OB1OCc2cc(F)ccc21</smiles>

1.8

Figure 1.3. Structure of Tavaborole (1.8). synthetase was achieved through a spiro complex of $\mathbf{1 . 8}$ with the cis 2'- and 3'-hydroxyls of the terminal adenosine (Figure 1.4). In fact, complexation of boron with cis-diols has recently been found to play a crucial role in natural processes of several organisms including animals, plants, and bacteria. Although research on the role of boron in living organisms is in an early stage, the known functions of these complexes range from structural support in plant cell walls ${ }^{26}$ to quorum

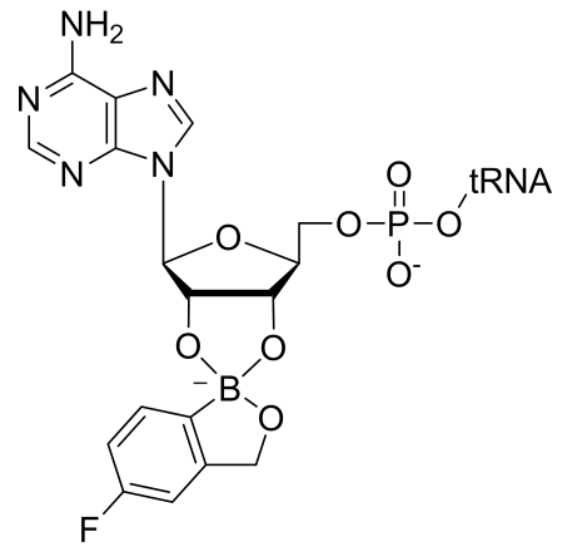

Figure 1.4. Spiro complex of AN2690 and leucyl tRNA synthetase.

sensing, or bacterial signaling through the excretion of signal molecules. ${ }^{27}$ The recent success of boronic acids as therapeutic tools with unique physiochemical properties continues to provide the fuel for their incorporation into potential drugs, ${ }^{28}$ however, they have predominately been examined as valuable synthetic intermediates. 


\subsection{Synthetic intermediates - transforming the C-B bond}

Previously defined as organometallic compounds, boronic acids combine aspects of organic and inorganic chemistry, which permits an unusual mixture of properties when considering the reactivity of the carbon-boron bond. Exchange of the boryl moiety for a variety of carbon-, nitrogen-, and oxygen-linked functionalities provides a convenient route to complex structures that may be difficult to achieve by other means. Transformations of boron-containing intermediates date back to 1956, when Brown reported the anti-Markovnikov hydration of terminal alkenes to provide the primary alcohols using a 2-step procedure that involved the Markovnikov hydroboration of alkene $\mathbf{1 . 9}$ with diborane (originally generated in situ by mixing sodium borohydride with aluminum trichloride, and used directly starting in 1957) to yield alkylborane intermediate $\mathbf{1 . 1 0}$ and subsequent oxidation of the C-B bond in the presence of sodium hydroxide and hydrogen peroxide to yield the alcohol 1.11 (Scheme 1.2). ${ }^{29,30}$ Unfortunately, the instability of boranes deterred synthetic chemists from pursuing organoboron intermediates for quite some time. ${ }^{31}$ In 1979, Suzuki and Miyaura revitalized the field when they pioneered a transition metal-catalyzed procedure to transform a carbon-boron bond into a carbon-carbon bond by cross-coupling a stable boronic ester with an alkenyl or alkynyl halide. ${ }^{32}$ Unbeknownst at the time, this single discovery led to an exponential growth of research on organoboron intermediates. Indeed, the Nobel Prize in Chemistry was awarded, in part, to

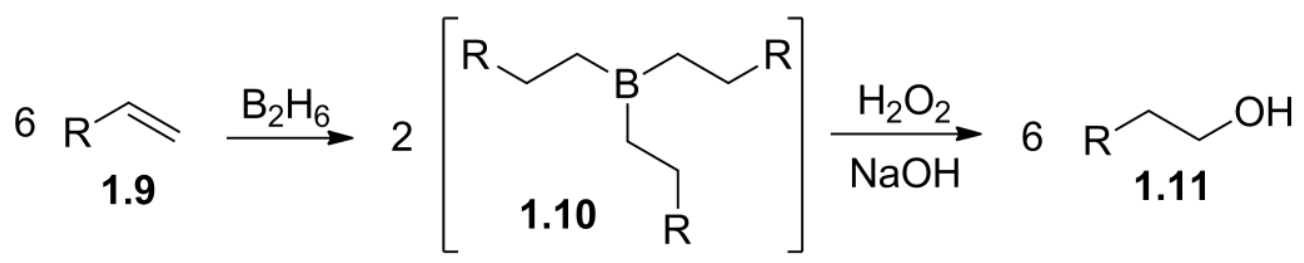

Scheme 1.2. Oxidation of a borane intermediate. 
Professor Akira Suzuki in 2010 for his contributions to the field.

Transformations of carbon-boron bonds are generally considered in terms of the hybridization of the carbon because the reactivity of $s p^{2}$ - and $s p^{3}$-bound boronic acids can be markedly different and the geometry of the boron atom in solution can be somewhat dynamic. A unique feature of organoboron compounds, independent of the hybridization of the central carbon, is the transfer of stereochemical integrity to the product when reacted with either stoichiometric reagents ${ }^{33}$ or cross-coupled using transition metal-catalysis. ${ }^{34}$ A retention of configuration is typically observed, however, examples of inversion exist. ${ }^{35}$ As a general rule, $s p^{2}$ C-B bonds are more likely to produce the desired product in transition metal-catalyzed couplings due to conformational restrictions-which greatly decrease the decomposition of intermediates by $\beta$-hydride elimination — and the enhanced stability from back bonding in organometallic intermediates. ${ }^{36}$ Scheme 1.3 illustrates the assortment of efficient transformations established for $s p^{2}$-hybridized organoboron intermediates (general structure 1.12).

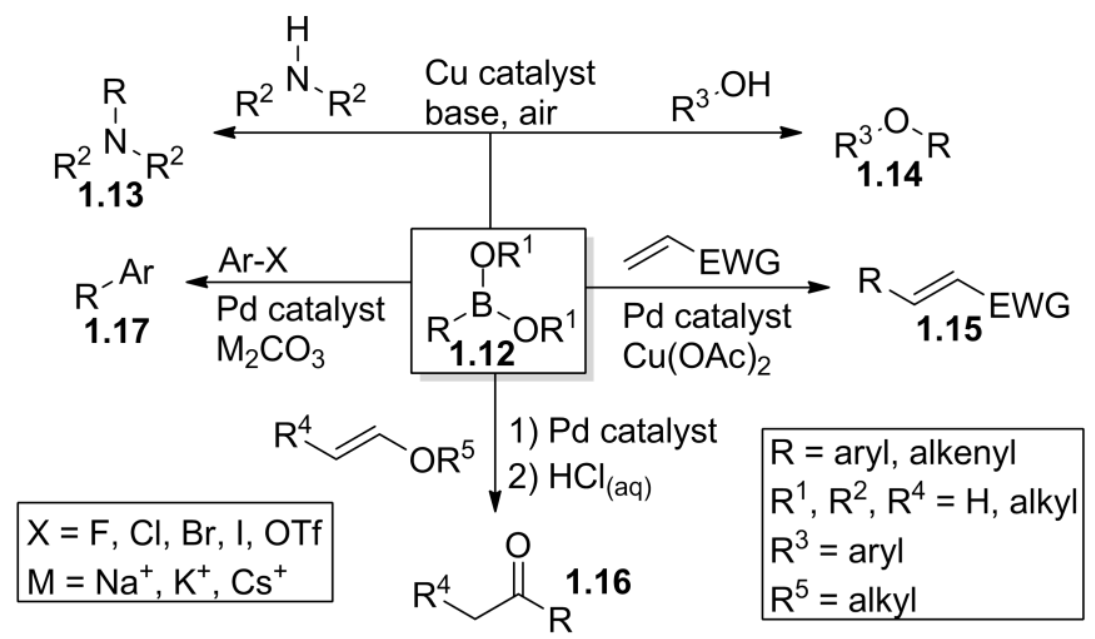

Scheme 1.3. Transformations of $s p^{2}$-hybridized organoboron compounds. 
Copper (II) salts have shown to be versatile catalysts in the oxidation of boronic acid/ester $\mathbf{1 . 1 2}$ to either amine $\mathbf{1 . 1 3}$ or ether $\mathbf{1 . 1 4}$ under similar conditions that were disclosed in three back to back publications by Chan, Evans, and Lam in $1998 .{ }^{37-39}$ General reaction conditions are operationally simple, utilizing a stoichiometric amine base and atmospheric oxygen to re-oxidize the catalyst and provide moderate to excellent yields typically ranging from 50-98\%. The limited number of reports involving copper-catalyzed transformations is likely due to the instability of organocuprates at room temperature. ${ }^{40,41}$ Alternatively, using copper (II) as a stoichiometric oxidant in the presence of a palladium catalyst allowed $\mathbf{1 . 1 2}$ to undergo a Mizoroki-Heck type reaction with alkenes to form a new carbon-carbon bond and afford structure 1.15. ${ }^{42}$ Further optimization of these conditions led to the report of a base- and oxidantfree oxidative Heck coupling in 2007 and expansion of the substrate scope to include vinyl ethers, which provide an interesting route to aryl ketone $\mathbf{1 . 1 6} .^{43}$ Stable organopalladium complexes have indeed been isolated and characterized, ${ }^{44}$ providing both mechanistic insight into cross-coupling reactions and motivation to pursue palladium as an effective catalyst.

The true foundation for palladium-catalyzed cross-coupling of $s p^{2}$-hybridized organoboronic acids can be traced much further back to the aforementioned report of the SuzukiMiyaura cross-coupling (SMC) reaction in $1979 .{ }^{32}$ A great deal of research has been done to expand the scope of organic halides for the synthesis of 1.17. Originally utilizing simple alkenyl bromides, a wide variety of organic halides and triflates may now be employed, ${ }^{45}$ including challenging aryl chloride substrates ${ }^{46}$ and even ortho, para-dinitrofluoroarenes. ${ }^{47}$ The commercial availability of an enormous selection of aryl, alkenyl, and alkynyl halides, in addition to high functional group tolerance as exemplified by late-stage SMC in the synthesis of 
complex therapeutics ${ }^{48}$ and natural products ${ }^{49}$ alike, have established this reaction as one of the most efficient and broadly applicable protocols in the history of synthetic chemistry.

The myriad of reports on other palladium-mediated coupling reactions of organometallic reagents with organic halides beginning in the late 1970s was remarkable. Notable examples include the use of Grignard ${ }^{50}$ and organolithium ${ }^{51}$ reagents by Murahashi, organoaluminum ${ }^{52}$ and zinc $^{53}$ reagents by Negishi, organostannanes by Migita $^{54}$ and Stille, ${ }^{55}$ alkenylcopper by Normant,${ }^{56}$ and organosilanes by Hiyama. ${ }^{57}$ A consistent conclusion in these transformations is a mechanism involving an oxidative addition, transmetallation, reductive elimination pathway, so it comes as no great surprise that the cross-coupling of organoboronic acids has been established to follow the same scheme. It is widely believed that oxidative addition of the zerovalent palladium catalyst (with 2 ligated phosphines) to the organic halide, producing an organopalladium(II) complex, is the rate-limiting step for catalyst turnover $^{58}$ and the accompanying order of reactivity for the halides is iodide $>$ triflate $>$ bromide $>$ chloride $^{59,60}$ SMC reactions are a peculiar case, however, because they tend to deviate from common trends and also require excess carbonate base. In fact, Fu reported an extensive investigation on a highly reactive system using potassium fluoride as base to provide excellent yields, even with typically unreactive electron-rich chlorides, and consequently revealed a particularly interesting trend. ${ }^{61}$ In a chemoselectivity experiment between bromide and triflate, the bromide reacted preferentially. Furthermore, the competition between chloride and triflate could be controlled through selection of the proper catalyst: $\mathrm{Pd}_{2}(\mathrm{dba})_{3}+2 \mathrm{P}\left({ }^{t} \mathrm{Bu}\right)_{3}$ allows the chloride to react while $\mathrm{Pd}(\mathrm{OAc})_{2}+2 \mathrm{P}(\mathrm{Cy})_{3}$ reversed the chemoselectivity. The authors claimed that the substitution of carbonate for fluoride base increased reactivity in their hands, however, the opposite trend has 
also been identified elsewhere. ${ }^{62}$ What is evident from these results is that the SMC mechanism is more complex than originally believed.

A few detailed investigations probing portions of the mechanism have indeed been disclosed, therefore, a combination of this data is required to comprehensively understand the role of each reaction component. Since boron is a semi-metal, the importance herein is to understand the conditions under which boron behaves more like a metal, or conversely a nonmetal, so one can begin to predict it's reactivity as applied to other systems. In 1998, Matos provided the first set of results aimed specifically at identifying the structures involved with several ambiguous steps of the oxidative addition, transmetallation, reductive elimination pathway including the rate-determining step, the role of base, and the origin of stereochemical retention that was typically observed. $^{63}$ Matos began with the alkyl-9-BBN (9borabicyclo[3.3.1]nonane) derivative $\mathbf{1 . 1 8}$ (Figure 1.5) because it was the most efficient coupling partner given the established protocol at the time. For comparative kinetic studies, the corresponding OBBD (9-oxa-10-borabicyclo[3.3.2]-decane) derivative, alkylborinate 1.19, was prepared as a less reactive organoboron substrate due to the increased electron density on boron from the donation of lone pair electrons by oxygen. Additionally, deuterium-substituted examples $(\mathbf{1 . 1 8 b} / \mathbf{1 . 1 9 b})$ were prepared to analyze the transfer of stereochemistry.

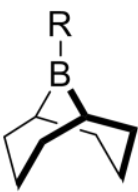

1.18

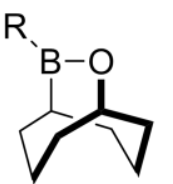

1.19

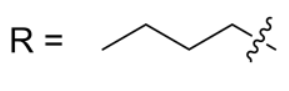

$1.18 a / 1.19 a$

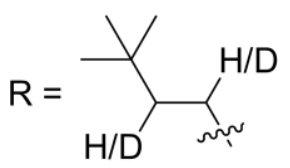

$1.18 \mathrm{~b} / 1.19 \mathrm{~b}$

Figure 1.5. Structures of alkyl-9-BBN 1.18 and alkyl-OBBD 1.19. 
Scheme 1.4. Overall conditions for kinetic studies.

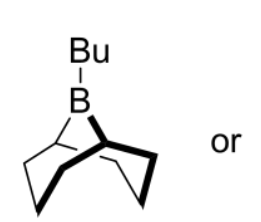

$1.18 \mathrm{a}$

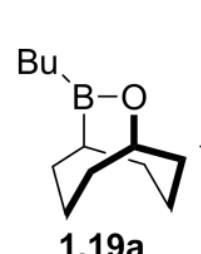

$1.19 a$

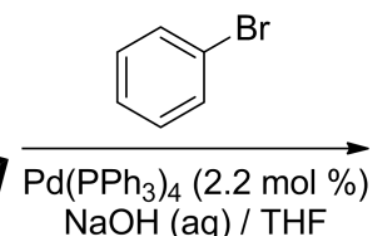

$\mathrm{NaOH}(\mathrm{aq}) / \mathrm{THF}$

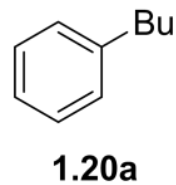

As previously mentioned, oxidative addition of the zerovalent metal complex to the organic halide is the rate-determining step in most palladium-catalyzed cross-couplings, but SMC reactions have shown experimental deviations that have led to more intensive studies. To systematically investigate these inconsistencies, compounds 1.18a and 1.19a were subjected to kinetic studies to evaluate the reaction order of each component. An arduous collection of initial rates were obtained while independently varying the concentration of the halide, organoboron, and base (overall reaction depicted in Scheme 1.4). Analysis of results for alkyl-9-BBN 1.18a revealed a rate that is first-order in bromobenzene, but zero-order in $\mathbf{1 . 1 8 a}$, which is supports oxidative insertion as the rate-determining step. However, the rate of reaction using alkylOBBD 1.19a was independent of both bromobenzene and organoboron concentration, but firstorder in base. Indeed, a similar shift in the slow step was observed for boronic acids when changing the halide from bromide to iodide. ${ }^{64}$ Stoichiometric spectroscopy experiments without the borane showed an equilibrium of the oxidative addition product, arylpalladium(II) bromide, and arylpalladium(II) hydroxide as result of ligand exchange. Taken together, these results suggest that displacement of halide on palladium by base is rate-limiting for less-reactive organoboron substrates, however, two possible pathways (ignoring the geometry of phosphine ligands on palladium because both cis $^{65}$ and $\operatorname{trans}^{66}$ isomers can promote the reaction) could account for these observed rates (Scheme 1.5). In path $\mathbf{A}$, base binds to the trivalent boron $\mathbf{1 . 2 1}$ to form tetracoordinate boron-“ate" 1.22, which facilitates displacement of the halide from 
Scheme 1.5. Possible halide displacement routes to hydroxo $\mu_{2}$-bridged transition state.

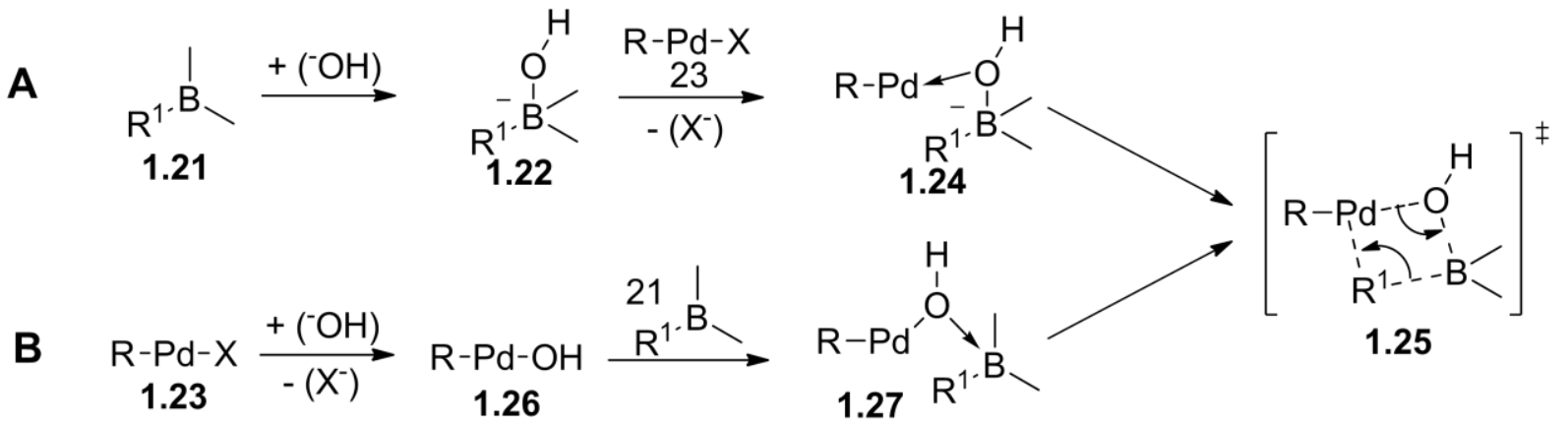

palladium complex $\mathbf{1 . 2 3}$ to provide hydroxo $\mu_{2}$-bridged complex 1.24. Alternatively, path B begins with the displacement of the halide from complex $\mathbf{1 . 2 3}$ by base to form palladium hydroxo complex 1.26, which then binds with trivalent boron $\mathbf{1 . 2 1}$ to provide a similar hydroxo $\mu_{2}$-bridged complex 1.27. Pathways $\mathbf{A}$ and $\mathbf{B}$ are kinetically indistinguishable given the current data and both lead to 4-member transmetallation transition state 1.25. In fact, this 4-member transition state is responsible for the retention of configuration observed in almost all SMC reactions. A third hypothetical situation indeed exists, where boron-"ate" 1.22 could react with palladium hydroxo complex 1.26, however, this is unlikely to contribute (vide infra). While this initial set of results unarguably confirmed the complexity of the SMC mechanism, several other considerations still needed to be addressed.

Recently, Hartwig disclosed an extensive mechanistic study focused on SMC of boronic acids, in particular the different transmetallation pathways previously examined by Matos and described in Scheme 1.5. Beginning with the independent synthesis of the 2 possible active intermediates, the boron-"ate" and palladium hydroxo complexes, it was determined that both were efficient under stoichiometric conditions (Scheme 1.6). He then reasoned that because both pathways are efficient, the contributions of path $\mathbf{A}$ and path $\mathbf{B}$ would be relative to the 
Scheme 1.6. Stoichiometric reactions of possible active intermediates.<smiles>Cc1ccc(-c2ccccc2)cc1</smiles>

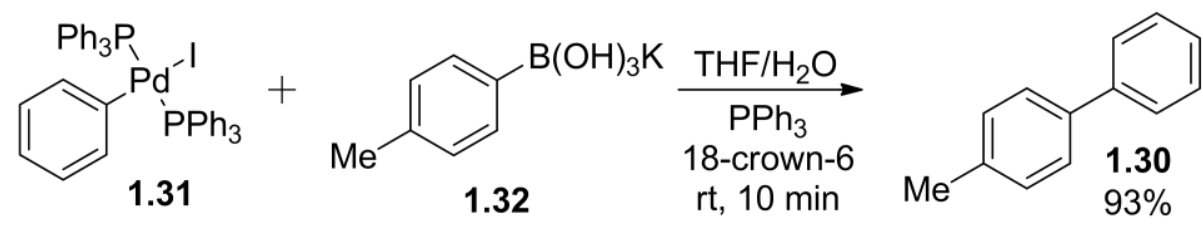

concentration of each "active" species is solution (Scheme 1.7). Examination of the equilibrium constants between free boronic acid (1.33) and boron-"ate" (1.34) revealed an approximately equal amount of each, and the same was determined between palladium halide (1.35) and palladium hydroxo (1.36) complexes, so concentration dependence was ultimately ruled out. They then revisited the stoichiometric reactions and determined the rate constants at low temperature, which showed that the reaction of palladium hydroxo complex with free boronic acid is more than 4 orders of magnitude faster than the reaction of palladium halide with trihydroxyborate, leading to the conclusion that path $\mathbf{B}$ is the correct mechanism in which the

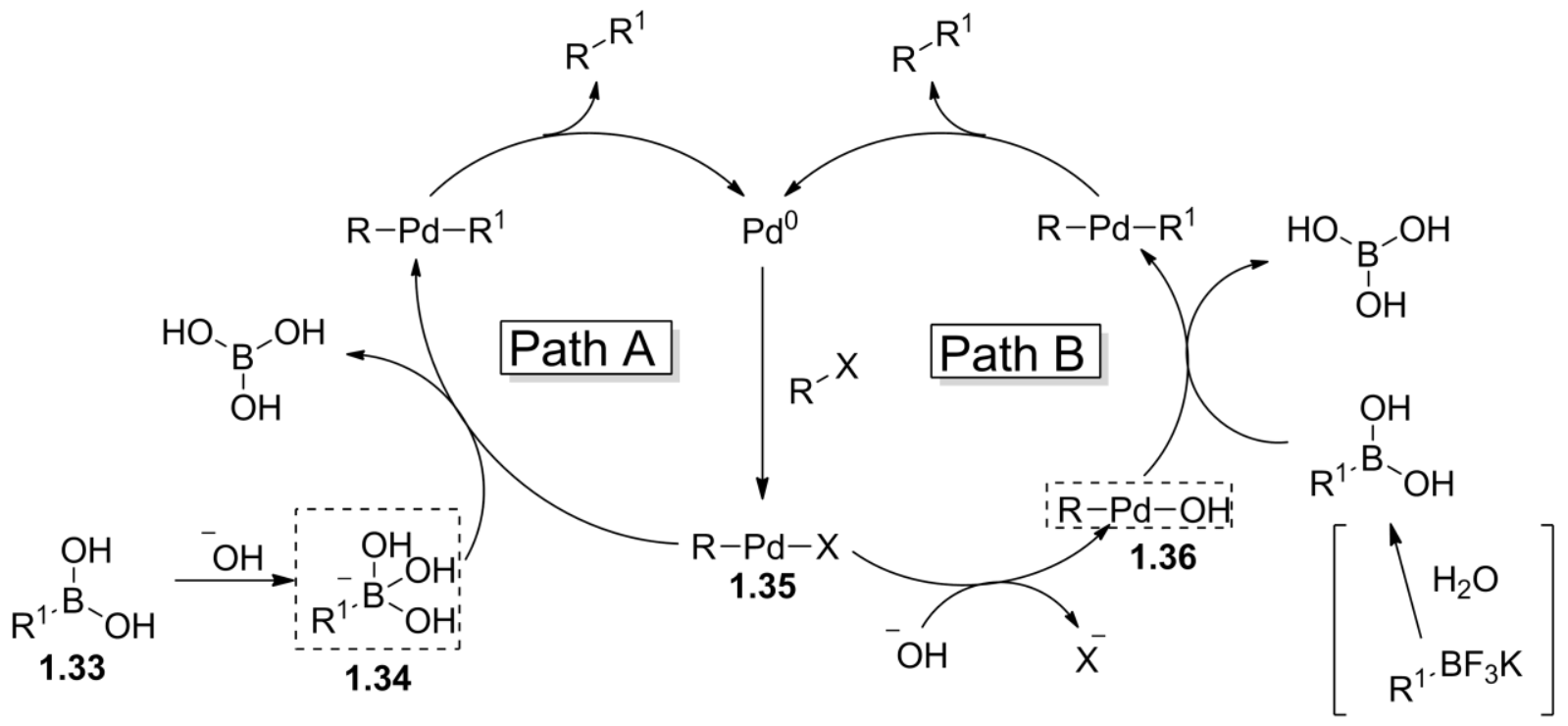

Scheme 1.7. Suzuki-Miyaura catalytic cycle. Dashed boxes identify the "active" intermediates. 
rate limiting step is formation of palladium hydroxo complex 1.36. The decreased reactivity of the trihydroxyborate is in agreement with separate reports of the cross-coupling of potassium organotrifluoroborates, which require the addition of water to achieve efficient conversion (vide supra). ${ }^{67}$ Water has specifically been implicated in the hydrolysis of the trifluoroborate to provide a free boronic acid in situ (see brackets in Scheme 1.7). ${ }^{68}$ With the recent identification of the active species involved in the rate determining step of the SMC reaction, we can now better understand the effects of changing additives, such as the strength of base, and tune the reactivity of the palladium catalyst to effect the transformation of traditionally unreactive substrates.

Transformations of $s p^{2} \mathrm{C}-\mathrm{B}$ bonds have been extremely successful using transition metal catalysis, however $s p^{3}$ C-B bonds are not typically converted using the same catalysts or mechanistic pathways due to rapid decomposition, for example through $\beta$-hydride elimination. In 1956, Brown discovered a unique set of conditions under which $s p^{3} \mathrm{C}$-B bonds react in the absence of transition metals (vide supra; Scheme 1.2). The key to obtaining a successful transformation was the use of an atypical chemical structure in which a nucleophilic functionality was directly bound to a leaving group (1.37), leading to an alkyl migration in intermediate 1.38 as illustrated in Scheme 1.8. In fact, this mechanistic consideration has been consistently found in all non-catalyzed reactions of organoboron compounds and is the primary

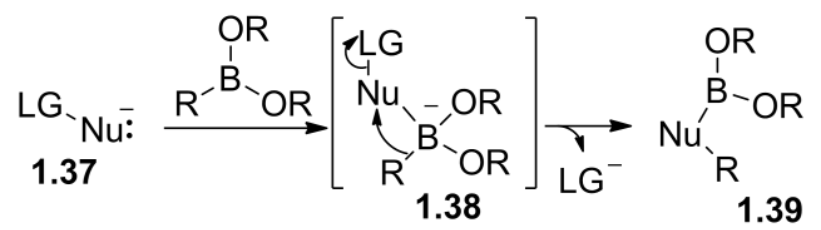

Scheme 1.8. Key mechanistic condiseration for $s p^{3} \mathrm{C}$ B bonds. 
reason for the excellent chemoselectivity and stability observed in using boronic acid derivatives as synthetic intermediates. In addition, the migratory $s p^{3}$ carbon is not re-hybridized during the course of the reaction and preserves the original stereochemistry. ${ }^{69}$

Several major contributions to the field that highlight the utility of this mechanism are described in Scheme 1.9. Although oxidation of 1.40 to alcohol 1.41 is efficient using the aforementioned alkaline peroxide solution, ${ }^{29}$ a more mild sodium perborate reagent was discovered to affect the same transformation in excellent yield, but with greater functional group tolerance. $^{70}$ Similarly, organolithium reagents lead to the formation of carbon-carbon single bonds such as in the synthesis of $\alpha$-haloboronic ester $\mathbf{1 . 4 2}$ from a lithiated chloroalkane ${ }^{71}$ and $\beta$ hydroxyboronic ester $\mathbf{1 . 4 3}$ from a lithiated epoxide. ${ }^{72}$ As expected in the proposed mechanism, stereochemical information is transferred in these reactions. Carbon-nitrogen bonds can also be introduced with the same methodology and stereochemical integrity, for example, by reaction with hydroxylamine- $O$-sulfonic acid to provide primary amine $1.44 .^{73}$ Conversely, palladium-

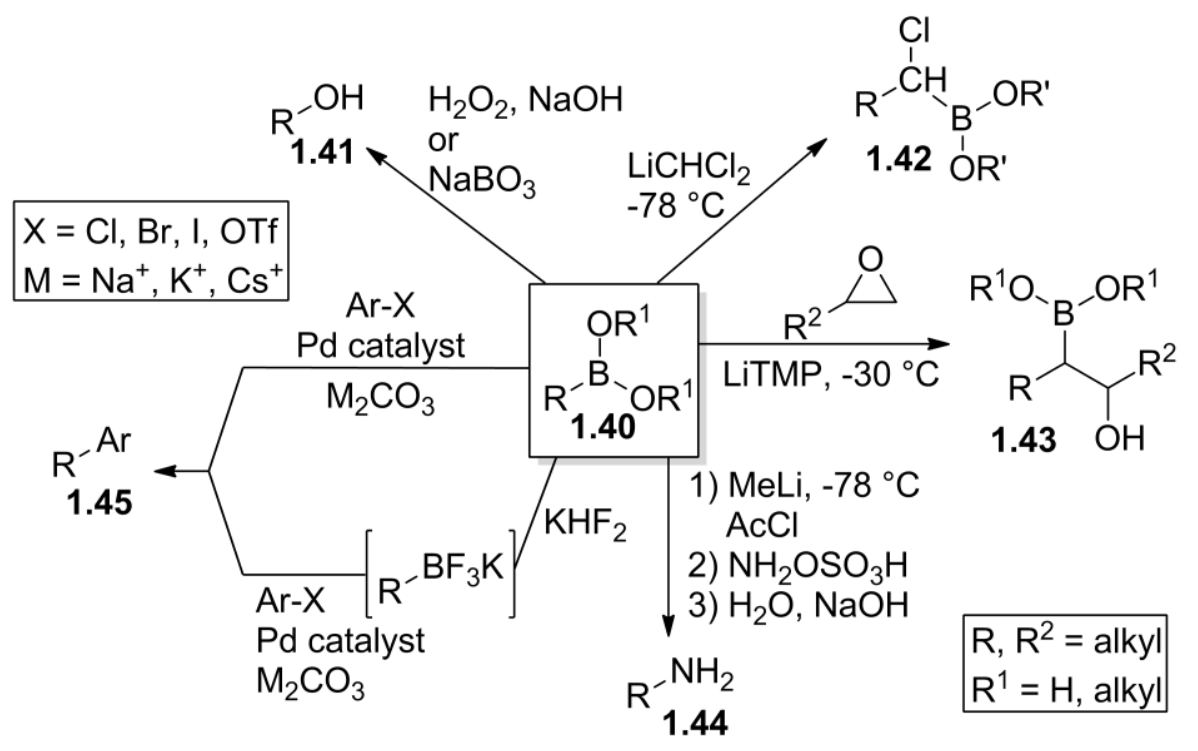

Scheme 1.9. Transformations of $s p^{3}$-hybridized organoboron compounds. 
catalyzed SMC reactions of alkylboronic acids and esters have proven to be very difficult due to decomposition of intermediates. ${ }^{74}$ Even so, a few specific examples of SMC have been reported for the preparation of $\mathbf{1 . 4 5}$ directly from an alkylboronic ester, ${ }^{75}$ or by first converting to the potassium organotrifluoroborate salt. ${ }^{76,77}$ The exploration of organoboronic acids derivatives as synthetic intermediates is a developing field, however, carbon-boron bonds are not found in naturally occurring chemical structures so they must be specifically introduced. Thus, their utility is inherently limited to the scope of organoboron preparation methods.

\subsection{Preparation of organoboron compounds}

The first suggested synthesis of a boronic ester was reported by Frankland in 1860 through the atmospheric oxidation of a trialkylborane, however, this method is generally considered undesirable due to critical limitations; the three alkyl substituents must be identical and the product decomposed in water to the corresponding boronic acid. ${ }^{78,79}$ In 1954 , Schlesinger reported the diboration of ethylene using an electrophilic tetrachlorodiboron, but similarly, the product was too unstable to prove useful. ${ }^{31}$ Despite these initial suggestions that organoboron compounds are not suitable for further examination as synthetic intermediates, a promising avenue was found when cyclic complexes were formed upon treatment with several 1,2-diols, some of which showed a dramatic increase in stability. ${ }^{3}$ In fact, the synthesis of organoboronic acids that are "protected" by complexation with 1,2-diols dominate the literature.

Two practical methods currently exist for the formation of carbon-boron bonds. The oldest approach exploits the electrophilicity of a trialkylborate for the trapping of a Grignard reagent (1.46) $)^{80,81}$ and later organolithium reagent $(\mathbf{1 . 4 7})^{82}$ for the synthesis of aryl boronic acids 
Scheme 1.10. Electrophilic trapping of trialkylborates.

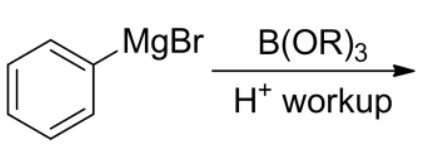

1.46<smiles>OB(O)c1ccccc1</smiles>

1.48

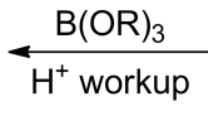

${ }^{\mathrm{Li}}$

1.47

(1.48; Scheme 1.10). 1.46 and 1.47 are highly reactive reagents, but suffer from severe drawbacks because they are harsh nucleophiles, strong bases, and prone to self-decomposition. A second method was developed to provide more mild and controllable conditions for the construction of $\mathrm{C}-\mathrm{B}$ bonds, utilizing diboron reagents in the presence of a transition metal catalyst to assist in breaking the moderately strong boron-boron bond $(68 \mathrm{kcal} / \mathrm{mol}){ }^{2}$ This approach has been proven to be effective for the mono- and diboration of alkenes, and the boryl substitution of $\mathrm{C}-\mathrm{H}$ and $\mathrm{C}-\mathrm{X}$ bonds, significantly expanding the breadth of achievable organoboron structures. ${ }^{83}$ Beginning with the most common diboron reagent 1.49 [bis(pinacolato)diboron], the structure of the borated product can easily be controlled through the

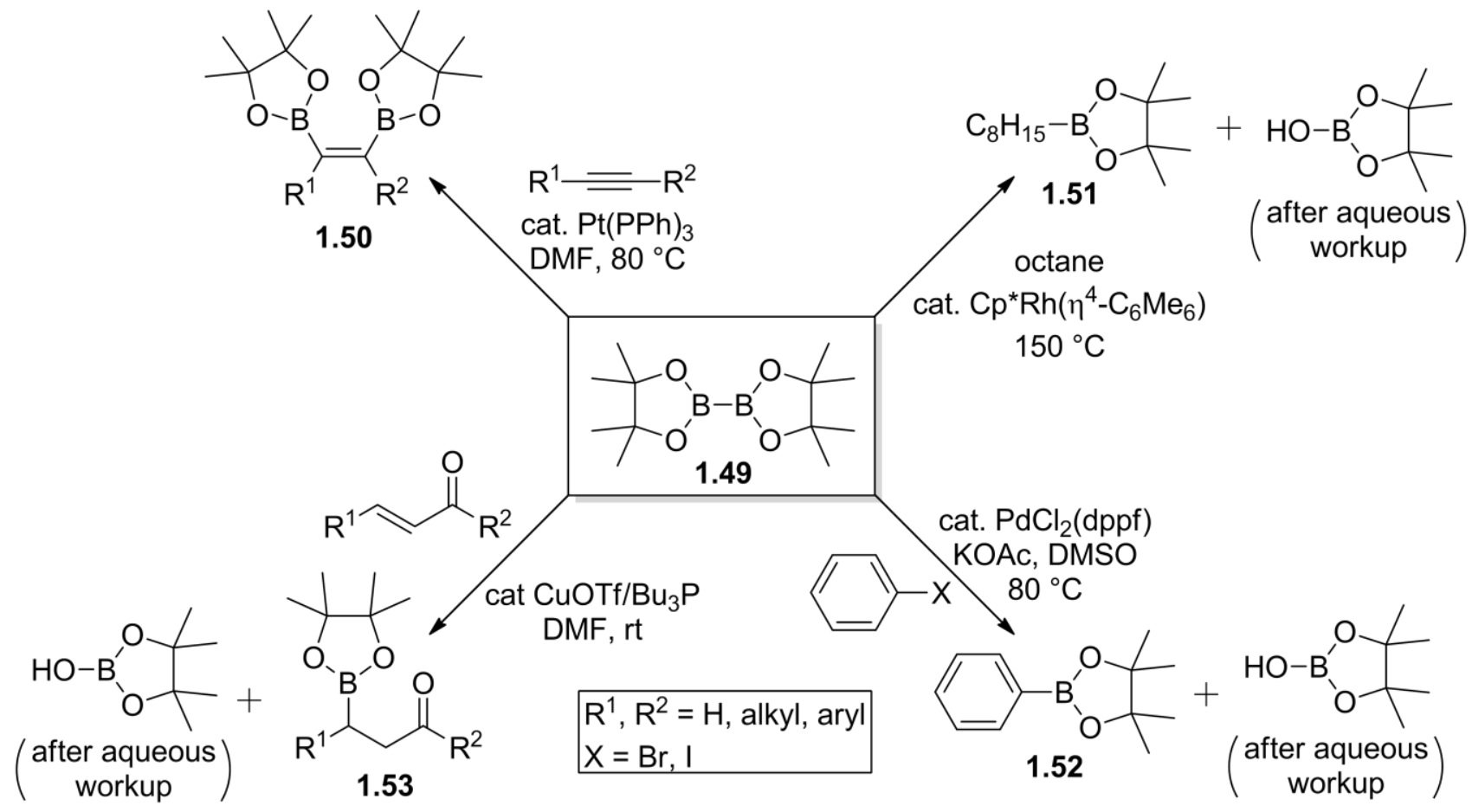

Scheme 1.11. Divergent organoboron synthesis with bis(pinacolato)diboron 1.49 . 
choice of catalyst and conditions (Scheme 1.11). Notable milestones in this field include: the diboration of both terminal and internal alkynes with $>99 \%$ cis-selectivity using a platinum(0) catalyst to produce diboryl alkene $\mathbf{1 . 5 0}^{84}$ and the following extension to alkene substrates, ${ }^{85,86} \mathrm{C}$ $\mathrm{H}$ activation of simple alkanes by a rhodium(I) catalyst at high temperature to provide alkylboronic ester $\mathbf{1 . 5 1},{ }^{87}$ and SMC-type cross-coupling with aryl halides in the presence of a palladium(0) source - typically generated in situ - to prepare aryboronic ester $\mathbf{1 . 5 2},{ }^{88}$ which was later extended to other substrates ${ }^{89-91}$ and also accomplished with a copper salt. ${ }^{92}$ Of particular interest to our group was the copper-catalyzed conjugate addition of $\mathbf{1 . 4 9}$ to electron-deficient alkenes for the preparation of $\beta$-boryl carbonyl compounds $(\mathbf{1 . 5 3}),{ }^{93}$ which provided a route to boron-substituted amino acid analogs, as described below in greater detail. A few reports using gold $^{94,95}$ or iridium ${ }^{96}$ catalysts to affect these transformations have emerged, however, more preferable conditions are available with other metals.

The author of this dissertation was involved in the synthesis of N-terminal peptidic boronic acids, as a complement to C-terminal variants such as Velcade, ${ }^{23}$ for potential use as protease inhibitiors. Michael-type conjugate addition of an intermediate boryl nucleophile to $\alpha, \beta$-unsaturated ester $\mathbf{1 . 5 4}$ provided the desired positioning of the pinacol-protected boronic acid-to mimic the scissile amide bond-in a single step (1.55; Scheme 1.12). Subsequent saponification of the ester provided amino acid analogue $\mathbf{1 . 5 6}$ for incorporation into a short peptide sequence through standard solid phase peptide synthesis (SPPS) techniques with HCTU coupling chemistry. During the side chain deprotection step in SPPS, the pinacol group was removed as well, providing $\mathrm{N}$-terminal peptidic boronic acid 1.57. Indeed, the utility of these small boronic acid peptides was exemplified by the selective inhibition of human ClpXP over human Lon, which are two serine proteases with common substrates. ${ }^{17}$ Although further 
Scheme 1.12. Synthesis of boron-containing amino acid analogues.<smiles>[R]C=C([R])C(=O)O[AlH2]</smiles>

1.54

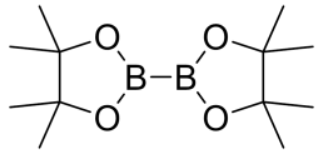

(1.1 equiv)

$\mathrm{CuCl}(3 \mathrm{~mol} \%)$ DPEphos (3 mol \%) $\mathrm{NaO}^{t} \mathrm{Bu}(9 \mathrm{~mol} \%)$ $\mathrm{MeOH}$ (2 equiv) THF, rt, 1-24 h

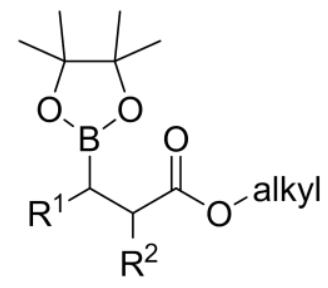

1.55

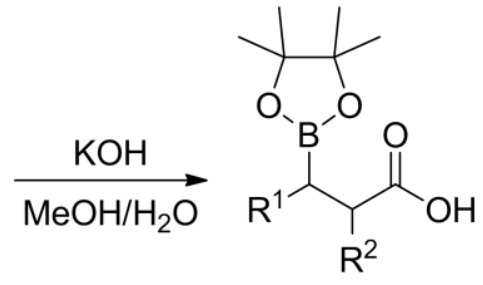

1.56

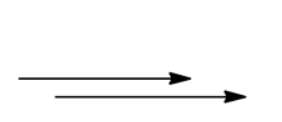

applications of peptide $\mathbf{1 . 5 7}$ are being considered, the conditions for the $\beta$-boration protocol were troublesome. As a synthetic chemistry group, we were concerned by the number of additives required-including an expensive phosphine and strong base (Scheme 1.12)—and the lack of definitive mechanistic evidence for the role of each. To understand the origin of these requirements, it is important to examine the history of advancements and variations of the $\beta$ boration protocol.

The first conjugate addition of diboron 1.49 to an electron-deficient alkene, 1.58, was reported in 1997 using a platinum catalyst (path A; Scheme 1.13). ${ }^{97}$ Under similar conditions, a rhodium catalyst was shown in 2002 to affect the same transformation, albeit in lower yields (path B). ${ }^{98}$ A nickel-phosphine complex developed in 2007 provided inconsistent yields of $\mathbf{1 . 5 9}$ (path C),${ }^{99}$ and comparable results were published in 2010 using palladium (path D) ${ }^{75}$ Several drawbacks are evident using these conditions, including the use of an expensive metal catalyst and ligand, high temperatures ( $\mathbf{A}$ and $\mathbf{B})$, excess base $(\mathbf{C}$ and $\mathbf{D})$, long reaction times, or a complicated solvent system (C). Two metal-free protocols have indeed been described with $\mathrm{N}$ - 
Scheme 1.13. $\beta$-Boration with A) platinum, B) rhodium, C) nickel, and D) palladium catalysts.

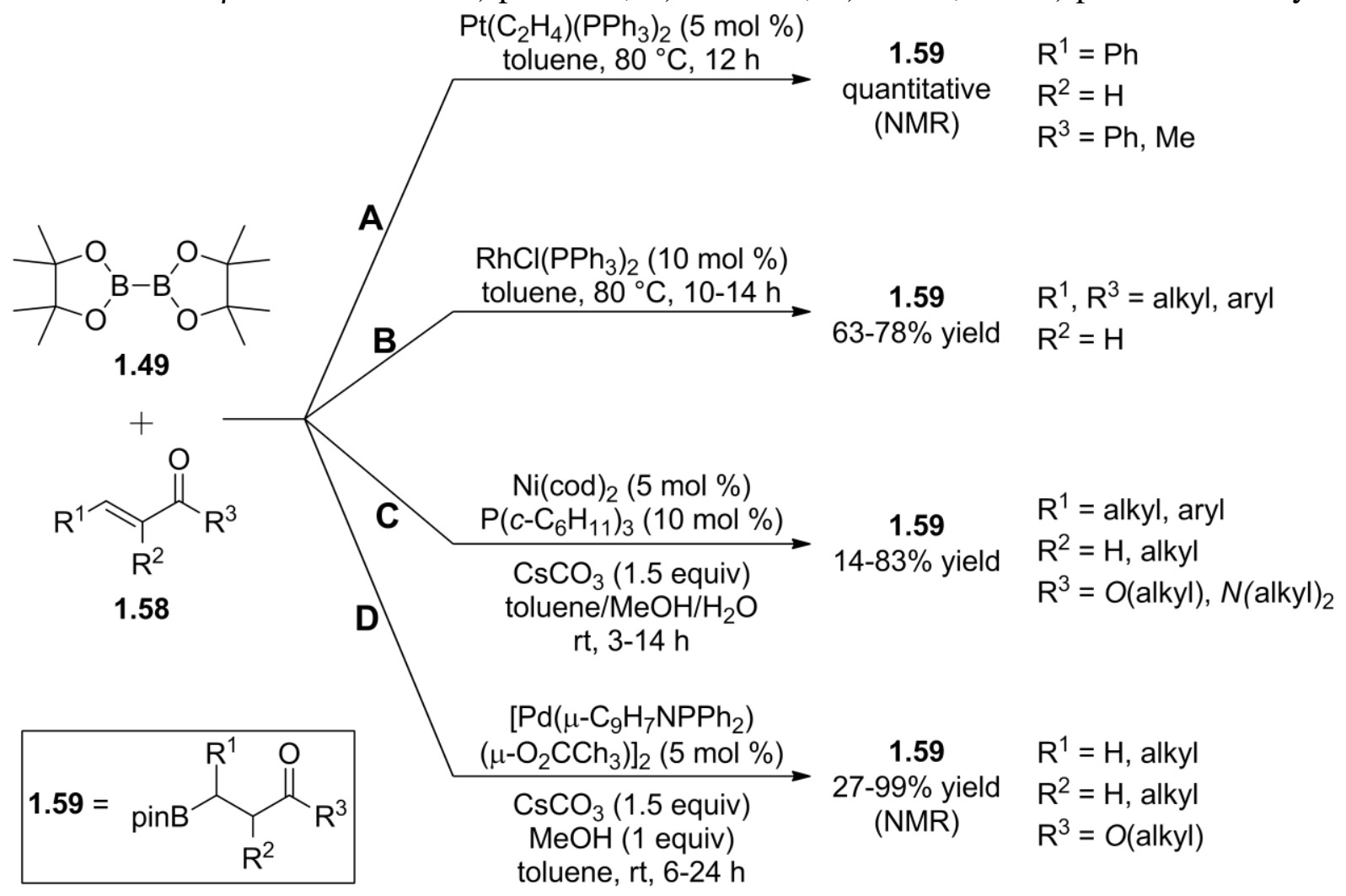

heterocyclic carbene (NHC) ${ }^{100}$ and phosphine catalysts; ${ }^{101}$ however, they are difficult to repeat which leads to concerns of contamination. None of these reports have affected the field as much as those utilizing a copper catalyst, first reported independently by $\mathrm{Hosomi}^{102}$ and Miyaura ${ }^{89}$ in 2000. In addition to the significantly lower price of copper salts, Yun discovered in 2006 that alcohol additives dramatically increased the reaction rate and afforded the desired products in only a few hours. ${ }^{103}$ The specific role of the alcohol additive, first proposed to assist in catalyst turnover by serving as a proton source, was supported by DFT calculations two years later. ${ }^{104}$ However, phosphine and strong base were also necessary to achieve sufficient yields of $\beta$ borated product with copper at room temperature, which add to the cost and operational difficulty of this method, and restrict the use of sensitive substrates. Nonetheless, the efficiency of copper-catalyzed boration methods have led to the development of a myriad of asymmetric 
methods with chiral phosphine, ${ }^{4,105-108}$ amine, ${ }^{33}$ and NHC ligands. ${ }^{109}$ Furthermore, the coppermediated transformation could be extended beyond the 3,4-boryl addition with $\alpha, \beta$-unsaturated carbonyl substrates to $\mathrm{S}_{\mathrm{N}} 2$ ' substitution of allylic carbonates, ${ }^{110}$ 1,2-addition to aldehydes, ${ }^{111}$ and conjugate addition to tert-butylsulfinyl aldimines, ${ }^{112}$ which exemplifies the seemingly unlimited utility of this method.

\subsection{Dissertation overview}

Chapter 1 describes the general properties of organoboron compounds including structure, stability, and mechanisms of reactivity. The current and potential utility of organoboron compounds as pharmaceutical agents is discussed, focusing on the unique selectivity of boron towards alcoholic residues. Applications as synthetic intermediates is then presented, focusing on the rationale behind reactivity and the conditional factors that contribute to successful transformations. Finally, because carbon-boron bonds are not naturally occurring, the history of available synthetic methods is examined to identify the current strengths and weaknesses.

In Chapter 2, the theory, synthesis, and unambiguous structural analysis of an unsymmetrical, internally activated diboron reagent is described. This novel reagent allows for the copper-catalyzed $\beta$-boration reaction to occur in the absence of phosphine or tert-butoxide, which offers an improvement to the established protocol and also provides mechanistic insight into the role of base in previous methods. A kinetic study on the effect of protic additives improved the reaction efficiency, which allowed the substrate scope to be extended to difficult substrates, such as $\alpha, \beta$-unsaturated aldehydes. Based on the new information gathered, a plausible catalytic cycle was proposed. 
Chapter 3 describes an application of the novel diboron reagent presented in Chapter 2 towards generating a difficult molecular structure using allenoates as the substrates. From racemic starting materials, a single diastereomer was formed in good yield in the absence of a chiral ligand or auxiliary. A rationale for this stereochemical induction is presented, along with a proposed catalytic cycle and a demonstrated utility of the resulting vinyl boronic ester by SMC to prepare a trisubstituted alkene with defined stereochemistry.

In Chapter 4 , an unexpected $\beta$-boration reaction in water and open to air is described using a commercially available diboron reagent. A low copper catalyst load and amine ligand provided excellent product yields, notwithstanding the insolubility of both starting materials. UV-Vis, ${ }^{11} \mathrm{~B}$ NMR, and solvent kinetic isotope effect studies suggested an interesting bifunctional role of the amine; as a ligand for copper and Bronsted base to promote proton transfer in the rate-determining step. Initial kinetic studies also suggest the possibility of an autocatalytic reaction. Attempts to ascertain enantioselective conditions were unsuccessful, but rationalized by a dynamic catalyst structure and weak metal to ligand bonding.

Chapter 5 contains general methods, instrumentation, experimental details and product characterizations for Chapters 2-4. Included therein are several interesting analytical results, such as a 2-dimensional NMR spectrum to identify a carbon that was not observed in the 1dimensional spectrum and an example NOE spectrum to identify the stereochemistry of the resulting alkenes in Chapter 3.

\subsection{References for Chapter 1}

1. Hall, D. G. Boronic Acids: Preparation and Applications in Organic Synthesis, Medicine and Materials; 2nd ed.; Wiley-VCH, 2011. 
2. Sana, M.; Leroy, G.; Wilante, C. Enthalpies of Formation and Bond Energies in Lithium, Beryllium, and Boron Derivatives. A Theoretical Attempt for Data Rationalization Organometallics 1991, 10, 264-270.

3. Kuivila, H. G.; Keough, A. H.; Soboczenski, E. J. Areneboronates From Diols and Polyols $J$. Org. Chem. 1954, 19, 780-783.

4. Schiffner, J. A.; Müther, K.; Oestreich, M. Enantioselective Conjugate Borylation Angew. Chem. Int. Ed. 2010, 49, 1194-1196.

5. Rettig, S. J.; Trotter, J. Crystal and Molecular Structure of $\beta$-Phenyl-diptychboroxazolidine Can. J. Chem. 1975, 53, 1393-1401.

6. Matteson, D. S. Stereodirected Synthesis with Organoboranes; Springer: Berlin; New York, 1995.

7. Darses, S.; Genet, J.-P. Potassium Organotrifluoroborates: New Perspectives in Organic Synthesis Chem. Rev. 2008, 108, 288-325.

8. Brauer, D. J.; Bürger, H.; Pawelke, G. Fluorine Substitution Effects in Organoborate Chemistry: Vibrational and X-ray Structural Analyses of $\mathrm{K}\left[\mathrm{CH}_{3} \mathrm{BF}_{3}\right]$ J. Organomet. Chem. 1982, 238, 267-279.

9. Brown, H. C.; Midland, M. M.; Kabalka, G. W. Stoichiometrically Controlled Reaction of Organoboranes with Oxygen Under Very Mild Conditions to Achieve Essentially Quantitative Conversion into Alcohols J. Am. Chem. Soc. 1971, 93, 1024-1025.

10. London, R. E.; Gabel, S. A. Formation of a Trypsin-Borate-4-Aminobutanol Ternary Complex Biochemistry 2002, 41, 5963-5967.

11. Transue, T. R.; Krahn, J. M.; Gabel, S. A.; DeRose, E. F.; London, R. E. X-ray and NMR Characterization of Covalent Complexes of Trypsin, Borate, and Alcohols Biochemistry 2004, 43, 2829-2839.

12. Kettner, C.; Mersinger, L.; Knabb, R. The Selective Inhibition of Thrombin by Peptides of Boroarginine J. Biol. Chem. 1990, 265, 18289-18297.

13. Soskel, N. T.; Watanabe, S.; Hardie, R.; Shenvi, A. B.; Punt, J. A.; Kettner, C. A New Peptide Boronic Acid Inhibitor of Elastase-Induced Lung Injury in Hamsters Am. Rev. Respir. Dis. 1986, 133, 639.

14. Snow, R. J.; Bachovchin, W. W.; Barton, R. W.; Campbell, S. J.; Coutts, S. J.; Freeman, D. M.; Gutheil, W. G.; Kelly, T. A.; Kennedy, C. A. Studies on Proline Boronic Acid Dipeptide Inhibitors of Dipeptidyl Peptidase IV: Identification of a Cyclic Species Containing a B-N Bond J. Am. Chem. Soc. 1994, 116, 10860-10869. 
15. Priestley, E. S.; De Lucca, I.; Ghavimi, B.; Erickson-Viitanen, S.; Decicco, C. P. P1 Phenethyl Peptide Boronic Acid Inhibitors of HCV NS3 Protease Bioorg. Med. Chem. Lett. 2002, 12, 3199-3202.

16. Chen, Y.; Shoichet, B.; Bonnet, R. Structure, Function, and Inhibition along the Reaction Coordinate of CTX-M $\beta$-Lactamases J. Am. Chem. Soc. 2005, 127, 5423-5434.

17. Knott, K.; Fishovitz, J.; Thorpe, S. B.; Lee, I.; Santos, W. L. N-Terminal Peptidic Boronic Acids Selectively Inhibit Human ClpXP Org. Biomol. Chem. 2010, 8, 3451-3456.

18. London, R. E.; Gabel, S. A. Development and Evaluation of a Boronate Inhibitor of $\gamma$ Glutamyl Transpeptidase Arch. Biochem. Biophys. 2001, 385, 250-258.

19. Albers, H. M. H. G.; van Meeteren, L. A.; Egan, D. A.; van Tilburg, E. W.; Moolenaar, W. H.; Ovaa, H. Discovery and Optimization of Boronic Acid Based Inhibitors of Autotaxin J. Med. Chem. 2010, 53, 4958-4967.

20. Baggio, R.; Elbaum, D.; Kanyo, Z. F.; Carroll, P. J.; Cavalli, R. C.; Ash, D. E.; Christianson, D. W. Inhibition of Mn2+2-Arginase by Borate Leads to the Design of a Transition State Analogue Inhibitor, 2(S)-Amino-6-boronohexanoic Acid J. Am. Chem. Soc. 1997, 119, 81078108.

21. Baker, S. J.; Tomsho, J. W.; Benkovic, S. J. Boron-Containing Inhibitors of Synthetases Chem. Soc. Rev. 2011, 40, 4279-4285.

22. Adams, J.; Behnke, M.; Chen, S.; Cruickshank, A. A.; Dick, L. R.; Grenier, L.; Klunder, J. M.; Ma, Y.-T.; Plamondon, L.; Stein, R. L. Potent and Selective Inhibitors of the Proteasome: Dipeptidyl Boronic Acids Bioorg. Med. Chem. Lett. 1998, 8, 333-338.

23. Groll, M.; Berkers, C. R.; Ploegh, H. L.; Ovaa, H. Crystal Structure of the Boronic AcidBased Proteasome Inhibitor Bortezomib in Complex with the Yeast 20S Proteasome Structure 2006, 14, 451-456.

24. Borissenko, L.; Groll, M. 20S Proteasome and Its Inhibitors: Crystallographic Knowledge for Drug Development Chem. Rev. 2007, 107, 687-717.

25. Baker, S. J.; Zhang, Y.-K.; Akama, T.; Lau, A.; Zhou, H.; Hernandez, V.; Mao, W.; Alley, M. R. K.; Sanders, V.; Plattner, J. J. Discovery of a New Boron-Containing Antifungal Agent, 5 Fluoro-1,3-dihydro-1-hydroxy-2,1-benzoxaborole (AN2690), for the Potential Treatment of Onychomycosis J. Med. Chem. 2006, 49, 4447-4450.

26. Goldbach, H. E.; Wimmer, M. A. Boron in Plants and Animals: Is There a Role Beyond Cell-Wall Structure? J. Plant Nutr. Soil Sci. 2007, 170, 39-48.

27. Dembitsky, V. M.; Al Quntar, A. A. A.; Srebnik, M. Natural and Synthetic Small BoronContaining Molecules as Potential Inhibitors of Bacterial and Fungal Quorum Sensing Chem. Rev. 2011, 111, 209-237. 
28. Baker, S. J.; Ding, C. Z.; Akama, T.; Zhang, Y.-K.; Hernandez, V.; Xia, Y. Therapeutic Potential of Boron-Containing Compounds Future Medicinal Chemistry 2009, 1, 1275-1288.

29. Brown, H. C.; Rao, B. C. S. A New Technique for the Conversion of Olefins into Organoboranes and Related Alcohols J. Am. Chem. Soc. 1956, 78, 5694-5695.

30. Brown, H.; Rao, B. C. Hydroboration of Olefins. A Remakably Fast Room-Temperature Addition of Diborane to Olefins J. Org. Chem. 1957, 22, 1136-1137.

31. Urry, G.; Kerrigan, J.; Parsons, T. D.; Schlesinger, H. I. Diboron Tetrachloride, $\mathrm{B}_{2} \mathrm{Cl}_{4}$, as a Reagent for the Synthesis of Organoboron Compounds. The Reaction of Diboron Tetrachloride with Ethylene J. Am. Chem. Soc. 1954, 76, 5299-5301.

32. Miyaura, N.; Yamada, K.; Suzuki, A. A New Stereospecific Cross-Coupling by the Palladium-Catalyzed Reaction of 1-Alkenylboranes with 1-Alkenyl or 1-Alkynyl Halides Tetrahedron Lett. 1979, 20, 3437-3440.

33. Chen, I. H.; Kanai, M.; Shibasaki, M. Copper(I)-Secondary Diamine Complex-Catalyzed Enantioselective Conjugate Boration of Linear $\beta, \beta$-Disubstituted Enones Org. Lett. 2010, 12, 4098-4101.

34. Kurahashi, T.; Hata, T.; Masai, H.; Kitagawa, H.; Shimizu, M.; Hiyama, T. Geminal Dimetalation of Alkylidene-Type Carbenoids with Silylboranes and Diborons Tetrahedron 2002, 58, 6381-6395.

35. Ohmura, T.; Awano, T.; Suginome, M. Stereospecific Suzuki-Miyaura Coupling of Chiral $\alpha$-(Acylamino)benzylboronic Esters with Inversion of Configuration J. Am. Chem. Soc. 2010, 132, 13191-13193.

36. Parshall, G. W.; Mrowca, J. J. $\sigma$-Alkyl and -Aryl Derivatives of Transition Metals In Advances in Organometallic Chemistry; Stone, F. G. A., Robert, W., Eds.; Academic Press: 1969; Vol. Volume 7, pp 157-209.

37. Chan, D. M. T.; Monaco, K. L.; Wang, R.-P.; Winters, M. P. New $N$ - and $O$-Arylations with Phenylboronic Acids and Cupric Acetate Tetrahedron Lett. 1998, 39, 2933-2936.

38. Lam, P. Y. S.; Clark, C. G.; Saubern, S.; Adams, J.; Winters, M. P.; Chan, D. M. T.; Combs, A. New Aryl/Heteroaryl C-N Bond Cross-Coupling Reactions via Arylboronic Acid/Cupric Acetate Arylation Tetrahedron Lett. 1998, 39, 2941-2944.

39. Evans, D. A.; Katz, J. L.; West, T. R. Synthesis of Diaryl Ethers Through the CopperPromoted Arylation of Phenols with Arylboronic Acids. An Expedient Synthesis of Thyroxine Tetrahedron Lett. 1998, 39, 2937-2940.

40. Gilman, H.; Jones, R. G.; Woods, L. A. The Preparation of Methylcopper and Some Observations on the Decomposition of Organocopper Compounds J. Org. Chem. 1952, 17, 16301634. 
41. Whitesides, G. M.; Stedronsky, E. R.; Casey, C. P.; San Filippo, J. Mechanism of Thermal Decomposition of ${ }^{n}$ butyl(tri- ${ }^{n}$ butylphosphine) copper(I) J. Am. Chem. Soc. 1970, 92, 1426-1427.

42. Du, X.; Suguro, M.; Hirabayashi, K.; Mori, A.; Nishikata, T.; Hagiwara, N.; Kawata, K.; Okeda, T.; Wang, H. F.; Fugami, K.; Kosugi, M. Mizoroki-Heck Type Reaction of Organoboron Reagents with Alkenes and Alkynes. A Pd(II)-Catalyzed Pathway with $\mathrm{Cu}(\mathrm{OAc})_{2}$ as an Oxidant Org. Lett. 2001, 3, 3313-3316.

43. Ruan, J.; Li, X.; Saidi, O.; Xiao, J. Oxygen and Base-Free Oxidative Heck Reactions of Arylboronic Acids with Olefins J. Am. Chem. Soc. 2008, 130, 2424-2425.

44. Canty, A. J.; Jin, H.; Roberts, A. S.; Skelton, B. W.; Traill, P. R.; White, A. H. Synthesis and Characterization of Ambient Temperature Stable Organopalladium(IV) Complexes, Including Aryl-, $\eta^{1}$-Allyl-, Ethylpalladium(IV), and Pallada(IV)cyclopentane Complexes. Structures of the Poly(pyrazol-1-yl)borate Complexes $\mathrm{PdMe}_{3}\left\{(\mathrm{pz})_{3} \mathrm{BH}\right\}$ and $\mathrm{PdMe}_{3}\{(\mathrm{pz}) 4 \mathrm{~B}\}$ and Three Polymorphs of $\mathrm{PdMe}_{2} \mathrm{Et}\left\{(\mathrm{pz})_{3} \mathrm{BH}\right\}$ Organometallics 1995, 14, 199-206.

45. Miyaura, N.; Suzuki, A. Palladium-Catalyzed Cross-Coupling Reactions of Organoboron Compounds Chem. Rev. 1995, 95, 2457-2483.

46. Wolfe, J. P.; Buchwald, S. L. A Highly Active Catalyst for the Room-Temperature Amination and Suzuki Coupling of Aryl Chlorides Angew. Chem. Int. Ed. 1999, 38, 2413-2416.

47. Widdowson, D. A.; Wilhelm, R. Palladium Catalysed Suzuki Reactions of Fluoroarenes Chem. Commun. 2003.

48. Chen, Z.; O’Donnell, C. J.; Maderna, A. Synthesis of 3-Methoxy-9-(3,4,5trimethoxyphenyl)-6,7-dihydro-5H-benzo[7]annulen-4-ol, a Potent Antineoplastic Benzosuberene Derivative for Anti-Cancer Chemotherapy Tetrahedron Lett. 2012, 53, 64-66.

49. Garg, N. K.; Caspi, D. D.; Stoltz, B. M. The Total Synthesis of (+)-Dragmacidin F J. Am. Chem. Soc. 2004, 126, 9552-9553.

50. Yamamura, M.; Moritani, I.; Murahashi, S.-I. The Reaction of $\sigma$-Vinylpalladium Complexes with Alkyllithiums. Stereospecific Syntheses of Olefins from Vinyl Halides and Alkyllithiums $J$. Organomet. Chem. 1975, 91, C39-C42.

51. Murahashi, S.; Yamamura, M.; Yanagisawa, K.; Mita, N.; Kondo, K. Stereoselective Synthesis of Alkenes and Alkenyl Sulfides from Alkenyl Halides Using Palladium and Ruthenium Catalysts J. Org. Chem. 1979, 44, 2408-2417.

52. Baba, S.; Negishi, E. A Novel Stereospecific Alkenyl-Alkenyl Cross-Coupling by a Palladium- or Nickel-Catalyzed Reaction of Alkenylalanes with Alkenyl Halides J. Am. Chem. Soc. 1976, 98, 6729-6731.

53. Negishi, E.; King, A. O.; Okukado, N. Selective Carbon-Carbon Bond Formation via Transition Metal Catalysis. A Highly Selective Synthesis of Unsymmetrical Biaryls and 
Diarylmethanes by the Nickel- or Palladium-Catalyzed Reaction of Aryl- and Benzylzinc Derivatives with Aryl Halides J. Org. Chem. 1977, 42, 1821-1823.

54. Kosugi, M.; Shimizu, Y.; Migita, T. Alkylation, Arylation, and Vinylation of Acyl Chlorides by Means of Organotin Compounds in the Presence of Catalytic Amounts of Tetrakis(triphenylphosphine)palladium(0) Chem. Lett. 1977, 1423.

55. Milstein, D.; Stille, J. K. Palladium-Catalyzed Coupling of Tetraorganotin Compounds with Aryl and Benzyl Halides. Synthetic Utility and Mechanism J. Am. Chem. Soc. 1979, 101, 49924998.

56. Jabri, N.; Alexakis, A.; Normant, J. F. Vinyl-Copper Derivatives: Synthesis of Conjugated Dienes of Very High Stereoisomeric Purity Tetrahedron Lett. 1981, 22, 959-962.

57. Hatanaka, Y.; Hiyama, T. Cross-Coupling of Organosilanes with Organic Halides Mediated by a Palladium Catalyst and Tris(diethylamino)sulfonium Difluorotrimethylsilicate J. Org. Chem. 1988, 53, 918-920.

58. Amatore, C.; Jutand, A. Mechanistic and Kinetic Studies of Palladium Catalytic Systems $J$. Organomet. Chem. 1999, 576, 254-278.

59. Stille, J. K.; Lau, K. S. Y. Mechanisms of Oxidative Addition of Organic Halides to Group 8 Transition-Metal Complexes Acc. Chem. Res. 1977, 10, 434-442.

60. Jutand, A.; Mosleh, A. Rate and Mechanism of Oxidative Addition of Aryl Triflates to Zerovalent Palladium Complexes. Evidence for the Formation of Cationic ( $\sigma$-Aryl)palladium Complexes Organometallics 1995, 14, 1810-1817.

61. Littke, A. F.; Dai, C.; Fu, G. C. Versatile Catalysts for the Suzuki Cross-Coupling of Arylboronic Acids with Aryl and Vinyl Halides and Triflates under Mild Conditions J. Am. Chem. Soc. 2000, 122, 4020-4028.

62. Punji, B.; Ganesamoorthy, C.; Balakrishna, M. S. Suzuki Cross-Coupling Reactions Catalyzed by Palladium Complex of an Inexpensive Phosphinite, 2-

Diphenylphosphinoxynaphthyl J. Mol. Catal. A: Chem. 2006, 259, 78-83.

63. Matos, K.; Soderquist, J. A. Alkylboranes in the Suzuki-Miyaura Coupling: Stereochemical and Mechanistic Studies J. Org. Chem. 1998, 63, 461-470.

64. Smith, G. B.; Dezeny, G. C.; Hughes, D. L.; King, A. O.; Verhoeven, T. R. Mechanistic Studies of the Suzuki Cross-Coupling Reaction J. Org. Chem. 1994, 59, 8151-8156.

65. Liang, L.-C.; Chien, P.-S.; Huang, M.-H. Catalytic Suzuki Coupling Reactions by Amido Phosphine Complexes of Palladium Organometallics 2005, 24, 353-357.

66. Smith, R. C.; Bodner, C. R.; Earl, M. J.; Sears, N. C.; Hill, N. E.; Bishop, L. M.; Sizemore, N.; Hehemann, D. T.; Bohn, J. J.; Protasiewicz, J. D. Suzuki and Heck Coupling Reactions 
Mediated by Palladium Complexes Bearing Trans-Spanning Diphosphines J. Organomet. Chem. 2005, 690, 477-481.

67. Molander, G. A.; Biolatto, B. Palladium-Catalyzed Suzuki-Miyaura Cross-Coupling Reactions of Potassium Aryl- and Heteroaryltrifluoroborates J. Org. Chem. 2003, 68, 4302-4314.

68. Butters, M.; Harvey, J. N.; Jover, J.; Lennox, A. J. J.; Lloyd-Jones, G. C.; Murray, P. M. Aryl Trifluoroborates in Suzuki-Miyaura Coupling: The Roles of Endogenous Aryl Boronic Acid and Fluoride Angew. Chem. 2010, 122, 5282-5286.

69. Brown, H. C.; Mark Midland, M.; Kabalka, G. W. Organoboranes for Synthesis. Stoichiometrically Controlled Reaction of Organoboranes with Oxygen Under Mild Conditions to Achieve Quantitative Conversion to Alcohols Tetrahedron 1986, 42, 5523-5530.

70. Kabalka, G. W.; Shoup, T. M.; Goudgaon, N. M. Sodium Perborate: A Mild and Convenient Reagent for Efficiently Oxidizing Trialkylboranes Tetrahedron Lett. 1989, 30, 1483-1486.

71. Matteson, D. S.; Majumdar, D. $\alpha$-Chloro Boronic Esters from Homologation of Boronic Esters J. Am. Chem. Soc. 1980, 102, 7588-7590.

72. Vedrenne, E.; Wallner, O. A.; Vitale, M.; Schmidt, F.; Aggarwal, V. K. Homologation of Boronic Esters with Lithiated Epoxides for the Stereocontrolled Synthesis of 1,2- and 1,3-Diols and 1,2,4-Triols Org. Lett. 2009, 11, 165-168.

73. Brown, H. C.; Kim, K. W.; Cole, T. E.; Singaram, B. Chiral Synthesis via Organoboranes. Synthetic Utility of Boronic Esters of Essentially 100\% Optical Purity. Synthesis of Primary Amines of Very High Enantiomeric Purities J. Am. Chem. Soc. 1986, 108, 6761-6764.

74. Otsuka, S.; Nakamura, A.; Yoshida, T.; Naruto, M.; Ataka, K. Chemistry of Alkoxycarbonyl, Acyl, and Alkyl Compounds of Nickel(II) and Palladium(II) J. Am. Chem. Soc. 1973, 95, 3180-3188.

75. Bonet, A.; Gulyás, H.; Koshevoy, I. O.; Estevan, F.; Sanaú, M.; Úbeda, M. A.; Fernández, E. Tandem $\beta$-Boration/Arylation of $\alpha, \beta$-Unsaturated Carbonyl Compounds by Using a Single Palladium Complex To Catalyse Both Steps Chem. Eur. J. 2010, 16, 6382-6390.

76. Sandrock, D. L.; Jean-Gérard, L.; Chen, C.-y.; Dreher, S. D.; Molander, G. A. Stereospecific Cross-Coupling of Secondary Alkyl $\beta$-Trifluoroboratoamides J. Am. Chem. Soc. 2010, 132, 17108-17110.

77. Molander, G. A.; Sandrock, D. L. Orthogonal Reactivity in Boryl-Substituted Organotrifluoroborates J. Am. Chem. Soc. 2008, 130, 15792-15793.

78. Frankland, E.; Duppa, B. F. Vorläufige Notiz über Boräthyl Justus Liebigs Annalen der Chemie 1860, 115, 319-322.

79. Frankland, E.; Duppa, B. On Boric Ethide Proceedings of the Royal Society of London 1860, 10, 568-570. 
80. Seaman, W.; Johnson, J. R. Derivatives of Phenylboric Acid, Their Preparation and Action upon Bacteria J. Am. Chem. Soc. 1931, 53, 711-723.

81. Bean, F. R.; Johnson, J. R. Derivatives of PhenylBoric Acid, Their Preparation and Action upon Bacteria. Hydroxyphenylboric Acids J. Am. Chem. Soc. 1932, 54, 4415-4425.

82. Brown, H. C.; Cole, T. E. Organoboranes. A Simple Preparation of Boronic Esters from Organolithium Reagents and Selected Trialkoxyboranes Organometallics 1983, 2, 1316-1319.

83. Ishiyama, T.; Miyaura, N. Metal-Catalyzed Reactions of Ciborons for Synthesis of Organoboron Compounds Chem. Rec. 2004, 3, 271-280.

84. Ishiyama, T.; Matsuda, N.; Miyaura, N.; Suzuki, A. Platinum(0)-Catalyzed Diboration of Alkynes J. Am. Chem. Soc. 1993, 115, 11018-11019.

85. Ishiyama, T.; Yamamoto, M.; Miyaura, N. Diboration of Alkenes with Bis(pinacolato)diboron Catalysed by a Platinum(0) Complex Chem. Commun. 1997, 689.

86. Iverson, C. N.; Smith, M. R. Efficient Olefin Diboration by a Base-Free Platinum Catalyst Organometallics 1997, 16, 2757-2759.

87. Chen, H.; Schlecht, S.; Semple, T. C.; Hartwig, J. F. Thermal, Catalytic, Regiospecific Functionalization of Alkanes Science 2000, 287, 1995-1997.

88. Ishiyama, T.; Murata, M.; Miyaura, N. Palladium(0)-Catalyzed Cross-Coupling Reaction of Alkoxydiboron with Haloarenes: A Direct Procedure for Arylboronic Esters J. Org. Chem. 1995, 60, 7508-7510.

89. Ishiyama, T.; Itoh, Y.; Kitano, T.; Miyaura, N. Synthesis of Arylboronates via the Palladium(0)-Catalyzed Cross-Coupling Reaction of Tetra(alkoxo)diborons with Aryl Triflates Tetrahedron Lett. 1997, 38, 3447-3450.

90. Ishiyama, T.; Ishida, K.; Miyaura, N. Synthesis of Pinacol Arylboronates via CrossCoupling Reaction of Bis(pinacolato)diboron with Chloroarenes Catalyzed by Palladium(0)Tricyclohexylphosphine Complexes Tetrahedron 2001, 57, 9813-9816.

91. Takagi, J.; Takahashi, K.; Ishiyama, T.; Miyaura, N. Palladium-Catalyzed Cross-Coupling Reaction of Bis(pinacolato)diboron with 1-Alkenyl Halides or Triflates: Convenient Synthesis of Unsymmetrical 1,3-Dienes via the Borylation-Coupling Sequence J. Am. Chem. Soc. 2002, 124, 8001-8006.

92. Kleeberg, C.; Dang, L.; Lin, Z.; Marder, Todd B. A Facile Route to Aryl Boronates: RoomTemperature, Copper-Catalyzed Borylation of Aryl Halides with Alkoxy Diboron Reagents Angew. Chem. Int. Ed. 2009, 48, 5350-5354.

93. Ito, H.; Yamanaka, H.; Tateiwa, J.; Hosomi, A. Boration of an $\alpha, \beta$-Enone Using a Diboron Promoted by a Copper(I)-Phosphine Mixture Catalyst Tetrahedron Lett. 2000, 41, 6821-6825. 
94. Baker, R. T.; Nguyen, P.; Marder, T. B.; Westcott, S. A. Transition Metal Catalyzed Diboration of Vinylarenes Angew. Chem. Int. Ed. 1995, 34, 1336-1338.

95. Ramírez, J.; Sanaú, M.; Fernández, E. Gold(0) Nanoparticles for Selective Catalytic Diboration Angew. Chem. Int. Ed. 2008, 47, 5194-5197.

96. Ishiyama, T.; Takagi, J.; Ishida, K.; Miyaura, N.; Anastasi, N. R.; Hartwig, J. F. Mild Iridium-Catalyzed Borylation of Arenes. High Turnover Numbers, Room Temperature Reactions, and Isolation of a Potential Intermediate J. Am. Chem. Soc. 2001, 124, 390-391.

97. G. Lawson, Y.; J. Gerald Lesley, M.; C. Norman, N.; R. Rice, C.; B. Marder, T. Platinum Catalysed 1,4-Diboration of $\alpha, \beta$-Unsaturated Ketones Chem. Commun. 1997.

98. Kabalka, G. W.; Das, B. C.; Das, S. Rhodium-Catalyzed 1,4-Addition Reactions of Diboron Reagents to Electron Deficient Olefins Tetrahedron Lett. 2002, 43, 2323-2325.

99. Hirano, K.; Yorimitsu, H.; Oshima, K. Nickel-Catalyzed $\beta$-Boration of $\alpha, \beta$-Unsaturated Esters and Amides with Bis(pinacolato)diboron Org. Lett. 2007, 9, 5031-5033.

100. Lee, K. S.; Zhugralin, A. R.; Hoveyda, A. H. Efficient C-B Bond Formation Promoted by N-Heterocyclic Carbenes: Synthesis of Tertiary and Quaternary B-Substituted Carbons Through Metal-Free Catalytic Boron Conjugate Additions to Cyclic and Acyclic $\alpha, \beta$-Unsaturated Carbonyls J. Am. Chem. Soc. 2009, 131, 7253-7255.

101. Bonet, A.; Gulyas, H.; Fernandez, E. Metal-Free Catalytic Boration at the $\beta$-Position of $\alpha, \beta$-Unsaturated Compounds: A Challenging Asymmetric Induction Angew. Chem. Int. Ed. 2010, 49, 5130-5134.

102. Ito, H.; Yamanaka, H.; Tateiwa, J.-i.; Hosomi, A. Boration of an $\alpha, \beta$-Enone Using a Diboron Promoted by a Copper(I)-Phosphine Mixture Catalyst Tetrahedron Lett. 2000, 41, 68216825.

103. Mun, S.; Lee, J.-E.; Yun, J. Copper-Catalyzed $\beta$-Boration of $\alpha, \beta$-Unsaturated Carbonyl Compounds: Rate Acceleration by Alcohol Additives Org. Lett. 2006, 8, 4887-4889.

104. Dang, L.; Lin, Z. Y.; Marder, T. B. DFT Studies on the Borylation of $\alpha, \beta$-Unsaturated Carbonyl Compounds Catalyzed by Phosphine Copper(I) Boryl Complexes and Observations on the Interconversions Between $O$ - and $C$-bound enolates of $\mathrm{Cu}, \mathrm{B}$, and $\mathrm{Si}$ Organometallics 2008, 27, 4443-4454.

105. Lee, J. E.; Yun, J. Catalytic Asymmetric Boration of $\alpha, \beta$-Unsaturated Esters and Nitriles Angew. Chem. Int. Ed. 2008, 47, 145-147.

106. Chen, I. H.; Yin, L.; Itano, W.; Kanai, M.; Shibasaki, M. Catalytic Asymmetric Synthesis of Chiral Tertiary Organoboronic Esters through Conjugate Boration of $\beta$-Substituted Cyclic Enones J. Am. Chem. Soc. 2009, 131, 11664-11665. 
107. Fleming, W. J.; Muller-Bunz, H.; Lillo, V.; Fernandez, E.; Guiry, P. J. Axially Chiral P-N Ligands for the Copper Catalyzed $\beta$-Borylation of $\alpha, \beta$-Unsaturated Esters Org. Biomol. Chem. 2009, 7, 2520-2524.

108. Lillo, V.; Bonet, A.; Fernandez, E. Asymmetric Induction on $\beta$-Boration of $\alpha, \beta$ Unsaturated Compounds: An Inexpensive Approach Dalton Trans. 2009, 2899-2908.

109. Lillo, V.; Prieto, A.; Bonet, A.; Díaz-Requejo, M. M.; Ramírez, J.; Pérez, P. J.; Fernández, E. Asymmetric $\beta$-Boration of $\alpha, \beta$-Unsaturated Esters with Chiral (NHC)Cu Catalysts Organometallics 2008, 28, 659-662.

110. Ito, H.; Kawakami, C.; Sawamura, M. Copper-Catalyzed $\gamma$-Selective and Stereospecific Substitution Reaction of Allylic Carbonates with Diboron: Efficient Route to Chiral Allylboron Compounds J. Am. Chem. Soc. 2005, 127, 16034-16035.

111. Laitar, D. S.; Tsui, E. Y.; Sadighi, J. P. Catalytic Diboration of Aldehydes via Insertion into the Copper-Boron Bond J. Am. Chem. Soc. 2006, 128, 11036-11037.

112. Beenen, M. A.; An, C.; Ellman, J. A. Asymmetric Copper-Catalyzed Synthesis of $\alpha$-Amino Boronate Esters from N-tert-Butanesulfinyl Aldimines J. Am. Chem. Soc. 2008, 130, 6910-6911. 


\section{Chapter 2 Structure and reactivity of a preactivated $s p^{2}-s p^{3}$ diboron reagent: catalytic regioselective boration of $\alpha, \beta$-unsaturated conjugated compounds}

\subsection{Contributions}

This chapter is based on two similar publications on a diboron reagent developed by the Santos group [Reprinted/adapted with permission from (1: Gao, M.; Thorpe, S.B.; Santos, W.L. Org. Lett. 2009, 11, 3478-3481. Copyright 2009 American Chemical Society) ${ }^{1}$ and (2: Gao, M.; Thorpe, S.B.; Kleeberg, C.; Slebodnick, C.; Marder, T.B.; Santos, W.L. J. Org. Chem. 2011, 76, 3997-4007. Copyright 2011 American Chemical Society) ${ }^{2}$ ]. The author's contribution included synthesis of both the racemic and enantiopure variants of the diboron reagent, optimization of reaction conditions, and expansion to various substrates including performing the reaction, purification, and all necessary characterizations. The crystal structure of $(R, R)$-2.13 and kinetic data on additives were obtained by Dr. Ming Gao. The crystal structure of racemic-2.13 and characterizations of the NHC adduct $\mathbf{2 . 1 9}^{3}$ were obtained by Dr. Christian Kleeberg. The final manuscripts were prepared by Dr. Webster Santos with major contributions by Dr. Ming Gao and Dr. Todd Marder. The author contributed significantly to the revision and submission of the manuscripts. 


\subsection{Abstract}

A novel $s p^{2}-s p^{3}$ diboron reagent has been developed for the copper-catalyzed $\beta$-boration of $\alpha, \beta$-unsaturated conjugated compounds. The reaction proceeds under mild conditions with various substrates, i.e., $\alpha, \beta$-unsaturated esters, ketones, nitriles, ynones, amides, and aldehydes, in the absence of additives such as phosphine and sodium tert-butoxide to provide $\beta$ borylhomoenolates in good to excellent yields. The presence of a $s p^{3}$-hybridized boron center, unambigously confirmed by X-ray crystallography, sufficiently activates the unsymmetrical pinacolato diisopropanolaminato diboron (PDIPA diboron) to transfer the $s p^{2}$-hybridized boron moiety chemoselectively. These observations suggest that the activation of one of the boron atoms is an essential step in the $\mathrm{Cu}$-catalyzed $\beta$-boration catalytic cycle.

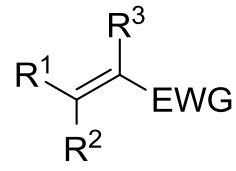

28 examples $\mathrm{EWG}=\mathrm{COOR}, \mathrm{COR}$, $\mathrm{CHO}, \mathrm{CN}, \mathrm{CONMe}_{2}$

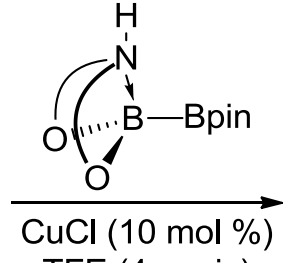

TFE (4 equiv) no base no ligand

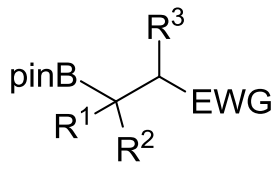

up to $96 \%$ yield 


\subsection{Introduction}

Organoboron compounds have emerged as versatile intermediates for the synthesis of many organic compounds. ${ }^{4-7}$ As such, considerable effort has been committed to their preparation. Notably, transition metal-catalyzed boration with diboron compounds is particularly effective. These reactions include catalytic diboration, ${ }^{8-33} \mathrm{C}-\mathrm{H}$ boration ${ }^{34-45}$ and $\mathrm{C}-\mathrm{X}$ boration, ${ }^{46-}$ 53 and involve a catalytic cycle that employs a metal boryl species ${ }^{54-64}$ generated by transmetalation or oxidative addition. Over the past decade, developing methods for the nucleophilic boration of electron deficient alkenes has generated increasing interest. In contrast to electron-rich alkene or alkyne substrates, regioselective boration under conventional hydroboration conditions is not possible with $\alpha, \beta$-unsaturated carbonyl compounds ${ }^{65}$ because of the competing reduction of the carbonyl, as demonstrated by the chemoselectivity in the CoreyBakshi-Shibata reduction of $\alpha, \beta$-enones and -ynones to allyl and propargyl alcohols, respectively. ${ }^{66}$ However, transition metal catalysis has provided a route for synthesizing organoboron derivatives. ${ }^{5,756}$ Stoichiometric or catalytic reactions of metal boryl complexes have been studied with platinum, ${ }^{67-69}$ rhodium, ${ }^{70,71}$ nickel, ${ }^{72}$ zinc $^{73}$ and copper $^{74-84}$ systems. In particular, the copper-catalyzed reaction has emerged as a very convenient method for the conjugate addition of diboron reagents to $\alpha, \beta$-unsaturated carbonyl compounds, mostly because copper salts are cheap and mild alcohol additives provide significant rate enhancement in these systems. ${ }^{74}$ Furthermore, enantioselective methods now exist. ${ }^{78,82,83,85,86}$ Recently, metal-free, $N$ heterocyclic carbene (NHC)- or phosphine-promoted processes were reported by Hoveyda ${ }^{87}$ and Fernandez, ${ }^{88}$ respectively. 
Figure 2.1. Structures of diboron compounds.<smiles>c1ccc2c(c1)OB(B1Oc3ccccc3O1)O2</smiles>

bis(catecholato)diboron, $\mathrm{B}_{2} \mathrm{Cat}_{2}(2.1)$<smiles>OB(O)B(O)O</smiles>
tetra(hydroxy)diborane, $\mathrm{B}_{2}(\mathrm{OH})_{4}(2.4)$<smiles>CC1(C)COB(B2OCC(C)(C)CO2)OC1</smiles>

bis(neopentyl glycolato)diboron, $\mathrm{B}_{2}$ neop $_{2}(\mathbf{2 . 2})$

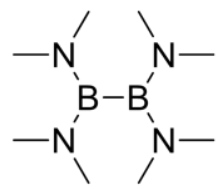

tetra(dimethylamino)diborane, (2.5)<smiles>CC1(C)OB(B2OC(C)(C)C(C)(C)O2)OC1(C)C</smiles>

bis(pinacolato)diboron, $\mathrm{B}_{2} \mathrm{pin}_{2}$ (2.3)

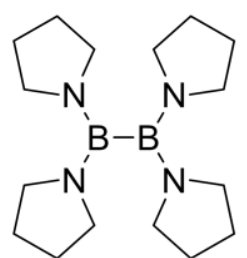

tetra(pyrrolidino)diborane,

(2.6)

In contrast to the myriad of investigations of various catalyst systems, few studies exploring new diboron reagents have been reported. The boron source in these transformations is thus far limited to the tetra(alkoxo)diboron reagents $\mathrm{B}_{2} \mathrm{cat}_{2} \mathbf{2 . 1},{ }^{89-91} \mathrm{~B}_{2}$ neop $_{2} \mathbf{2 . 2},{ }^{92-94} \mathrm{~B}_{2}$ pin $_{2}$ 2.3, ${ }^{95,96}$ and recently $\mathrm{B}_{2}(\mathrm{OH})_{4} \mathbf{2 . 4},{ }^{97}$ in part due to their commercial availability and greater stability than tetra(amino)diboranes, ${ }^{96}$ such as 2.5 and $\mathbf{2 . 6}$ (Figure 2.1). These symmetrical reagents contain two $s p^{2}$-hybridized boron atoms. Alternative, stable diboron reagents are warranted in order to take advantage of the boronate group as an intermediate for installing other functional groups and exploiting the unique biological activities ${ }^{98}$ of boronic acids. Differentially protected, unsymmetrical diboron compounds are expected to have the advantage of transferring boryl groups with chemoselectivity. ${ }^{99}$ For example, $N$-methyliminodiacetic acid $(\text { MIDA) })^{100-105}$ and 1,8-diaminonaphthalene ${ }^{106-108}$ (dan) moieties (Figure 2.2) provide a convenient protecting group strategy in iterative Suzuki-Miyaura coupling reactions. These protected boryl groups are inert under the coupling conditions but become reactive upon treatment with base or acid, respectively, believed to result from hydrolysis in situ to the corresponding boronic acid. 
Burke observed the exceptional tolerance of MIDA $s p^{3}$-boronates (hypothesized to contain a "protected" $p$ orbital) towards a variety of common functional group conversions, including halogenation, protection/deprotection, Evans aldol, olefinations, reductive amination, and even the powerful Jones oxidation
Figure 2.2. Structure and hydrolysis of MIDA (2.7) and dan (2.8) moieties.

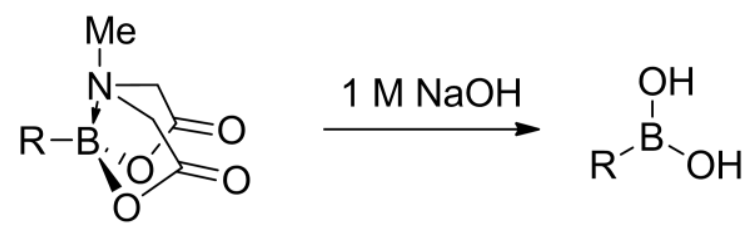

2.7

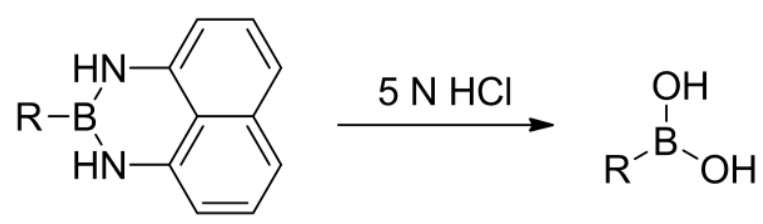

$\left(\mathrm{CrO}_{3} / \mathrm{H}_{2} \mathrm{SO}_{4}\right) .{ }^{103}$ Decomposition was detected only in the presence of hard nucleophiles, such as aluminum hydrides, tetrabutylammonium fluoride (TBAF), metal alkoxides, and aqueous base $\left(\mathrm{NaOH}\right.$ or $\left.\mathrm{NaHCO}_{3}\right)$. Indeed, he has exploited these properties in the first total synthesis of several complex natural products through iterative SMC strategies, for example, the dineolignin ratanhine 2.9 (Scheme 2.1A) isolated from the medicinal plant Ratanhiae radix. ${ }^{109}$ Suginome has developed the orthogonal strategy using (dan)-protected boronates ${ }^{106-108}$ — which are removed in aqueous acid - and shown additional examples of chemoselective functionalization of differentially protected diboryl alkenes. ${ }^{99}$ An impressive illustration of the boron protection strategy was reported by Molander, ${ }^{110}$ in which a one-pot hydroboration and bidirectional SMC of alkenyl-containing organotrifluoroborates utilized the orthogonal reactivity of $\mathrm{R}-\mathrm{BF}_{3} \mathrm{~K}$ and alkyl-9-BBN moieties towards cross-coupling (Scheme 2.1B). Finally, the synthesis of enantiopure ( $>99 \%) \beta, \beta$-diboronyl esters bearing two orthogonally protected boryl groups, and the subsequent SMC scheme to generate a quaternary carbon in $>95 \%$ ee, was recently developed. ${ }^{111}$ Naturally, we became interested in exploring the distinctive reactivities of both $s p^{2}$ and $s p^{3}$ boronic acid derivatives. 
Scheme 2.1. A) Iterative SMC with MIDA boronates and B) one-pot hydroboration and bidirectional SMC.

A
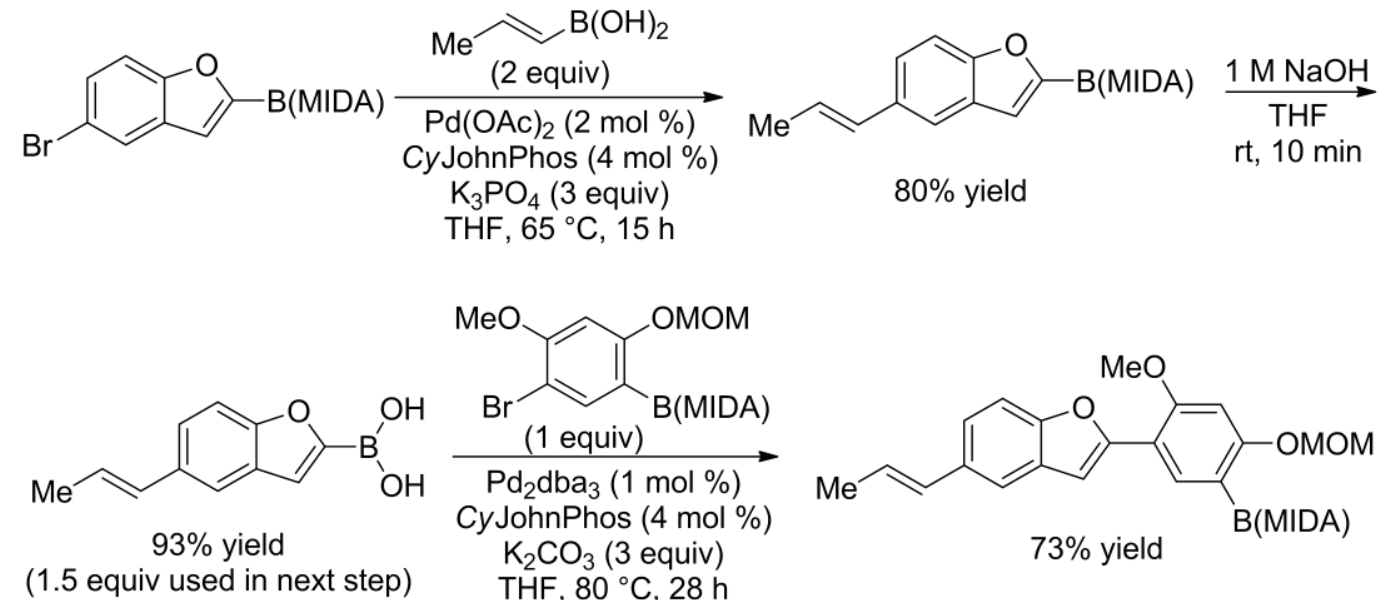

(1.5 equiv used in next step)

THF, $80{ }^{\circ} \mathrm{C}, 28 \mathrm{~h}$
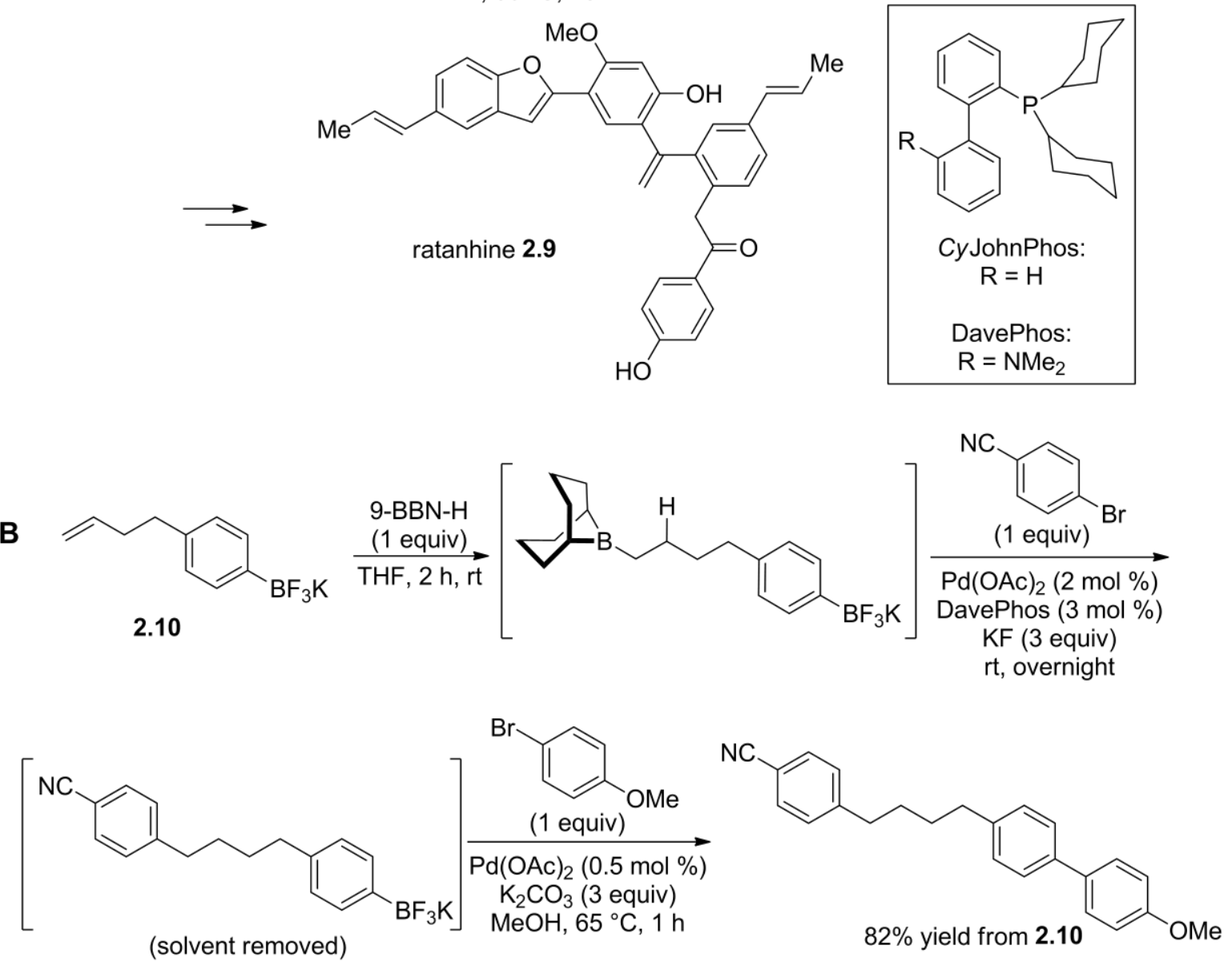


\subsection{Design and synthesis of a novel "mixed" diboron reagent}

We were intrigued by a report that addition of base improved the copper catalyzed boration of unsaturated carbonyl compounds with $\mathbf{2 . 3} \cdot{ }^{76}$ It has been suggested that the base acts to "externally" activate the B-B bond by complexation prior to transfer at the copper center, in effect generating a $s p^{2}-s p^{3}$ hybridized diboron (2.11 Figure 2.3). We hypothesized that a "preactivated" diboron reagent $\mathbf{2 . 1 2}$

could undergo the same transformation without the need for an alkoxide, providing a milder reaction condition. We pursued the exploration of

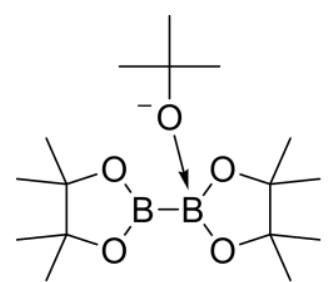

2.11

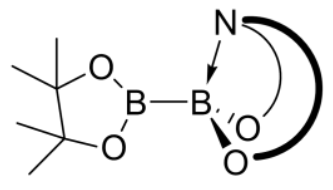

2.12

aminodiols, which were originally activation.

found to form adducts with boron in $1955^{112}$ and have since been observed to stabilize the boron atom against hydrolysis and auto-oxidation. ${ }^{4}$ We discovered that treatment of $\mathbf{2 . 3}$ with racemic bis(2-hydroxypropyl)amine in a combination of ether and dichloromethane readily provided "mixed" diboron 2.13, also referred to as PDIPA (pinacolato diisopropanolaminato) diboron (Scheme 2.2). This method can easily prepare 40 grams of 2 in a single batch, with $31 \%$ recovered starting material (2.3) that can be recycled. Analysis of the ${ }^{11} \mathrm{~B}$ NMR of $\mathbf{2 . 1 3}$ shows the appearance of two distinct peaks at $\delta 35.5$ and 9.0 and the loss of starting material signal $(\delta$ 31.1), consistent with the presence of tri- and tetra coordinate boron centers, respectively (Figure 2.4). ${ }^{113}$ To our knowledge, this is the first report of a $s p^{2}-s p^{3}$ hybridized diboron. Both $1 \mathrm{D}\left({ }^{1} \mathrm{H}\right.$,

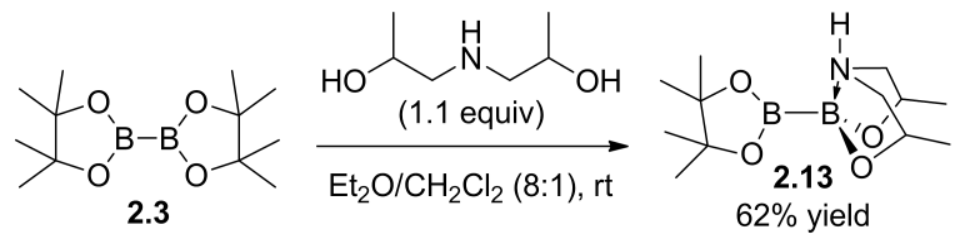

Scheme 2.2. Synthesis of racemic PDIPA diboron 2.13. 
${ }^{13} \mathrm{C}$ ) and 2D (COSY, HMQC) NMR studies indicate the structure of $\mathbf{2 . 1 3}$ to be a diastereomeric mixture of trans/cis form (1:1.2), as expected from the starting diol.

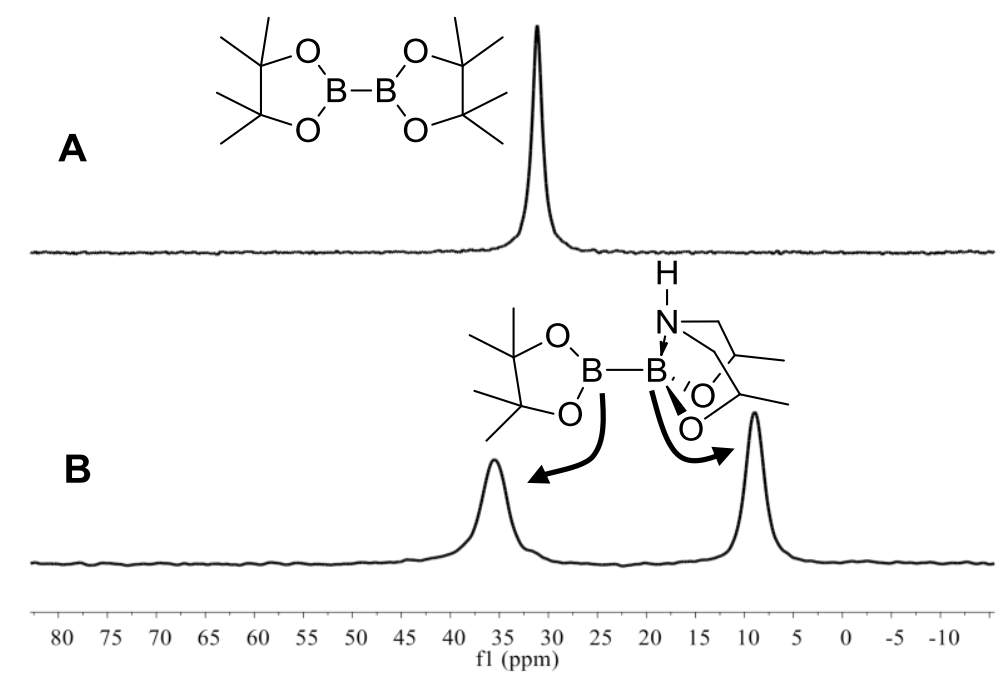

Figure 2.4. ${ }^{11}$ B NMR spectra of $2.3(\mathbf{A})$ and $2.13(B)$ in

$\mathrm{CD}_{3} \mathrm{CN}$ at room temperature.

\subsection{Reactivity of PDIPA diboron towards copper-catalyzed $\beta$-boration}

With mixed diboron $\mathbf{2 . 1 3}$ in hand, we examined its reactivity in the $\beta$-boration of benzyl acrylate 2.14a (Table 2.1). Using a catalytic amount of $\mathrm{CuCl}$ in the presence of 1.1 equivalents of mixed diboron reagent $\mathbf{2 . 1 3}$ dissolved in $\mathrm{CH}_{2} \mathrm{Cl}_{2}, \mathbf{2 . 1 4 a}$ was found to undergo the $\beta$ - boration to afford product 2.15a in moderate yield (entry 1). Analysis of $\mathbf{2 . 1 5} \mathbf{a}$ demonstrated that the $s p^{2}$ hybridized boron was selectively transferred to the $\beta$-carbon of $\mathbf{2 . 1 4 a}$. This finding is consistent with the activation of a diboron proposed by Miyaura, where a base functions to activate a diboron reagent generating, in situ, a mixed $s p^{2}-s p^{3}$ hybridized diboron. ${ }^{76}$ Increasing the equiv of 2.13 to 1.5 provided a slight increase in yield (67\%, entry 2). Addition of DPEphos led to a decrease in yield (entry 3), but the concomitant addition of $\mathrm{MeOH}$ provided a higher yield (entry 4). Encouraged by these results, we changed the ligand to $(n-\mathrm{Bu})_{3} \mathrm{P}$ and a better $\sigma$ donor $N$ - 
Table 2.1. Cu-Catalyzed addition of mixed diboron 2.13 to benzyl acrylate under various conditions. ${ }^{a}$

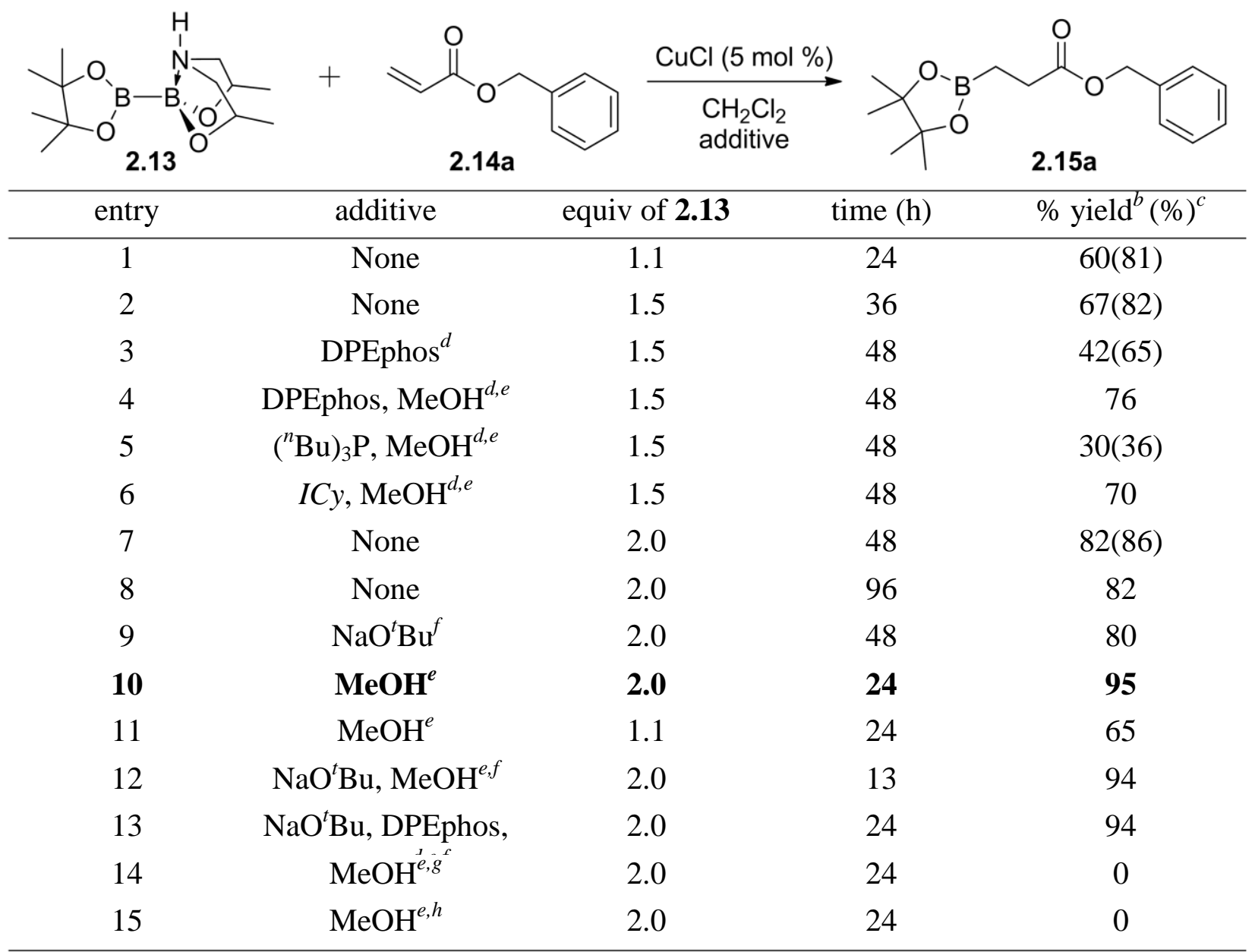

${ }^{a}$ Each reaction was performed at least three times. General procedure: $\mathbf{2 . 1 3}$ in $\mathrm{CH}_{2} \mathrm{Cl}_{2}$ was added to a solution of $\mathrm{CuCl}\left(0.05\right.$ equiv) in $\mathrm{CH}_{2} \mathrm{Cl}_{2}$ at $\mathrm{rt}$ followed by $\mathbf{2 . 1 4 a}$ ( 1 equiv) at $0{ }^{\circ} \mathrm{C}$, then the mixture was allowed to warm to $\mathrm{rt} .{ }^{b}$ Isolated yield. ${ }^{c}$ Corrected yield based on recovered 2.14a. ${ }^{d}$ Ligand (0.03 equiv). ${ }^{e} \mathrm{MeOH}$ (4 equiv). ${ }^{f} \mathrm{NaO}{ }^{t} \mathrm{Bu}\left(0.05\right.$ equiv). ${ }^{g}$ In the absence of $\mathrm{CuCl}^{h}{ }^{h} \mathbf{2 . 3}$ was used instead of $\mathbf{2 . 1 3}$.

heterocyclic carbene ICy. However, both ligands provided unsatisfactory yields (entries 5-6).

Indeed, we were delighted to discover that copper-stabilizing additives (DPEphos and trialkylphosphines) and boron-activating agents $(\mathrm{NaO} t \mathrm{Bu}$ and $N$-heterocyclic carbene) were not required. This is noteworthy not only because these additives are expensive, but also because PDIPA diboron is predicted to be useful for reactions of base sensitive substrates. Increasing the equivalency of $\mathbf{2 . 1 3}$ as well as the reaction time to 96 hours afforded 2.15a in good yield (entries 
7-8). Attempts with added base did not improve the yield (entry 9). Surprisingly, optimum conditions were found when using $\mathrm{MeOH}$ (4 equiv) and $\mathbf{2 . 1 3}$ ( 2 equiv) to provide the $\beta$-boration product in $95 \%$ yield within 24 hours (entry 10). A lower stoichiometry of $\mathbf{2 . 1 3}$ provided the product in moderate yield (entry 11). No further improvement in yield was observed when adding either base only or base with ligand (entries 12-13). As expected, the reaction did not work when no copper catalyst was present (entry 14). Under the same reaction conditions as entry 10, no reaction products were detected when symmetrical diboron $\mathbf{2 . 3}$ instead of $\mathbf{2 . 1 3}$ was used (entry 15). The important result in entry 15 proves that our hypothesized "internal activation" of a diboron reagent was successful.

With the optimal reaction conditions determined (entry 10, Table 2.1), the generality of this copper-catalyzed boration was first demonstrated by reaction with various $\alpha, \beta$-unsaturated conjugated compounds (Table 2.2). Simple esters such as benzyl acrylate 2.14a, methyl acrylate 2.14b, ethyl acrylate $\mathbf{2 . 1 4 c}$, tert-butyl acrylate $\mathbf{2 . 1 4 d}$, and $n$-butyl acrylate $\mathbf{2 . 1 4 e}$ afforded the corresponding products 4a-e in excellent yields (91-96\%) within 24 hours (entries 1-5). However, the more substituted methacrylate esters $\mathbf{2 . 1 4 f - h}$ were converted to the desired products $2.15 \mathbf{f}-\mathbf{h}$ only in moderate yields, although some starting material was recovered (entries 6-8). Fortunately, $\alpha, \beta$-unsaturated ketones were also borated in good yields. Treatment of methyl vinyl ketone with mixed diboron $\mathbf{2 . 1 3}$ under optimal conditions afforded 2.15i in 76\% yield (entry 9). $\beta$-Substituted acrylates failed to react under these conditions (not shown), however $\beta$-substituted $\alpha, \beta$-unsaturated ketone $\mathbf{2 . 1 4} \mathbf{j}$ and cyclic enone $\mathbf{2 . 1 4 k}$ were borated in high yields, although an increase in reaction time was necessary (entries 10-11). The difference in reactivity between esters and ketones can arise from the decreased electrophilicity of the ester. 
Table 2.2. Copper-catalyzed $\beta$-boration of various unsaturated conjugated compounds. ${ }^{a}$

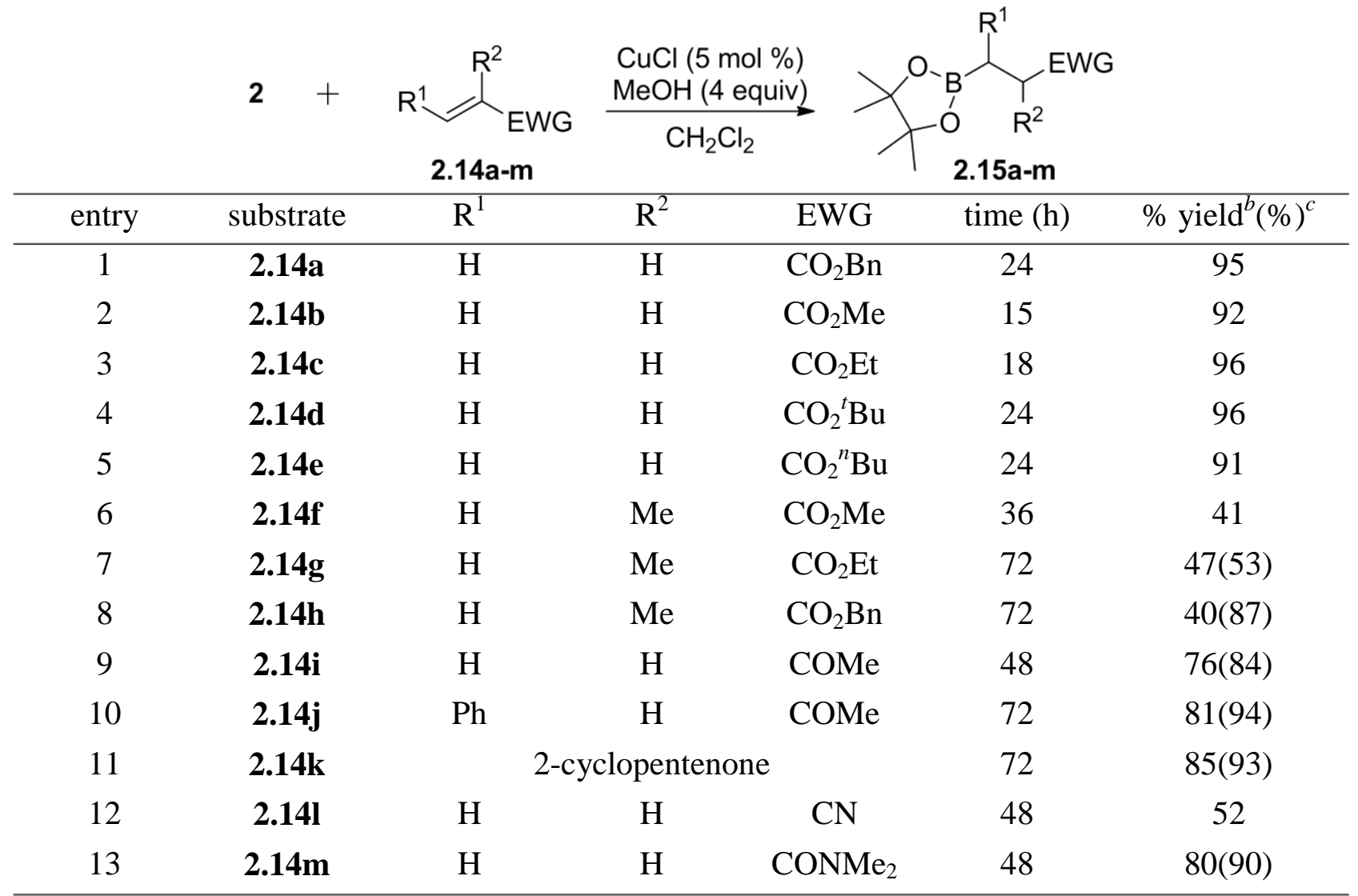

${ }^{a}$ Each reaction was performed at least three times. Conditions: 2.13 (2.0 equiv), $\mathrm{CuCl}(0.05$ equiv), 2.14 ( 1 equiv) and $\mathrm{MeOH}$ (4 equiv), $0{ }^{\circ} \mathrm{C}$ to rt. ${ }^{b}$ Isolated yield. ${ }^{c}$ Corrected yield based on recovered 2.14.

Interestingly, acrylonitrile $\mathbf{2 . 1 4 l}$ and $N, N$-dimethylacrylamide $\mathbf{2 . 1 4 m}$ also underwent the $\beta$ boration reaction smoothly in good yield (entries 12-13).

Finally, we attempted the $\beta$-boration reaction with mixed diboron $\mathbf{2 . 1 3}$ to 3-butyn-2-one 2.14n. Surprisingly, 2.14n undergoes the boration twice to furnish $\beta$, $\beta$-diborated product $2.15 n$

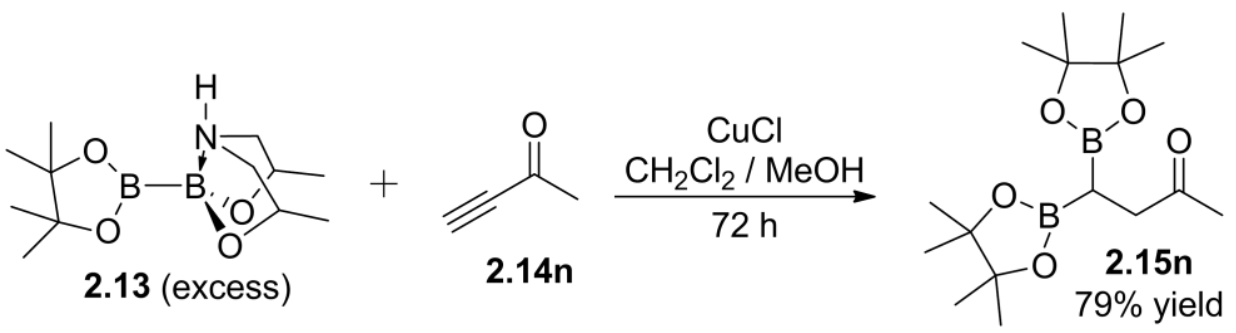

Scheme 2.3. $\beta, \beta$-Diboration of acetylenic ketone 2.14n. 
in 79\% yield (Scheme 2.3). To the best of our knowledge, this is the first example of catalytic addition of a diboron reagent to an $\alpha, \beta$-acetylenic ketone affording a $\beta, \beta$-diborated product, although the monoboration of $\alpha, \beta$-acetylenic esters with bis(pinacolato)diboron was prevoiusly reported by Yun. ${ }^{79}$ We can envision the transformation of these types of products into other useful functional groups

\subsection{Further development - introduction}

Having obtained a promising initial set of results, we set out to address several unanswered questions in greater detail, the most troublesome of which was the requirement of 2 equivalents of racemic PDIPA diboron for efficient conversion. In a complementary second report, we disclosed the synthesis, characterization and reactivity of a single enantiomer of $\mathbf{2 . 1 3}$, and demonstrated that a diastereomeric mixture is sufficient to effect the boration reaction. ${ }^{2} \mathrm{~A}$ screening of additives revealed an alcohol with greater rate acceleration, which allowed us to eliminate the necessity for excess diboron reagent and expand the substrate scope (up to 28 examples) including highly sensitive $\alpha, \beta$-unsaturated aldehydes. In addition, we significantly increased the understanding of the mechanism of the reaction based on X-ray crystal structures of PDIPA diboron; one trigonal planar boron atom is coordinated by a pinacolate moiety and the other displays a distorted tetrahedral geometry and coordination to a diisopropanolaminate moiety. Coordination of $\mathrm{N}$ to B increases B-B bond length and sufficiently activates the diboron reagent for boryl group transfer to copper.

\subsection{Synthesis and characterization of $(R, R)$-PDIPA diboron}

In order to determine unambiguously the coordination at the boron atoms, we prepared an enantiomerically pure sample of PDIPA diboron 2.13. Treatment of benzylamine with 2 equiv of $(R)$-propylene oxide $\mathbf{2 . 1 6}$ in methanol at $60{ }^{\circ} \mathrm{C}$ readily afforded $(R, R)-\mathbf{2 . 1 7}$ in $88 \%$ yield 
Scheme 2.4. Synthesis of enantiomerically pure PDIPA diboron, $(R, R)-\mathbf{2 . 1 3}$.

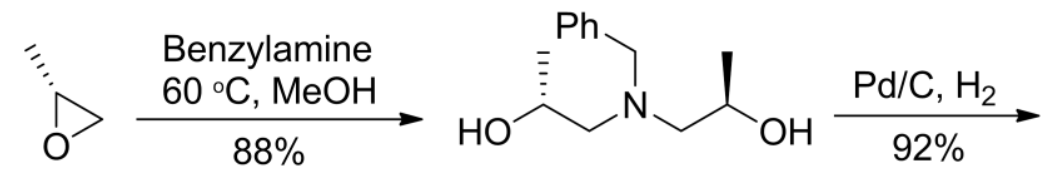

(R)-2.16

$(R, R)-2.17$

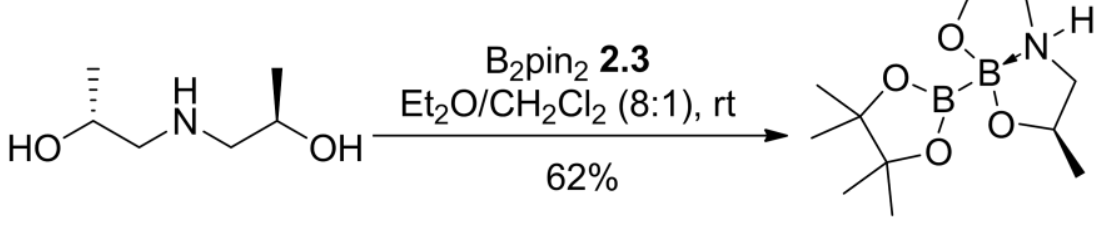

$(R, R)-2.18$

$(R, R)-2.13$

(Scheme 2.4). ${ }^{114}$ The benzyl protecting group was removed by heterogeneous catalytic hydrogenation to provide $(R, R)-\mathbf{2 . 1 8}$ in $92 \%$ yield, which reacted with $\mathbf{2 . 3}$ under the same conditions used for racemic $\mathbf{2 . 1 3}{ }^{1}$ to provide $(4 R, 8 R)$-PDIPA diboron $((R, R)-\mathbf{2 . 1 3})$ after filtration. The characterization $\left({ }^{1} \mathrm{H},{ }^{13} \mathrm{C},{ }^{11} \mathrm{~B} \mathrm{NMR}\right)$ of $(R, R)-\mathbf{2 . 1 3}$ is consistent with the presence of a single diastereomer, with the expected signals ${ }^{1}$ at 35.5 and $9.0 \mathrm{ppm}$ in the ${ }^{11} \mathrm{~B}$ NMR spectrum.

Additionally, the chemical shifts for $\mathbf{2 . 1 3}$ are markedly different from those initially reported by Hoveyda ${ }^{87}$ for an in situ formed $s p^{2}-s p^{3}$ tetraalkoxydiboron compound, i.e., the NHC diboron adduct (2.19; Figure 2.5) wherein both the $s p^{2}$ -

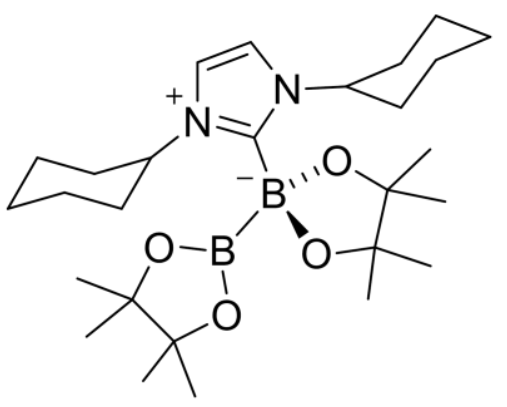
and $s p^{3}$-hybridized boron atoms were reported to have upfield chemical shifts of $\delta 6.3$ and $4.5 \mathrm{ppm}$. The initially reported NMR data for $\mathbf{2 . 1 9}$ were suspicious, as they are not in agreement with ${ }^{11} \mathrm{~B}$ NMR data reported for other

Figure 2.5. Adduct NHC 2.19. $\quad s p^{2}-s p^{3}$ diboron compounds. ${ }^{115,116}$ This prompted us to investigate the intriguing 2.19 adduct. While a detailed discussion of these findings were recently published separately by our collaborator, ${ }^{3}$ we note that in the solid state, $\mathbf{2 . 1 9}$ has, indeed, an $s p^{2}-s p^{3}$ diboron structure as confirmed by single-crystal X-ray diffraction, and displays ${ }^{11} \mathrm{~B}$ NMR signals at 37.2 and $2.4 \mathrm{ppm}\left(\right.$ at $5{ }^{\circ} \mathrm{C}$ in $\mathrm{THF}-\mathrm{d}_{8}$ ), for the $s p^{2}$ and $s p^{3}$ boron 
centers, respectively. The incorrect ${ }^{11} \mathrm{~B}$ NMR data initially reported by Hoveyda ${ }^{87}$ are understandable considering the dynamic behavior of $\mathbf{2 . 1 9}$ in solution, ${ }^{109,110}$ leading to an extremely broad signal at ambient temperature which is difficult to observe. Thus, the ${ }^{11} \mathrm{~B}$ NMR data initially reported for $\mathbf{2 . 1 9}$ by Hoveyda are likely due to impurities in the sample rather than the adduct itself. ${ }^{117}$

Recrystallization of $(R, R)-\mathbf{2 . 1 3}$ from acetonitrile yielded colorless single crystals suitable for X-ray diffraction analysis (Figure 2.6). The crystal structure unambiguously confirmed the presence of both 3- and 4-coordinate boron centers in the $s p^{2}-s p^{3}$ diboron compound. The environment of the $s p^{3}$ boron atom B2 is tetrahedral; however, it is significantly distorted, as
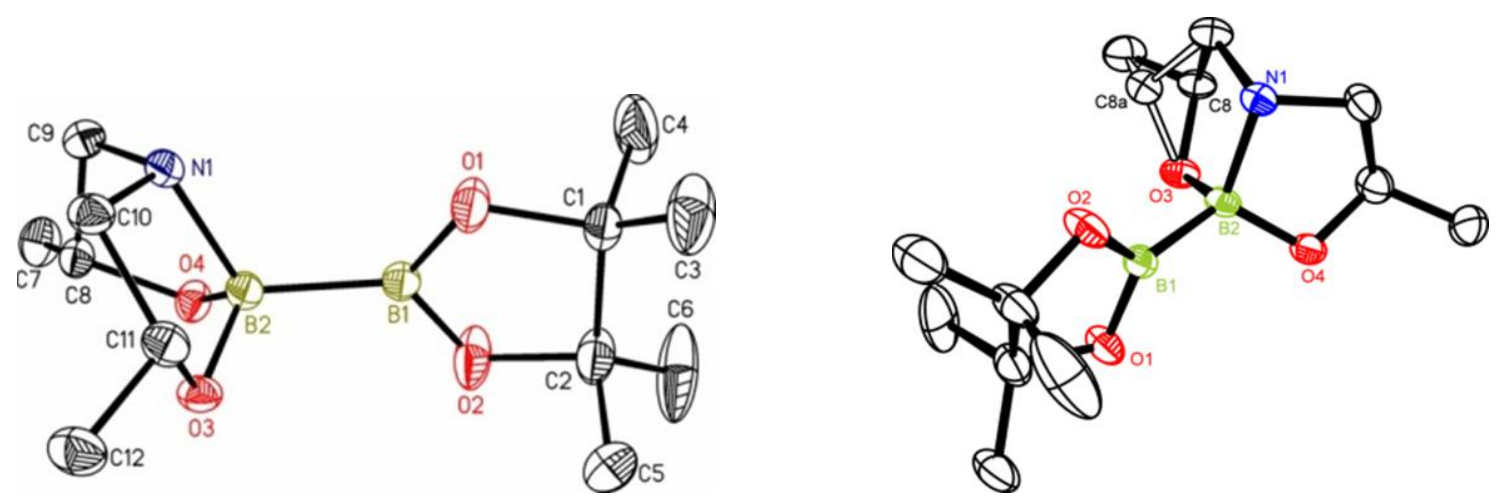

Figure 2.6. Anisotropic displacement ellipsoid drawings $(50 \%)$ of $(R, R)-\mathbf{2 . 1 3}($ left $)$ and 2.13 (right). Hydrogen atoms have been omitted for clarity. Selected bond lengths $[\AA]$ and angles $\left[^{\circ}\right]: \quad(R, R)-2.13: \quad \mathrm{B} 1-\mathrm{B} 2 \quad 1.721(2), \mathrm{B} 2-\mathrm{N} 1 \quad 1.6743(19), \mathrm{O} 4-\mathrm{B} 2$ 1.4475(19), O3-B2 1.4925(19), B1-O1 1.367(2), B1-O2 1.3678(19), N1-B2-B1 116.16(11), O3-B2-N1 98.98(11), O4-B2-N1 102.02(11); O3-B2-O4 112.04(11), O3-B2-B1 108.82(12), O4-B2B1 117.31(12); 2.13: B1-B2 1.722(4), B2-N1 1.657(3), O4-B2 1.445(3), O3-B2 1.494(3), B1O1 1.388(4), B1-O2 1.365(6), N1-B2-B1 117.0(2), O3-B2-N1 99.3(2), O4-B2-N1 102.1(2), O3-B2-O4 113.3(2), O3-B2-B1 108.5(2), O4-B2-B1 115.6(2). 
especially apparent from the X-B2-X angles (maximum deviation from $109.47^{\circ}$ : $10.45^{\circ}(\mathrm{O} 3-\mathrm{B} 2$ N1); average deviation from 109.47: $8.21^{\circ}$ ), as a consequence of the bicyclic nature of the DIPA moiety. Although external Lewis base chelation to diboron compounds has been reported, ${ }^{115,116,118}$ to the best of our knowledge, this is the first reported crystal structure of an internally chelated $s p^{2}-s p^{3}$ hybridized diboron compound. The entire structure of the B(DIPA)

Table 2.3. B-B distances in selected diboron compounds.

\begin{tabular}{|c|c|c|}
\hline compound & B-B dist. / & $\Delta(\mathbf{B}-\mathbf{B})^{a} / \AA$ \\
\hline $\mathrm{B}_{2} \operatorname{pin}_{2}(\mathbf{2 . 3})^{123}$ & $1.710(5)$ & \\
\hline $\mathrm{PDIPA} \mathrm{B}_{2}((R, R)-\mathbf{2 . 1 3})^{2}$ & $1.721(2)$ & $0.012^{b}$ \\
\hline$\left(\left[\text { PDIPA B }{ }_{2}\right][\mathrm{K}(\text { thf })]\right)_{2}\left(\left((\mathbf{2 . 2 0}) \text { thf }_{2}\right)^{2}\right.$ & $1.735(2)$ & $0.025^{b}$ \\
\hline $\mathrm{B}_{2} \operatorname{pin}_{2}(\mathrm{CyNHC})^{3}$ & $1.743(2)$ & 0.033 \\
\hline $\mathrm{B}_{2}\left(1,2-\mathrm{O}_{2} \mathrm{C}_{6} \mathrm{H}_{4}\right)_{2}{ }^{92}$ & $1.678(3)$ & \\
\hline $\mathrm{B}_{2}\left(1,2-\mathrm{O}_{2} \mathrm{C}_{6} \mathrm{H}_{4}\right)_{2}\left(4-\mathrm{MeC}_{5} \mathrm{H}_{4} \mathrm{~N}\right)^{116}$ & $1.706(3)$ & 0.028 \\
\hline $\mathrm{B}_{2}\left(1,2-\mathrm{O}_{2} \mathrm{C}_{6} \mathrm{H}_{4}\right)_{2}\left(4-\mathrm{MeC}_{5} \mathrm{H}_{4} \mathrm{~N}\right)_{2}{ }^{116}$ & $1.713(4)$ & 0.035 \\
\hline $\mathrm{B}_{2}\left(1,2-\mathrm{S}_{2} \mathrm{C}_{6} \mathrm{H}_{4}\right)_{2}{ }^{90}$ & $1.673(4)^{c}$ & \\
\hline $\mathrm{B}_{2}\left(1,2-\mathrm{S}_{2} \mathrm{C}_{6} \mathrm{H}_{4}\right)_{2}\left(4-\mathrm{MeC}_{5} \mathrm{H}_{4} \mathrm{~N}\right)^{115}$ & $1.701(7)$ & 0.028 \\
\hline $\mathrm{B}_{2}\left(1,2-\mathrm{S}_{2} \mathrm{C}_{6} \mathrm{H}_{4}\right)_{2}\left(\mathrm{PMe}_{2} \mathrm{Ph}\right)^{115}$ & $1.689(5)$ & 0.016 \\
\hline $\mathrm{B}_{2}\left(1,2-\mathrm{S}_{2} \mathrm{C}_{6} \mathrm{H}_{4}\right)_{2}\left(\mathrm{PEt}_{3}\right)^{115}$ & $1.707(3)$ & 0.034 \\
\hline $\mathrm{B}_{2}\left(1,2-\mathrm{S}_{2} \mathrm{C}_{6} \mathrm{H}_{4}\right)_{2}(\text { phen })^{118}$ & $1.707(13)$ & 0.034 \\
\hline $\mathrm{B}_{2}\left(1,2-\mathrm{S}_{2} \mathrm{C}_{6} \mathrm{H}_{4}\right)_{2}(\mathrm{bpy})^{118}$ & $1.630(5)^{c}$ & 0.043 \\
\hline $\mathrm{B}_{2} \mathrm{Cl}_{3}\left(\mathrm{MeNCH}_{2} \mathrm{CH}_{2} \mathrm{NMe}_{2}\right)^{124}$ & $1.699(4)$ & \\
\hline $\begin{array}{l}\text { (1-Mesityl-5,7-dimethyl-9H-10- } \\
\text { (mesityl-(methoxy)boryl)-10-boraphenanthrenyl)lithium }{ }^{125}\end{array}$ & $1.725(6)$ & \\
\hline $\begin{array}{l}\text { (1-Mesityl-5,7-dimethyl-9-methoxy-9'- } \\
\text { (methyl-(methoxy)boryl)-9-borafluorenyl)lithium }{ }^{125}\end{array}$ & $1.720(7)$ & \\
\hline $\begin{array}{l}\text { B,P;B',P'-Bi(bis(dimethylamino)boryl-1,3- } \\
\text { bis(isopropyl)-4,5-benzo-1,3,2-di-phosphaborolane) }\end{array}$ & $1.744(9)$ & \\
\hline$t$-Butyl(trichloro)dimethylammoniodiborane ${ }^{127}$ & $1.704(5)$ & \\
\hline $\begin{array}{l}\text { 2,5-bis(Dimethylamino)-2,3,5,6- } \\
\text { tetrakis(3,5-bis(trifluoromethyl)phenoxy)-2,3,5,6-tetrabora-1,4 } \\
\text { dioxane }\end{array}$ & $1.737(6)$ & \\
\hline
\end{tabular}


fragment is, not surprisingly, similar to the structures in compounds of the type R-B(deaH) $\left(\right.$ deaH $\left.=\left(\mathrm{OCH}_{2} \mathrm{CH}_{2}\right)_{2} \mathrm{NH}, \quad \mathrm{R}=\mathrm{C}_{6} \mathrm{H}_{5}, \mathrm{C}_{10} \mathrm{H}_{7}, \mathrm{C}_{3} \mathrm{H}_{5}, \mathrm{C}_{8} \mathrm{H}_{11}, \mathrm{C}_{8} \mathrm{H}_{7}, \mathrm{C}_{12} \mathrm{H}_{9}, \mathrm{C}_{13} \mathrm{H}_{17} \mathrm{O}_{3}\right) .{ }^{119}$ Complexation of N1 to B2 pyramidalizes B2 with an N1-B2 bond length of 1.6743(19) $\AA$, which is longer than in related trigonal tetraaminodiboranes, ${ }^{120-122}$ and similar to those in $\mathrm{R}-\mathrm{B}(\mathrm{deaH})$ compounds $(\mathrm{B}-\mathrm{N}=1.66(2) \AA$ on average $) .{ }^{119}$ The distances O4-B2 (1.4475(19)) and O3-B2 (1.4925(19)) are significantly increased compared to $\mathrm{O}-\left(s p^{2}\right) \mathrm{B}$ distances in related arylboronates. ${ }^{53}$ The B-B distance in $(R, R)-\mathbf{2 . 1 3}$ is significantly longer $(0.012 \AA)$ than in 2.3 (B-B $1.710(1) \AA)^{123}$ due to the change in hybridization of one of the boron atoms, i.e., the increase in $p$-character, accompanied by the loss of any $\mathrm{O}-\mathrm{B} \pi$-bonding. This bond length change upon hybridization is found to a similar extent in all crystallized $s p^{2}-s p^{3}$ diboron compounds (Table 2.3), ${ }^{124-128}$ and is consistent with DFT calculations on the adduct $2.19 .^{87}$ The polarization of, or increased electron density in, the B-B bond in $\mathbf{2 . 1 3}$ should increase its propensity to undergo transmetalation to copper, ${ }^{1}$ enhancing the rates of $\mathrm{Cu}$-catalyzed boration reactions.

\subsection{Re-optimization: additives}

In the initial disclosure of our copper-catalyzed boration methodology, we demonstrated the efficient conversion of benzyl acrylate to the corresponding borated product 2.15a in the presence of a catalytic amount of $\mathrm{CuCl}$ and methanol. In the process, we established the chemoselective transfer of the pinacolate protected, $s p^{2}$-hybridized boron from 2.13. As previously shown in Table 2.2, a variety of ester substituents were tolerated, affording the corresponding products 2.15a-e in excellent yields (91-96\%). However, when additional groups are present at the $\alpha$ - or $\beta$-position $(\mathbf{2 . 1 5 f - k})$, the reactions yields were lower, presumably as a result of a combination of steric and electronic effects. ${ }^{129}$ 
In order to improve the reaction conditions and expand the scope of the reaction to other $\alpha, \beta$-unsaturated compounds, we studied the effect of additives on the yield and efficiency of the $\beta$-boration reaction. The critical importance of $\mathrm{MeOH}$ as an additive, initially disclosed by Yun $^{74}$ and supported by DFT calculations, ${ }^{129}$ was substantiated by our previous work. ${ }^{1}$ We investigated whether the identity of the protic additive had a significant effect on the reaction rate and conversion yield (Figure 2.5). First, we monitored the conversion of 2-cyclohexenone to $\beta$-borated cyclohexanone $\mathbf{2 . 2 2 h}$ following addition of $\mathbf{2 . 1 3}$ ( 2 equiv), protic additive ( 2 equiv) and $\mathrm{CuCl}(5 \mathrm{~mol} \%)$ in methylene chloride. As expected, $\mathrm{MeOH}$ and $\mathrm{EtOH}$ accelerated the boration to a similar degree with $>90 \%$ conversion after 5 hours compared to $81 \%$ for the control reaction (without additive, although $\mathbf{2 . 1 3}$ contains an acidic $\mathrm{N}-\mathrm{H}$ proton). We next investigated

Figure 2.7. Boration of 2-cylohexenone with 2 equivalents of diboron $\mathbf{2 . 1 3}$ in the presence of various additives. Conversion measured by GC analysis.
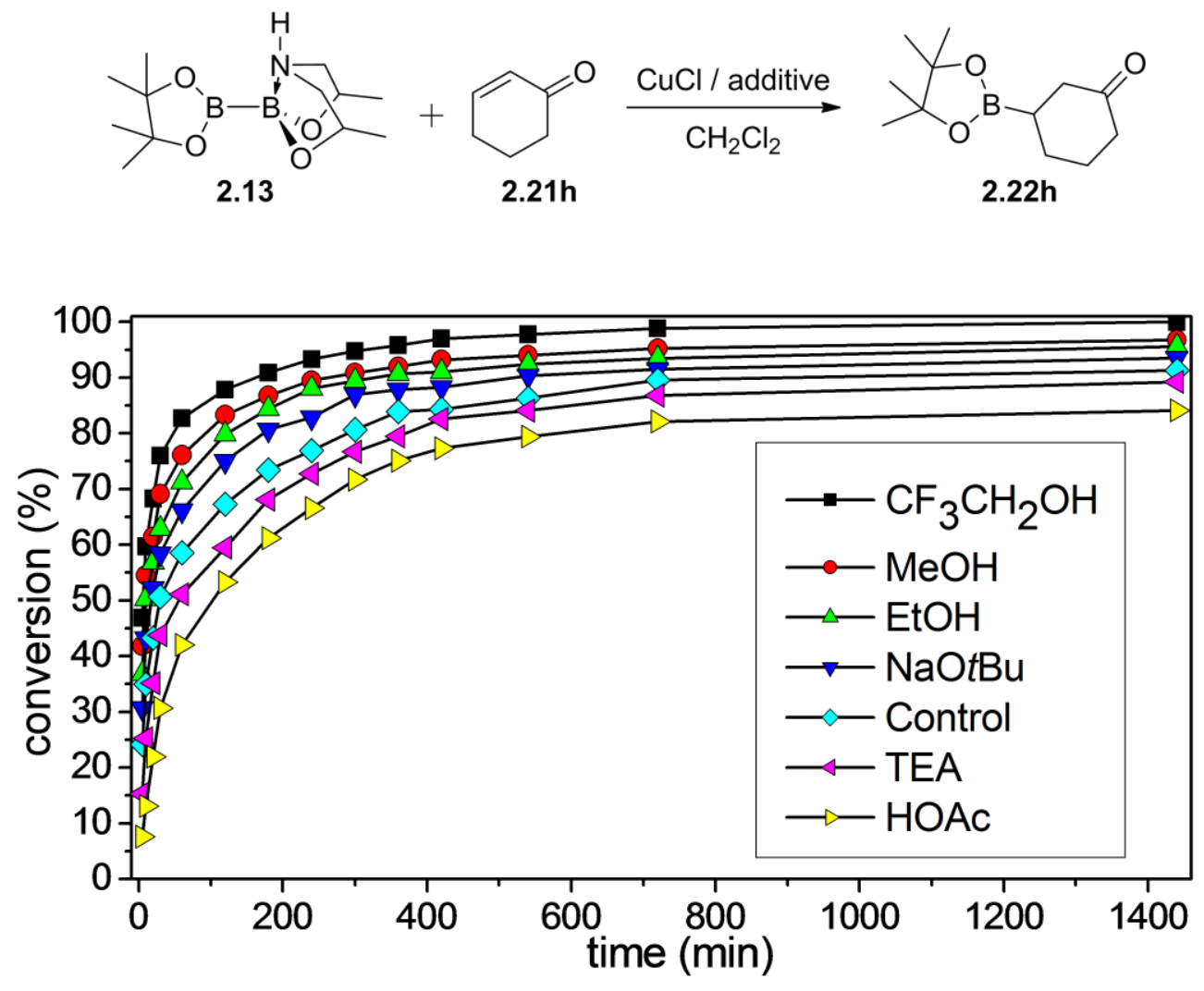
the effect of acetic acid and found the reaction to be sluggish, which is not surprising given that 2.13 rapidly decomposes under acidic conditions. To our delight, however, 2,2,2trifluoroethanol (TFE) was found to be the best additive, affording the desired boronate $\mathbf{2 . 2 2 h}$ in $>90 \%$ conversion in slightly over 3 hours.

Next, we examined the effect of base, noting that a catalytic amount of $\mathrm{NaO}^{t} \mathrm{Bu}$ did enhance the reaction rate. ${ }^{1}$ We hypothesized that the addition of a stoichiometric amount of base such as triethylamine or $\mathrm{NaO}^{t} \mathrm{Bu}$ might accelerate the reaction via removal of the $\mathrm{N}-\mathrm{H}$ proton in 2.13 providing an anionic diboron reagent in which lengthening of the B-B bond and the anionic charge could further facilitate boryl group transfer to copper. To our disappointment, neither provided a significant improvement. This is explained by the finding that reaction of $\mathbf{2 . 1 3}$ with a stoichiometric amount of $\mathrm{KO}^{t} \mathrm{Bu}$ indeed leads to the deprotonation of 2.13. However, the initial deprotonation product rearranges to an isomeric species, $\mathbf{2 . 2 0}$, wherein one of the alkoxy groups of the DIPA moiety migrates to the neighboring boron atom (Figure 2.6). This rearrangement is understandable considering the superior $\pi$-donor capabilities (to boron) of the $\mathrm{NR}_{2}$ group compared to the alkoxy group. Hence, the $s p^{2}$ boron atom is bound to one $\mathrm{NR}_{2}$ and one alkoxy group while the $s p^{3}$ boron atom is bound to three alkoxy groups. Compound $\mathbf{2 . 2 0}$ crystallizes as a potassium-bridged centrosymmetric dimer containing two molecules of THF $((\mathbf{2 . 2 0}) \text { thf })_{2}$. As compound 2.20 was obtained from a mixture of diastereomers of $\mathbf{2 . 1 3}$ (1:1.2 by $\left.{ }^{1} \mathrm{H} \mathrm{NMR}\right)$, it too

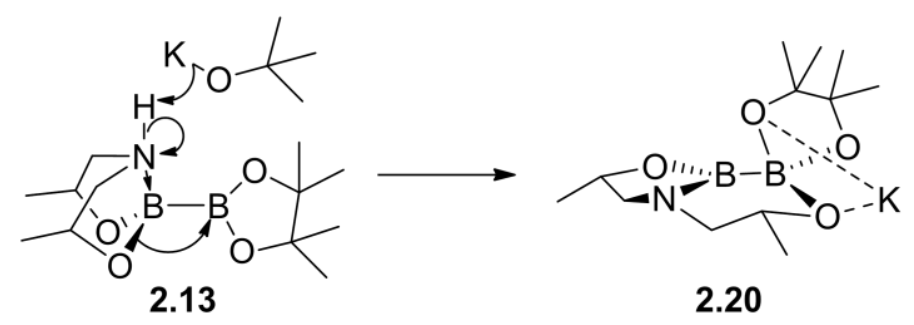

Scheme 2.5. Rearrangement of $\mathbf{2 . 1 3}$ to $\mathbf{2 . 2 0}$ with potassium tert-butoxide. 

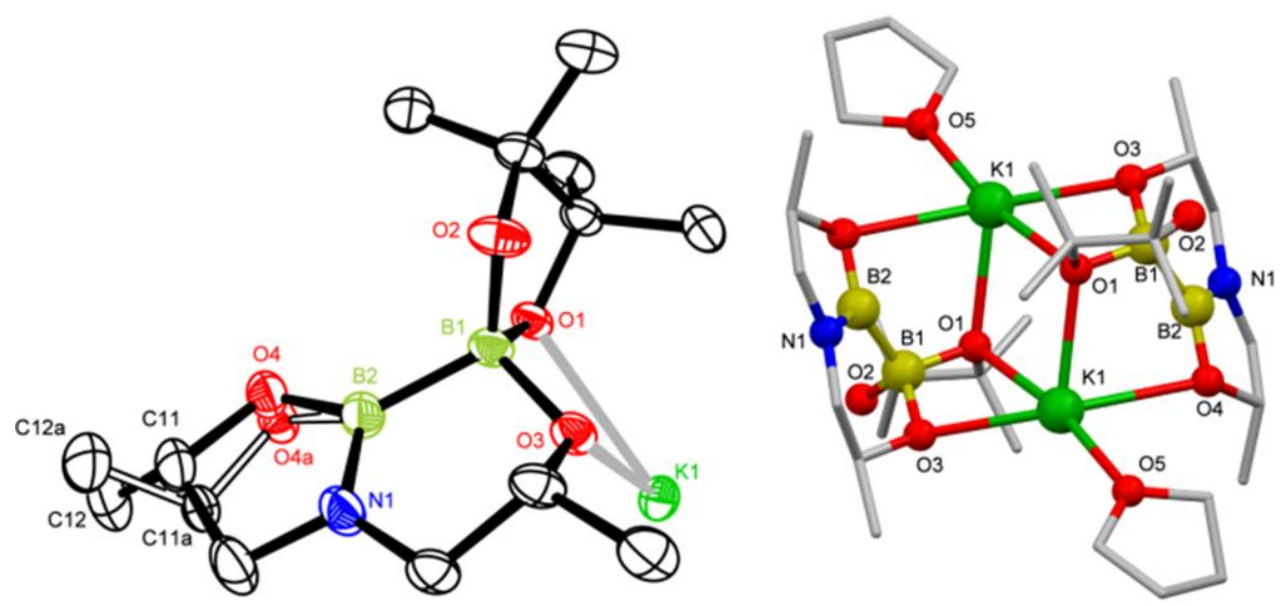

Figure 2.8. Perspective view of one formula unit of $\mathbf{2 . 2 0}$ (left) and a view of the potassiumbridged dimer of $((\mathbf{2 . 2 0}) \text { thf })_{2}$ (right). Thermal ellipsoids are drawn at the $50 \%$ probability level; hydrogen atoms and disorder of the THF moiety are omitted for clarity. Selected bond distances ( $(\AA)$ and angles $\left({ }^{\circ}\right)$ : B1-B2 1.735(2), O1-B1 1.498(2), O2-B1 1.486(2), O3-B1 1.524(2), O4-B2 1.400(4), N1-B2 1.408(2), O1-B1-O2 104.1(1), O1-B1-O3 107.8(1), O2-B1O3 108.9(1), O1-B1-B2 115.8(1), O2-B1-B2 116.2(1), O3-B1-B2 103.8(1).

consists of a mixture of diastereomers, resulting in a disorder of the atom pairs $\mathrm{O} 4 / \mathrm{O} 4 \mathrm{a}$, C11/C11a and C12/C12a. Despite the connectivity in $\mathbf{2 . 2 0}$ being different from that in $\mathbf{2 . 1 3}$, similar principal structural features can be found, namely a virtually planar environment at one boron atom (B2) and a distorted tetrahedral environment at the other boron atom (B1). The distance of the $\mathrm{NR}_{2}$ nitrogen atom $\mathrm{N} 1$ to the boron atom $\mathrm{B} 2$ is, as expected, much shorter than the N-B distance in the $\mathrm{NR}_{2} \mathrm{H}$ adduct 2.13, accounting for the stronger N-B bond in $\mathbf{2 . 2 0}$, in accordance with N-B distances found in related trigonal tetraaminodiboranes. ${ }^{120-123}$ However, the initially suggested lengthening of the B-B bond compared to $\mathbf{2 . 1 3}$ (Figure 2.5, Table 2.4) is indeed observed. Nonetheless, formation of $\mathbf{2 . 2 0}$ is detrimental to the catalytic reaction as with 
the two boron centers now being bridged, transmetalation of one of the boron moieties to $\mathrm{Cu}$ is less effective.

\subsection{Re-optimization: stoichiometry and other reaction conditions}

We next investigated ways to obtain high yields using a smaller excess of $\mathbf{2 . 1 3}$ and TFE as the additive (Table 2.4). With $\mathrm{CuCl}(5 \%)$ and $\mathbf{2 . 1 3}$ (2 equiv), 2-cyclohexenone 2.21h underwent the $\beta$-boration reaction to afford product $\mathbf{2 . 2 2} \mathbf{h}$ in good conversion (entry 1). To

Table 2.4. Addition of $\mathbf{2 . 1 3}$ to 2 -cyclohexenone under various conditions. ${ }^{a}$

\begin{tabular}{|c|c|c|c|c|}
\hline & $2.21 \mathrm{~h}$ & & $2.22 \mathrm{~h}$ & \\
\hline entry & catalyst, loading (mol\%) & equiv of $\mathbf{2 . 1 3}$ & $t\left({ }^{\circ} \mathrm{C}\right)$ & $\operatorname{conv}^{b}(\%)$ \\
\hline 1 & $\mathrm{CuCl}, 5$ & 2 & $\mathrm{rt}$ & 87.8 \\
\hline $2^{c}$ & $\mathrm{CuCl}, 5$ & 2 & $\mathrm{rt}$ & 87.1 \\
\hline 3 & $\mathrm{CuCl}, 5$ & 1.2 & $\mathrm{rt}$ & 73.1 \\
\hline $4^{c}$ & $\mathrm{CuCl}, 5$ & 1.2 & $\mathrm{rt}$ & 73.7 \\
\hline 5 & $\mathrm{CuCl}, 5$ & 2 & 40 & 91.3 \\
\hline 6 & $\mathrm{CuCl}, 5$ & 1.5 & 40 & 88.4 \\
\hline 7 & $\mathrm{CuCl}, 5$ & 1.2 & 40 & 82.3 \\
\hline 8 & $\mathrm{CuCl}, 10$ & 1.2 & 40 & 89.0 \\
\hline 9 & $\mathrm{CuCl}, 10$ & 1.2 & $\mathrm{rt}$ & 82.9 \\
\hline 10 & CuOAc, 10 & 1.2 & 40 & 85.1 \\
\hline 11 & {$[\mathrm{Rh}(\operatorname{cod}) \mathrm{Cl}]_{2}, 10$} & 1.2 & 40 & 80.1 \\
\hline 12 & $\mathrm{ZnCl}_{2}, 10$ & 1.2 & 40 & 17.3 \\
\hline 13 & $\mathrm{Ni}(\operatorname{cod})_{2}, 10$ & 1.2 & 40 & 16.2 \\
\hline 14 & $\mathrm{Pt}(\operatorname{cod}) \mathrm{Cl}_{2}, 10$ & 1.2 & 40 & 21.6 \\
\hline
\end{tabular}

${ }^{a}$ General procedure: $\mathbf{2 . 1 3}$ in $\mathrm{CH}_{2} \mathrm{Cl}_{2}$ was added to a solution of metal catalyst in $\mathrm{CH}_{2} \mathrm{Cl}_{2}$ at $\mathrm{rt}$ followed by $\mathbf{2 . 2 1 h}$ ( 1 equiv) and $\mathrm{CF}_{3} \mathrm{CH}_{2} \mathrm{OH}$ (4 equiv). Then the mixture was stirred at the indicated temperature. ${ }^{b}$ Conversion was determined by $\mathrm{GC}$ analysis. ${ }^{c}(R, R)-\mathbf{2 . 1 3}$ was used instead of 2.13. 
confirm that the $\beta$-boration reaction was unaffected by the optical purity of the diboron reagent, we employed enantiopure $(R, R)-\mathbf{2 . 1 3}$ or $\mathbf{2 . 1 3}$ and found the same reactivity and conversion yields (entries 1-4). As a result, racemic $\mathbf{2 . 1 3}$ was used in all subsequent reactions. Slightly increasing the reaction temperature to $40{ }^{\circ} \mathrm{C}$ gave higher conversion (entry 5). We next tried to decrease the number of equivalents of $\mathbf{2 . 1 3}$, but a change from 2 to 1.5 (entry 6) or 1.2 (entry 7 ) equivalents resulted in slightly decreased yields of $\mathbf{2 . 2 2 h}$. To our delight, increasing the catalyst loading to $10 \mathrm{~mol} \% \mathrm{CuCl}$, with 1.2 equivalents of $\mathbf{2 . 1 3}$ gave excellent conversion after 2 hours (entry 8). As expected, the reaction was slightly less efficient when the reaction was run at room temperature (entry 9). Interestingly, changing the catalyst to $\mathrm{CuOAc}$ or $[\mathrm{Rh}(\operatorname{cod}) \mathrm{Cl}]_{2}$ also afforded the desired product in excellent yield (entries 10-11). However, when we surveyed other metals as catalysts including zinc, nickel and platinum complexes, only poor conversions were observed (entries 12-14).

\subsection{Full scope of ketones and aldehydes}

With a revised set of optimal reaction conditions determined (entry 8, Table 2.4), we tested the $\beta$-boration conditions with more reactive $\alpha, \beta$-unsaturated ketones (Table 2.5). As shown in entries 1-3, simple acyclic vinyl ketones with methyl 2.21a, ethyl 2.21b, and propyl 2.21c groups afforded the corresponding products 2.22 a-c in up to $95 \%$ isolated yield within 12 hours. The lower isolated yield in the case of 2.21a may be due, in part, to its volatility. $\beta$ Substituted enones containing methyl and ethyl groups also provided the desired products $\mathbf{2 . 2 2 d}$ e in excellent yields (entries 4-5). In addition, $\beta$-phenyl substituted enones 2.21f-g provided products 2.22f-g in good yields (entries 7-8). The decrease in reactivity of these substrates might arise from a combination of steric and electronic effects of the phenyl ring. Cyclic substrates 
Table 2.5. Copper-catalyzed $\beta$-boration of $\alpha, \beta$-unsaturated ketones.<smiles>[R]C(=O)C([R])=C([R])[R]</smiles>

2.21a-I

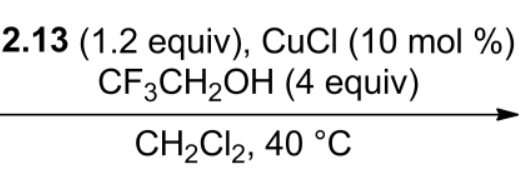

$\mathrm{CH}_{2} \mathrm{Cl}_{2}, 40{ }^{\circ} \mathrm{C}$<smiles>[R]C(=O)C([R])C([R])([R])B1OC(C)(C)C(C)(C)O1</smiles>

2.22a-I

\begin{tabular}{cccccccc}
\hline entry & substrate & $\mathrm{R}^{1}$ & $\mathrm{R}^{2}$ & $\mathrm{R}^{3}$ & $\mathrm{R}^{4}$ & time (h) & $\begin{array}{c}\% \text { yield }^{a} \\
(\%)^{b}\end{array}$ \\
\hline 1 & $\mathbf{2 . 2 1 a}$ & $\mathrm{H}$ & $\mathrm{H}$ & $\mathrm{H}$ & $\mathrm{Me}$ & 12 & 74 \\
2 & $\mathbf{2 . 2 1 b}$ & $\mathrm{H}$ & $\mathrm{H}$ & $\mathrm{H}$ & $\mathrm{Et}$ & 12 & 87 \\
3 & $\mathbf{2 . 2 1 c}$ & $\mathrm{H}$ & $\mathrm{H}$ & $\mathrm{H}$ & $\mathrm{Pr}$ & 12 & 95 \\
4 & $\mathbf{2 . 2 1 d}$ & $\mathrm{Me}$ & $\mathrm{H}$ & $\mathrm{H}$ & $\mathrm{Me}$ & 16 & 90 \\
5 & $\mathbf{2 . 2 1 e}$ & $\mathrm{Me}$ & $\mathrm{H}$ & $\mathrm{H}$ & $\mathrm{Et}$ & 16 & 92 \\
6 & $\mathbf{2 . 2 1 f}$ & $\mathrm{Ph}$ & $\mathrm{H}$ & $\mathrm{H}$ & $\mathrm{Me}$ & 36 & 80 \\
7 & $\mathbf{2 . 2 1 g}$ & $\mathrm{Ph}$ & $\mathrm{H}$ & $\mathrm{H}$ & $\mathrm{Ph}$ & 36 & 83 \\
8 & $\mathbf{2 . 2 1 h}$ & & $2-$ cyclohexenone & & 24 & 82 \\
9 & $\mathbf{2 . 2 1 i}$ & & $2-$ cyclopentenone & & 24 & 82 \\
10 & $\mathbf{2 . 2 1 j}$ & $\mathrm{Me}$ & $\mathrm{Me}$ & $\mathrm{H}$ & $\mathrm{Me}$ & 48 & $41(55)$ \\
11 & $\mathbf{2 . 2 1 \mathbf { c } ^ { c }}$ & $\mathrm{Me}$ & $\mathrm{H}$ & $\mathrm{Me}$ & $\mathrm{Me}$ & 48 & $35(48)$ \\
12 & $\mathbf{2 . 2 1 l ^ { d }}$ & $\mathrm{H}$ & \multicolumn{2}{c}{$\left(\mathrm{CH}_{2}\right)_{4}$} & $\mathrm{Me}$ & 48 & 61 \\
\hline
\end{tabular}

${ }^{a}$ Isolated yield. ${ }^{b} 2$ equiv of $\mathbf{2 . 1 3}$ was used. ${ }^{c} \mathrm{dr}=6.7: 1 .{ }^{d} \mathrm{dr}=4.3: 1$.

cyclohexenone $2.21 \mathrm{~h}$ and cyclopentenone $2.21 \mathrm{i}$ were also converted to their respective $\beta$-borated products in good yields (entries 10-11). Additionally, sterically encumbered $\mathbf{2 . 2 1 j}$ resulted in a boronate with a quaternary carbon center, and the disubstituted enones $\mathbf{2 . 2 1 k}$-l were converted to the desired products $\mathbf{2 . 2 2} \mathbf{j}-\mathbf{l}$ in moderate yields (entry 10-12). Interestingly, the disubstituted ketones 2.21k and 2.211 resulted in products with good diastereoselectivity towards the cis product (6.7:1 and 4.3:1, respectively), which lends support to aspects of the proposed mechanism: syn addition of the boryl cuprate followed by rapid protonation of the resulting organocuprate (vide infra). Enone 2.211 shows improved selectivity in comparison to the NHCcatalyzed case. ${ }^{87}$ It should be noted that compared with our previous studies, the improved $\beta$ boration protocol gave faster rates with similar yields and required only 1.2 equivalents of 2.13.

Perhaps the most challenging substrates for metal-catalyzed boron addition reactions are $\alpha, \beta$-unsaturated aldehydes. Aromatic aldehydes have been shown to react in a 1,2-fashion using 
a $\mathrm{Cu}-\mathrm{NHC}$ catalyst system. ${ }^{130,131}$ Thus, in addition to the 1,4 -selective diboration of $\alpha, \beta$ unsaturated aldehydes, there can be a competing 1,2-diboron addition reaction. To date, there have only been three reported cases of boron addition to $\alpha, \beta$-unsaturated aldehydes, $\mathrm{using} \mathrm{Pt}{ }^{68}$ $\mathrm{Rh}^{70}$ and $\mathrm{Cu}^{82}$ as catalysts. However, some of these methods require harsh reaction condition such as high reaction temperature; ${ }^{68,70}$ some only reported $\mathrm{GC}^{70,82}$ yields.

Taking advantage of our milder reaction conditions, we examined the borylation of a series of $\alpha, \beta$-unsaturated aldehydes. As shown in Scheme 2.6, crotonaldehyde was readily converted into the boronate $\mathbf{2 . 2 3}$ in $>99 \%$ conversion after 3 hours with moderate isolated yield. 2-Ethylacrolein and methacrolein also proceeded in moderate yields affording compounds $\mathbf{2 . 2 4}$

Scheme 2.6. Copper-catalyzed $\beta$-boration of other $\alpha, \beta$-unsaturated conjugated compounds.<smiles>CC(CC=O)B1OC(C)(C)C(C)(C)O1</smiles>

$2.23(54 \%)^{a}$ conversion $>99 \%$

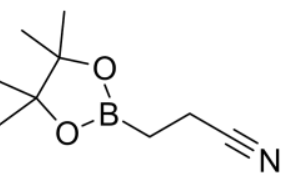

$2.141(52 \%)^{\mathrm{a}}$ conversion $>99 \%$<smiles>CCC(CC=O)B1OC(C)(C)C(C)(C)O1</smiles>

$2.24(57 \%)^{a}$ conversion $>99 \%$<smiles>CC(C=O)CB1OC(C)(C)C(C)(C)O1</smiles>

$2.25(30 \%)^{a}$ conversion $75 \%^{\mathrm{b}}$<smiles>[R]C(C)=C([R])C=O</smiles>

2.13, $\mathrm{CuCl}, \mathrm{TFE}$

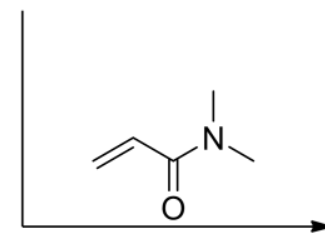<smiles>CC1(C)OB(C(CC=O)c2ccccc2)OC1(C)C</smiles>

$2.26(21 \%)^{a}$ conversion $66 \%^{\mathrm{b}}$
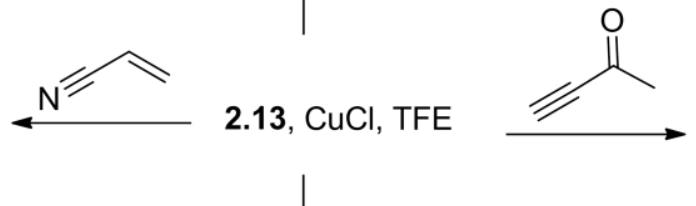
and 2.25, respectively. Using cinnamaldehyde as substrate, the reaction proceeded to $66 \%$ conversion after 3 hours (or $97 \%$ after 24 hours) affording a $21 \%$ yield of $\mathbf{2 . 2 6}$. In comparison, the $\mathrm{CuCl} / \mathrm{DPEphos} / \mathrm{NaO} t \mathrm{Bu}$ system $^{74}$ with $\mathbf{2 . 3}$ as the boron source and cinnamaldehyde as substrate via Yun's method gave only $73 \%$ conversion after 24 hours and $<10 \%$ isolated yield. Thus, the mild reaction conditions using $\mathbf{2 . 1 3}$ offer a significant advantage relative to previously reported protocols and provide access to difficult products.

\subsection{Proposed catalytic cycle}

A possible catalytic cycle for the copper-catalyzed boration with $\mathbf{2 . 1 3}$ is shown in Scheme 2.7. On the basis of the above experimental results and the $\mathrm{X}$-ray structure of $(R, R)$ 2.13, the catalytic cycle starts with an activated diboron compound. In our view, the formation of a $s p^{2}-s p^{3}$ hybridized diboron compound is critical for the transmetalation of the $\left(s p^{2}\right)$-Bpin
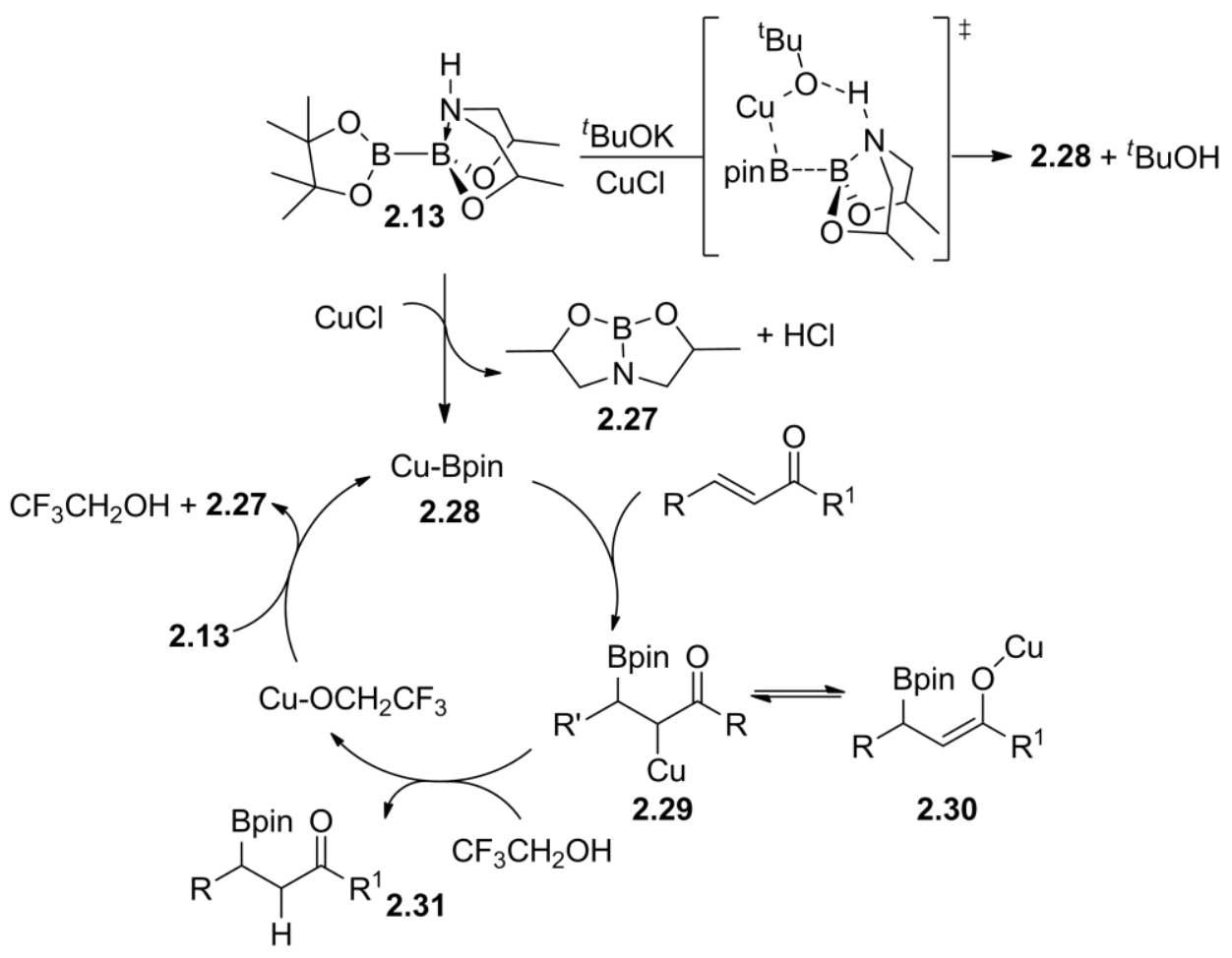

Scheme 2.7. A proposed catalytic cycle. 
moiety to copper to form the active boryl copper complex 2.28. This is consistent with the use of stoichiometric amounts of tert-butoxide (i.e., excess with respect to the amount of the copper catalyst) $^{74,78,79,83}$ in reactions employing $\mathbf{2 . 3}$ as the boron source and related to the activation of 2.3 with NHC ligand in the copper-free diboration of $\alpha, \beta$-unsaturated compounds. ${ }^{87}$ Alternatively, with a catalytic amount of tert-butoxide present, a $\mathrm{Cu}-\mathrm{O}^{t} \mathrm{Bu}$ species can be formed, which can deprotonate $\mathbf{2 . 1 3}$ and transmetalate faster than $\mathrm{CuCl}$ to form $\mathbf{2 . 2 8}$, resulting in more rapid catalyst initiation. Boryl-cuprate $\mathbf{2 . 2 8}$ likely adds to the substrate in a concerted 3,4conjugate addition mechanism, as supported by DFT calculations ${ }^{129}$ and the observed diastereomeric ratios of $\mathbf{2 . 2 2 k}$ and $\mathbf{2 . 2 2 l}$ (vide supra). The resulting C-enolate $\mathbf{2 . 2 9}$ is likely in equilibrium with $O$-enolate 2.30, either of which could undergo protolytic cleavage by $\mathrm{MeOH}$ or TFE to form the product $\mathbf{2 . 3 1}$ and a copper alkoxide species, which regenerates 2.28 in the

presence of $2.13 .{ }^{74}$ The aforementioned cis-selectivity observed in products $2.21 \mathrm{k}-1$ in the absence of chiral ligands suggest that the protonation of organocuprate $\mathbf{2 . 2 9}$ is more rapid than tautamerization to $\mathbf{2 . 3 0}$, or intermediate $\mathbf{2 . 2 9 / 2 . 3 0}$ is more structurally complex.

\subsection{Conclusions}

In summary, we disclosed the first synthesis of a preactivated diboron reagent $(\mathbf{2 . 1 3})$ which contains one $s p^{2}$ and one $s p^{3}$ hybridized boron atom, as observed by ${ }^{11} \mathrm{~B}$ NMR spectroscopy. We first demonstrated its reactivity, in the absence of phosphine or alkoxide additives, toward copper-catalyzed $\beta$-boration of $13 \alpha, \beta$-unsaturated conjugated compounds in up to $96 \%$ yield. Our results established that the $s p^{2}$ hybridized boron of the mixed diboron reagent is selectively transferred to the $\beta$-carbon of conjugated substrates. In addition, we provided the first example of catalytic addition of a diboron reagent to an $\alpha, \beta$-acetylenic ketone to afford a $\beta, \beta$-diborated ketone. 
In a subsequent, more detailed study we aimed to address several problematic issues and unanswered questions from the initial project. First, enantiopure $(R, R)-\mathbf{2 . 1 3}$ was synthesized starting with a chiral epoxide. The $s p^{3}$ hybridized, pyramidal DIPA-coordinated boron atom was unambiguously identified based on X-ray crystallographic analysis of $(R, R)$-2.13 and indicates the critical role of an activating nucleophile, such as tert-butoxide, for the reaction of diboron compounds. These results provide mechanistic insights into the activation of related reactions involving $N$-heterocyclic carbene-Cu catalysts. To improve reaction conditions, we screened a variety of additives and found trifluoroethanol to provide the greatest rate enhancement. Incorporating this additive, we established that the enantiopurity of $\mathbf{2 . 1 3}$ was not responsible for the initially required 2 equivalents of diboron reagent and re-optimized the conditions with only 1.2 equivalents. Under new conditions, we expanded the scope of the reaction to a variety of $\alpha, \beta$-unsaturated ketones, highly reactive aldehydes and substrates containing other functional groups. Finally, we proposed a plausible catalytic cycle based on a combination of literature precedence and new data collected from the study of unsymmetrical diboron reagents in our lab.

\subsection{References for chapter 2}

1. Gao, M.; Thorpe, S. B.; Santos, W. L. $\mathrm{sp}^{2}-\mathrm{sp}^{3}$ Hybridized Mixed Diboron: Synthesis, Characterization and Copper-Catalyzed $\beta$-Boration of $\alpha, \beta$-Unsaturated Conjugated Compounds Org. Lett. 2009, 11, 3478-3481.

2. Gao, M.; Thorpe, S. B.; Kleeberg, C.; Slebodnick, C.; Marder, T. B.; Santos, W. L. Structure and Reactivity of a Preactivated $\mathrm{sp}^{2}-\mathrm{sp}^{3}$ Diboron Reagent: Catalytic Regioselective Boration of $\alpha, \beta$-Unsaturated Conjugated Compounds J. Org. Chem. 2011, 76, 3997-4007.

3. Kleeberg, C.; Crawford, A. G.; Batsanov, A. S.; Hodgkinson, P.; Apperley, D. C.; Cheung, M. S.; Lin, Z.; Marder, T. B. Spectroscopic and Structural Characterization of the CyNHC Adduct of $\mathrm{B}_{2} \mathrm{pin}_{2}$ in Solution and in the Solid State J. Org. Chem. 2012, 77, 785-789.

4. Hall, D. G. Boronic Acids: Preparation and Applications in Organic Synthesis, Medicine and Materials; 2nd ed.; Wiley-VCH, 2011. 
5. Beletskaya, I.; Moberg, C. Element-Element Additions to Unsaturated Carbon-Carbon Bonds Catalyzed by Transition Metal Complexes Chem. Rev. 2006, 106, 2320-2354.

6. Beletskaya, I.; Moberg, C. Element-Element Addition to Alkynes Catalyzed by the Group 10 Metals Chem. Rev. 1999, 99, 3435-3462.

7. Miyaura, N.; Suzuki, A. Palladium-Catalyzed Cross-Coupling Reactions of Organoboron Compounds Chem. Rev. 1995, 95, 2457-2483.

8. Ishiyama, T.; Matsuda, N.; Miyaura, N.; Suzuki, A. Platinum(0)-Catalyzed Diboration of Alkynes J. Am. Chem. Soc. 1993, 115, 11018-11019.

9. Baker, R. T.; Nguyen, P.; Marder, T. B.; Westcott, S. A. Transition Metal Catalyzed Diboration of Vinylarenes Angew. Chem. Int. Ed. 1995, 34, 1336-1338.

10. Ishiyama, T.; Kitano, T.; Miyaura, N. Platinum(0)-Catalyzed Diboration of Allenes with Bis(pinacolato)diboron Tetrahedron Lett. 1998, 39, 2357-2360.

11. Ishiyama, T.; Momota, S.; Miyaura, N. Platinum(0)-Catalyzed Diboration of Methylenecyclopropanes with Bis(pinacolato)diboron: A Selective Route to 2,4-Bis(boryl)-1butenes Synlett 1999, 1999, 1790,1792.

12. Yang, F.-Y.; Cheng, C.-H. Unusual Diboration of Allenes Catalyzed by Palladium Complexes and Organic Iodides: A New Efficient Route to Biboronic Compounds J. Am. Chem. Soc. 2001, 123, 761-762.

13. Morgan, J. B.; Miller, S. P.; Morken, J. P. Rhodium-Catalyzed Enantioselective Diboration of Simple Alkenes J. Am. Chem. Soc. 2003, 125, 8702-8703.

14. Pelz, N. F.; Woodward, A. R.; Burks, H. E.; Sieber, J. D.; Morken, J. P. PalladiumCatalyzed Enantioselective Diboration of Prochiral Allenes J. Am. Chem. Soc. 2004, 126, 1632816329.

15. Sieber, J. D.; Morken, J. P. Sequential Pd-Catalyzed Asymmetric Allene Diboration/ $\alpha$ Aminoallylation J. Am. Chem. Soc. 2006, 128, 74-75.

16. Cho, H. Y.; Morken, J. P. Diastereoselective Construction of Functionalized Homoallylic Alcohols by Ni-Catalyzed Diboron-Promoted Coupling of Dienes and Aldehydes J. Am. Chem. Soc. 2008, 130, 16140-16141.

17. Marder, T.; Norman, N. Transition Metal Catalysed Diboration Top. Catal. 1998, 5, 63-73.

18. Ishiyama, T.; Miyaura, N. Chemistry of Group 13 Element-Transition Metal Linkage — The Platinum- and Palladium-Catalyzed Reactions of (Alkoxo)diborons J. Organomet. Chem. 2000, $611,392-402$.

19. Ishiyama, T.; Miyaura, N. Metal-Catalyzed Reactions of Ciborons for Synthesis of Organoboron Compounds Chem. Rec. 2004, 3, 271-280. 
20. Lesley, G.; Nguyen, P.; Taylor, N. J.; Marder, T. B.; Scott, A. J.; Clegg, W.; Norman, N. C. Synthesis and Characterization of Platinum(II)-Bis(boryl) Catalyst Precursors for Diboration of Alkynes and Diynes: Molecular Structures of cis- $\left[\left(\mathrm{PPh}_{3}\right)_{2} \mathrm{Pt}(\mathrm{B}-4-\mathrm{Butcat})_{2}\right]$, cis$\left[\left(\mathrm{PPh}_{3}\right)_{2} \mathrm{Pt}(\mathrm{Bcat})_{2}\right]$, cis-[(dppe $\left.) \mathrm{Pt}(\mathrm{Bcat})_{2}\right]$, cis-[(dppb)Pt(Bcat $\left.)_{2}\right],(\mathrm{E})-(4-$ $\left.\mathrm{MeOC}_{6} \mathrm{H}_{4}\right) \mathrm{C}(\mathrm{Bcat}) \mathrm{CH}(\mathrm{Bcat}),(\mathrm{Z})-\left(\mathrm{C}_{6} \mathrm{H}_{5}\right) \mathrm{C}(\mathrm{Bcat}) \mathrm{C}\left(\mathrm{C}_{6} \mathrm{H}_{5}\right)$ (Bcat), and (Z,Z)-(4$\left.\mathrm{MeOC}_{6} \mathrm{H}_{4}\right) \mathrm{C}(\mathrm{Bcat}) \mathrm{C}(\mathrm{Bcat}) \mathrm{C}(\mathrm{Bcat}) \mathrm{C}\left(4-\mathrm{MeOC}_{6} \mathrm{H}_{4}\right)(\mathrm{Bcat})\left(\mathrm{cat}=1,2-\mathrm{O}_{2} \mathrm{C}_{6} \mathrm{H}_{4}\right.$; dppe = $\left.\mathrm{Ph}_{2} \mathrm{PCH}_{2} \mathrm{CH}_{2} \mathrm{PPh}_{2} ; \mathrm{dppb}=\mathrm{Ph}_{2} \mathrm{P}\left(\mathrm{CH}_{2}\right)_{4} \mathrm{PPh}_{2}\right)$ Organometallics 1996, 15, 5137-5154.

21. Iverson, C. N.; Smith, M. R. Mechanistic Investigation of Stoichiometric Alkyne Insertion into Pt-B Bonds and Related Chemistry Bearing on the Catalytic Diborylation of Alkynes Mediated by Platinum(II) Diboryl Complexes Organometallics 1996, 15, 5155-5165.

22. Ishiyama, T.; Yamamoto, M.; Miyaura, N. Platinum(0)-Catalysed Diboration of Alka-1,3Dienes with Bis(pinacolato)diboron Chem. Commun. 1996, 2073.

23. Iverson, C. N.; Smith, M. R. Efficient Olefin Diboration by a Base-Free Platinum Catalyst Organometallics 1997, 16, 2757-2759.

24. Ishiyama, T.; Yamamoto, M.; Miyaura, N. Diboration of Alkenes with Bis(pinacolato)diboron Catalysed by a Platinum(0) Complex Chem. Commun. 1997, 689.

25. Dai, C.; Marder, T. B.; Robins, E. G.; Yufit, D. S.; Howard, J. A. K.; Scott, A. J.; Clegg, W. Rhodium Catalysed Diboration of Unstrained Internal Alkenes and a New and General Route to Zwitterionic $\left[\mathrm{L}_{2} \mathrm{Rh}\left(6\right.\right.$-catBcat) (cat $\left.=1,2-\mathrm{O}_{2} \mathrm{C}_{6} \mathrm{H}_{4}\right)$ complexes Chem. Commun. 1998, 19831984.

26. Marder, T. B.; Norman, N. C.; Rice, C. R. Platinum Catalysed Diboration of Terminal Alkenes with Chiral Diborane Compounds Tetrahedron Lett. 1998, 39, 155-158.

27. Mann, G.; John, K. D.; Baker, R. T. Platinum-Catalyzed Diboration Using a Commercially Available Catalyst: Diboration of Aldimines to $\alpha$-Aminoboronate Esters Org. Lett. 2000, 2, 2105-2108.

28. Thomas, R. L.; Souza, F. E. S.; Marder, T. B. Highly Efficient Monophosphine Platinum Catalysts for Alkyne Diboration J. Chem. Soc., Dalton Trans. 2001, 1650.

29. Nguyen, P.; Coapes, R. B.; Woodward, A. D.; Taylor, N. J.; Burke, J. M.; Howard, J. A. K.; Marder, T. B. Rhodium(I) Catalysed Diboration of (E)-Styrylboronate Esters: Molecular Structures of (E)-p-MeO- $\mathrm{C}_{6} \mathrm{H}_{4}-\mathrm{CH}=\mathrm{CH}-\mathrm{B}\left(1,2-\mathrm{O}_{2} \mathrm{C}_{6} \mathrm{H}_{4}\right)$ and p-MeO- $\mathrm{C}_{6} \mathrm{H}_{4}-\mathrm{CH}_{2} \mathrm{C}\{\mathrm{B}(1,2-$ $\left.\left.\mathrm{O}_{2} \mathrm{C}_{6} \mathrm{H}_{4}\right)\right\}_{3}$ J. Organomet. Chem. 2002, 652, 77-85.

30. Ramírez, J.; Corberán, R.; Sanaú, M.; Peris, E.; Fernandez, E. Unprecedented Use of Silver(I) N-Heterocyclic Carbene Complexes for the Catalytic Preparation of 1,2-Bis(boronate) Esters Chem. Commun. 2005, 3056.

31. Trudeau, S.; Morgan, J. B.; Shrestha, M.; Morken, J. P. Rh-Catalyzed Enantioselective Diboration of Simple Alkenes: Reaction Development and Substrate Scope J. Org. Chem. 2005, 70, 9538-9544. 
32. Corberán, R.; Ramírez, J.; Poyatos, M.; Peris, E.; Fernández, E. Coinage Metal Complexes with N-Heterocyclic Carbene Ligands as Selective Catalysts in Diboration Reaction Tetrahedron: Asymmetry 2006, 17, 1759-1762.

33. Lillo, V.; Fructos, Manuel R.; Ramírez, J.; Braga, Ataualpa A. C.; Maseras, F.; DíazRequejo, M. M.; Pérez, Pedro J.; Fernández, E. A Valuable, Inexpensive Cu/N-Heterocyclic Carbene Catalyst for the Selective Diboration of Styrene Chem. Eur. J. 2007, 13, 2614-2621.

34. Chen, H.; Schlecht, S.; Semple, T. C.; Hartwig, J. F. Thermal, Catalytic, Regiospecific Functionalization of Alkanes Science 2000, 287, 1995-1997.

35. Ishiyama, T.; Takagi, J.; Ishida, K.; Miyaura, N.; Anastasi, N. R.; Hartwig, J. F. Mild Iridium-Catalyzed Borylation of Arenes. High Turnover Numbers, Room Temperature Reactions, and Isolation of a Potential Intermediate J. Am. Chem. Soc. 2002, 124, 390-391.

36. Mkhalid, I. A. I.; Barnard, J. H.; Marder, T. B.; Murphy, J. M.; Hartwig, J. F. C-H Activation for the Construction of C-B Bonds Chemical Reviews 2009, 110, 890-931.

37. Iverson, C. N.; Smith, M. R. Stoichiometric and Catalytic B-C Bond Formation from Unactivated Hydrocarbons and Boranes J. Am. Chem. Soc. 1999, 121, 7696-7697.

38. Shimada, S.; Batsanov, A. S.; Howard, J. A. K.; Marder, T. B. Formation of Aryl- and Benzylboronate Esters by Rhodium-Catalyzed C-H Bond Functionalization with Pinacolborane Angew. Chem. Int. Ed. 2001, 40, 2168-2171.

39. Cho, J. Y.; Tse, M. K.; Holmes, D.; Maleczka, R. E., Jr.; Smith, M. R., III Remarkably Selective Iridium Catalysts for the Elaboration of Aromatic C-H Bonds Science 2002, 295, 305308.

40. Ishiyama, T.; Takagi, J.; Hartwig, J. F.; Miyaura, N. A Stoichiometric Aromatic C-H Borylation Catalyzed by Iridium(I)/2,2'-Bipyridine Complexes at Room Temperature Angew. Chem. Int. Ed. 2002, 41, 3056-3058.

41. Lam, W. H.; Lam, K. C.; Lin, Z.; Shimada, S.; Perutz, R. N.; Marder, T. B. Theoretical Study of Reaction Pathways for the Rhodium Phosphine-Catalysed Borylation of C-H Bonds with Pinacolborane Dalton Trans. 2004, 1556.

42. Coventry, D. N.; Batsanov, A. S.; Goeta, A. E.; Howard, J. A. K.; Marder, T. B.; Perutz, R. N. Selective Ir-Catalysed Borylation of Polycyclic Aromatic Hydrocarbons: Structures of Naphthalene-2,6-bis(boronate), Pyrene-2,7-bis(boronate) and Perylene-2,5,8,11-tetra(boronate) Esters Chem. Commun. 2005, 2172.

43. Mkhalid, I. A. I.; Coventry, D. N.; Albesa-Jove, D.; Batsanov, A. S.; Howard, J. A. K.; Perutz, R. N.; Marder, T. B. Ir-Catalyzed Borylation of C-H Bonds in N-Containing Heterocycles: Regioselectivity in the Synthesis of Heteroaryl Boronate Esters Angew. Chem. Int. Ed. 2006, 45, 489-491. 
44. Miyaura, N. Metal-Catalyzed Reactions of Organoboronic Acids and Esters Bull. Chem. Soc. Jpn. 2008, 81, 1535-1553.

45. Kawamorita, S.; Ohmiya, H.; Hara, K.; Fukuoka, A.; Sawamura, M. Directed Ortho Borylation of Functionalized Arenes Catalyzed by a Silica-Supported Compact

Phosphine-Iridium System J. Am. Chem. Soc. 2009, 131, 5058-5059.

46. Ishiyama, T.; Murata, M.; Miyaura, N. Palladium(0)-Catalyzed Cross-Coupling Reaction of Alkoxydiboron with Haloarenes: A Direct Procedure for Arylboronic Esters J. Org. Chem. 1995, 60, 7508-7510.

47. Takagi, J.; Takahashi, K.; Ishiyama, T.; Miyaura, N. Palladium-Catalyzed Cross-Coupling Reaction of Bis(pinacolato)diboron with 1-Alkenyl Halides or Triflates: Convenient Synthesis of Unsymmetrical 1,3-Dienes via the Borylation-Coupling Sequence J. Am. Chem. Soc. 2002, 124, 8001-8006.

48. Billingsley, K. L.; Barder, T. E.; Buchwald, S. L. Palladium-Catalyzed Borylation of Aryl Chlorides: Scope, Applications, and Computational Studies Angew. Chem. Int. Ed. 2007, 46, 5359-5363.

49. Morgan, A. B.; Jurs, J. L.; Tour, J. M. Synthesis, Flame-Retardancy Testing, and Preliminary Mechanism Studies of Nonhalogenated Aromatic Boronic Acids: A New Class of Condensed-Phase Polymer Flame-Retardant Additives for Acrylonitrile-Butadiene-Styrene and Polycarbonate J. Appl. Polym. Sci. 2000, 76, 1257-1268.

50. Rosen, B. M.; Huang, C.; Percec, V. Sequential Ni-Catalyzed Borylation and CrossCoupling of Aryl Halides via in Situ Prepared Neopentylglycolborane Org. Lett. 2008, 10, 2597 2600 .

51. Wilson, D. A.; Wilson, C. J.; Rosen, B. M.; Percec, V. Two-Step, One-Pot Ni-Catalyzed Neopentylglycolborylation and Complementary $\mathrm{Pd} / \mathrm{Ni}$-Catalyzed Cross-Coupling with Aryl Halides, Mesylates, and Tosylates Org. Lett. 2008, 10, 4879-4882.

52. Zhu, W.; Ma, D. Formation of Arylboronates by a CuI-Catalyzed Coupling Reaction of Pinacolborane with Aryl Iodides at Room Temperature Org. Lett. 2005, 8, 261-263.

53. Kleeberg, C.; Dang, L.; Lin, Z.; Marder, T. B. A Facile Route to Aryl Boronates: RoomTemperature, Copper-Catalyzed Borylation of Aryl Halides with Alkoxy Diboron Reagents Angew. Chem. Int. Ed. 2009, 48, 5350-5354.

54. Hartwig, J. F., Waltz, K. M., Muhoro, C. N., He, X.; Eisenstein, O.; Bosque, R.; Maseras, F Advances in Boron Chemistry; Siebert, W., Ed.; The Royal Society of Chemistry: Cambridge, 1997; Vol. Spec. Publ. No. 201.

55. Wadepohl, H. Hypoelectronic Dimetallaboranes Angew Chem Int Ed Engl 2002, 41, 42204223. 
56. Irvine, G. J.; Lesley, M. J. G.; Marder, T. B.; Norman, N. C.; Rice, C. R.; Robins, E. G.; Roper, W. R.; Whittell, G. R.; Wright, L. J. Transition Metal-Boryl Compounds: Synthesis, Reactivity, and Structure Chem. Rev. 1998, 98, 2685-2722.

57. Braunschweig, H. Transition Metal Complexes of Boron Angew. Chem. Int. Ed. 1998, 37, 1786-1801.

58. Smith, M. R. Advances in Metal Boryl and Metal-Mediated B-X Activation Chemistry In Progress in Inorganic Chemistry; John Wiley \& Sons, Inc.: 1999; pp 505-567.

59. Braunschweig, H.; Colling, M. Transition Metal Complexes of Boron - Synthesis, Structure and Reactivity Coord. Chem. Rev. 2001, 223, 1-51.

60. Aldridge, S.; Coombs, D. L. Transition Metal Boryl and Borylene Complexes: Substitution and Abstraction Chemistry Coord. Chem. Rev. 2004, 248, 535-559.

61. Braunschweig, H.; Kollann, C.; Rais, D. Transition-Metal Complexes of Boron - New Insights and Novel Coordination Modes Angew. Chem. Int. Ed. 2006, 45, 5254-5274.

62. Marder, T. B. In Specialist Periodical Reports: Organometallic Chemistry; Fairlamb, I. J. S., Lynam, J. M., Eds.; Royal Society of Chemistry: Cambridge, U.K., 2008; Vol. 34, p 46.

63. Kays, D.; Aldridge, S. Transition Metal Boryl Complexes; Marder, T., Lin, Z., Eds.; Springer Berlin / Heidelberg: 2008; Vol. 130, pp 29-122.

64. Dang, L.; Lin, Z.; Marder, T. B. Boryl Ligands and Their Roles in Metal-Catalysed Borylation Reactions Chem. Commun. 2009, 3987-3995.

65. For one contrary example, see Hewes, J. D.; Kreimendahl, C. W.; Marder, T. B.; Hawthorne, M. F. Metal-Promoted Insertion of an Activated Alkene into a Boron-Hydrogen Bond of an Exopolyhedral Nido-Rhodacarborane: Rhodium-Catalyzed Hydroboration J. Am. Chem. Soc. 1984, 106, 5757.

66. Corey, E. J.; Helal, C. J. Reduction of Carbonyl Compounds with Chiral Oxazaborolidine Catalysts: A New Paradigm for Enantioselective Catalysis and a Powerful New Synthetic Method Angew. Chem. Int. Ed. 1998, 37, 1986-2012.

67. Lawson, Y. G.; Lesley, M. J. G.; Norman, N. C.; Rice, C. R.; Marder, T. B. Platinum Catalysed 1,4-Diboration of $\alpha, \beta$-Unsaturated Ketones Chem. Commun. 1997, 2051-2052.

68. Abu Ali, H.; Goldberg, I.; Srebnik, M. Addition Reactions of Bis(pinacolato)diborane to Carbonyl Enones and Synthesis of (pinacolato) ${ }_{2} \mathrm{BCH}_{2} \mathrm{~B}$ and (pinacolato) ${ }_{2} \mathrm{BCH}_{2} \mathrm{CH}_{2} \mathrm{~B}$ by Insertion and Coupling Organometallics 2001, 20, 3962-3965.

69. Bell, N. J.; Cox, A. J.; Cameron, N. R.; Evans, J. S. O.; Marder, T. B.; Duin, M. A.; Elsevier, C. J.; Baucherel, X.; Tulloch, A. A. D.; Tooze, R. P. Platinum Catalysed 3,4- and 1,4-Diboration of $\alpha, \beta$-Unsaturated Carbonyl Compounds Using Bis-Pinacolatodiboron Chem. Commun. 2004, 1854-1855. 
70. Kabalka, G. W.; Das, B. C.; Das, S. Rhodium-Catalyzed 1,4-Addition Reactions of Diboron Reagents to Electron Deficient Olefins Tetrahedron Lett. 2002, 43, 2323-2325.

71. Shiomi, T.; Adachi, T.; Toribatake, K.; Zhou, L.; Nishiyama, H. Asymmetric Beta-Boration of $\alpha, \beta$-Unsaturated Carbonyl Compounds Promoted by Chiral Rhodium-Bisoxazolinylphenyl Catalysts Chem. Commun. 2009, 5987-5989.

72. Hirano, K.; Yorimitsu, H.; Oshima, K. Nickel-Catalyzed $\beta$-Boration of $\alpha, \beta$-Unsaturated Esters and Amides with Bis(pinacolato)diboron Org. Lett. 2007, 9, 5031-5033.

73. Kajiwara, T.; Terabayashi, T.; Yamashita, M.; Nozaki, K. Syntheses, Structures, and Reactivities of Borylcopper and -Zinc Compounds: 1,4-Silaboration of an $\alpha, \beta$-Unsaturated Ketone to Form a $\gamma$-Siloxyallylborane Angew. Chem. Int. Ed. 2008, 47, 6606-6610.

74. Mun, S.; Lee, J.-E.; Yun, J. Copper-Catalyzed $\beta$-Boration of $\alpha, \beta$-Unsaturated Carbonyl Compounds: Rate Acceleration by Alcohol Additives Org. Lett. 2006, 8, 4887-4889.

75. Ito, H.; Yamanaka, H.; Tateiwa, J.-i.; Hosomi, A. Boration of an $\alpha, \beta$-Enone Using a Diboron Promoted by a Copper(I)-Phosphine Mixture Catalyst Tetrahedron Lett. 2000, 41, 68216825.

76. Takahashi, K.; Ishiyama, T.; Miyaura, N. A Borylcopper Species Generated from Bis(pinacolato)diboron and its Additions to $\alpha, \beta$-Unsaturated Carbonyl Compounds and Terminal Alkynes J. Organomet. Chem. 2001, 625, 47-53.

77. Takahashi, K.; Ishiyama, T.; Miyaura, N. Addition and Coupling Reactions of Bis(pinacolato)diboron Mediated by $\mathrm{CuCl}$ in the Presence of Potassium Acetate Chem. Lett. 2000, 982-983.

78. Lee, J. E.; Yun, J. Catalytic Asymmetric Boration of $\alpha, \beta$-Unsaturated Esters and Nitriles Angew. Chem. Int. Ed. 2008, 47, 145-147.

79. Lee, J.-E.; Kwon, J.; Yun, J. Copper-Catalyzed Addition of Diboron Reagents to $\alpha, \beta$ Acetylenic Esters: Efficient Synthesis of $\beta$-Boryl- $\alpha, \beta$-Ethylenic Esters Chem. Commun. 2008, 733-734.

80. Sim, H.-S.; Feng, X.; Yun, J. Copper-Catalyzed Enantioselective $\beta$-Boration of Acyclic Enones Chem. Eur. J. 2009, 15, 1939-1943.

81. Chea, H.; Sim, H. S.; Yun, J. Copper-Catalyzed Conjugate Addition of Diboron Reagents to $\alpha, \beta$-Unsaturated Amides: Highly Reactive Copper-1,2-Bis(diphenylphosphino)benzene Catalyst System Adv. Synth. Catal. 2009, 351, 855-858.

82. Lillo, V.; Prieto, A.; Bonet, A.; Díaz-Requejo, M. M.; Ramírez, J.; Pérez, P. J.; Fernández, E. Asymmetric $\beta$-Boration of $\alpha, \beta$-Unsaturated Esters with Chiral (NHC)Cu Catalysts Organometallics 2008, 28, 659-662. 
83. Chen, I. H.; Yin, L.; Itano, W.; Kanai, M.; Shibasaki, M. Catalytic Asymmetric Synthesis of Chiral Tertiary Organoboronic Esters through Conjugate Boration of $\beta$-Substituted Cyclic Enones J. Am. Chem. Soc. 2009, 131, 11664-11665.

84. Fleming, W. J.; Muller-Bunz, H.; Lillo, V.; Fernandez, E.; Guiry, P. J. Axially Chiral P-N Ligands for the Copper Catalyzed $\beta$-Borylation of $\alpha, \beta$-Unsaturated Esters Org. Biomol. Chem. 2009, 7, 2520-2524.

85. Schiffner, Julia A.; Müther, K.; Oestreich, M. Enantioselective Conjugate Borylation Angew. Chem. Int. Ed. 2010, 49, 1194-1196.

86. Lillo, V.; Bonet, A.; Fernandez, E. Asymmetric Induction on $\beta$-Boration of $\alpha, \beta$-Unsaturated Compounds: An Inexpensive Approach Dalton Trans. 2009, 2899-2908.

87. Lee, K. S.; Zhugralin, A. R.; Hoveyda, A. H. Efficient C-B Bond Formation Promoted by NHeterocyclic Carbenes: Synthesis of Tertiary and Quaternary B-Substituted Carbons Through Metal-Free Catalytic Boron Conjugate Additions to Cyclic and Acyclic $\alpha, \beta$-Unsaturated Carbonyls J. Am. Chem. Soc. 2009, 131, 7253-7255.

88. Bonet, A.; Gulyas, H.; Fernandez, E. Metal-Free Catalytic Boration at the $\beta$-Position of $\alpha, \beta$ Unsaturated Compounds: A Challenging Asymmetric Induction Angew. Chem. Int. Ed. 2010, 49, 5130-5134.

89. Brotherton, R. J.; Woods, W. G. US 3009941, 1961.

90. Welch, C. N.; Shore, S. G. Boron Heterocycles. Preparation and Characterization of Selected Heteronuclear Diboron Ring Systems Inorg. Chem. 1968, 7, 225-230.

91. Lesley, M. J. G.; Norman, N. C.; Rice, C. R.; Reger, D. L.; Little, C. A.; Lamba, J. J. S.; Brown, K. J.; Peters, J. C.; Thomas, J. C.; Sahasrabudhe, S.; Yearwood, B. C.; Atwood, D. A.; Hill, R. F.; Wood, G. L.; Danzer, R.; Paine, R. T.; Wagner, N. L.; Murphy, K. L.; Haworth, D. T.; Bennett, D. W.; Byers, P. K.; Canty, A. J.; Honeyman, R. T.; Arnáiz, F. J.; Miranda, M. J.; Bohle, D. S.; Sagan, E. S.; Chivers, T.; Sandblom, N.; Schatte, G. Main Group Compounds In Inorganic Syntheses; John Wiley \& Sons, Inc.: 2004; pp 1-48.

92. Nguyen, P.; Lesley, G.; Taylor, N. J.; Marder, T. B.; Pickett, N. L.; Clegg, W.; Elsegood, M. R. J.; Norman, N. C. Oxidative Addition of B-B Bonds by Rhodium(I) Phosphine Complexes Molecular-Structures of $\mathrm{B}_{2} \mathrm{Cat}_{2}\left(\mathrm{Cat}=1,2-\mathrm{O}_{2} \mathrm{C}_{6} \mathrm{H}_{4}\right)$ and Its 4-Bu(T) and 3,5- $\mathrm{Bu}_{2}(\mathrm{~T})$ Analogs Inorg. Chem. 1994, 33, 4623-4624.

93. Lawlor, F. J.; Norman, N. C.; Pickett, N. L.; Robins, E. G.; Nguyen, P.; Lesley, G.; Marder, T. B.; Ashmore, J. A.; Green, J. C. Bis-Catecholate, Bis-Dithiocatecholate, and Tetraalkoxy Diborane Compounds: Aspects of Synthesis and Electronic Structure Inorg. Chem. 1998, 37, 5282-5288.

94. Clegg, W.; Elsegood, M. R. J.; Lawlor, F. J.; Norman, N. C.; Pickett, N. L.; Robins, E. G.; Scott, A. J.; Nguyen, P.; Taylor, N. J.; Marder, T. B. Structural Studies of Bis-Catecholate, BisDithiocatecholate, and Tetraalkoxy Diborane Compounds Inorg. Chem. 1998, 37, 5289-5293. 
95. Männig, D.; Nöth, H. Contributions to the Chemistry of Boron. A Convenient Synthesis of Catecholatoborane and Diborane J. Chem. Soc., Dalton Trans. 1985, 1689.

96. Ishiyama, T.; Murata, M.; Ahiko, T.-A.; Miyaura, N. Bis(pinacolato)diboron Org. Synth. 2000, 77, 176.

97. Molander, G. A.; McKee, S. A. Copper-Catalyzed $\beta$-Boration of $\alpha, \beta$-Unsaturated Carbonyl Compounds with Tetrahydroxydiborane Org. Lett. 2011, 13, 4684-4687.

98. For an FDA-approved boronic acid, see Kane, R. C.; Bross, P. F.; Farrell, A. T.; Pazdur, R. Oncologist 2003, 8, 508.

99. Iwadate, N.; Suginome, M. Differentially Protected Diboron for Regioselective Diboration of Alkynes: Internal-Selective Cross-Coupling of 1-Alkene-1,2-diboronic Acid Derivatives $J$. Am. Chem. Soc. 2010, 132, 2548-2549.

100. Mancilla, T.; Contreras, R.; Wrackmeyer, B. New Bicyclic Organylboronic Esters Derived from Iminodiacetic Acids J. Organomet. Chem. 1986, 307, 1-6.

101. Knapp, D. M.; Gillis, E. P.; Burke, M. D. A General Solution for Unstable Boronic Acids: Slow-Release Cross-Coupling from Air-Stable MIDA Boronates J. Am. Chem. Soc. 2009, 131, 6961-6963.

102. Gillis, E. P.; Burke, M. D. A Simple and Modular Strategy for Small Molecule Synthesis: Iterative Suzuki-Miyaura Coupling of B-Protected Haloboronic Acid Building Blocks J. Am. Chem. Soc. 2007, 129, 6716-6717.

103. Gillis, E. P.; Burke, M. D. Multistep Synthesis of Complex Boronic Acids from Simple MIDA Boronates J. Am. Chem. Soc. 2008, 130, 14084-14085.

104. Gillis, E. P.; Burke, M. D. Iterative Cross-Coupling with MIDA Boronates: Towards a General Strategy for Small-Molecule Synthesis Adrichimica Acta 2009, 42, 17-27.

105. Uno, B. E.; Gillis, E. P.; Burke, M. D. Vinyl MIDA Boronate: A Readily Accessible and Highly Versatile Building Block for Small Molecule Synthesis Tetrahedron 2009, 65, 31303138.

106. Iwadate, N.; Suginome, M. Synthesis of B-Protected $\beta$-Styrylboronic Acids via IridiumCatalyzed Hydroboration of Alkynes with 1,8-Naphthalenediaminatoborane Leading to Iterative Synthesis of Oligo(phenylenevinylene)s Org. Lett. 2009, 11, 1899-1902.

107. Noguchi, H.; Shioda, T.; Chou, C.-M.; Suginome, M. Differentially Protected Benzenediboronic Acids: Divalent Cross-Coupling Modules for the Efficient Synthesis of Boron-Substituted Oligoarenes Org. Lett. 2008, 10, 377-380.

108. Noguchi, H.; Hojo, K.; Suginome, M. Boron-Masking Strategy for the Selective Synthesis of Oligoarenes via Iterative Suzuki-Miyaura Coupling J. Am. Chem. Soc 2007, 129, 758-759. 
109. Arnone, A.; Di Modugno, V.; Nasini, G.; Vajna de Pava, O. Studies on Ratanhiae Radix. Isolation of Ratanhine, a New Dineolignan from the Medicinal Ratanhiae Radix Gazz. Chim.

Ital. 1990, 120, 397.

110. Molander, G. A.; Sandrock, D. L. Orthogonal Reactivity in Boryl-Substituted Organotrifluoroborates J. Am. Chem. Soc. 2008, 130, 15792-15793.

111. Lee, J. C.; McDonald, R.; Hall, D. G. Enantioselective Preparation and Chemoselective Cross-Coupling of 1,1-Diboron Compounds Nat Chem 2011, 3, 894-899.

112. Letsinger, R. L.; Skoog, I. Organoboron Compounds. Aminoethyl Diarylborinates J. Am. Chem. Soc. 1955, 77, 2491-2494.

113. Wrackmeyer, B. Nuclear Magnetic Resonance Spectroscopy of Boron Compounds Containing Two-, Three-, and Four-Coordinate Boron. In Annual Reports in NMR Spectroscopy; Webb, G. A., Ed.; Academic Press: San Diego, CA, 1988; pp 205-314.

114. Yan, Y.; Zhang, X. Six-Membered Bis(azaphosphorinane), Readily Available Ligand for Highly Enantioselective Asymmetric Hydrogenations Tetrahedron Lett. 2006, 47, 1567-1569.

115. Nguyen, P.; Dai, C. Y.; Taylor, N. J.; Power, W. P.; Marder, T. B.; Pickett, N. L.; Norman, N. C. Lewis Base Adducts of Diboron Compounds - Molecular-Structures of $\left[\mathrm{B}_{2}(\mathrm{Cat})_{2}(4-\right.$ Picoline)] and $\left[\mathrm{B}_{2}(\mathrm{Cat})_{2}(4-\mathrm{Picoline})_{2}\right]\left(\mathrm{Cat}=1,2-\mathrm{O}_{2} \mathrm{C}_{6} \mathrm{H}_{4}\right)$ Inorg. Chem. 1995, 34, 4290-4291.

116. Clegg, W.; Dai, C. Y.; Lawlor, F. J.; Marder, T. B.; Nguyen, P.; Norman, N. C.; Pickett, N. L.; Power, W. P.; Scott, A. J. Lewis-Base Adducts of the Diborane Compounds $\mathrm{B}_{2}\left(1,2-\mathrm{E}_{2} \mathrm{C}_{6} \mathrm{H}_{4}\right)_{2}$ (E=O or S) Dalton Trans. 1997, 839-846.

117. A correction was recently published; see Lee, K.S.; Zhugralin, A. R.; Hoveyda, A. H. J. Am. Chem. Soc. 2010, 132, 12766.

118. Dai, C.; Johnson, S. M.; Lawlor, F. J.; Lightfoot, P.; Marder, T. B.; Norman, N. C.; Orpen, A. G.; Pickett, N. L.; Quayle, M. J.; Rice, C. R. 2,2'-Bipyridyl and 1,10-Phenanthroline Adducts of the Diborane Compound $\mathrm{B}_{2}\left(1,2-\mathrm{S}_{2} \mathrm{C}_{6} \mathrm{H}_{4}\right)_{2}$ Polyhedron 1998, 17, 4139-4143.

119. Fusstetter, H.; Huffman, J. C.; Noth, H.; Schaeffer, R. Contributions to Chemistry of Boron. Crystal and Molecular-Structure of B,B'-Bis(1,3-Dimethyl-1,3,2-Diazaborolidin-2-Y1) $Z$ Naturforsch B 1976, 31, 1441-1446.

120. Nöth, H.; Knizek, J.; Ponikwar, W. Contribution to the Chemistry of Boron, A BoronBoron Double Bond in the Dianions of Tetra(amino)diborates Eur. J. Inorg. Chem. 1999, 1999, 1931-1937.

121. Moezzi, A.; Olmstead, M. M.; Power, P. P. The Structure of 1,2-Diaryl-1,2Bis(Dimethylamino)Diboron Compounds and Related Species - Boron-Nitrogen Analogs of Buta-1,3-Dienes Dalton Trans. 1992, 2429-2434. 
122. Abu Ali, H.; Goldberg, I.; Srebnik, M. Tetra(pyrrolidino)diborane, $\left[\left(\mathrm{C}_{4} \mathrm{H}_{8} \mathrm{~N}\right)_{2} \mathrm{~B}\right]_{2}$, as a New Improved Alternative Synthetic Route to Bis(pinacolato)diborane - Crystal Structures of the Intermediates Eur. J. Inorg. Chem. 2002, 73-78.

123. Nöth, H. Contributions to the Chemistry of Boron, The Crystal and Molecular Structure of a 1.3.2-Dioxaborolan-2-yl-1'.3'.2'-dioxaborolane Z Naturforsch B 1984, 39, 1463-1466.

124. Haubold, W.; Hrebicek, J.; Sawitzki, G. Diborane Molecules with Boron Atoms with Different Coordination-Number Z Naturforsch B 1984, 39, 1027-1031.

125. Grigsby, W. J.; Power, P. One-Electron Reductions of Organodiborane Compounds: Singly Reduced Anions and Rearrangement Reactions Chem. Eur. J. 1997, 3, 368-375.

126. Kaufmann, B.; Jetzfellner, R.; Leissring, E.; Issleib, K.; Noth, H.; Schmidt, M.

Contributions to the Chemistry of Boron. Studies on Benzo-1,3,2-diphosphaborolanes, Benzo1,4,2,3-diphosphadiborinanes and Benzo-1,5,2,3,4-diphosphatriborepanes Chem. Ber. Recl. 1997, 130, 1677-1692.

127. Neu, A.; Mennekes, T.; Paetzold, P.; Englert, U.; Hofmann, M.; Schleyer, P. V. Novel Tetraalkyltetraboranes of the Type $\mathrm{B}_{4} \mathrm{R}_{4}, \mathrm{~B}_{4} \mathrm{H}_{2} \mathrm{R}_{4}$ and $\mathrm{B}_{4} \mathrm{H}_{4} \mathrm{R}_{4}$ Inorg. Chim. Acta 1999, 289, 5869.

128. Clegg, W.; Marder, T. B.; Nlate, S.; Scott, A. J. 2,3,5,6-Tetrakis[3,5bis(trifluoromethyl)phenoxy]-2,5-bis(dimethylamino), , 3,5,6-Tetrabora-1,4-dioxane Diethyl Ether 0.667-Solvate Acta Crystallogr. C 2007, 63, 603-605.

129. Dang, L.; Lin, Z. Y.; Marder, T. B. DFT Studies on the Borylation of $\alpha, \beta$-Unsaturated Carbonyl Compounds Catalyzed by Phosphine Copper(I) Boryl Complexes and Observations on the Interconversions Between $O$ - and $C$-bound enolates of $\mathrm{Cu}, \mathrm{B}$, and $\mathrm{Si}$ Organometallics 2008, $27,4443-4454$.

130. Laitar, D. S.; Tsui, E. Y.; Sadighi, J. P. Catalytic Diboration of Aldehydes via Insertion into the Copper-Boron Bond J. Am. Chem. Soc. 2006, 128, 11036-11037.

131. Zhao, H. T.; Dang, L.; Marder, T. B.; Lin, Z. Y. DFT Studies on the Mechanism of the Diboration of Aldehydes Catalyzed by Copper(I) Boryl Complexes J. Am. Chem. Soc. 2008, 130, 5586-5594. 


\section{Chapter 3 Regio- and stereoselective copper-catalyzed $\beta$ - borylation of allenoates by a preactivated diboron}

\subsection{Contributions}

All work described in this chapter, including boration reactions, purification procedures, characterizations, and cross-coupling was performed by the author of this dissertation. The author also significantly contributed to the writing and editing of the manuscript, which was subsequently published (Reproduced by permission of The Royal Society of Chemistry). ${ }^{1}$ Allenoate starting materials were synthesized by a 3-step procedure briefly described herein, and in detail in the related portion of the Experimental in Chapter 5. The first two steps of the synthesis were performed by Xi Guo, who provided the author with the phosphonium bromide salts in pure enough form to perform the subsequent Wittig-type reaction. The final manuscript was prepared by Dr. Webster L. Santos. 


\subsection{Abstract}

Organoboron compounds increasingly provide access to the formation of difficult carboncarbon bonds. Indeed, the Suzuki-Miyaura coupling reaction, which employs a boronic acid and organohalide, is a powerful method for the construction of complex molecules partly because of its functional group tolerance. Thus, the development of methods that selectively installs the boronyl moiety is of utmost importance. We report a mild and efficient copper-catalyzed borylation of electron deficient allenoates using an $s p^{2}-s p^{3}$ mixed hybridized diboron which regioselectively installs a boron moiety on the $\beta$-position with exclusive ( $Z$ )-double bond geometry. To the best of our knowledge, this reaction is the first example of a boryl addition to electrophilic allenoates. The reaction provides $\beta$-borylated $\beta, \gamma$-unsaturated esters with exclusive (Z)-double bond geometry.

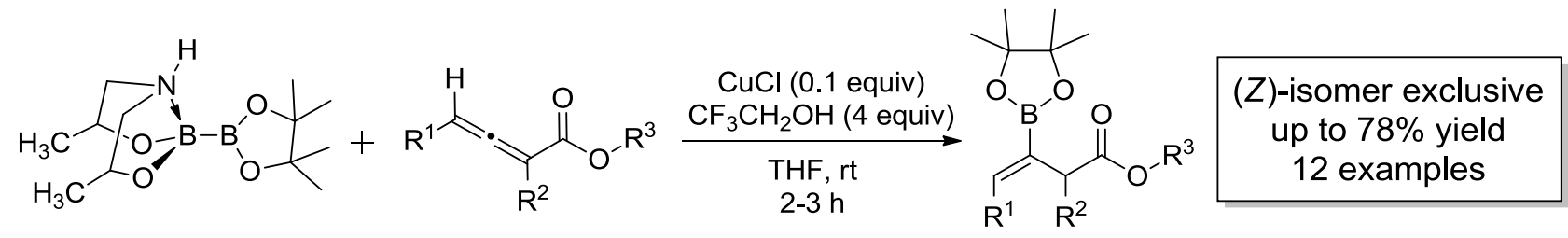




\subsection{Introduction}

In recent years, allenes have emerged as an important structural unit in the construction of complex molecules. ${ }^{2-4}$ For example, cycloaddition, radical, nucleophilic addition and metalation reactions demonstrate the versatility and unique reactivity of allenes. ${ }^{5}$ Because of their potential in organic synthesis and other applications, their preparation is subject to intense investigation. In particular, the reactivity of electron-deficient allenes can be tuned to produce either $\beta, \gamma$-unsaturated carbonyl compounds or $\gamma$-addition products depending on the reaction conditions. For example, Shibasaki and co-workers elegantly developed the construction of highly functionalized $\delta$-lactones with tetrasubstituted chiral centers (3.4) using a three
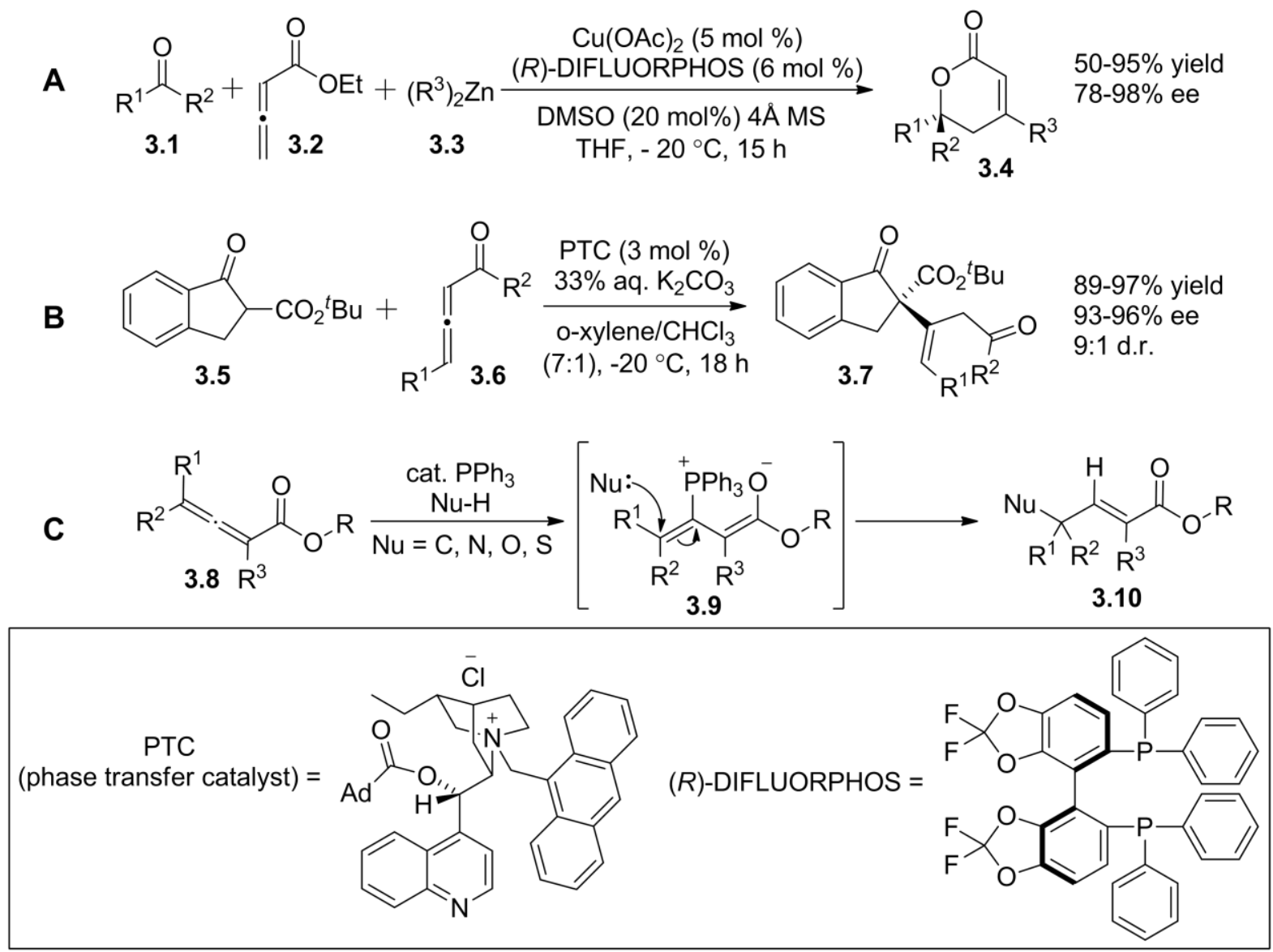

Scheme 3.1. A) Three component coupling, B) conjugate addition, and C) $\gamma$-addition reactions with allenoates. 
component assembly of ketones (3.1), allenic esters (3.2), and dialkylzincs (3.3; Scheme 3.1A). ${ }^{6-}$ 8 Jorgensen demonstrated the organocatalytic asymmetric conjugate addition of $\beta$-ketoesters (3.5) to electron-deficient allenes $(\mathbf{3 . 6})$ to form tertiary and quaternary stereogenic centers $(\mathbf{3 . 7}$; Scheme 3.1B). ${ }^{9}$ These reactions produce $\beta, \gamma$-unsaturated carbonyl compounds, and examples in the literature are limited. However, the regioselectivity of the reaction can be reversed. Indeed, Lewis bases such as phosphines catalyze $\gamma$-additions of carbon, nitrogen, oxygen and sulfur nucleophiles to allenoates through a phosphonium enolate intermediate (3.9) to provide the corresponding $\alpha, \beta$-unsaturated esters (3.10; Scheme 3.1C). ${ }^{10-18}$

Transition metal-catalyzed reactions of electrophilic allenoates generate molecular scaffolds with functional and structural diversity. ${ }^{2,19}$ For example, 1,2-allenyl carboxylic acids (3.11) cycloisomerize in the presence of a copper (I) source $^{20}$ to provide $\mathbf{3 . 1 3}$ or undergo halolactonization with copper (II) halides to provide 3.16 (Scheme 3.2). ${ }^{21}$ Upon closer comparison, the competition between the formation of $\mathbf{3 . 1 3}$ and $\mathbf{3 . 1 6}$ is a direct consequence of the oxidation state of copper. In fact, using 2 equivalents of copper (I) chloride will still produce protonated lactone 3.13. While both pathways likely proceed through a similar intermediate $\mathbf{3 . 1 2}$ during cyclization, copper (II) complex $\mathbf{3 . 1 4}$ is rapidly oxidized by excess $\mathrm{CuX}_{2}$ to copper (III)

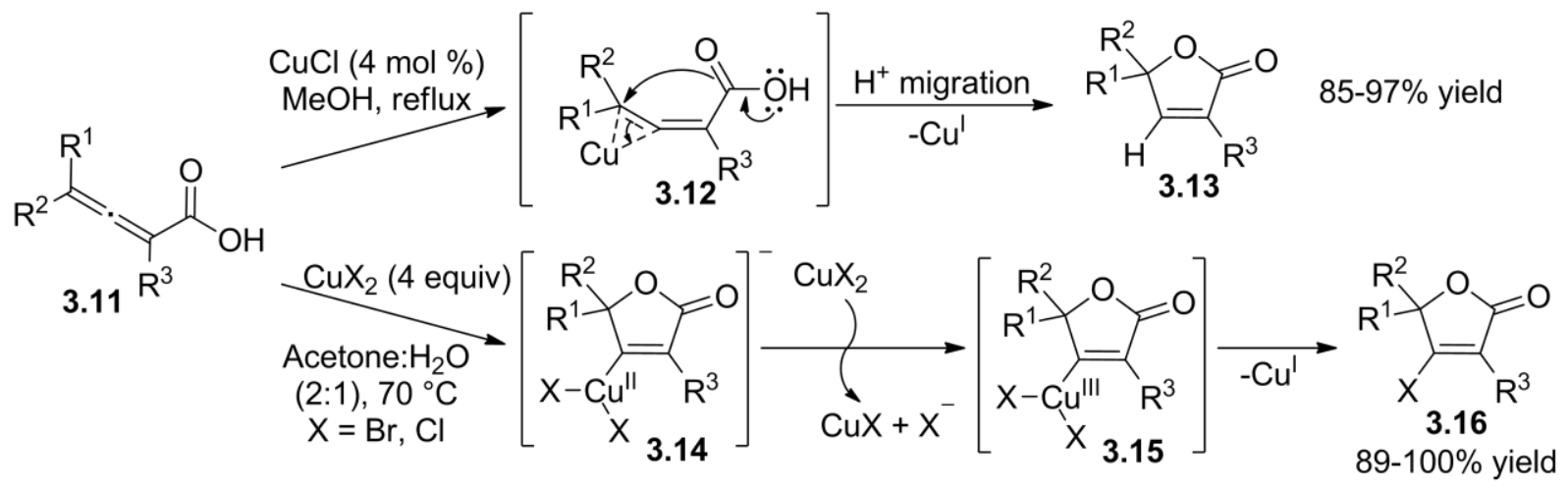

Scheme 3.2. Divergent pathways in the presence of copper halides. 
complex 3.15, which provides unsaturated halolactone 3.16 after reductive elimination. These intermediates are useful building blocks in the synthesis of more elaborate chemical structures, the latter especially with cross-coupling reactions. Because our research involves copper catalysis and we did not desire a cyclic product, it was important to avoid the combination of polar, protic solvent and high temperature in our initial considerations (vide infra).

As complementary reacting partners, organoboron compounds increasingly provide access to the formation of difficult carbon-carbon bonds. Indeed, the Suzuki-Miyaura coupling reaction, which employs a boronic acid and organohalide, is a powerful method for the construction of complex molecules partly because of its functional group tolerance. ${ }^{22}$ Thus far, silaboration of 3.18 using 3.17 as the boration reagent, ${ }^{23-27}$ intramolecular cyanoboration of 3.20 ${ }^{28}$ and diboration of $\mathbf{3 . 2 3}$ with diboron $\mathbf{3 . 2 2}^{29-33}$ (note: the ratio of external addition product 3.24 to internal product 3.25 was dependent on the catalyst system employed) have been<smiles>CB1OC(C)(C)C(C)(c2ccccc2)O1</smiles>
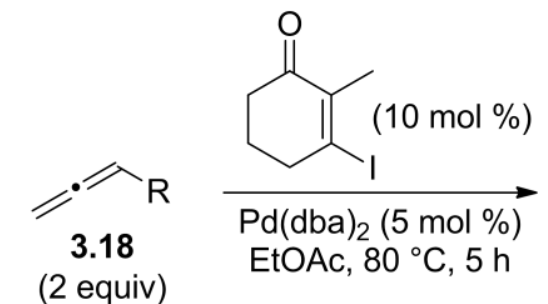

(2 equiv)

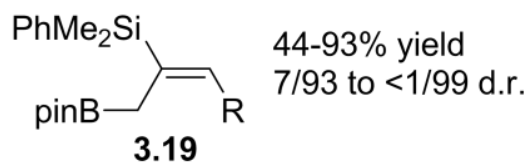

3.19

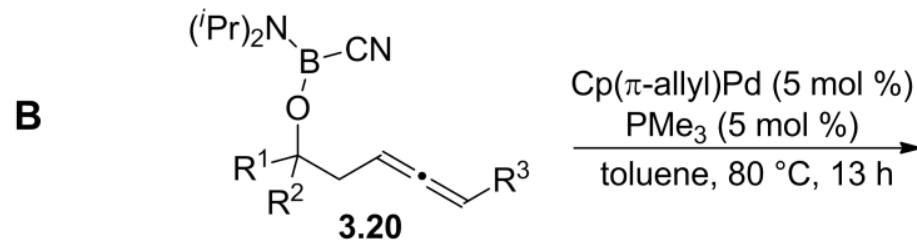<smiles>[R]CC1CC([R2])OB1N(O)P</smiles>
$64-83 \%$ yield

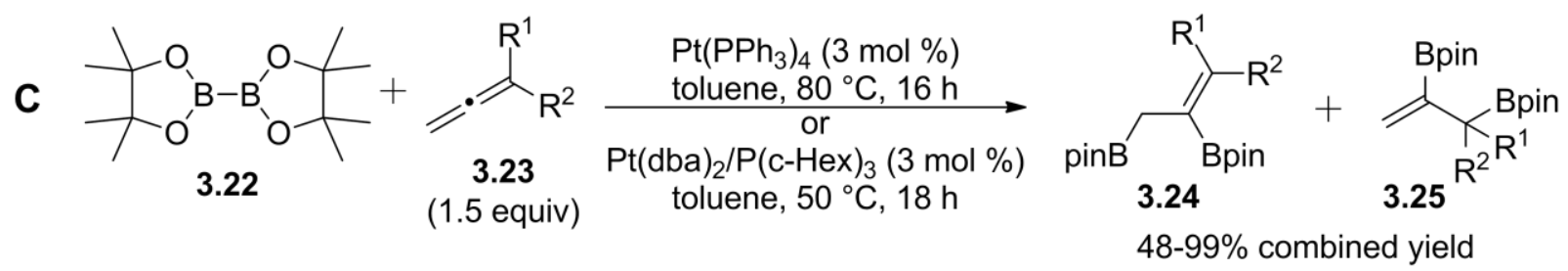

Scheme 3.3. Examples of A) silaboration, $\mathbf{B}$ ) cyanoboration, and $\mathbf{C})$ diboration of allenes. 
achieved with allenes using late transition metals (Scheme 3.3). However, direct borylation of electron-deficient allenes had not been reported. In pursuit of expanding the scope of our previous research, we envisioned that the internally activated, $s p^{2}-s p^{3}$ hybridized diboron compound designed in our lab, PDIPA diboron 2.13, could affect the transformation of allenes in a similar manner to the previously demonstrated copper-catalyzed, $\beta$-borylation of $\alpha, \beta$ unsaturated conjugated compounds. ${ }^{34}$ Thus, we investigated the utility of $\mathbf{2 . 1 3}$ to the borylation of electrophilic allenoates. These substrates are attractive because they give rise to $\beta, \gamma-$ unsaturated carbonyl compounds, as opposed to acetylenic esters which produce the more thermodynamically favored $\alpha, \beta$-unsaturated carbonyl compounds, ${ }^{35}$ allowing for further functionalization of the resulting nonconjugated olefin. In addition, we were excited by the possibility that a racemic mixture of the starting allenoate forms a product containing a defined double bond geometry and a vinyl boronic ester, which is potentially a Suzuki-Miyaura crosscoupling partner. ${ }^{22}$

\subsection{Optimization and substrate scope of the $\beta$-boration of allenoates}

To explore the feasibility of the borylation reaction, we explored reaction conditions to generate $\beta$-borylated $\beta, \gamma$-unsaturated ethyl ester 3.27b using commercially available ethyl 2,3butadienoate 3.26b as the substrate. As shown in Table 3.1, agents with strong sigma bond donor capacity to activate bis(pinacolato)diboron such as $\mathrm{N}$-heterocyclic carbenes $(\mathrm{NHC}),{ }^{36}$ (IMe) $\mathrm{CO}_{2}{ }^{37}$ and $(\mathrm{ICy}) \mathrm{BF}_{4},{ }^{38}$ promoted the borylation reaction with good yields (entries 1-2). However, the use of strong base to generate the carbene can be a disadvantage for sensitive substrates. In addition, NHC ligands are expensive and difficult to handle. With the effort to use 
Table 3.1. Optimization of reaction conditions. ${ }^{a}$

\begin{tabular}{|c|c|c|c|c|}
\hline entry & catalyst & $\begin{array}{l}212 \\
\text { solvent }\end{array}$ & additives (equiv) & $\operatorname{conv} \%^{b}$ \\
\hline 1 & $\mathrm{CuCl}^{c}$ & $\mathrm{ACN}$ & $(\mathrm{IMe}) \mathrm{CO}_{2}(0.1)$ & 81.3 \\
\hline 2 & $\mathrm{CuCl}^{c}$ & THF & $(\mathrm{ICy}) \mathrm{BF}_{4}(.05), \mathrm{NaO}^{t} \mathrm{Bu}(0.1)$ & 95.1 \\
\hline 3 & $\mathrm{CuCl}^{d}$ & $\mathrm{CH}_{2} \mathrm{Cl}_{2}$ & TFE (4) & 96.9 \\
\hline 4 & $\mathrm{CuCl}^{d}$ & $\mathrm{CH}_{2} \mathrm{Cl}_{2}$ & - & 96.4 \\
\hline 5 & $\mathrm{CuCl}^{d}$ & $\mathrm{CH}_{2} \mathrm{Cl}_{2}$ & $\mathrm{NaO}^{t} \mathrm{Bu}(0.1)$ & 98.3 \\
\hline 6 & $\mathrm{CuCl}^{d}$ & $\mathrm{CH}_{2} \mathrm{Cl}_{2}$ & DPEphos (0.1) & 45.7 \\
\hline 7 & $\mathrm{CuCl}^{d}$ & $\mathrm{CH}_{2} \mathrm{Cl}_{2}$ & $\mathrm{NaO}^{t} \mathrm{Bu}(0.1), \mathrm{TFE}(4)$ & 97.5 \\
\hline 8 & ${ }^{d}$ & $\mathrm{CH}_{2} \mathrm{Cl}_{2}$ & - & 4.9 \\
\hline 9 & $\mathrm{CuCl}^{d}$ & DMF & - & 78.0 \\
\hline 10 & $\mathrm{CuCl}^{e}$ & THF & - & 98.3 \\
\hline 11 & $\mathrm{CuCl}^{f}$ & THF & TFE (4) & 96.7 \\
\hline 12 & $\mathrm{CuBr}^{e}$ & THF & - & 87.8 \\
\hline 13 & $\mathrm{CuBr}_{2}{ }^{e}$ & THF & - & 76.6 \\
\hline 14 & $\mathrm{CuCl}_{2}{ }^{e}$ & THF & - & 86.7 \\
\hline 15 & {$[\mathrm{Rh}(\operatorname{cod}) \mathrm{Cl}]_{2}^{e}$} & THF & - & ND \\
\hline 16 & $\mathrm{Pt}(\operatorname{cod}) \mathrm{Cl}_{2}{ }^{e}$ & THF & - & ND \\
\hline 17 & $\mathrm{Ni}(\operatorname{cod})^{e}$ & THF & - & $\mathrm{ND}$ \\
\hline 18 & $\mathrm{Ag}\left(\mathrm{NO}_{3}\right)^{e}$ & THF & - & 1.5 \\
\hline
\end{tabular}

\footnotetext{
${ }^{a}$ PDIPA diboron (2.13, 1.2 equiv), catalyst ( 0.1 equiv), and additives were suspended in solvent and stirred for 5 minutes. Ethyl 2,3-butadienoate 3.26b (1.0 equiv) was then added and the reaction was stirred for 2 hours at the indicated temperature. ${ }^{b}$ Conversion was determined by GC analysis of the crude material. Values are not corrected. ${ }^{c}$ The reaction was performed at $\mathrm{rt}$ and bis(pinacolato)diboron was used instead of 2.13. ${ }^{d}$ The reaction was heated to $40{ }^{\circ} \mathrm{C}$. ${ }^{e}$ The reaction was heated to $70{ }^{\circ} \mathrm{C} .{ }^{f}$ The reaction was performed at rt. Abbreviations: DPEphos $=$ bis(2-diphenylphosphinophenyl)ether; $(\mathrm{IMe}) \mathrm{CO}_{2}=1,3$-dimethylimidazolium carboxylate; $(\mathrm{ICy}) \mathrm{BF}_{4}=1,3$-dicyclohexylimidazolium tetrafluoroborate; TFE $=2,2,2$-trifluoroethanol; $\mathrm{ND}=$ none detected.
} 
milder reaction conditions, we investigated whether a preactivated diboron also effects the desired transformation. To our delight, treating allenoate $\mathbf{3 . 2 6 b}$ with a catalytic amount of $\mathrm{CuCl}$, trifluoroethanol (TFE) and 2.13 in dichloromethane produced 3.27b in excellent yield (entry 3). Interestingly, running the reaction in the absence of TFE successfully provided the product in similar conversion (entries 4 and 10), which is in sharp contrast to the optimization studies using less reactive enone and acrylate substrates (see Chapter 2). In the presence of other additives such as base and phosphine ligand, moderate to excellent product formation was detected (entries 5-7); although a copper stabilizing DPEphos dramatically decreased the product yield (compare entries 4 vs 6). As expected, when the reaction was attempted without a copper catalyst, the reaction was sluggish (entry 8). Evaluation of the effect of solvent revealed that the reaction was tolerant of aprotic solvents used-protic solvents result in the decomposition of $\mathbf{2 . 1 3}$-although the reaction performed in THF was most effective (entries 4, 9 and 10) and ultimately, easiest to purify due to the lower solubility of an unidentified black precipitate (presumably $\mathrm{Cu}^{0}$ ) in $\mathrm{THF}$ which was removed by filtration through celite. We also screened the effect of temperature, as our previously optimized conditions with PDIPA diboron required gentle heating, but we aimed to avoid cyclization by-products in this case (vide supra). Applying lessons learned from our kinetic study of additives discussed in Chapter 2, we discovered that the borylation reaction is efficient at room temperature in the presence of TFE (compare entries 1-10 vs 11). In fact, the rate-enhancement effects of TFE become more pronounced with more difficult substrates. $\mathrm{CuCl}$ as the copper source appears to be important since $\mathrm{CuBr}$ and various $\mathrm{Cu}$ (II) sources afforded the product in moderate yields (entries 12-14). Finally, an examination of other transition metals such as rhodium, platinum, nickel and silver resulted in minor or undetectable desired product formation, typically consuming the allenoate starting material and providing a complex mixture 
of unidentified side products (entries 15-18). Thus, subsequent investigations used $10 \mathrm{~mol} \%$ $\mathrm{CuCl}, 4$ equivalents of TFE, allenoate substrate and 1.2 equivalents of $\mathbf{2 . 1 3}$ in $\mathrm{THF}$ at room temperature.

With the optimized conditions in hand, we next investigated the scope of the reaction using various allenoates. The only commercially available allenoate at the time was ethyl 2,3butadienoate $\mathbf{3 . 2 6 b}$, so steric and electronic substitutions had to be specifically introduced. Fortunately, Kwon recently established a method to synthesize substituted allenoates using simple, cheap, and available starting materials (Scheme 3.4). ${ }^{39}$ The identity of $\alpha$-substituent $\mathbf{R}^{\mathbf{2}}$ and ester $\mathbf{R}^{\mathbf{3}}$ originated from the choice of bromoacetyl bromide $\mathbf{3 . 2 8}$, which was esterified upon treatment with alcohol 3.29. Bromoester 3.30 was obtained in up to $84 \%$ yield and subsequently treated with triphenylphosphine, which precipitated phosphonium bromide $\mathbf{3 . 3 1}$ in near quantitative yield. The final step, which installed $\gamma$-substituent $\mathbf{R}^{\mathbf{1}}$, was a combination Wittig reaction / elimination with acetyl chloride $\mathbf{3 . 3 2}$ to provide the desired racemic allenoate $\mathbf{3 . 2 6}$. Final purification of $\mathbf{3 . 2 6}$ was extremely difficult, owing to a combination of low boiling point and several stoichiometric by-products including triphenylphosphine oxide, which is notoriously difficult to remove. ${ }^{40,41}$ The low yields of purified allenoates are indeed consistent with those reported for similar structures by Kwon (2-41\%). ${ }^{39,42}$

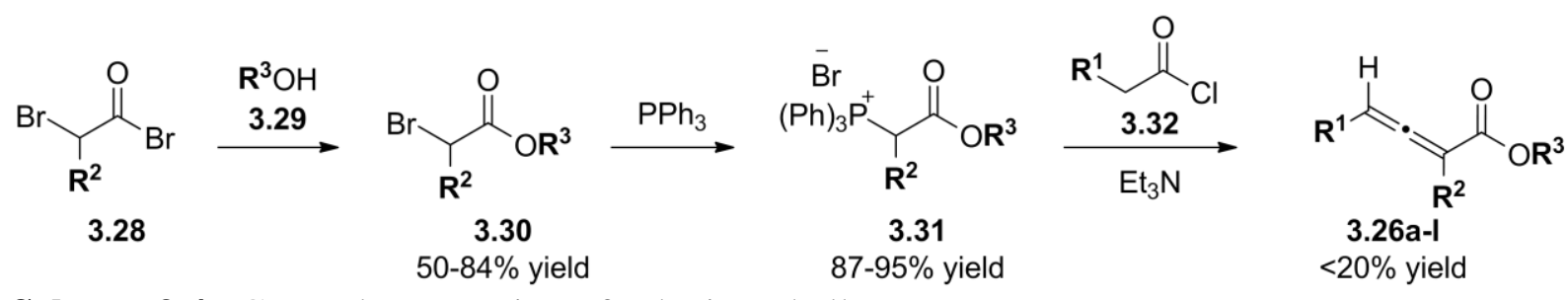

Scheme 3.4. General preparation of substituted allenoates. 
Table 3.2. $\beta$-Borylation of allenoates. ${ }^{a}$<smiles>[R]C=C=C([R])C(=O)O[R]</smiles>

3.26a-I<smiles>CC1C[NH+]2CC(B3OC(C)(C)C(C)(C)O3)OC1C2</smiles>

2.13
$\mathrm{CuCl}(10 \mathrm{~mol} \%)$

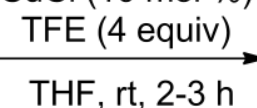

THF, rt, 2-3 h

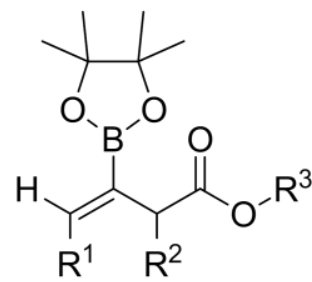

3.27a-I

\begin{tabular}{ccccccc}
\hline entry & $\mathrm{R}^{1}$ & $\mathrm{R}^{2}$ & $\mathrm{R}^{3}$ & product & $Z / E^{b}$ & $\%^{c}{\text { yield }(\%)^{d}}^{-}$ \\
\hline 1 & $\mathrm{H}$ & $\mathrm{H}$ & $\mathrm{Me}$ & $\mathbf{3 . 2 7 a}$ & - & 59 \\
2 & $\mathrm{H}$ & $\mathrm{H}$ & $\mathrm{Et}$ & $\mathbf{3 . 2 7 b}$ & - & 60 \\
3 & $\mathrm{H}$ & $\mathrm{H}$ & $\left(\mathrm{CH}_{2}\right)_{3} \mathrm{Ph}$ & $\mathbf{3 . 2 7} \mathrm{c}$ & - & $41(71)$ \\
4 & $\mathrm{Ph}$ & $\mathrm{H}$ & $\mathrm{Me}$ & $\mathbf{3 . 2 7 d}$ & $100: 0$ & 41 \\
5 & $\mathrm{Ph}$ & $\mathrm{H}$ & $\mathrm{Et}$ & $\mathbf{3 . 2 7}$ & $100: 0$ & 46 \\
6 & $\mathrm{Ph}$ & $\mathrm{H}$ & $\left(\mathrm{CH}_{2}\right)_{3} \mathrm{Ph}$ & $\mathbf{3 . 2 7 f}$ & $100: 0$ & $14(45)$ \\
7 & $\mathrm{Me}$ & $\mathrm{H}$ & $\mathrm{Me}$ & $\mathbf{3 . 2 7 g}$ & $100: 0$ & 72 \\
8 & $\mathrm{Me}$ & $\mathrm{H}$ & $\mathrm{Et}$ & $\mathbf{3 . 2 7 h}$ & $100: 0$ & 58 \\
9 & $\mathrm{Me}$ & $\mathrm{H}$ & ${ }^{i} \mathrm{Pr}$ & $\mathbf{3 . 2 7 i}$ & $100: 0$ & 78 \\
10 & $\mathrm{Me}$ & $\mathrm{H}$ & ${ }^{t} \mathrm{Bu}$ & $\mathbf{3 . 2 7} \mathbf{j}$ & $100: 0$ & 71 \\
11 & $\mathrm{Me}$ & $\mathrm{H}$ & $o$-nitrobenzyl & $\mathbf{3 . 2 7 k}$ & $100: 0$ & $33(75)$ \\
12 & $\mathrm{Me}$ & $\mathrm{Me}$ & $\mathrm{Et}$ & $\mathbf{3 . 2 7 1}$ & $100: 0$ & $38^{e}(81)$ \\
\hline
\end{tabular}

${ }^{a}$ PDIPA diboron (2.13, 1.2 equiv) and $\mathrm{CuCl}$ (0.1 equiv) were suspended in solvent and stirred for 5 minutes. Allenoate (1.0 equiv) and TFE ( 4 equiv) were then added and the reaction was stirred at room temperature until the starting material was consumed by TLC. ${ }^{b}$ The ratio of (E)/(Z) isomers were determined by GC and the geometry of the product was assigned based on NOESY experiments. ${ }^{c}$ Isolated Yield. ${ }^{d}$ Corrected yield with recovered starting material. ${ }^{e}$ Reaction was stirred 24 hours before workup. Product contaminated with $22 \% \alpha, \beta$-unsaturated isomer.

With a reasonably effective method to prepare our starting materials, we continued to

examine the scope of the reaction. The results of our study are summarized in Table 3.2.

Increasing the size of the ester moiety from methyl to ethyl on unsubstituted allenoates provided the $\beta$-borylated $\beta, \gamma$-unsaturated ethyl esters 3.27a-b in good yields (entries 1-2). A change to the bulkier 3-phenylpropyl ester 3.26c resulted in slight decrease in yield with some unreacted 
starting material isolated (entry 3). Longer reaction times did not provide full conversion of 3.26c or an increase in product yield, so it is likely that PDIPA diboron was consumed or decomposed. Gratifyingly, the presence of a bulky phenyl substituent on the $\gamma$-position allowed the borylation to proceed in moderate yields (entries 4-6). When the phenyl substituent was replaced with a less sterically demanding methyl group, the products were isolated in higher yields (58-78\%, entries 7-10). The presence of a bulky ortho-nitrobenzyl moiety resulted in a much lower yield in part because this group is sensitive to light (entry 11). Finally, $\alpha, \gamma-$ disubstituted ethyl allenoate $\mathbf{3 . 2 6 1}$ was converted to the product in only moderate yield presumably because of the bulkiness of the substrate (entry 12). As a noteworthy consequence of the mild reaction conditions, all monosubstituted allenoates provided the nonconjugated $\beta, \gamma$ unsaturated esters. However, a limitation of this protocol is evident with an increase in substitution, because product 3.271 was contaminated with the $\alpha, \beta$-unsaturated isomer, which likely formed through isomerization of the desired product, but could also be the result of a competing $\gamma$-addition of the boryl cuprate to the starting allenoate.

\subsection{Rationale for diastereoselectivity, proposed mechanism, and product}

\section{utility}

It is important to highlight that the copper catalyzed $\beta$-borylation reaction proceeded not only regioselectively but also diastereoselectively. In contrast with phosphine-catalyzed reactions to electrophilic allenoates that afford $\gamma$-substituted products, ${ }^{5}$ the copper-catalyzed reaction regioselectively installed the boronyl moiety on the $\beta$-position. In addition, under the reaction conditions of our investigation, we did not observe any cycloisomerization products seen in other copper-catalyzed reactions with allenoates (vide supra). ${ }^{7}$ Interestingly, the 
geometry of the double bond on the resulting product was determined to be $Z$ based on 1D NOESY experiments, and ${ }^{1} \mathrm{H}$ NMR and GC-MS analysis of the crude reaction mixture showed exclusive formation of this product. The stereoselectivity of the reaction can be rationalized simply by analysis of the

Figure 3.1. Steric interactions lead to exclusive formation of the $(Z)$-isomer.

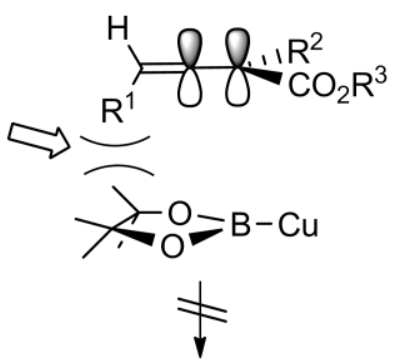

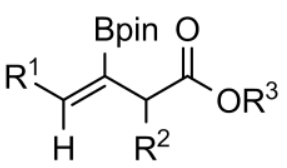

$(E)$
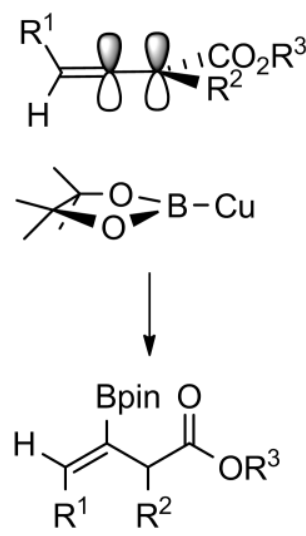

$(Z)$ approach of the boryl-cuprate intermediate (Figure 3.1). Since the two double bonds of the allene are orthogonal to each other, addition of the bulky pinacol boryl group to the $\beta$-carbon is expected to occur on the opposite side of the $\gamma$-substituent of the allenoate because of a strong steric interaction. Furthermore, 1,3-allylic strain in the $(E)$-isomer should favor the formation of the more stable $(Z)$-isomer. Delightfully, only the $(Z)$-product was observed even with the minimal steric repulsion of a methyl substituent. Finally, we were pleased to find that although the allenoate substrates were used as racemic mixtures, the reaction provides a single product.

A possible catalytic cycle for the $\beta$-borylation reaction is shown in Scheme $\mathbf{3 . 5}$. Preactivated $s p^{2}-s p^{3}$ hybridized diboron 2.13 is sufficiently activated to transmetalate with $\mathrm{CuCl}$ to generate nucleophilic boryl species 3.34. DFT calculations on the copper-catalyzed borylation of related $\alpha, \beta$-unsaturated carbonyl compounds suggest the formation of metalated intermediate 3.35 through a 3,4-conjugate addition mechanism, which is in equilibrium with $O$-enolate $3.36{ }^{43}$ Organocuprate 3.35/3.36 can be protonated through transmetallation with trifluoroethanol to yield the desired $\beta$-borylated $\beta, \gamma$-unsaturated ester 3.27 with the simultaneous regeneration of copper-alkoxide $\mathbf{3 . 3 7}$ that continues the catalytic cycle by transmetallation with another 
Scheme 3.5. Proposed reaction mechanism.
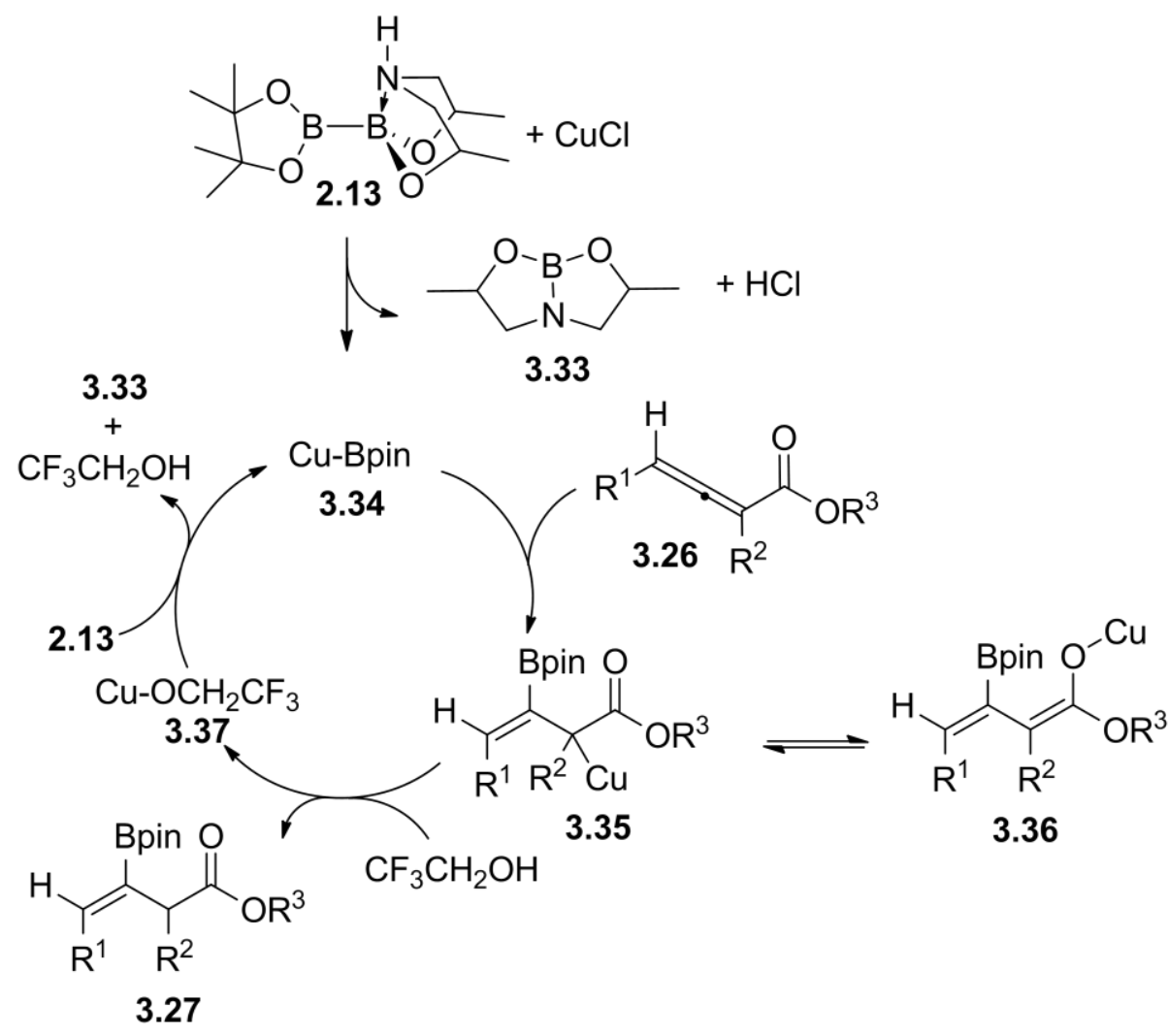

equivalent of 2.13. The essential role of TFE is to accelerate the reaction by protonation of 3.35/3.36 and formation of copper-alkoxide 3.37 .

To demonstrate the utility of the regio- and stereoselective borylation reaction, SuzukiMiyaura cross coupling reaction between product $\mathbf{3 . 2 7} \mathrm{g}$ and iodobenzene $\mathbf{3 . 3 8}$ was attempted (Scheme 3.6A). In this case, the coupled product $(\boldsymbol{E})-3.39$ was isolated in quantitative yield as a single diastereomer, as confirmed by GC/MS and ${ }^{1} \mathrm{H}$ NMR analysis, and did not isomerize to the $\alpha, \beta$-unsaturated ester. In contrast, 3.39 was previously synthesized as part of a mixture of $\alpha, \beta$ and $\beta, \gamma$-unsaturated structural isomers, each as a $3 / 1$ mixture of $E / Z$ stereoisomers, from an unusual and difficult to prepare cyclopropanone acetal derivative (3.40; Scheme 3.6B). ${ }^{44}$ 
Scheme 3.6. A) Coupling of $\beta$-boronic ester with iodobenzene. B) Previous method to obtain 3.39.
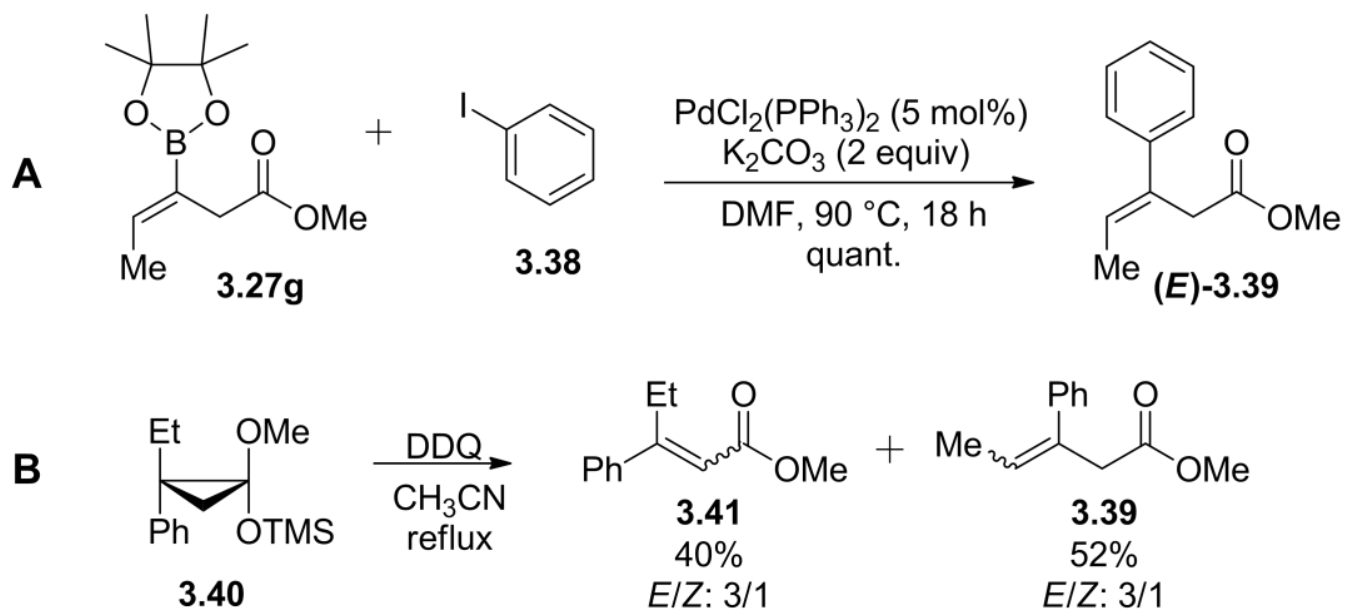

\subsection{Conclusions}

In conclusion, an efficient copper-catalyzed regioselective borylation of allenoates was developed using the internally activated, $s p^{2}-s p^{3}$ hybridized diboron reagent developed in our lab. To the best of our knowledge, this reaction is the first example of a boryl addition to electrophilic allenoates. The reaction provided nonconjugated $\beta$-borylated $\beta, \gamma$-unsaturated esters in 2 to 3 hours at room temperature with exclusive $(Z)$-double bond geometry. These borylated products are useful intermediates for subsequent elaboration to more complex structures, as exemplified by the SMC reaction with iodobenzene to yield a trisubstituted alkene as a single diastereomer.

\subsection{References for Chapter 3}

1. Thorpe, S. B.; Guo, X.; Santos, W. L. Regio- and Stereoselective Copper-Catalyzed $\beta$ Borylation of Allenoates by a Preactivated Diboron Chem. Commun. 2011, 47, 424-426.

2. Ma, S. Transition Metal-Catalyzed/Mediated Reaction of Allenes with a Nucleophilic Functionality Connected to the $\alpha$-Carbon Atom Acc. Chem. Res. 2003, 36, 701-712.

3. Zimmer, R.; Dinesh, C. U.; Nandanan, E.; Khan, F. A. Palladium-Catalyzed Reactions of Allenes Chem. Rev. 2000, 100, 3067-3126. 
4. Cowen, B. J.; Miller, S. J. Enantioselective Catalysis and Complexity Generation from Allenoates Chem. Soc. Rev. 2009, 38, 3102-3116.

5. Ma, S. Some Typical Advances in the Synthetic Applications of Allenes Chem. Rev. 2005, 105, 2829-2872.

6. Oisaki, K.; Zhao, D.; Kanai, M.; Shibasaki, M. Catalytic Enantioselective Alkylative Aldol Reaction: Efficient Multicomponent Assembly of Dialkylzincs, Allenic Esters, and Ketones Toward Highly Functionalized $\delta$-Lactones with Tetrasubstituted Chiral Centers J. Am. Chem. Soc. 2007, 129, 7439-7443.

7. Zhao, D.; Oisaki, K.; Kanai, M.; Shibasaki, M. Catalytic Enantioselective Intermolecular Reductive Aldol Reaction to Ketones Tetrahedron Lett. 2006, 47, 1403-1407.

8. Zhao, D.; Oisaki, K.; Kanai, M.; Shibasaki, M. Dramatic Ligand Effect in Catalytic Asymmetric Reductive Aldol Reaction of Allenic Esters to Ketones J. Am. Chem. Soc. 2006, $128,14440-14441$.

9. Elsner, P.; Bernardi, L.; Salla, G. D.; Overgaard, J.; Jorgensen, K. A. Organocatalytic Asymmetric Conjugate Addition to Allenic Esters and Ketones J. Am. Chem. Soc. 2008, 130, 4897-4905.

10. Trost, B. M.; Li, C.-J. Novel "Umpolung" in C-C Bond Formation Catalyzed by Triphenylphosphine J. Am. Chem. Soc. 1994, 116, 3167-3168.

11. Trost, B. M.; Li, C.-J. Phosphine-Catalyzed Isomerization-Addition of Oxygen Nucleophiles to 2-Alkynoates J. Am. Chem. Soc. 1994, 116, 10819-10820.

12. Zhang, C.; Lu, X. Umpolung Addition Reaction of Nucleophiles to 2,3-Butadienoates Catalyzed by a Phosphine Synlett 1995, 1995, 645-646.

13. Chen, Z.; Zhu, G.; Jiang, Q.; Xiao, D.; Cao, P.; Zhang, X. Asymmetric Formation of Quaternary Carbon Centers Catalyzed by Novel Chiral 2,5-Dialkyl-7-phenyl-7phosphabicyclo[2.2.1] heptanes J. Org. Chem. 1998, 63, 5631-5635.

14. Smith, S. W.; Fu, G. C. Asymmetric Carbon-Carbon Bond Formation $\gamma$ to a Carbonyl Group: Phosphine-Catalyzed Addition of Nitromethane to Allenes J. Am. Chem. Soc. 2009, 131, 14231-14233.

15. Liu, B.; Davis, R.; Joshi, B.; Reynolds, D. W. Phosphine-Catalyzed Annulation of Thioamides and 2-Alkynoates: A New Synthesis of Thiazolines J. Org. Chem. 2002, 67, 45954598.

16. Lu, C.; Lu, X. Tandem Reactions to Construct Heterocycles via Phosphine-Catalyzed Umpolung Addition and Intramolecular Conjugate Addition Org. Lett. 2002, 4, 4677-4679.

17. Chung, Y. K.; Fu, G. C. Phosphine-Catalyzed Enantioselective Synthesis of Oxygen Heterocycles Angew. Chem. Int. Ed. 2009, 48, 2225-2227. 
18. Sun, J.; Fu, G. C. Phosphine-Catalyzed Formation of Carbon-Sulfur Bonds: Catalytic Asymmetric Synthesis of $\gamma$-Thioesters J. Am. Chem. Soc. 2010, 132, 4568-4569.

19. Ma, S. Electrophilic Addition and Cyclization Reactions of Allenes Acc. Chem. Res. 2009, $42,1679-1688$.

20. Ma, S.; Yu, Z.; Wu, S. CuCl-Catalyzed Cycloisomerization Reaction of 1,2-Allenyl Carboxylic Acids. A Cost-Effective Synthesis of $\beta$-Unsubstituted Butenolides Tetrahedron 2001, $57,1585-1588$.

21. $\mathrm{Ma}, \mathrm{S}$; $\mathrm{Wu}, \mathrm{S}$. CuX $\mathrm{C}_{2}$-Mediated Cyclization Reaction of 2,3-Allenoic Acids. An Efficient Route to $\beta$-Halobutenolides J. Org. Chem. 1999, 64, 9314-9317.

22. Hall, D. G. Boronic Acids: Preparation and Applications in Organic Synthesis, Medicine and Materials; 2nd ed.; Wiley-VCH, 2011.

23. Suginome, M.; Ito, Y. Regio- and Stereoselective Synthesis of Boryl-Substituted Allylsilanes via Transition Metal-Catalyzed Silaboration J. Organomet. Chem. 2003, 680, 43-50.

24. Onozawa, S.-y.; Hatanaka, Y.; Tanaka, M. Palladium-Catalysed Borylsilylation and Borylstannylative Dimerization of 1,2-Dienes Chem. Commun. 1999.

25. Suginome, M.; Ohmori, Y.; Ito, Y. Highly Regioselective Silaboration of 3-Substituted 1,2Dienes Catalyzed by Palladium/2,6-Xylyl Isocyanide Synlett 1999, 1567-1568.

26. Chang, K.-J.; Rayabarapu, D. K.; Yang, F.-Y.; Cheng, C.-H. Unusual Palladium-Catalyzed Silaboration of Allenes Using Organic Iodides as Initiators: Mechanism and Application J. Am. Chem. Soc. 2004, 127, 126-131.

27. Suginome, M.; Ohmura, T.; Miyake, Y.; Mitani, S. i.; Ito, Y.; Murakami, M. EnantiofaceSelective Palladium-Catalyzed Silaboration of Allenes via Double Asymmetric Induction J. Am. Chem. Soc. 2003, 125, 11174-11175.

28. Yamamoto, A.; Ikeda, Y.; Suginome, M. Palladium-Catalyzed Intramolecular Cyanoboration of Allenes Leading to the Regioselective Synthesis of $\beta$-Cyanoallylboranes Tetrahedron Lett. 2009, 50, 3168-3170.

29. Woodward, A. R.; Burks, H. E.; Chan, L. M.; Morken, J. P. Concatenated Catalytic Asymmetric Allene Diboration/Allylation/Functionalization Org. Lett. 2005, 7, 5505-5507.

30. Yang, F.-Y.; Cheng, C.-H. Unusual Diboration of Allenes Catalyzed by Palladium Complexes and Organic Iodides: A New Efficient Route to Biboronic Compounds J. Am. Chem. Soc. 2001, 123, 761-762.

31. Ishiyama, T.; Kitano, T.; Miyaura, N. Platinum(0)-Catalyzed Diboration of Allenes with Bis(pinacolato)diboron Tetrahedron Lett. 1998, 39, 2357-2360. 
32. Burks, H. E.; Liu, S.; Morken, J. P. Development, Mechanism, and Scope of the PalladiumCatalyzed Enantioselective Allene Diboration J. Am. Chem. Soc. 2007, 129, 8766-8773.

33. Pelz, N. F.; Woodward, A. R.; Burks, H. E.; Sieber, J. D.; Morken, J. P. PalladiumCatalyzed Enantioselective Diboration of Prochiral Allenes J. Am. Chem. Soc. 2004, 126, 1632816329.

34. Gao, M.; Thorpe, S. B.; Santos, W. L. $\mathrm{sp}^{2}-\mathrm{sp}^{3}$ Hybridized Mixed Diboron: Synthesis, Characterization and Copper-Catalyzed $\beta$-Boration of $\alpha, \beta$-Unsaturated Conjugated Compounds Org. Lett. 2009, 11, 3478-3481.

35. Lee, J.-E.; Kwon, J.; Yun, J. Copper-Catalyzed Addition of Diboron Reagents to $\alpha, \beta$ Acetylenic Esters: Efficient Synthesis of $\beta$-Boryl- $\alpha, \beta-$ Ethylenic Esters Chem. Commun. 2008, 733-734.

36. Bonet, A.; Gulyas, H.; Fernandez, E. Metal-Free Catalytic Boration at the $\beta$-Position of $\alpha, \beta$ Unsaturated Compounds: A Challenging Asymmetric Induction Angew. Chem. Int. Ed. 2010, 49, 5130-5134.

37. Voutchkova, A. M.; Feliz, M.; Clot, E.; Eisenstein, O.; Crabtree, R. H. Imidazolium Carboxylates as Versatile and Selective N-Heterocyclic Carbene Transfer Agents: Synthesis, Mechanism, and Applications J. Am. Chem. Soc. 2007, 129, 12834-12846.

38. Lee, K. S.; Zhugralin, A. R.; Hoveyda, A. H. Efficient C-B Bond Formation Promoted by NHeterocyclic Carbenes: Synthesis of Tertiary and Quaternary B-Substituted Carbons Through Metal-Free Catalytic Boron Conjugate Additions to Cyclic and Acyclic $\alpha, \beta$-Unsaturated Carbonyls J. Am. Chem. Soc. 2009, 131, 7253-7255.

39. Creech, G. S.; Kwon, O. Alcohol-Assisted Phosphine Catalysis: One-Step Syntheses of Dihydropyrones from Aldehydes and Allenoates Org. Lett. 2008, 10, 429-432.

40. Charette, A. B.; Boezio, A. A.; Janes, M. K. Synthesis of a Triphenylphosphine Reagent on Non-Cross-Linked Polystyrene Support: Application to the Staudinger/Aza-Wittig Reaction Org. Lett. 2000, 2, 3777-3779.

41. Lipshutz, B. H.; Blomgren, P. A. Efficient Scavenging of $\mathrm{Ph}_{3} \mathrm{P}$ and $\mathrm{Ph}_{3} \mathrm{PO}$ with HighLoading Merrifield Resin Org. Lett. 2001, 3, 1869-1871.

42. Zhu, X.-F.; Henry, C. E.; Wang, J.; Dudding, T.; Kwon, O. Phosphine-Catalyzed Synthesis of 1,3-Dioxan-4-ylidenes Org. Lett. 2005, 7, 1387-1390.

43. Dang, L.; Zhao, H. T.; Lin, Z. Y.; Marder, T. B. Understanding the Higher Reactivity of $\mathrm{B}_{2} \mathrm{cat}_{2}$ Versus $\mathrm{B}_{2} \mathrm{pin}_{2}$ in Copper(I)-Catalyzed Alkene Diboration Reactions Organometallics 2008, 27, 1178-1186.

44. Oku, A.; Abe, M.; Iwamoto, M. Electron Transfer Profile of Cyclopropanone Acetals in the Nonirradiated Reaction with Tetracyanoethylene, Chloranil, and Dicyanodichlorobenzoquinone J. Org. Chem. 1994, 59, 7445-7452. 


\section{Chapter 4 Unexpected copper(II) catalysis: catalytic amine base promoted $\beta$-borylation of $\alpha, \beta$-unsaturated carbonyl compounds in water}

\subsection{Contributions}

Most work described in this chapter was performed by the author of this dissertation and duplicated by Joseph Calderone of the Santos group, including optimization, substrate scope, and UV-vis experiments and physical characterizations. The author was singly responsible for solvent kinetic isotope measurements, screening for enantioselectivity, and significantly contributed to the writing and editing of the manuscript, which was subsequently published (Reprinted/adapted with permission from Thorpe, S.B.; Calderone, J.A.; Santos, W.L. Org. Lett. 2012, 14, 1918-1921. Copyright 2012 American Chemical Society). ${ }^{1}$ The final manuscript was prepared by Dr. Webster L. Santos. 


\subsection{Abstract}

A convenient and practical method for the $\beta$-borylation of acyclic and cyclic $\alpha, \beta$ unsaturated ketones and esters using bis(pinacolato)diboron has been developed. In sharp contrast to $\mathrm{Cu}^{\mathrm{I}}$-catalyzed conjugative borylation, the current protocol is efficient using catalytic amounts of $\mathrm{Cu}^{\mathrm{II}}$ and various amine bases entirely in water under atmospheric condition at $\mathrm{rt}$, furnishing products in up to $98 \%$ yield. Mechanistic investigation using UV-Vis spectroscopy, ${ }^{11} \mathrm{~B}$ NMR and solvent kinetic isotope effect suggest that the role of the amine is not only to coordinate to $\mathrm{Cu}^{\mathrm{II}}$ but also to activate a nucleophilic water molecule to form the reactive $\mathrm{sp}^{2}-\mathrm{sp}^{3}$ diboron complex.

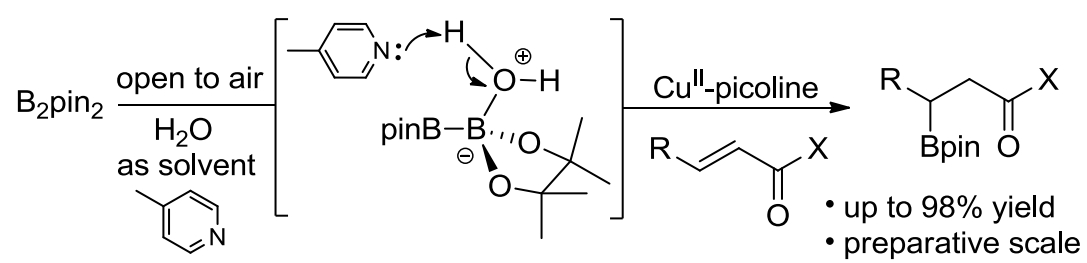




\subsection{Introduction}

Preparation of organoboronic acids and their derivatives remains an active area of intense research because of their functional group tolerance and remarkable versatility to be converted into a wide variety of functional groups. ${ }^{2,3}$ In particular, the Suzuki-Miyaura cross-coupling (SMC) reaction provides a convenient route to construct difficult $\mathrm{C}-\mathrm{C}$ bonds. Although the use of SMC has become ubiquitous, the cross-coupling of $s p^{3}$ carbon centers remains a challenge. Recent advances in this field include stereospecific cross-coupling of secondary benzylic boronates, ${ }^{4} \quad \alpha$-(acylamino)benzylboronic $\quad$ esters, ${ }^{5} \quad$ non-benzylic $\quad$ secondary alkyl $\beta-$ trifluoroboratohomoenolates, ${ }^{6,7}$ and alkyl-1,1-diboron compounds. ${ }^{8}$ Indeed, methods to prepare alkylboronic acid SMC substrates are necessary to access increasingly more complex molecules. Two approaches currently exist for $\alpha, \beta$-unsaturated carbonyl compounds: organometallic conjugate addition to $\beta$-borylated compounds ${ }^{9}$ and transition metal-catalyzed borylation. ${ }^{10-12}$ Among the transition metal-catalyzed methods, the $\mathrm{Cu}^{\mathrm{I}}$-catalyzed conjugate borylation of electron-deficient olefins has garnered significant attention (Scheme 4.1). Building on the pioneering work of Hosomi ${ }^{13}$ and Miyaura, ${ }^{14,15}$ Yun expanded the scope of substrates from unsaturated ketones and esters to include more challenging $\alpha, \beta$-unsaturated amides. ${ }^{16}$ Catalytic asymmetric variants as well as metal-free conditions have also been developed. ${ }^{10,17-22}$ Although

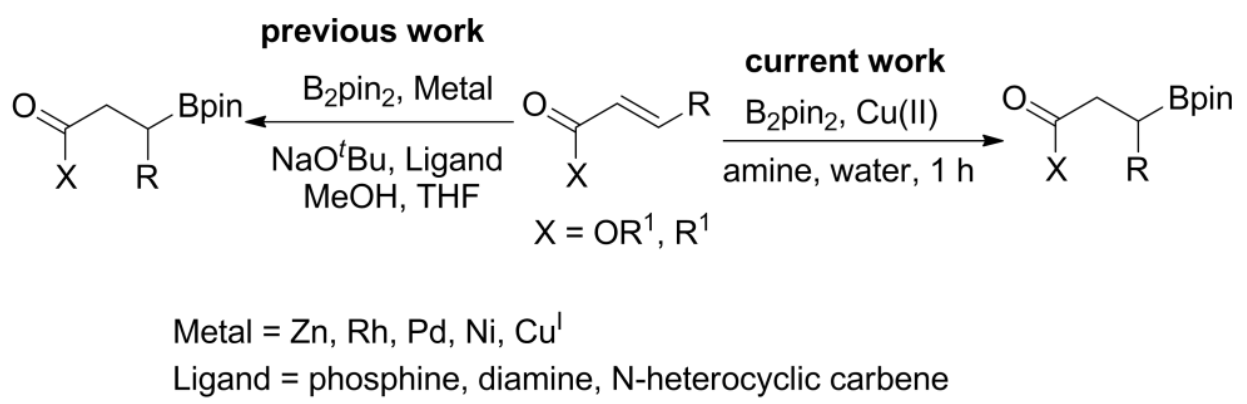

Scheme 4.1. Metal-catalyzed conjugate borylation approaches. 
other transition metals $\left(\mathrm{Pt},{ }^{23-25} \mathrm{Pd},{ }^{26} \mathrm{Rh}^{27,28} \mathrm{Ni}^{29}\right.$ and $\mathrm{Zn}^{30}$ ) were effective as catalysts, $\mathrm{Cu}^{\mathrm{I}-}$ catalyzed reports dominate the literature in part because copper is an inexpensive metal and its reactivity can be tuned by altering the ligands. Bis(pinacolato)diboron $\left(\mathrm{B}_{2} \mathrm{pin}_{2}\right)$ is widely used as the boron source in a majority of reports; however, other reagents such as pinacolatodiisopropanolaminato diboron $^{31-33}$ and tetrahydroxydiborane ${ }^{34}$ can be used as alternatives.

Despite the great number of reports detailing the installation of boron on the $\beta$-carbon of an $\alpha, \beta$-unsaturated carbonyl, most reaction conditions have disadvantages: some are uneconomical (employing expensive ligands and high catalyst loading), others are harsh (strong base such as tert-butoxide is required), and more importantly, the reactions are air-sensitive, often requiring the use of a glove-box or Schlenck techniques. Thus, there is a need for a more efficient and convenient method for the synthesis of alkylboronic acids. As part of our initial considerations, we desired to address an additional concern that is often overlooked: the environmental impact by production of hazardous waste.

The development of more efficient chemical transformations is crucial for the sustainability of industry and academia alike. Decreasing the environmental impacts of chemical modification, purification, and analysis, ${ }^{35}$ primarily from the generation of hazardous waste, has been an area of growing concern for twenty years. ${ }^{36}$ In fact, a detailed evaluation of current efforts and policies addressing green chemistry and sustainability in fine chemicals, pharmaceuticals, and related industries was recently compiled by Watson. ${ }^{37}$ A variety of initiatives have been investigated to address these issues. According to Watson's survey, the most encouraged improvement is the development of efficient catalysts which can replace stoichiometric reagents. Furthermore, the complementary recycling of both transition metal and 
organocatalysts through immobilization have proven to be highly effective techniques for the improvement of reaction conditions. ${ }^{38}$ The use of biocatalysts as alternatives to traditional transition metal complexes has been successful as well, often providing high yields and excellent stereoselectivities, ${ }^{39}$ and benefitting from a greater availability than the much less abundant earth metals. Of almost equal consideration in Watson's survey, and of particular concern to environmental chemists, is the reaction medium. ${ }^{40}$ In fact, waste from solvent use is reported to account for 80 to $90 \%$ of the total non-product mass utilized in industrial chemical processes. $^{41}$ Research in this field is typically focused on one of two main approaches; performing reactions in the absence of solvent (neat) or replacing hazardous media with environmentally benign solvents. According to a 2008 report by the United States EPA, the use of organic solvents is the

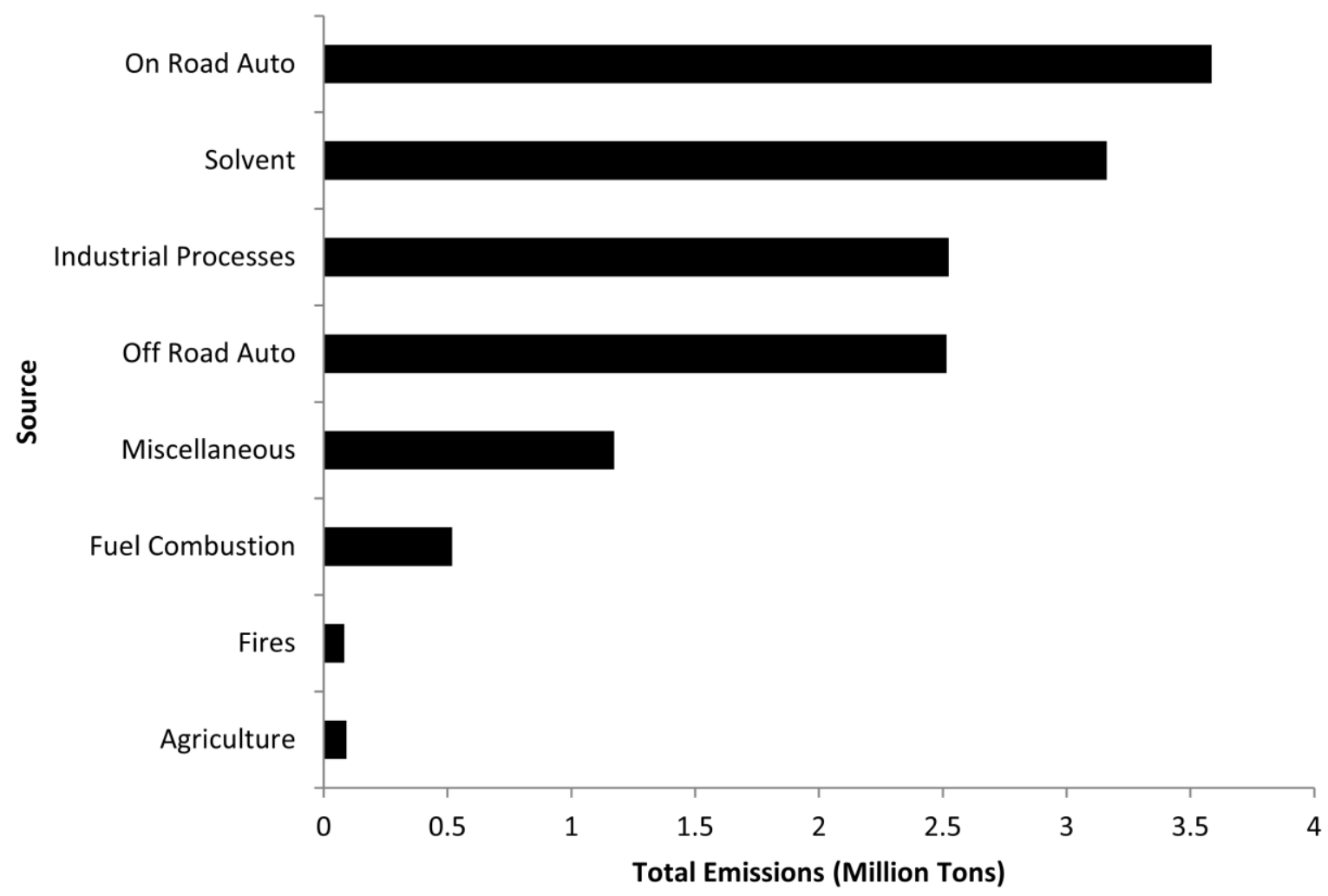

Figure 4.1. National VOC emissions in 2008, by source. Chart prepared from data provided on www.epa.gov. 
second leading contributor to national volatile organic compound (VOC) emissions, surpassed only by on-road vehicles (Figure 4.1).

Changing from typical organic solvents to ionic liquids, liquid polymers, supercritical fluids, water and other non-toxic, biodegradable media will allow traditional reactions to proceed while drastically reducing the global emission of VOCs and the economic costs of processing hazardous waste. We hypothesized that a $\beta$-boration protocol could be developed that would not require VOCs as reaction solvent, and use only minimal solvent during purification. This chapter describes an amine base promoted $\beta$-borylation protocol of $\alpha, \beta$-unsaturated carbonyls in water and open to air, with purification through a simple extraction. In addition, we demonstrate the first $\mathrm{Cu}^{\mathrm{II}}$-catalyzed $\beta$-borylation reaction and provide mechanistic insight to the efficient borylation reaction.

\subsection{Optimization of the $\beta$-boration of 2-cyclohexen-1-one}

Previous work in our laboratory established that complexation of $\mathrm{B}_{2} \mathrm{pin}_{2}$ by a Lewis base is necessary for the in situ formation of an activated diboron. ${ }^{31-33}$ Hence, we began our investigation by screening suitable additives that can affect the borylation reaction in water without any organic co-solvent. ${ }^{42}$ Preliminary studies indicated that amine bases are inefficient in catalyzing the $\beta$-borylation reaction in organic solvents in the presence of copper. Surprisingly, we found that addition of a catalytic amount of inexpensive, commercially available amines allowed the efficient conversion of 2-cyclohexenone 4.1a to the corresponding boratohomoenolate 4.3a in the presence of $\mathrm{CuCl}_{2}$ in water (Table 4.1). In marked contrast to $\mathrm{Cu}^{\mathrm{I}}$-catalyzed $\beta$-borylation in organic solvents, ${ }^{15-19,22,31,33,34,43-49}$ the current protocol is most efficient with a $\mathrm{Cu}^{\mathrm{II}}$ source (vide infra). $\mathrm{Cu}^{\mathrm{II}}$ salts are especially convenient because of their high 
Table 4.1. Screening of additives and reaction conditions. ${ }^{a}$

\begin{tabular}{|c|c|c|}
\hline entry & base additive & conv $\%^{b}$ \\
\hline 1 & benzylamine & 98.2 \\
\hline 2 & piperidine & 96.6 \\
\hline 3 & triethylamine & 95.0 \\
\hline 4 & TMEDA & 98.2 \\
\hline 5 & DBU & 95.6 \\
\hline 6 & pyridine & 98.1 \\
\hline 7 & 4-picoline & $>99.9$ \\
\hline 8 & 3-picoline & 98.4 \\
\hline 9 & 2,6-lutidine & 97.5 \\
\hline 10 & DMAP $^{c}$ & 99.8 \\
\hline 11 & imidazole & 97.8 \\
\hline 12 & quinoline & 76.9 \\
\hline 13 & 2,2'-bipyridine ${ }^{c}$ & 17.7 \\
\hline 14 & proton sponge & 99.8 \\
\hline 15 & none & 20.3 \\
\hline 16 & 4-picoline & $42.9\left(0^{d}\right)$ \\
\hline 17 & sodium acetate & 86.0 \\
\hline 18 & sodium hydroxide & 86.0 \\
\hline 19 & 4-picoline $e^{e}$ & 0 \\
\hline
\end{tabular}

\footnotetext{
${ }^{a}$ Reaction conditions: $\mathrm{B}_{2} \mathrm{pin}_{2}$ (1.1 equiv.), 2-cyclohexen-1-one (1.0 equiv.) and amine ( $2 \mathrm{~mol} \%$ ) were added to a 1-dram, PTFE vial with a magnetic stir bar. $1.5 \mathrm{ml}$ of a stock $\mathrm{CuCl}_{2}(1.72 \mathrm{mM})$ solution in water was added and stirred vigorously for $1 \mathrm{~h}$ at rt. ${ }^{b}$ Conversion determined by GC analysis. ${ }^{c}$ Amine was dissolved in THF before addition. ${ }^{d}$ In the absence of $\mathrm{CuCl}_{2}$ using nuclease-free or MilliQ water. ${ }^{e}$ Using pinB$\mathrm{OH}$ (independently synthesized) instead of $\mathrm{B}_{2} \mathrm{pin}_{2}$.
}

solubility in water and resistance to oxidation upon exposure to air. Gratifyingly, we found that a variety of primary, secondary, and tertiary aliphatic amines provided excellent conversion to 4.3a (entries 1-4). Use of a strong base was also effective (entry 5). Heteroaromatic amines 
performed better on average than aliphatic amines, with 4-picoline giving the highest conversion (entries 6-11). Quinoline showed decreased activity, likely due to decreased solubility in water (entry 12). On the other hand, 2,2'-bipyridine gave a significantly lower conversion, possibly as a result of rigid bidentate binding to copper (entry 13). ${ }^{50}$ Proton sponge also provided excellent conversion (entry 14). As expected, the reaction was sluggish in the absence of amine or copper (entries 15-16). As shown in entry 16, when the reaction was run using in-house deionized water, a background conversion of $43 \%$ resulted, suggesting a possibility of transition metal-free reaction. However, analysis of the deionized water revealed $40 \mathrm{ppb} \mathrm{Cu}$ by ICP-MS, an indication that a minute level of copper is capable of catalyzing the transformation.

Although many amines participate as good additives, we chose 4-picoline for further optimization since it gave the highest conversion. When a more sterically demanding substrate, 3-methylcyclohexenone 4.1b, was used (Table 4.2), the desired product 4.3b was only observed in good conversion with 1:5 Cu:amine stoichiometry (compare entries 1 vs 2). Further survey of copper sources revealed that a more water soluble $\mathrm{CuSO}_{4}$ resulted in excellent conversion and that other copper(II) sources were also effective (entries 3-6). We were surprised to discover that $\mathrm{Cu}^{\mathrm{II}}$ was an effective borylation catalyst since, to the best of our knowledge, only $\mathrm{Cu}^{\mathrm{I}}$ catalyst systems had previously been reported. Simultaneous to the preparation of this manuscript for publication, Córdova reported the copper(II) triflate catalyzed boration of cinnamaldehyde as part of a three-component enantionselective coupling for the preparation of chiral homoallylboronates. ${ }^{51}$ To investigate the $\mathrm{Cu}^{\mathrm{II}}$ catalysis, the reaction was run with $\mathrm{CuCl}$ with good conversion (entry 7); however, this result is misleading because $\mathrm{Cu}^{\mathrm{I}}$ disproportionates (to $\mathrm{Cu}^{0}$ and $\mathrm{Cu}^{\mathrm{II}}$ ) in water and provides a $\mathrm{Cu}^{\mathrm{II}}$ source. In fact, a distinct difference in the physical 
Table 4.2. Screening of copper sources and stoichiometry. ${ }^{a}$

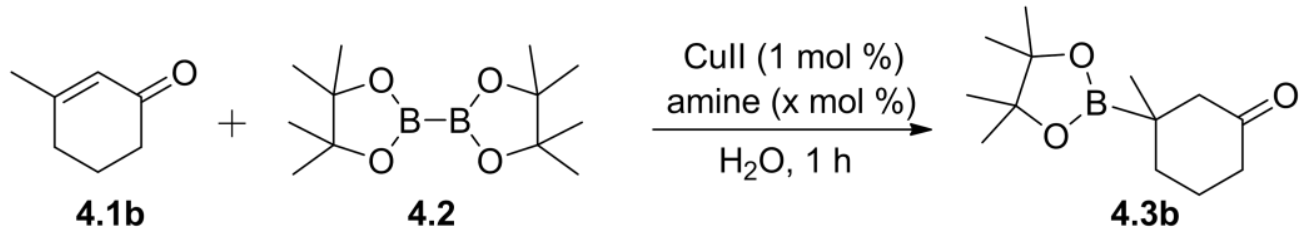

\begin{tabular}{cccc}
\hline entry & $\mathrm{Cu}$ source & 4-picoline (mol \%) & conv $\%^{b}$ \\
\hline 1 & $\mathrm{CuCl}_{2}$ & $2 \%$ & $<1$ \\
2 & $\mathrm{CuCl}_{2}$ & $5 \%$ & 72.8 \\
3 & $\mathrm{CuSO}_{4}$ & $2 \%$ & 39.9 \\
4 & $\mathrm{CuSO}_{4}$ & $5 \%$ & 89.5 \\
5 & $\mathrm{Cu}\left(\mathrm{OAc}_{2}\right)_{2}$ & $5 \%$ & 84.0 \\
6 & $\mathrm{Cu}\left(\mathrm{BF}_{4}\right)_{2}$ & $5 \%$ & 78.3 \\
7 & $\mathrm{CuCl}$ & $5 \%$ & 77.4 \\
8 & $\mathrm{CuSO}_{4}{ }^{c}$ & $5 \%$ & 33.5 \\
9 & $\mathrm{CuSO}_{4}{ }^{d}$ & $5 \%$ & 24.5 \\
10 & $\mathrm{CuSO}_{4}{ }^{e}$ & $5 \%$ & 32.0 \\
11 & none $^{a}$ & $5 \%$ & $<1$ \\
\hline${ }^{a}$ Reaction conditions identical to Table $1 .{ }^{b}$ Conversion determined by GC analysis. \\
With 20 mol \% ascorbic acid. ${ }^{c}$ With 10 mol \% ascorbic acid. ${ }^{e}$ With 1 mol \% ascorbic \\
acid.
\end{tabular}

appearance of the copper sources was observed. For example, black precipitate appeared upon addition of $\mathrm{CuCl}$ to water, while $\mathrm{CuSO}_{4}$ provided a homogeneous pale blue solution. Interestingly, the same black precipitate is observed with $\mathrm{Cu}^{\mathrm{I}}$ catalyzed borations in organic solvents. To further confirm that $\mathrm{Cu}^{\mathrm{I}}$ is not the active catalyst, $\mathrm{CuSO}_{4}$ was reduced in situ to $\mathrm{Cu}^{\mathrm{I}}$ in the presence of excess ascorbic acid. ${ }^{52,53}$ As expected, the conversion decreased, however trace $\mathrm{Cu}^{\mathrm{II}}$ is likely still present that is capable of catalyzing the reaction (vide supra) because of the fast oxidation of $\mathrm{Cu}^{\mathrm{I}}$ by molecular oxygen, especially in the presence of copper-stabilizing ligands (entry 8 ) ${ }^{54}$ Taken together, these studies suggest that $\mathrm{Cu}^{\mathrm{II}}$ is the active catalyst under aqueous conditions and that $\mathrm{Cu}^{\mathrm{II}}$ may be the active catalyst for reactions run in organic solvents. 


\subsection{Substrate scope of copper(II) catalyzed $\beta$-boration in water}

With the optimized conditions in hand (Table 4.2, entry 4), we explored the scope and limitations of this reaction with a variety of $\alpha, \beta$-unsaturated carbonyl compounds (Scheme 4.2).

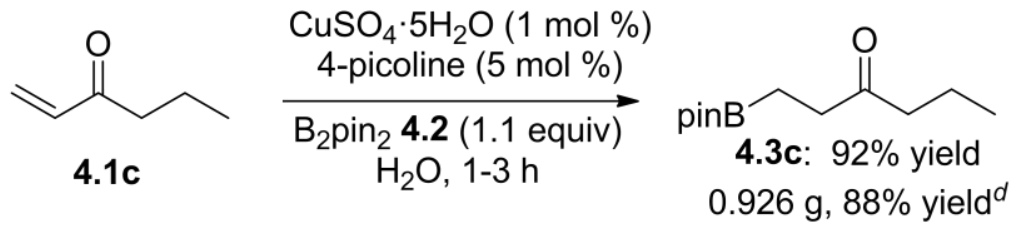<smiles>[B][B]C(C)CC(=O)CC</smiles>

4.3d: $83 \%$ yield<smiles>CC(=O)CC(BP)C=C(C)C</smiles>

4.3g: $87 \%$ yield<smiles>O=C1CCC(BO)C1</smiles>

4.3h: $47 \%$ yield as $\mathrm{BF}_{3} \mathrm{~K}$ 4.3i: $78 \%$ yield<smiles>CCCCCC(Br)CC(C)=O</smiles>

4.3e: $98 \%$ yield<smiles>CCCCCCC(=O)c1ccccc1</smiles>
$1.609 \mathrm{~g}, 96 \%$ yield $^{\mathrm{d}}$<smiles>[B]PBC1CCCC(=O)C1</smiles>

4.3a: $85 \%$ yield $0.935 \mathrm{~g}, 83 \%$ yield $^{d}$<smiles>CC1([PbH])CCCC(=O)C1</smiles>

4.3b: $75 \%$ yield<smiles>O=C(CC[B]O)OCc1ccccc1</smiles>

4.3j: $98 \%$ yield<smiles>COC(=O)CC(C)[B][PH]</smiles>

4.3k: $72 \%$ yield $1.605 \mathrm{~g}, 75 \%$ yield $^{d}$<smiles>CCOC(=O)CC(C)P</smiles><smiles>COC(=O)C(C)C[PbH]</smiles>

4.3m: $76 \%$ yield $0.916 \mathrm{~g}, 78 \%$ yield $^{d}$

4.3I: $76 \%$ yield<smiles>CC(BP)CC(=O)OC(C)(C)C</smiles>

4.3n: $55 \%$ yield $\left(72 \%^{c}\right)$ as $\mathrm{BF}_{3} \mathrm{~K}$ 4.30: $46 \%$ yield

Scheme 4.2. $\mathrm{Cu}^{\mathrm{II}}$-catalyzed boryl conjugate addition with acyclic and cyclic $\alpha, \beta-$ unsaturated ketones and esters. ${ }^{a}$

${ }^{a}$ Reaction conditions: $\mathrm{B}_{2} \operatorname{pin}_{2}$ (1.1 equiv.), 1 (1.0 equiv.) and 4-picoline (0.05 equiv.) were added to a $5 \mathrm{ml}$ round-bottomed flask with a magnetic stirbar. $\mathrm{CuSO}_{4}(1 \mathrm{~mol} \%)$ dissolved in $3 \mathrm{~mL}$ de-ionized water was added and the reaction was stirred vigorously for 1-3 h at rt. ${ }^{b}$ Chalcone was dissolved in minimal THF before addition. ${ }^{c}$ NMR yield. ${ }^{d}$ Preparative scale. 
For example, borylated acyclic ketones $4.3 \mathrm{c}-\mathrm{f}$ were synthesized in good to excellent yield (up to 98\% isolated yield). Furthermore, a conjugated dienone was regiospecifically borylated on the beta position to afford $4.3 \mathrm{~g}$. Cyclic enones $(4.3 \mathrm{a}-\mathrm{b}$ and $\mathbf{4 . 3 \mathrm { h }})$ were also readily transformed in good yields; cyclopentenone resulted in moderate yield as the pinacol ester $\mathbf{4 . 3 h}$ but conversion to the trifluoroborate salt $\mathbf{4 . 3 i}$ significantly improved the isolated product yield. To our delight, more electronically-demanding esters were easily converted into borylated products. Unsubstituted benzyl acrylate generated $\mathbf{4 . 3}$ in excellent yield, while other $\alpha$ - and $\beta$-substituted products 4.3k-m were generated in consistent good yields. A limitation of the reaction is evident with tert-butyl crotonate, which afforded the product $4.3 \mathrm{n}$ in only $55 \%$ yield (although, this was not consistently replicable) and only $46 \%$ yield as the potassium trifluoroborate salt $\mathbf{4 . 3 0}$. To demonstrate the practical utility of the developed protocol, we performed reactions on a preparative scale. Indeed, the borylated products $(4.3 \mathrm{a}, 4.3 \mathrm{c}, 4.3 \mathrm{f}, 4.3 \mathrm{k}$ and $4.3 \mathrm{~m})$ were efficiently formed in yields within experimental error of the small scale version. Moreover, the products in Scheme 4.2 were isolated by simple extraction step (except for water soluble $\mathbf{4 . 3 h}$ ) because the alkene starting materials were consumed and any excess $\mathrm{B}_{2} \mathrm{pin}_{2}$ decomposed into water soluble pinB-OH. Although the current conditions cannot yet be extended to $\alpha, \beta$ unsaturated amides, tetrahydroxydiboron as the boron source provided a moderate yield of $\mathbf{4 . 3 c}$ upon treatment with pinacol (Scheme 4.3).

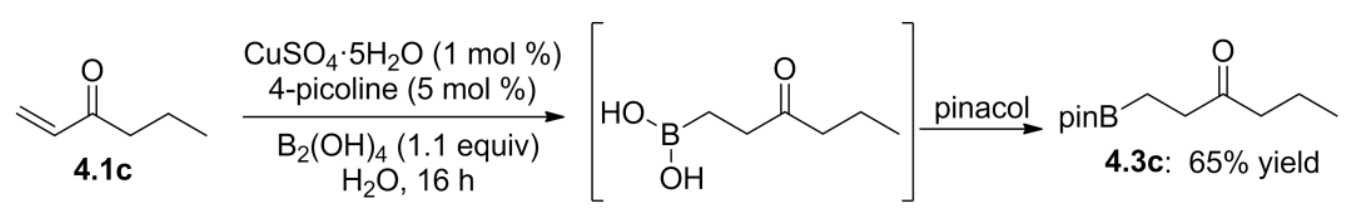

Scheme 4.3. Tetra(hydroxy)diborane as the boron source. 


\subsection{Mechanistic investigations}

To gain insight into the effect of amine base on the $\mathrm{Cu}^{\mathrm{II}}$-catalyzed reaction in water, we performed ${ }^{11} \mathrm{~B}$ NMR experiments at $4{ }^{\circ} \mathrm{C}$ (Figure 4.2). Investigation in neat 4-picoline suggests that the amine does not participate in Lewis acid-base coordination because a single boron chemical shift is observed at $31 \mathrm{ppm}$, indicative of uncomplexed $\mathrm{B}_{2} \mathrm{pin}_{2}$ (Figure 4.2A). This result is not surprising since $\mathrm{B}_{2} \mathrm{pin}_{2}$ is sterically hindered, and 4-picoline has only been observed to coordinate with more Lewis acidic bis(catecholato)diboron. ${ }^{55,56}$ Furthermore, when water $^{57}$ was used as the NMR solvent, only $\mathrm{B}_{2} \mathrm{pin}_{2}$ and its decomposition product, pinBOH (confirmed by independent synthesis) , were

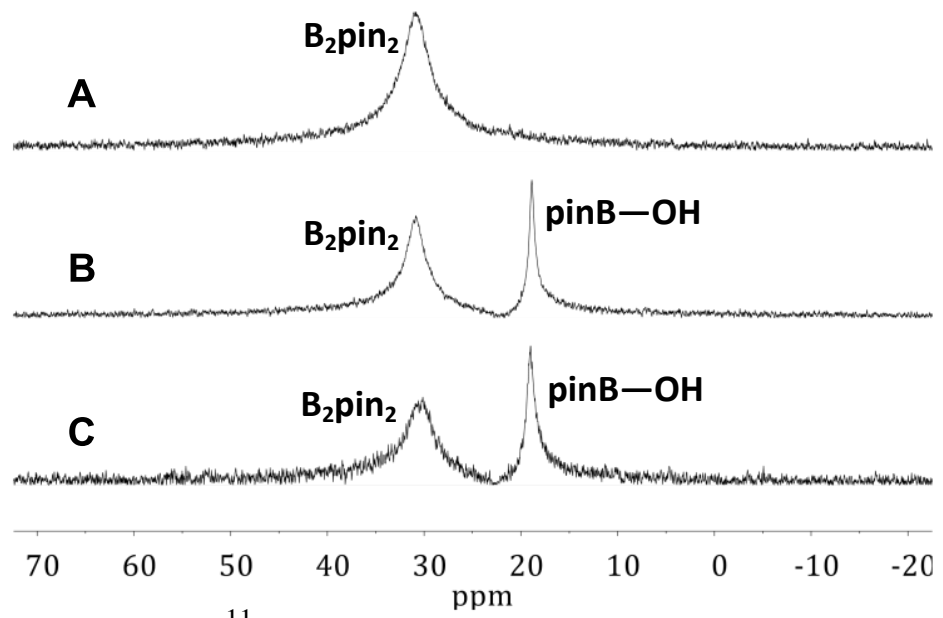
detected (Figures 4.2B and 4.2C). Figure 4.2. ${ }^{11} \mathrm{~B}$ NMR spectra of $\mathrm{B}_{2} \mathrm{pin}_{2}$ in A) 4To prove that pinBOH was not a equiv) at $4{ }^{\circ} \mathrm{C}$. reactive intermediate, a boration was attempted using pinBOH as the boron source and no product was detected (Table 4.1, entry 19), suggesting that the reactive intermediate has a halflife too short to be observed on the NMR time scale. UV-Vis measurements with increasing stoichiometry of 4-picoline: $\mathrm{Cu}^{\text {II }}$ revealed the expected coordination of amine to copper-i.e. successive coordination of 4-picoline to copper results in blue shift in the spectrum (Figure 4.3). ${ }^{58}$ We also determined that the reaction was efficient when the amine was exchanged with $\mathrm{NaOAc}, \mathrm{NaOH}$ and non-coordinating proton sponge (Table 4.1, entries 14, 17-18). 
Furthermore, a solvent kinetic isotope effect (SKIE; $\mathrm{H}_{2} \mathrm{O}$ vs $\mathrm{D}_{2} \mathrm{O}$ ) was observed, suggesting a possible deprotonation in the rate determining step (RDS). As the reaction order has not been determined, we plotted the data using the three most common characteristic kinetics plots

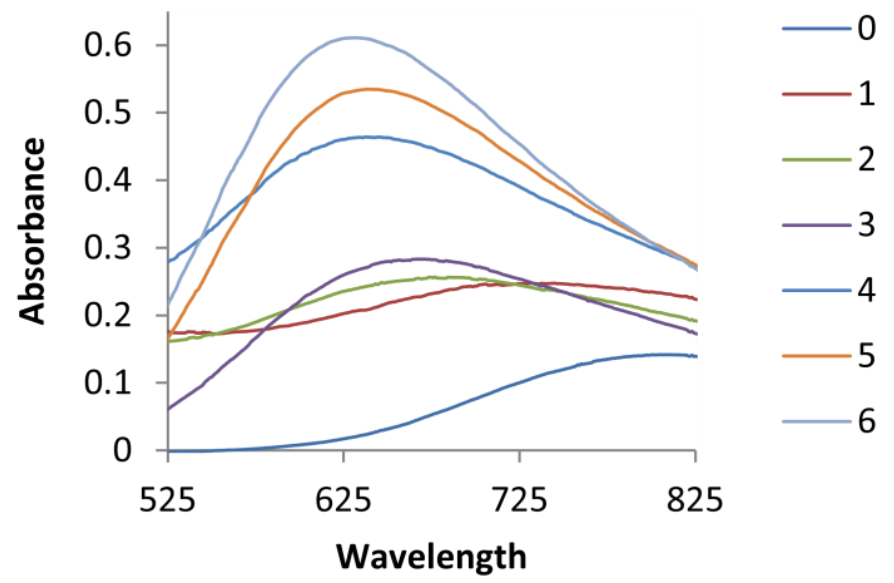

Figure 4.3. UV-Vis spectra of $\mathrm{CuSO}_{4}$ with increasing equivalents of 4-picoline.

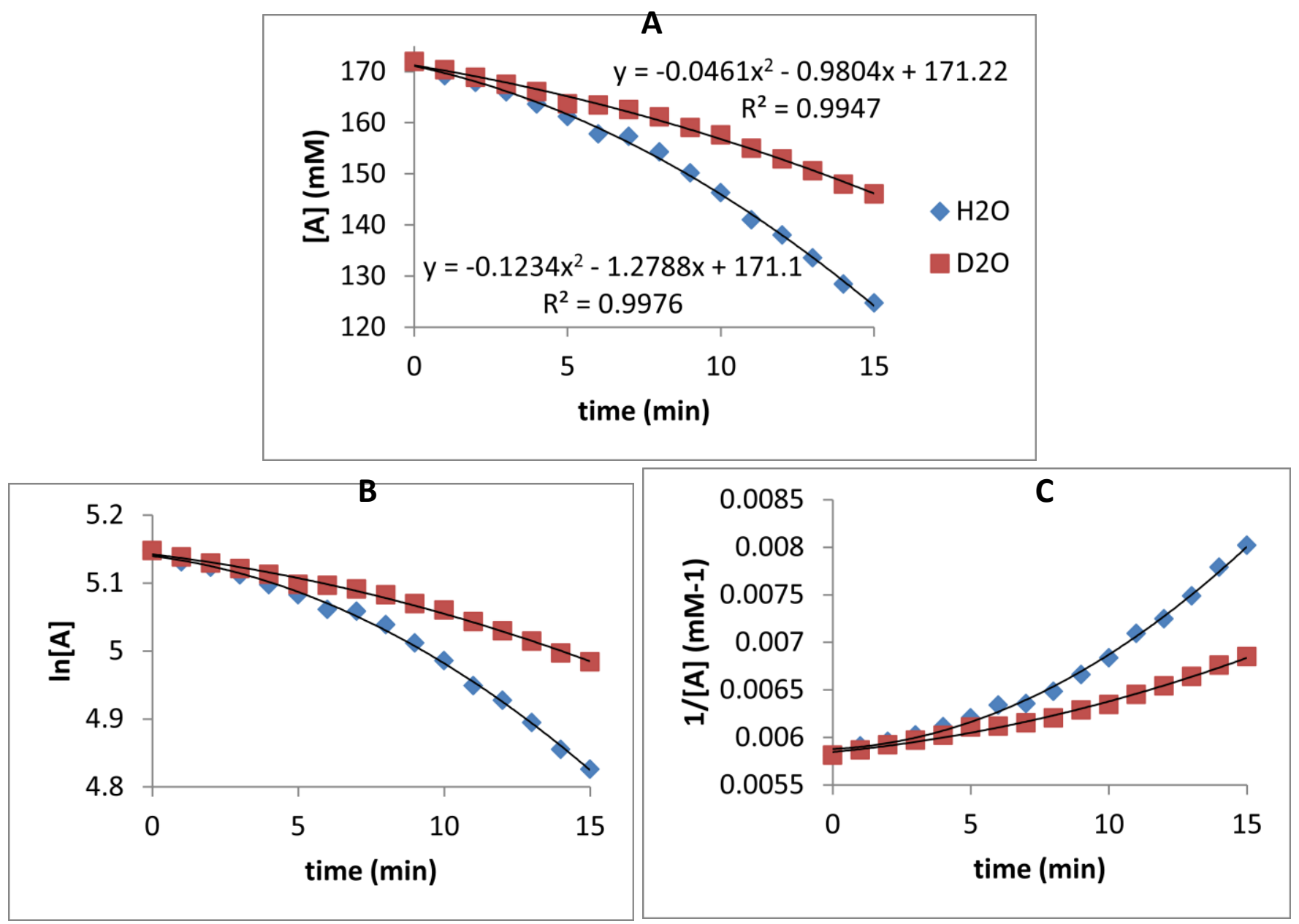

Figure 4.4. (A) $0^{\text {th }},(\mathbf{B}) 1^{\text {st }}$, and (C) $2^{\text {nd }}$ order treatments of SKIE data, where $[\mathbf{A}]=$ starting material. 
for $0^{\text {th }}, 1^{\text {st }}$, and $2^{\text {nd }}$ order reactions (Figure 4.4), which should provide a straight line when the experimental results are consistent with $0^{\text {th }}, 1^{\text {st }}$, or $2^{\text {nd }}$ order kinetics, respectively. However, a straight line was not observed using any of these treatments, suggesting that the mechanism is more complex than the simple scheme $\mathrm{A} \rightarrow \mathrm{B}$, or $\mathrm{A}+\mathrm{B} \rightarrow \mathrm{C}$. In fact, it appears that the rate of product formation is increasing with time based on the upward curvature of Figure 4.4A, which is indicative of an autocatalytic reaction where either the product or byproduct (presumably pinB-OH) activates a key intermediate to enhance the reaction rate. ${ }^{59}$

To further investigate this hypothesis, we examined the general mechanism of an autocatalytic reaction, as described in Figure 4.5, in which two pathways could lead to product. The first pathway is first order on the concentration of $\mathbf{A}$ and described by the rate constant $\mathrm{k}_{1}$. The second, more complex, pathway involves the formation of an activated complex, $\mathbf{A B} \mathbf{B}^{*}$, from one equivalent of product $\mathbf{B}$ and one equivalent of starting material $\mathbf{A}$, and is described by the rate constant $\mathrm{k}_{2}$. This activated complex, $\mathbf{A B}{ }^{*}$, then rapidly provides 2 equivalents of product $\mathbf{B}$. This mechanism allows a simple differential rate law to be examined for preliminary analysis of autocatalysis, where the observed rate is described by Equation 4.1. Assuming also that 1 equivalent of starting material A yields 1 equivalent of autocatalytic product $\mathbf{B}$ - which is reasonable for this reaction based on experimental observations and reaction protocol— the

$$
\text { Equation 4.1 } \frac{-d[A]}{d t}=k_{1}[A]+k_{2}[A][B]
$$

Equation 4.2 $[B]=[A]_{o}-[A]$

Equation 4.3 $\frac{-d[A]}{d t} \frac{1}{[A]}=-k_{2}[A]+\left(k_{1}+k_{2}[A]_{0}\right)$

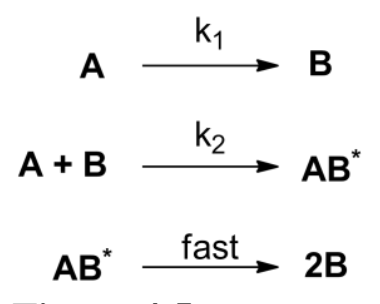

Figure 4.5.

Mechanism of autocatalysis. 
Figure 4.6. Differential rate law plots of $\mathrm{H}_{2} \mathrm{O}$ and $\mathrm{D}_{2} \mathrm{O}$.

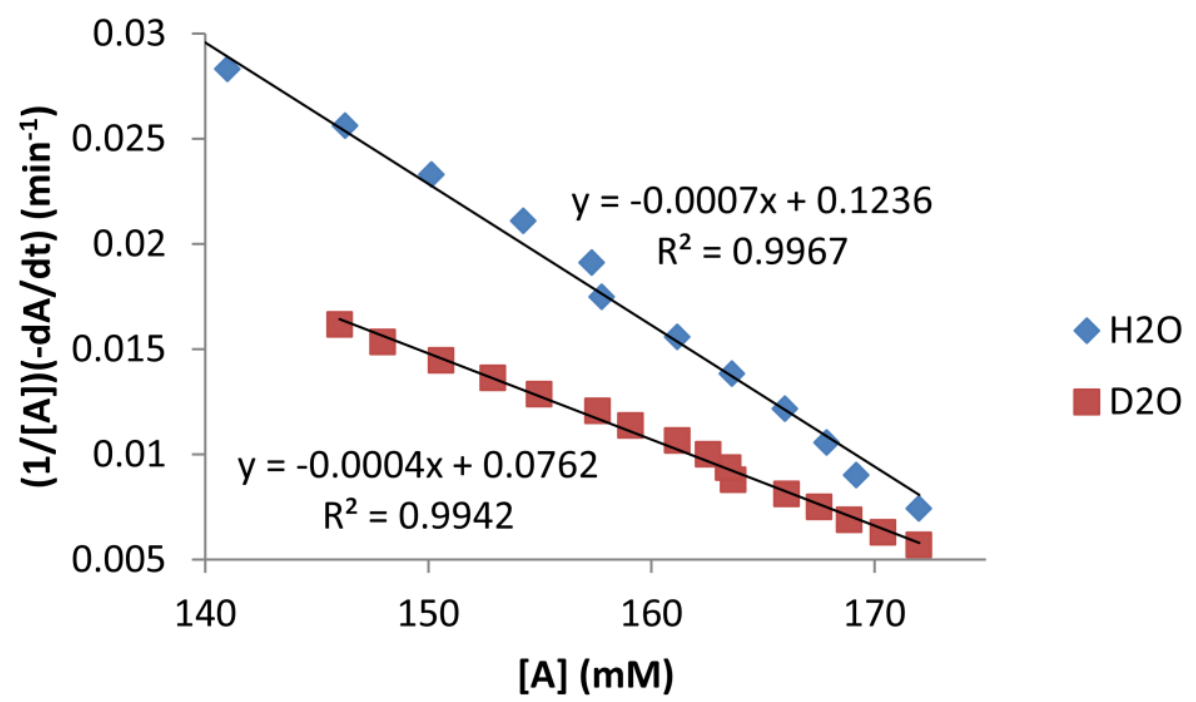

concentration of $\mathbf{B}$ should be directly related to the loss of starting material, which provides the mass-balanced Equation 4.2. The combination and rearrangement of Equations 4.1 and 4.2 yields Equation 4.3, which should provide a straight line-in the case of an autocatalytic reaction -when $(-\mathrm{dA} / \mathrm{dt})(1 /[\mathrm{A}])$ is plotted against $[\mathrm{A}]{ }^{60}$ The slope of the line affords the value of $\mathrm{k}_{2}$; and $\mathrm{k}_{1}$ can be determined from the y-intercept. As shown in Figure 4.6, an accurate linear fit was obtained using this treatment. The rate constants for the noncatalytic $\left(\mathrm{k}_{1}\right)$ and catalytic $\left(\mathrm{k}_{2}\right)$ mechanisms for reactions in $\mathrm{H}_{2} \mathrm{O}$ and $\mathrm{D}_{2} \mathrm{O}$ were acquired from the best fit lines and compared in terms of SKIE (results summarized in Table 4.3). Error was assessed using linear regression analysis and the reported values are at the 95\% confidence level, including propagation of error from calculations. A significant SKIE value of approximately 1.6 was obtained for both $\mathrm{k}_{1}$ and $\mathrm{k}_{2}$, supporting the involvement of a deprotonation event in the RDS,

Table 4.3. Rate constants and SKIE.

\begin{tabular}{cccc} 
solvent & $\mathrm{H}_{2} \mathrm{O}$ & $\mathrm{D}_{2} \mathrm{O}$ & $\mathrm{k}_{\mathrm{H}} / \mathrm{k}_{\mathrm{D}}$ \\
\hline $\mathrm{k}_{1}\left(\mathrm{~min}^{-1}\right)$ & $0.1236 \pm 0.0034$ & $0.0761 \pm 0.0029$ & $\mathbf{1 . 6 2} \pm \mathbf{0 . 1 1}$ \\
$\mathrm{k}_{2}\left(\mu \mathrm{M}^{-1} \min ^{-1}\right)$ & $0.672 \pm 0.022$ & $0.409 \pm 0.018$ & $\mathbf{1 . 6 4} \pm \mathbf{0 . 1 3}$ \\
\hline
\end{tabular}


although additional kinetic experiments are required to accurately identify the components involved in the RDS and rule out other potential sources of rate acceleration, such as a change in the solution $\mathrm{pH}$.

On the basis of these observations, it is plausible to suggest that the role of the amine is twofold: (1) to form a stable 4-picoline- $\mathrm{Cu}^{\text {II }}$ complex 4.6 and (2) to act as a Bronsted base. Thus, we believe the catalytic cycle proceeds as described in Scheme 4.4. First, the highly insoluble diboron 4.2 is likely partially solvated as Lewis acid-base adduct 4.4 with water. The amine then deprotonates complex 4.4 to generate, in situ, a $s p^{2}-s p^{3}$ diboron 4.5 that is now capable of transmetalation with copper complex 4.6. The resulting nucleophilic 'boryl-copper' species $\mathbf{4 . 7}$

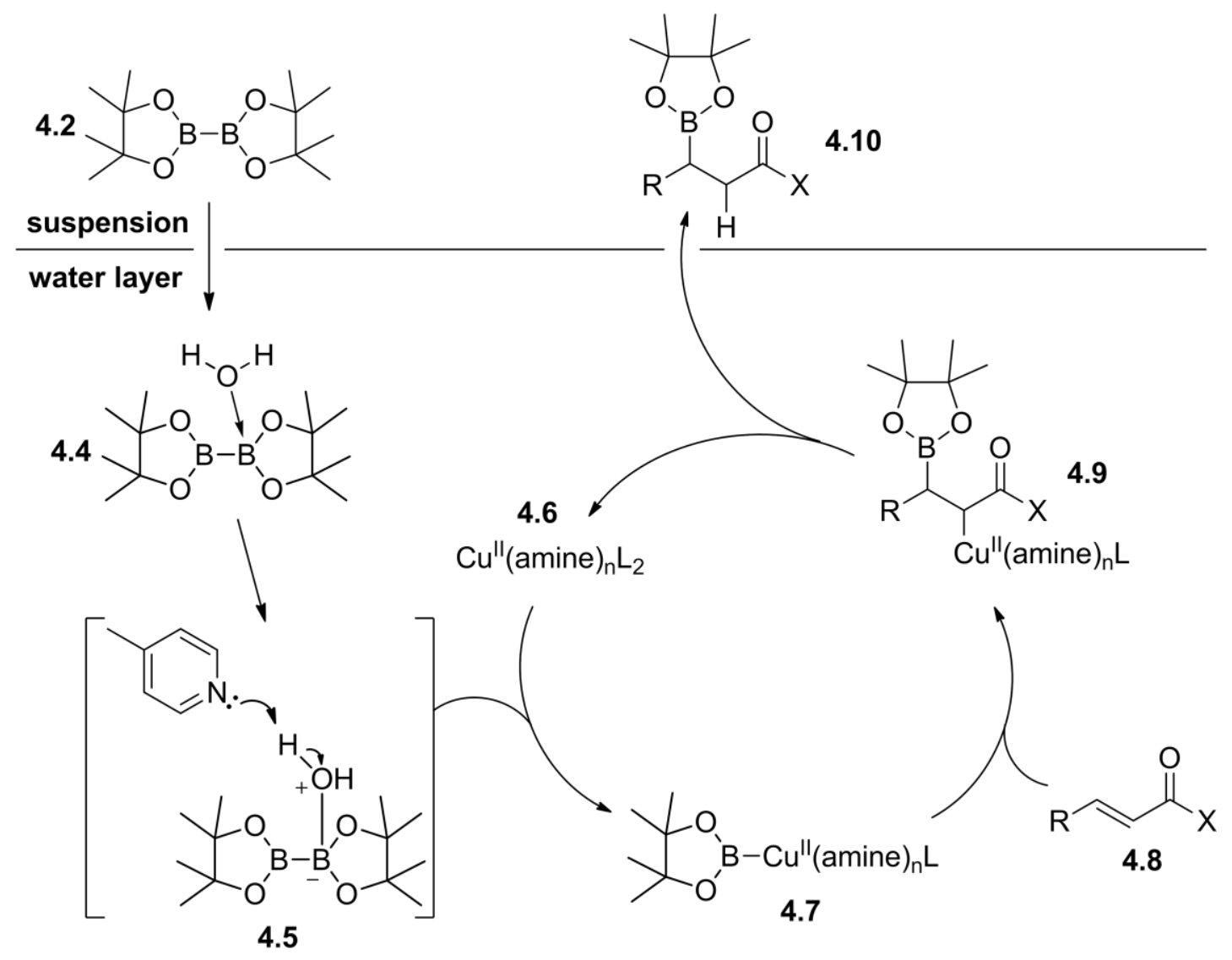

Scheme 4.4. Proposed mechanism. 
then undergoes 3,4-boryl conjugate addition with substrate 4.8, as supported by DFT calculations. $^{61}$ Intermediate 4.9 is rapidly hydrolyzed in water and borated product $\mathbf{4 . 1 0}$ is formed as an emulsion. The function of the proposed autocatalyst is not known and was omitted from the mechanism until it can be identified.

\subsection{Stereoinduction by chiral amines}

With an understanding of the mechanism, we wondered whether the amine could function simultaneously as a ligand and chiral auxiliary on copper to encourage the formation of a single enantiomer. In fact, only one example of achieving enantioselectivity — as a result of a chiral 1,2-diamine - in copper catalyzed $\beta$-boration reactions has been reported. ${ }^{47}$ Using $\beta, \beta$ disubstituted ketones, the corresponding products where obtained in high yield (71-95\%) and excellent ee (90-99\%), although the reaction required high catalyst- and chiral ligand loading, and was performed in organic solvent. We applied our aqueous protocol towards the enantioselective boration of a model substrate, chalcone 4.1f, by first screening various chiral amines (Scheme 4.5). In agreement with the decreased yield using bidentate ligand bipyridine observed during optimization (Table 4.1, entry 13), initial results suggested a correlation between reactivity of the catalyst complex and the binding mode of the amine ligand, where the order is tridentate $(\mathbf{L 1})<$ bidentate $(\mathbf{L 2})<$ monodentate $(\mathbf{L 3})$. This was unfortunately accompanied by a complete lack of enantioselectivity. The possibility of restriction to the latter subset of binding modes alluded to a theoretically difficult hurdle, because amines are weak field ligands, Jahn-Teller distortion in the $\mathrm{d}^{9}$ electron configuration of $\mathrm{Cu}^{\mathrm{II}}$ imparts a highly dynamic geometry $^{62}$ and additional lengthening of the metal-ligand bonds, ${ }^{63}$ and we cannot take advantage of increased stability and rigidity from multidentate interactions. The sum of these properties is a flexible catalyst with easily exchangeable - i.e. weakly bound-ligands, which is 
an undesirable feature when attempting to induce stereochemistry in small molecule synthesis.

Still hoping to stumble upon a diamond in the rough we continued to examine the efficacy of other commercially available amines, such as proline derivatives L4-L6, benzylamine L7,

Scheme 4.5. Screening of chiral amines for the enantioselective $\beta$-boration of chalcone.

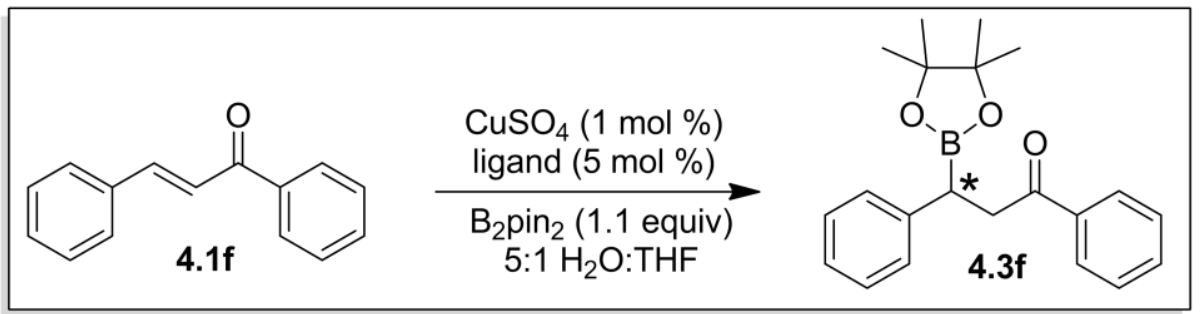

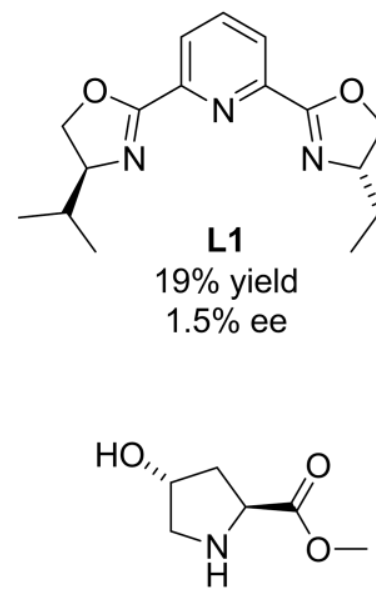

L5

$50 \%$ yield

$0 \%$ ee

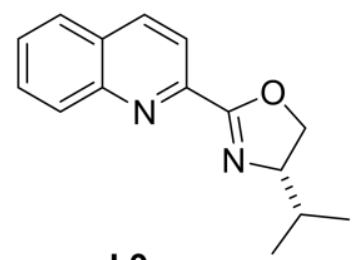

L9

no reaction<smiles>N[C@@H]1CCCC[C@H]1N</smiles>

L2

$43 \%$ yield

$9.7 \%$ ee<smiles>O=C(O)[C@H]1CCCN1</smiles>

L6 no reaction<smiles>C=CC1CC2CCN1CC2[C@H](O)c1ccnc2ccccc12</smiles>

$83 \%$ yield

$4.1 \%$ ee

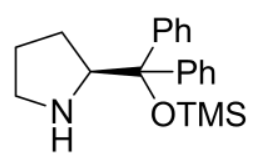

L4 $89 \%$ yield $7.6 \%$ ee<smiles>N[C@H](c1ccccc1O)[C@H](N)c1ccccc1O</smiles>

L7 $80 \%$ yield $1.8 \%$ ee
L8 $26 \%$ yield $16.2 \%$ ee<smiles>CC(C)[C@H](N)C(=O)Nc1ccccn1</smiles>

L10

$69 \%$ yield $5.4 \%$ ee

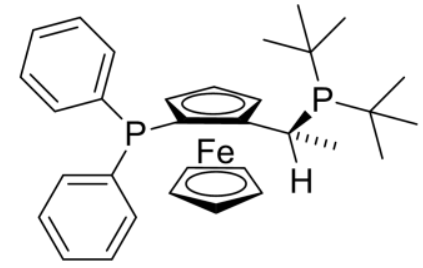

L11

$70 \%$ yield $52.8 \%$ ee ( $S$-isomer) 
diamine $\mathbf{L 8}$ and Quinox $\mathbf{L 9}$ but were unable to identify a system with greater stereoinduction than $16 \%$ ee. We synthesized valine derivative $\mathbf{L 1 0}{ }^{64}$ which we hoped would increase the rigidity of the related transition state by serving the dual role of a bidentate chelating ligand and Lewis base (Figure 4.6), however this did not

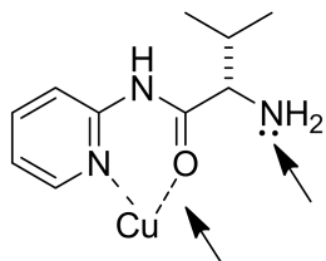

Figure 4.7. Proposed chelation and Lewis basicity of $\mathbf{L 1 0}$. lead to an increase in stereoselectivity. To provide evidence that our poor results were due - at least in part- to weak metal to ligand binding, we employed Josiphos L11 which has been previously shown to transfer chirality in organic solvents, ${ }^{65}$ and in fact obtained a 3:1 mixture of enantiomers. The combination of undesirable electronic properties in our catalyst system (vide supra) proved to play a larger role that the steric interactions between ligand and substrate, resulting in unsuccessful stereoinduction in water.

\subsection{Conclusions}

In conclusion, we have developed an efficient and practical catalytic method for the preparation of alkylboronates in good to excellent yields (up to 98\%) that is environmentally friendly. To the best of our knowledge, this is the first report of $\mathrm{Cu}^{\mathrm{II}}$-catalysis for this reaction, and also the first example with water as the only solvent. The high efficiency of this protocoli.e. completion in 3 hours or less-allowed the reaction to be run open to air without a detectable amount of autooxidation products being formed. We also provided evidence for the role of catalytic amine in the mechanism of the reaction and determined that preliminary kinetic data is suggestive of an autocatalytic reaction with a proton transfer involved in the rate-determining step. The chiral amines we screened did not show stereoselectivity and suggested that the metal to ligand bonding was not sufficient for the induction of stereochemistry. 


\subsection{References for Chapter 4}

1. Thorpe, S. B.; Calderone, J. A.; Santos, W. L. Unexpected Copper(II) Catalysis: Catalytic Amine Base Promoted $\beta$-Borylation of $\alpha, \beta$-Unsaturated Carbonyl Compounds in Water Org. Lett. 2012, 14, 1918-1921.

2. Hall, D. G. Boronic Acids: Preparation and Applications in Organic Synthesis, Medicine and Materials; 2nd ed.; Wiley-VCH, 2011.

3. Crudden, C. M.; Glasspoole, B. W.; Lata, C. J. Expanding the Scope of Transformations of Organoboron Species: Carbon-Carbon Bond Formation with Retention of Configuration Chem. Commun. 2009, 6704-6716.

4. Imao, D.; Glasspoole, B. W.; Laberge, V. r. S.; Crudden, C. M. Cross Coupling Reactions of Chiral Secondary Organoboronic Esters With Retention of Configuration J. Am. Chem. Soc. 2009, 131, 5024-5025.

5. Ohmura, T.; Awano, T.; Suginome, M. Stereospecific Suzuki-Miyaura Coupling of Chiral $\alpha$ (Acylamino)benzylboronic Esters with Inversion of Configuration J. Am. Chem. Soc. 2010, 132, 13191-13193.

6. Molander, G. A.; Petrillo, D. E. Suzuki-Miyaura Cross-Coupling of Potassium Trifluoroboratohomoenolates Org. Lett. 2008, 10, 1795-1798.

7. Sandrock, D. L.; Jean-Gérard, L.; Chen, C.-y.; Dreher, S. D.; Molander, G. A. Stereospecific Cross-Coupling of Secondary Alkyl $\beta$-Trifluoroboratoamides J. Am. Chem. Soc. 2010, 132, 17108-17110.

8. Lee, J. C.; McDonald, R.; Hall, D. G. Enantioselective Preparation and Chemoselective Cross-Coupling of 1,1-Diboron Compounds Nat Chem 2011, 3, 894-899.

9. Lee, J. C. H.; Hall, D. G. Chiral Boronate Derivatives via Catalytic Enantioselective Conjugate Addition of Grignard Reagents on 3-Boronyl Unsaturated Esters and Thioesters $J$. Am. Chem. Soc. 2010, 132, 5544-5545.

10. Schiffner, Julia A.; Müther, K.; Oestreich, M. Enantioselective Conjugate Borylation Angew. Chem. Int. Ed. 2010, 49, 1194-1196.

11. Bonet, A.; Sole, C.; Gulyás, H.; Fernández, E. Boron Conjugate Additions on Electron Deficient Olefins Towards Selective 1,3-Difunctionalization Curr. Org. Chem. 2010, 14, 25312548.

12. Mantilli, L.; Mazet, C. Copper-Catalyzed Asymmetric $\beta$-Boration of $\alpha, \beta$-Unsaturated Carbonyl Derivatives ChemCatChem 2010, 2, 501-504.

13. Ito, H.; Yamanaka, H.; Tateiwa, J.; Hosomi, A. Boration of an $\alpha, \beta$-enone using a diboron promoted by a copper(I)-phosphine mixture catalyst Tetrahedron Lett. 2000, 41, 6821-6825. 
14. Takahashi, K.; Takagi, J.; Ishiyama, T.; Miyaura, N. Synthesis of 1-Alkenylboronic Esters via Palladium-Catalyzed Cross-Coupling Reaction of Bis(pinacolato)diboron with 1-Alkenyl Halides and Triflates Chem. Lett. 2000, 29, 126-127.

15. Takahashi, K.; Ishiyama, T.; Miyaura, N. A Borylcopper Species Generated from Bis(pinacolato)diboron and its Additions to $\alpha, \beta$-Unsaturated Carbonyl Compounds and Terminal Alkynes J. Organomet. Chem. 2001, 625, 47-53.

16. Mun, S.; Lee, J.-E.; Yun, J. Copper-Catalyzed $\beta$-Boration of $\alpha, \beta$-Unsaturated Carbonyl Compounds: Rate Acceleration by Alcohol Additives Org. Lett. 2006, 8, 4887-4889.

17. Lee, J. E.; Yun, J. Catalytic Asymmetric Boration of $\alpha, \beta$-Unsaturated Esters and Nitriles Angew. Chem. Int. Ed. 2008, 47, 145-147.

18. Lillo, V.; Prieto, A.; Bonet, A.; Díaz-Requejo, M. M.; Ramírez, J.; Pérez, P. J.; Fernández, E. Asymmetric $\beta$-Boration of $\alpha, \beta$-Unsaturated Esters with Chiral (NHC)Cu Catalysts Organometallics 2008, 28, 659-662.

19. Chen, I. H.; Yin, L.; Itano, W.; Kanai, M.; Shibasaki, M. Catalytic Asymmetric Synthesis of Chiral Tertiary Organoboronic Esters through Conjugate Boration of $\beta$-Substituted Cyclic Enones J. Am. Chem. Soc. 2009, 131, 11664-11665.

20. Lillo, V.; Bonet, A.; Fernandez, E. Asymmetric Induction on $\beta$-Boration of $\alpha, \beta$-Unsaturated Compounds: An Inexpensive Approach Dalton Trans. 2009, 2899-2908.

21. Lee, K. S.; Zhugralin, A. R.; Hoveyda, A. H. Efficient C-B Bond Formation Promoted by NHeterocyclic Carbenes: Synthesis of Tertiary and Quaternary B-Substituted Carbons Through Metal-Free Catalytic Boron Conjugate Additions to Cyclic and Acyclic $\alpha, \beta$-Unsaturated Carbonyls J. Am. Chem. Soc. 2009, 131, 7253-7255.

22. Bonet, A.; Gulyas, H.; Fernandez, E. Metal-Free Catalytic Boration at the $\beta$-Position of $\alpha, \beta$ Unsaturated Compounds: A Challenging Asymmetric Induction Angew. Chem. Int. Ed. 2010, 49, 5130-5134.

23. Lawson, Y. G.; Lesley, M. J. G.; Norman, N. C.; Rice, C. R.; Marder, T. B. Platinum Catalysed 1,4-Diboration of $\alpha, \beta$-Unsaturated Ketones Chem. Commun. 1997, 2051-2052.

24. Abu Ali, H.; Goldberg, I.; Srebnik, M. Addition Reactions of Bis(pinacolato)diborane to Carbonyl Enones and Synthesis of (pinacolato) ${ }_{2} \mathrm{BCH}_{2} \mathrm{~B}$ and (pinacolato) ${ }_{2} \mathrm{BCH}_{2} \mathrm{CH}_{2} \mathrm{~B}$ by Insertion and Coupling Organometallics 2001, 20, 3962-3965.

25. Bell, N. J.; Cox, A. J.; Cameron, N. R.; Evans, J. S. O.; Marder, T. B.; Duin, M. A.; Elsevier, C. J.; Baucherel, X.; Tulloch, A. A. D.; Tooze, R. P. Platinum Catalysed 3,4- and 1,4-Diboration of $\alpha, \beta$-Unsaturated Carbonyl Compounds Using Bis-Pinacolatodiboron Chem. Commun. 2004, 1854-1855. 
26. Bonet, A.; Gulyás, H.; Koshevoy, I. O.; Estevan, F.; Sanaú, M.; Úbeda, M. A.; Fernández, E. Tandem $\beta$-Boration/Arylation of $\alpha, \beta$-Unsaturated Carbonyl Compounds by Using a Single Palladium Complex To Catalyse Both Steps Chem. Eur. J. 2010, 16, 6382-6390.

27. Kabalka, G. W.; Das, B. C.; Das, S. Rhodium-Catalyzed 1,4-Addition Reactions of Diboron Reagents to Electron Deficient Olefins Tetrahedron Lett. 2002, 43, 2323-2325.

28. Shiomi, T.; Adachi, T.; Toribatake, K.; Zhou, L.; Nishiyama, H. Asymmetric Beta-Boration of $\alpha, \beta$-Unsaturated Carbonyl Compounds Promoted by Chiral Rhodium-Bisoxazolinylphenyl Catalysts Chem. Commun. 2009, 5987-5989.

29. Hirano, K.; Yorimitsu, H.; Oshima, K. Nickel-Catalyzed $\beta$-Boration of $\alpha, \beta$-Unsaturated Esters and Amides with Bis(pinacolato)diboron Org. Lett. 2007, 9, 5031-5033.

30. Kajiwara, T.; Terabayashi, T.; Yamashita, M.; Nozaki, K. Syntheses, Structures, and Reactivities of Borylcopper and -Zinc Compounds: 1,4-Silaboration of an $\alpha, \beta$-Unsaturated Ketone to Form a $\gamma$-Siloxyallylborane Angew. Chem. Int. Ed. 2008, 47, 6606-6610.

31. Gao, M.; Thorpe, S. B.; Santos, W. L. $\mathrm{sp}^{2}-\mathrm{sp}^{3}$ Hybridized Mixed Diboron: Synthesis, Characterization and Copper-Catalyzed $\beta$-Boration of $\alpha, \beta$-Unsaturated Conjugated Compounds Org. Lett. 2009, 11, 3478-3481.

32. Thorpe, S. B.; Guo, X.; Santos, W. L. Regio- and Stereoselective Copper-Catalyzed $\beta$ Borylation of Allenoates by a Preactivated Diboron Chem. Commun. 2011, 47, 424-426.

33. Gao, M.; Thorpe, S. B.; Kleeberg, C.; Slebodnick, C.; Marder, T. B.; Santos, W. L. Structure and Reactivity of a Preactivated $\mathrm{sp}^{2}-\mathrm{sp}^{3}$ Diboron Reagent: Catalytic Regioselective Boration of $\alpha, \beta$-Unsaturated Conjugated Compounds J. Org. Chem. 2011, 76, 3997-4007.

34. Molander, G. A.; McKee, S. A. Copper-Catalyzed $\beta$-Boration of $\alpha, \beta$-Unsaturated Carbonyl Compounds with Tetrahydroxydiborane Org. Lett. 2011, 13, 4684-4687.

35. Henderson, R. K.; Jimenez-Gonzalez, C.; Constable, D. J. C.; Alston, S. R.; Inglis, G. G. A.; Fisher, G.; Sherwood, J.; Binks, S. P.; Curzons, A. D. Expanding GSK's Solvent Selection Guide - Embedding sustainability into Solvent Selection Starting at Medicinal Chemistry Green Chem. 2011, 13 .

36. Sheldon, R. Organic Synthesis; Past, Present and Future Chem. Ind. 1992, 903.

37. Watson, W. J. W. How do the Fine Chemical, Pharmaceutical, and Related Industries Approach Green Chemistry and Sustainability? Green Chem. 2012, 14.

38. Andrews, I.; Cui, J.; Dudin, L.; Dunn, P.; Hayler, J.; Hinkley, B.; Hughes, D.; Kaptein, B.; Lorenz, K.; Mathew, S.; Rammeloo, T.; Wang, L.; Wells, A.; White, T. D. Green Chemistry Articles of Interest to the Pharmaceutical Industry Org. Process Res. Dev. 2010, 14, 770-780.

39. Tao, J.; Xu, J.-H. Biocatalysis in Development of Green Pharmaceutical Processes Curr. Opin. Chem. Biol. 2009, 13, 43-50. 
40. Horvath, I. T. Solvents from Nature Green Chem. 2008, 10, 1024-1028.

41. Constable, D. J. C.; Jimenez-Gonzalez, C.; Henderson, R. K. Perspective on Solvent Use in the Pharmaceutical Industry Org. Process Res. Dev. 2007, 11, 133-137.

42. Chea, H.; Sim, H. S.; Yun, J. Ligandless Copper-Catalyzed $\beta$-Boration of $\alpha, \beta$-Unsaturated Compounds in Aqueous Solution Bull. Korean Chem. Soc. 2010, 31, 551-552.

43. Chea, H.; Sim, H. S.; Yun, J. Copper-Catalyzed Conjugate Addition of Diboron Reagents to $\alpha, \beta$-Unsaturated Amides: Highly Reactive Copper-1,2-Bis(diphenylphosphino)benzene Catalyst System Adv. Synth. Catal. 2009, 351, 855-858.

44. Sim, H.-S.; Feng, X.; Yun, J. Copper-Catalyzed Enantioselective $\beta$-Boration of Acyclic Enones Chem. Eur. J. 2009, 15, 1939-1943.

45. Takahashi, K.; Ishiyama, T.; Miyaura, N. Addition and Coupling Reactions of Bis(pinacolato)diboron Mediated by $\mathrm{CuCl}$ in the Presence of Potassium Acetate Chem. Lett. 2000, 982-983.

46. Fleming, W. J.; Muller-Bunz, H.; Lillo, V.; Fernandez, E.; Guiry, P. J. Axially Chiral P-N Ligands for the Copper Catalyzed $\beta$-Borylation of $\alpha, \beta$-Unsaturated Esters Org. Biomol. Chem. 2009, 7, 2520-2524.

47. Chen, I. H.; Kanai, M.; Shibasaki, M. Copper(I)-Secondary Diamine Complex-Catalyzed Enantioselective Conjugate Boration of Linear $\beta, \beta$-Disubstituted Enones Org. Lett. 2010, 12, 4098-4101.

48. Feng, X.; Yun, J. Catalytic Enantioselective Boron Conjugate Addition to Cyclic Carbonyl Compounds: A New Approach to Cyclic $\beta$-Hydroxy Carbonyls Chem. Commun. 2009, 65776579 .

49. Park, J. K.; Lackey, H. H.; Rexford, M. D.; Kovnir, K.; Shatruk, M.; McQuade, D. T. A Chiral 6-Membered N-Heterocyclic Carbene Copper(I) Complex That Induces High Stereoselectivity Org. Lett. 2010, 12, 5008-5011.

50. Ozutsumi, K.; Kawashima, T. Structure of Copper(II)-Bpy and -Phen Complexes: EXAFS and Spectrophotometric Studies on the Structure of Copper(II) Complexes with 2,2'-Bipyridine and 1,10-Phenanthroline in Aqueous Solution Inorg. Chim. Acta 1991, 180, 231-238.

51. Ibrahem, I.; Breistein, P.; Córdova, A. One-Pot Three-Component Catalytic Enantioselective Synthesis of Homoallylboronates Angew. Chem. Int. Ed. 2011, DOI: 10.1002/anie.201105458.

52. Rostovtsev, V. V.; Green, L. G.; Fokin, V. V.; Sharpless, K. B. A Stepwise Huisgen Cycloaddition Process: Copper(I)-Catalyzed Regioselective "Ligation" of Azides and Terminal Alkynes Angew. Chem. Int. Ed. 2002, 41, 2596-2599. 
53. Wang, Q.; Chan, T. R.; Hilgraf, R.; Fokin, V. V.; Sharpless, K. B.; Finn, M. G. Bioconjugation by Copper(I)-Catalyzed Azide-Alkyne [3 + 2] Cycloaddition J. Am. Chem. Soc. 2003, 125, 3192-3193.

54. Martell Arthur, E. Chelates of Ascorbic Acid In Ascorbic Acid: Chemistry, Metabolism, and Uses; American Chemical Society: 1982; Vol. 200, pp 153-178.

55. Clegg, W.; Dai, C. Y.; Lawlor, F. J.; Marder, T. B.; Nguyen, P.; Norman, N. C.; Pickett, N. L.; Power, W. P.; Scott, A. J. Lewis-Base Adducts of the Diborane Compounds $\mathrm{B}_{2}\left(1,2-\mathrm{E}_{2} \mathrm{C}_{6} \mathrm{H}_{4}\right)_{2}$ (E=O or S) Dalton Trans. 1997, 839-846.

56. Clegg, W.; Elsegood, M. R. J.; Lawlor, F. J.; Norman, N. C.; Pickett, N. L.; Robins, E. G.; Scott, A. J.; Nguyen, P.; Taylor, N. J.; Marder, T. B. Structural Studies of Bis-Catecholate, BisDithiocatecholate, and Tetraalkoxy Diborane Compounds Inorg. Chem. 1998, 37, 5289-5293.

57. Kokatla, H. P.; Thomson, P. F.; Bae, S.; Doddi, V. R.; Lakshman, M. K. Reduction of Amine N-Oxides by Diboron Reagents J. Org. Chem. 2011, 76, 7842-7848.

58. Leussing, D. L.; Hansen, R. C. The Copper(II)-Pyridine Complexes and their Reaction with Hydroxide Ions J. Am. Chem. Soc. 1957, 79, 4270-4273.

59. Espenson, J. H. Chemical Kinetics and Reaction Mechanisms; McGraw-Hill ; Primis Custom: New York, 2002.

60. Mata-Perez, F.; Perez-Benito, J. F. The Kinetic Rate Law for Autocatalytic Reactions $J$. Chem. Educ. 1987, 64, 925.

61. Zhao, H. T.; Dang, L.; Marder, T. B.; Lin, Z. Y. DFT Studies on the Mechanism of the Diboration of Aldehydes Catalyzed by Copper(I) Boryl Complexes J. Am. Chem. Soc. 2008, 130, 5586-5594.

62. Emsley, J.; Ernst, R.; Hathaway, B.; Warren, K.; Hathaway, B. A New Look at the Stereochemistry and Electronic Properties of Complexes of the Copper(II) Ion; Springer Berlin / Heidelberg: 1984; Vol. 57, pp 55-118.

63. Crabtree, R. H. The Organometallic Chemistry of the Transition Metals; Wiley: Hoboken, N.J., 2009.

64. Daka, P.; Xu, Z.; Alexa, A.; Wang, H. Primary Amine-Metal Lewis Acid Bifunctional Catalysts Based on a Simple Bidentate Ligand: Direct Asymmetric Aldol Reaction Chem. Commun. 2011, 47.

65. Schiffner, J. A.; Müther, K.; Oestreich, M. Enantioselective Conjugate Borylation Angew. Chem. Int. Ed. 2010, 49, 1194-1196. 


\section{Chapter 5 Experimental}

\subsection{General methods:}

All reactions in Chapters 2 and 3 were performed oven-dried glassware under nitrogen atmosphere using standard Schlenk techniques. All reactions in Chapter 4 were carried out open to air. Solvents were purchased from Fisher Scientific. Tetrahydrofuran, dichloromethane, acetonitrile and N,N-dimethylformamide for reaction solvents were prepared using an Innovative Technology Pure Solv-MD solvent purification system. De-ionized water was used straight from the house DI water tap and was not degassed or further purified. Bis(pinacolato)diboron was purchased from Boron Molecular and donated by AllyChem. All other commercial catalysts and substrates were purchased and used as received. TLC analyses were performed using EMD silica gel $60 \mathrm{~F}_{254}$ plates.

\subsection{Instrumentation:}

${ }^{1}$ H NMR spectra were recorded on either a JEOL EclipsePlus-500 or a Varian Inova-400 spectrometer. Chemical shifts are reported in ppm with the solvent resonance as the internal standard $\left(\mathrm{CDCl}_{3}: 7.26 \mathrm{ppm}\right.$ or acetone- $\left.d_{6}: 2.09 \mathrm{ppm}\right)$. Data are reported as follows: chemical shift, multiplicity $(\mathrm{s}=$ singlet, $\mathrm{d}=$ doublet, $\mathrm{t}=$ triplet, $\mathrm{q}=$ quartet, $\mathrm{m}=$ multiplet $)$, coupling

constants (Hz), and assignment. ${ }^{13} \mathrm{C}$ NMR spectra were recorded on a JEOL EclipsePlus-500 spectrometer. Chemical shifts are reported in ppm with the solvent resonance as the internal standard $\left(\mathrm{CDCl}_{3}: 77.16\right.$ ppm or acetone- $d_{6}$ methyl: 29.84$)$. The carbon directly attached to boron was not observed due to quadrupolar relaxation. ${ }^{11} \mathrm{~B}$ NMR spectra were recorded on a JEOL EclipsePlus-500 spectrometer. Chemical shifts are reported in ppm using boron trifluoride 
diethyl etherate as an external standard $\left[\mathrm{BF}_{3} \mathrm{O}\left(\mathrm{C}_{2} \mathrm{H}_{5}\right)_{2}: 0 \mathrm{ppm}\right] .{ }^{19} \mathrm{~F}$ NMR spectra $\left({ }^{1} \mathrm{H}\right.$ decoupled $)$ were recorded on a Bruker Avance II-500 spectrometer. Chemical shifts are reported in ppm using trifluoroacetic acid as an external standard $\left(\mathrm{CF}_{3} \mathrm{CO}_{2} \mathrm{H}: 0 \mathrm{ppm}\right)$. High resolution mass spectra (HRMS) were performed on an Agilent LC-ESI-TOF. Gas chromatography (GC) analyses were performed on a Hewlett Packard 6890 Series GC system coupled to a HP 5973 Mass Selective Detector. The column was an Agilent DB-5MS with a length of 30 m, I.D. of $250 \mu \mathrm{m}$, and film thickness of $0.25 \mu \mathrm{m}$. UV-Vis spectra were measured on a Molecular Devices SpectraMax Plus384 Absorbance Microplate Reader. Chiral analysis was performed on an Agilent 1100 Series HPLC using a Chiracel OD column. Elemental Microanalyses were performed by Atlantic Microlab, Georgia.

\subsection{Synthetic procedures - Chapter 2}

\section{4,8-dimethyl-2-(4,4,5,5-tetramethyl-1,3,2-dioxaborolan-2-yl)-1,3,6,2-dioxazaborocane}

\section{(2.13):}

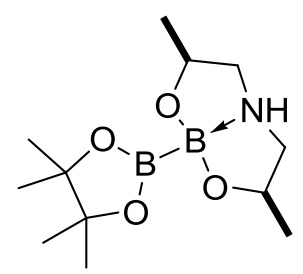

cis-2

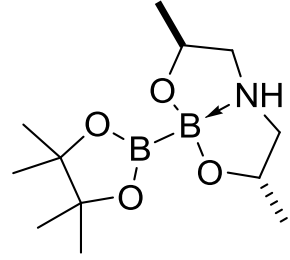

trans-2

To a solution of bis(pinacolato)diboron 2.3 (10 g, 39.4 mmol $)$ in diethyl ether $(160 \mathrm{~mL})$ was added bis $(2-$ hydroxypropyl)amine $(5.73 \mathrm{~g}, 43.3 \mathrm{mmol})$ in $\mathrm{CH}_{2} \mathrm{Cl}_{2}(20$ $\mathrm{mL})$. After 5 minutes, a white precipitate appeared and the reaction mixture was stirred at room temperature for 48 hours. The white solid was filtered and washed with copious amount of diethyl ether to provide the desired product $2(6.6 \mathrm{~g}, 62 \%$, trans:cis 1:1.2), which was sufficiently pure to perform the $\beta$-boration experiments. Recrystallization using $\mathrm{CH}_{2} \mathrm{Cl}_{2}$ and EtOac (1:2) afforded analytically pure product. [Starting material 2.3 could be recovered by purification using flash silica gel chromatography (1:1 
hexane:EtOAc) (3.1g, 31\%).] White solid. (cis/trans): ${ }^{1} \mathrm{H} \mathrm{NMR}\left(500 \mathrm{MHz}, \mathrm{CD}_{3} \mathrm{CN}\right) \delta 5.45$ (s, br, $1 \mathrm{H}, \mathrm{cis}), 5.18(\mathrm{~s}, \mathrm{br}, 1 \mathrm{H}$, trans), 4.13-4.04 (m, $2 \mathrm{H}$, cis; $1 \mathrm{H}$, trans), 3.70- $3.63(\mathrm{~m}, 1 \mathrm{H}$, trans), 3.32-3.27 (m, 1H, trans), $2.83(\mathrm{dd}, \mathrm{J}=11.7,4.5 \mathrm{~Hz}, 2 \mathrm{H}$, cis), $2.69(\mathrm{dd}, \mathrm{J}=11.5,3.7 \mathrm{~Hz}, 1 \mathrm{H}$, trans), 2.51-2.45 (m, 2H, cis), 2.27-2.22 (m, $1 \mathrm{H}$, trans), $1.92-1.86(\mathrm{~m}, 1 \mathrm{H}$, trans $), 1.15(\mathrm{~s}, 12 \mathrm{H}$, cis; $12 \mathrm{H}$, trans), $1.13(\mathrm{~d}, \mathrm{~J}=6.2 \mathrm{~Hz}, 3 \mathrm{H}$, trans), $1.12(\mathrm{~d}, \mathrm{~J}=6.2 \mathrm{~Hz}, 3 \mathrm{H}$, trans), $1.07(\mathrm{~d}, \mathrm{~J}=6.0$ $\mathrm{Hz}, 6 \mathrm{H}, \mathrm{cis}) ;{ }^{13} \mathrm{C}$ NMR $\left(125 \mathrm{MHz}, \mathrm{CD}_{3} \mathrm{CN}\right.$ ) $\delta 81.40$ (cis), 81.29 (trans), 70.68 (cis), 67.47 (trans), 66.82 (trans), 57.96 (trans), 57.82 (cis), 56.44 (trans), 24.71 (trans), 24.69 (trans), 24.65 (cis), 20.36 (cis), 19.04 (trans), 18.32 (trans); ${ }^{11} \mathrm{~B} \mathrm{NMR}\left(160 \mathrm{MHz}, \mathrm{CD}_{3} \mathrm{CN}\right) \delta 35.51$ ( $\left.s p^{2}-\mathrm{B}\right)$, $8.95\left(s p^{3}-\mathrm{B}\right)$; IR (NaCl) 3074, 2972, 2928, 2883, 1369, 1250, 1115, 1022, 970, 854, $806 \mathrm{~cm}-1$; HRMS (ESI+): Calcd for $\mathrm{C}_{12} \mathrm{H}_{26} \mathrm{~B}_{2} \mathrm{NO}_{4}$ [M+H]: 270.2048, Found: 270.2046; Calcd for $\mathrm{C}_{12} \mathrm{H}_{25} \mathrm{~B}_{2} \mathrm{NNaO}_{4}$ [M+Na]: 292.1867, Found: 292.1865; Elemental Analysis: Calcd for $\mathrm{C}_{12} \mathrm{H}_{25} \mathrm{~B}_{2} \mathrm{NO}_{4}$ : C, 53.59; H, 9.37; N, 5.21; Found: C, 53.69; H, 9.41; N, 5.14.

General procedure 1 for the $\beta$-boration of compounds 2.14a-n (Tables 2.1 and 2.2):

In a $25 \mathrm{~mL} 2$ neck round bottom flask (oven or flame dried under vacuum and purged with nitrogen) was added copper(I) chloride (3.68mg, $0.037 \mathrm{mmol}) . \mathrm{CH}_{2} \mathrm{Cl}_{2}(0.5 \mathrm{ml})$ was added and the suspension was stirred for 2 minutes. Mixed diboron $2.13(400 \mathrm{mg}, 1.487 \mathrm{mmol})$ in $\mathrm{CH}_{2} \mathrm{Cl}_{2}(12 \mathrm{ml})$ was added by syringe and the suspension was stirred for another 10 minutes (the solution turned brown). The mixture was then cooled in an ice bath and benzyl acrylate 2.14a $(121 \mathrm{mg}, 0.744 \mathrm{mmol})$ followed by methanol $(0.120 \mathrm{~mL}, 2.97 \mathrm{mmol})$ were added by syringe. The solution was allowed to warm to room temperature and stirred until no starting material was detected by TLC. The reaction mixture was filtered through a pad of celite, concentrated and 2.15a was purified by silica gel chromatography. 


\section{Characterization of $\beta$-boration products 2.15a-n:}

\section{benzyl 3-(4,4,5,5-tetramethyl-1,3,2-dioxaborolan-2-yl)propanoate (2.15a):}

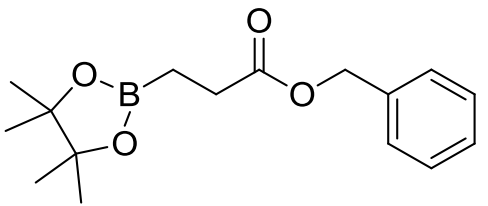

Compound 2.15a was synthesized using General Procedure 1 and purified by flash chromatography on silica gel to afford a yellow oil; ${ }^{1} \mathrm{H}$ NMR $\left(500 \mathrm{MHz}, \mathrm{CDCl}_{3}\right) \delta 7.52-7.27(\mathrm{~m}, 5 \mathrm{H}), 5.11(\mathrm{~s}$, 2H), $2.50(\mathrm{t}, \mathrm{J}=7.5 \mathrm{~Hz}, 2 \mathrm{H}), 1.22(\mathrm{~s}, 12 \mathrm{H}), 1.05(\mathrm{t}, \mathrm{J}=7.5 \mathrm{~Hz}, 2 \mathrm{H}) ;{ }^{13} \mathrm{C} \mathrm{NMR}(125 \mathrm{MHz}$, $\left.\mathrm{CDCl}_{3}\right) \delta 174.52,136.35,128.55,128.14,128.12,83.31,66.13,28.91,24.82,6.36 ;{ }^{11} \mathrm{~B}$ NMR $\left(160 \mathrm{MHz}, \mathrm{CDCl}_{3}\right): \delta 33.36$; IR $(\mathrm{NaCl}) 2978,1738,1381,1319,1142,970,698 \mathrm{~cm}^{-1}$; HRMS (ESI+): Calcd for $\mathrm{C}_{16} \mathrm{H}_{24} \mathrm{BO}_{4}[\mathrm{M}+\mathrm{H}]$ : 291.1768, Found: 291.1765; Calcd for $\mathrm{C}_{16} \mathrm{H}_{23} \mathrm{BNaO}_{4}$ [M+Na]: 313.1587, Found: 313.1588.

methyl 3-(4,4,5,5-tetramethyl-1,3,2-dioxaborolan-2-yl)propanoate (2.15b):

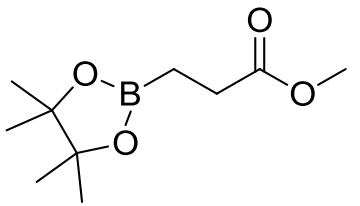

Compound 2.15b was synthesized using General Procedure 1 and purified by flash chromatography on silica gel to afford a colorless oil; ${ }^{1} \mathrm{H}$ NMR $\left(500 \mathrm{MHz}, \mathrm{CDCl}_{3}\right) \delta 3.63(\mathrm{~s}, 3 \mathrm{H}), 2.42(\mathrm{t}, \mathrm{J}=7.5 \mathrm{~Hz}, 2 \mathrm{H}), 1.22(\mathrm{~s}, 12 \mathrm{H})$, $1.00(\mathrm{t}, \mathrm{J}=7.5 \mathrm{~Hz}, 2 \mathrm{H}) ;{ }^{13} \mathrm{C}$ NMR $\left(125 \mathrm{MHz}, \mathrm{CDCl}_{3}\right) \delta 175.14,83.30,51.56,29.76,28.67$, 24.82; ${ }^{11} \mathrm{~B}$ NMR (160 MHz, $\left.\mathrm{CDCl}_{3}\right): \delta 33.36$; IR (NaCl) 2980, 1740, 1381, 1319, 1144, 970, 847 $\mathrm{cm}^{-1}$; HRMS (ESI+): Calcd for $\mathrm{C}_{10} \mathrm{H}_{20} \mathrm{BO}_{4}[\mathrm{M}+\mathrm{H}]$ : 215.1455, Found: 215.1447; Calcd for $\mathrm{C}_{10} \mathrm{H}_{19} \mathrm{BNaO}_{4}[\mathrm{M}+\mathrm{Na}]: 237.1274$, Found: 237.1268 .

ethyl 3-(4,4,5,5-tetramethyl-1,3,2-dioxaborolan-2-yl)propanoate (2.15c):<smiles>CCOC(=O)CCB1OC(C)(C)C(C)(C)O1</smiles> 
${ }^{1} \mathrm{H}$ NMR $\left(400 \mathrm{MHz}, \mathrm{CDCl}_{3}\right) \delta 4.08(\mathrm{q}, \mathrm{J}=7.1 \mathrm{~Hz}, 2 \mathrm{H}), 2.40(\mathrm{t}, \mathrm{J}=7.5 \mathrm{~Hz}, 2 \mathrm{H}), 1.23-1.20(\mathrm{~m}$, 15H), $0.99(\mathrm{t}, \mathrm{J}=7.5 \mathrm{~Hz}, 2 \mathrm{H}) ;{ }^{13} \mathrm{C} \mathrm{NMR}\left(125 \mathrm{MHz}, \mathrm{CDCl}_{3}\right) \delta 174.71,83.25,60.27,28.89$, 24.82, 14.31; ${ }^{11} \mathrm{~B}$ NMR (160 MHz, $\left.\mathrm{CDCl}_{3}\right): \delta 33.43$; IR (NaCl) 2980, 1736, 1381, 1319, 1144 , 970, $849 \mathrm{~cm}^{-1}$; HRMS (ESI+): Calcd for $\mathrm{C}_{11} \mathrm{H}_{22} \mathrm{BO}_{4}[\mathrm{M}+\mathrm{H}]: 229.1611$, Found: 229.1609; Calcd for $\mathrm{C}_{10} \mathrm{H}_{21} \mathrm{BNaO}_{4}$ [M+Na]: 251.1431, Found: 251.1428.

tert-butyl 3-(4,4,5,5-tetramethyl-1,3,2-dioxaborolan-2-yl)propanoate (2.15d):

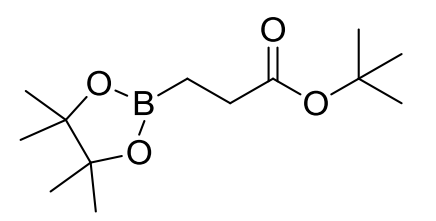

Compound 2.15d was synthesized using General Procedure 1 and purified by flash chromatography on silica gel to afford a colorless oil; ${ }^{1} \mathrm{H}$ NMR (500 MHz, $\left.\mathrm{CDCl}_{3}\right) \delta 2.34(\mathrm{t}, \mathrm{J}=7.5 \mathrm{~Hz}, 2 \mathrm{H}), 1.42(\mathrm{~s}, 9 \mathrm{H})$, $1.23(\mathrm{~s}, 12 \mathrm{H}), 0.96(\mathrm{t}, \mathrm{J}=7.5 \mathrm{~Hz}, 2 \mathrm{H}) ;{ }^{13} \mathrm{C} \mathrm{NMR}\left(125 \mathrm{MHz}, \mathrm{CDCl}_{3}\right) \delta 174.11,83.19,79.87$, 30.03, 29.78, 28.18, 24.86; ${ }^{11} \mathrm{~B} \mathrm{NMR}\left(160 \mathrm{MHz}, \mathrm{CDCl}_{3}\right): \delta 33.66 ; \mathrm{IR}(\mathrm{NaCl}) 2978,1730,1369$, 1319, 1140, 970, $845 \mathrm{~cm}^{-1}$; HRMS (ESI+): Calcd for $\mathrm{C}_{13} \mathrm{H}_{25} \mathrm{BNaO}_{4}$ [M+Na]: 279.1744, Found: 279.1749.

butyl 3-(4,4,5,5-tetramethyl-1,3,2-dioxaborolan-2-yl)propanoate (2.15e):

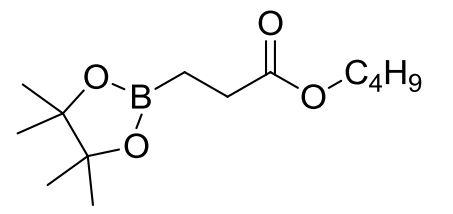

Compound 2.15e was synthesized using General Procedure 1 and purified by flash chromatography on silica gel to afford a colorless oil; ${ }^{1} \mathrm{H}$ NMR (500 MHz, $\left.\mathrm{CDCl}_{3}\right) \delta 4.05(\mathrm{t}, \mathrm{J}=6.7 \mathrm{~Hz}, 2 \mathrm{H}), 2.42(\mathrm{t}, \mathrm{J}=$ $7.5 \mathrm{~Hz}, 2 \mathrm{H}), 1.61-1.56(\mathrm{~m}, 2 \mathrm{H}), 1.40-1.32(\mathrm{~m}, 2 \mathrm{H}), 1.23(\mathrm{~s}, 12 \mathrm{H}), 1.01(\mathrm{t}, \mathrm{J}=7.5 \mathrm{~Hz}, 2 \mathrm{H}), 0.91$ $(\mathrm{t}, \mathrm{J}=7.4 \mathrm{~Hz}, 3 \mathrm{H}) ;{ }^{13} \mathrm{C} \mathrm{NMR}\left(125 \mathrm{MHz}, \mathrm{CDCl}_{3}\right) \delta 174.83,83.27,64.23,30.81,29.78,28.90$, 24.84, 19.20, 13.79; ${ }^{11} \mathrm{~B}$ NMR (160 MHz, $\left.\mathrm{CDCl}_{3}\right): \delta 33.58 ; \mathrm{IR}(\mathrm{NaCl}) 2963,2932,1738,1381$, 1319, 1144, 970, $841 \mathrm{~cm}^{-1}$; HRMS (ESI+): Calcd for $\mathrm{C}_{13} \mathrm{H}_{26} \mathrm{BO}_{4}[\mathrm{M}+\mathrm{H}]:$ 257.1924, Found: 257.1926; Calcd for $\mathrm{C}_{13} \mathrm{H}_{25} \mathrm{BNaO}_{4}[\mathrm{M}+\mathrm{Na}]: 279.1744$, Found: 279.1748. 
methyl 2-methyl-3-(4,4,5,5-tetramethyl-1,3,2-dioxaborolan-2-yl)propanoate (2.15f):

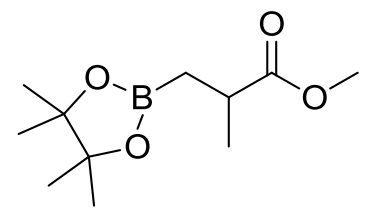

Compound 2.15f was synthesized using General Procedure 1 and purified by flash chromatography on silica gel to afford a colorless oil; ${ }^{1} \mathrm{H}$ NMR $\left(400 \mathrm{MHz}, \mathrm{CDCl}_{3}\right) \delta 3.65$ (s, 3H), 2.68 (sextet, J = $\left.7.2 \mathrm{~Hz}, 1 \mathrm{H}\right), 1.24$ (s, 6H), $1.23(\mathrm{~s}, 6 \mathrm{H}), 1.20(\mathrm{~d}, \mathrm{~J}=7.1 \mathrm{~Hz}, 3 \mathrm{H}), 1.12(\mathrm{dd}, \mathrm{J}=15.9,7.7 \mathrm{~Hz}, 1 \mathrm{H}), 0.93(\mathrm{dd}, \mathrm{J}=15.8,7.3$ $1 \mathrm{H}) ;{ }^{13} \mathrm{C}$ NMR $\left(125 \mathrm{MHz}, \mathrm{CDCl}_{3}\right) \delta 177.75,83.23,51.59,35.39,24.83,19.44 ;{ }^{11} \mathrm{~B}$ NMR $(160$ $\left.\mathrm{MHz}, \mathrm{CDCl}_{3}\right): \delta 33.21 ; \mathrm{IR}(\mathrm{NaCl}) 2980,1738,1373,1321,1146,1125,968,849 \mathrm{~cm}^{-1}$; HRMS (ESI+): Calcd for $\mathrm{C}_{11} \mathrm{H}_{22} \mathrm{BO}_{4}[\mathrm{M}+\mathrm{H}]$ : 229.1611, Found: 229.1610; Calcd for $\mathrm{C}_{10} \mathrm{H}_{21} \mathrm{BNaO}_{4}$ [M+Na]: 251.1431, Found: 251.1428.

ethyl 2-methyl-3-(4,4,5,5-tetramethyl-1,3,2-dioxaborolan-2-yl)propanoate (2.15g):

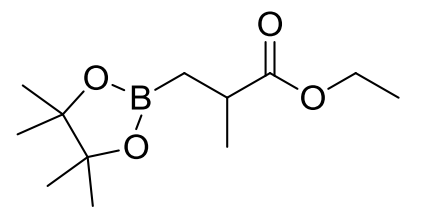

Compound 2.15g was synthesized using General Procedure $\mathbf{1}$ and purified by flash chromatography on silica gel to afford a colorless oil; ${ }^{1} \mathrm{H}$ NMR (500 MHz, $\left.\mathrm{CDCl}_{3}\right) \delta$ 4.17-4.02 (m, 2H), 2.64 (sextet, J = 7.1 $\mathrm{Hz}, 1 \mathrm{H}), 1.25-1.22(\mathrm{~m}, 15 \mathrm{H}), 1.18(\mathrm{~d}, \mathrm{~J}=7.0 \mathrm{~Hz}, 3 \mathrm{H}), 1.12(\mathrm{dd}, \mathrm{J}=15.9,7.5 \mathrm{~Hz}, 1 \mathrm{H}), 0.91$ (dd, J $=15.9,7.4 \mathrm{~Hz}, 1 \mathrm{H}) ;{ }^{13} \mathrm{C} \mathrm{NMR}\left(125 \mathrm{MHz}, \mathrm{CDCl}_{3}\right) \delta 177.35,83.19,60.21,35.48,24.83,19.42$, 16.31, 14.31; ${ }^{11} \mathrm{~B}$ NMR (160 MHz, $\left.\mathrm{CDCl}_{3}\right): \delta 33.20$; IR (NaCl) 2980, 1734, 1373, 1321, 1146, 970, $847 \mathrm{~cm}^{-1}$; HRMS (ESI+): Calcd for $\mathrm{C}_{12} \mathrm{H}_{24} \mathrm{BO}_{4}[\mathrm{M}+\mathrm{H}]: 243.1768$, Found: 243.1767; Calcd for $\mathrm{C}_{12} \mathrm{H}_{23} \mathrm{BNaO}_{4}[\mathrm{M}+\mathrm{Na}]: 265.1587$, Found: 265.1583.

benzyl 2-methyl-3-(4,4,5,5-tetramethyl-1,3,2-dioxaborolan-2-yl)propanoate (2.15h):<smiles>CC(CB1OC(C)(C)C(C)(C)O1)C(=O)OCc1ccccc1</smiles>

Compound 2.15h was synthesized using General Procedure 1 and purified by flash chromatography on silica gel to afford a yellow 
oil; ${ }^{1} \mathrm{H}$ NMR (500 MHz, $\left.\mathrm{CDCl}_{3}\right) \delta$ 7.35-7.27 (m, 5H), $5.10(\mathrm{q}, \mathrm{J}=12.5 \mathrm{~Hz}, 2 \mathrm{H}), 2.73$ (sextet, J = $7.2 \mathrm{~Hz}, 1 \mathrm{H}), 1.26-1.19(\mathrm{~m}, 15 \mathrm{H}), 1.17(\mathrm{dd}, \mathrm{J}=15.9,7.5 \mathrm{~Hz}, 1 \mathrm{H}), 0.95(\mathrm{dd}, \mathrm{J}=15.9,7.5 \mathrm{~Hz}, 1 \mathrm{H})$

${ }^{13} \mathrm{C}$ NMR $\left(125 \mathrm{MHz}, \mathrm{CDCl}_{3}\right) \delta 177.16,136.49,128.54,128.05,128.00,83.26,66.05,35.52$, 24.83, 19.42; ${ }^{11} \mathrm{~B}$ NMR $\left(160 \mathrm{MHz}, \mathrm{CDCl}_{3}\right): \delta$ 33.07; IR (NaCl) 2978, 1734, 1371, 1321, 1144 , 968, 847, $698 \mathrm{~cm}^{-1}$; HRMS (ESI+): Calcd for $\mathrm{C}_{17} \mathrm{H}_{26} \mathrm{BO}_{4}[\mathrm{M}+\mathrm{H}]$ : 305.1924, Found: 305.1929; Calcd for $\mathrm{C}_{17} \mathrm{H}_{25} \mathrm{BNaO}_{4}[\mathrm{M}+\mathrm{Na}]: 327.1744$, Found: 327.1750 .

\section{4-(4,4,5,5-tetramethyl-1,3,2-dioxaborolan-2-yl)butan-2-one (2.15i):}

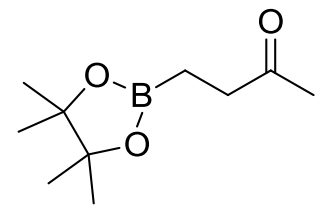

Compound 2.15i was synthesized using General Procedure $\mathbf{1}$ and purified by flash chromatography on silica gel to afford a colorless oil; ${ }^{1} \mathrm{H}$ NMR (500 $\mathrm{MHz}, \mathrm{CDCl} 3) \delta 2.57(\mathrm{t}, \mathrm{J}=7.1 \mathrm{~Hz}, 2 \mathrm{H}), 2.11(\mathrm{~s}, 3 \mathrm{H}), 1.22(\mathrm{~s}, 12 \mathrm{H}), 0.88(\mathrm{t}$, $\mathrm{J}=7.1 \mathrm{~Hz}, 2 \mathrm{H}) ;{ }^{13} \mathrm{C}$ NMR $(125 \mathrm{MHz}, \mathrm{CDCl} 3) \delta 209.31,83.17,38.51,29.43,24.82 ;{ }^{11} \mathrm{~B}$ NMR (160 MHz, CDCl3): $\delta 33.47$; IR (NaCl) 2980, 1717, 1379, 1315, 1146, 968, $849 \mathrm{~cm}^{-1}$; HRMS (ESI+): Calcd for $\mathrm{C}_{10} \mathrm{H}_{20} \mathrm{BO}_{3}[\mathrm{M}+\mathrm{H}]$ : 199.1506, Found: 199.1497; Calcd for $\mathrm{C}_{10} \mathrm{H}_{23} \mathrm{BNO}_{3}$ [M+NH 4 ]: 216.1771, Found: 216.1761; Calcd for $\mathrm{C}_{10} \mathrm{H}_{19} \mathrm{BNaO}_{3}$ [M+Na]: 221.1325, Found: 221.1315.

\section{4-phenyl-4-(4,4,5,5-tetramethyl-1,3,2-dioxaborolan-2-yl)butan-2-one (2.15j):}

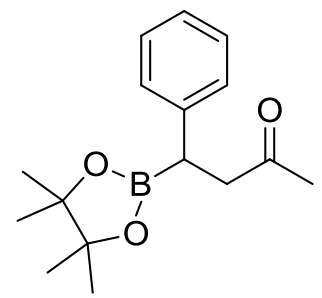

Compound 2.15j was synthesized using General Procedure $\mathbf{1}$ and purified by flash chromatography on silica gel to afford a yellow oil; ${ }^{1} \mathrm{H}$ NMR (500 $\left.\mathrm{MHz}, \mathrm{CDCl}_{3}\right) \delta$ 7.27-7.17 (m, 4H), 7.15-7.10 (m, 1H), $3.03(\mathrm{dd}, \mathrm{J}=18.3$, $10.8 \mathrm{~Hz}, 1 \mathrm{H}), 2.82(\mathrm{dd}, \mathrm{J}=18.3,5.3 \mathrm{~Hz}, 1 \mathrm{H}), 2.63(\mathrm{dd}, \mathrm{J}=10.8,5.3 \mathrm{~Hz}$

1H), $2.12(\mathrm{~s}, 3 \mathrm{H}), 1.21(\mathrm{~s}, 6 \mathrm{H}), 1.15(\mathrm{~s}, 6 \mathrm{H}) ;{ }^{13} \mathrm{C} \mathrm{NMR}\left(125 \mathrm{MHz}, \mathrm{CDCl}_{3}\right) \delta$ 208.41, 141.76, $128.55,128.27,125.62,83.47,47.59,29.67,26.99,24.60,24.59 ;{ }^{11} \mathrm{~B}$ NMR $\left(160 \mathrm{MHz}, \mathrm{CDCl}_{3}\right)$ : 
$\delta$ 32.16; IR (NaCl) 2978, 1713, 1366, 1319, 1144, 966, 854, $702 \mathrm{~cm}^{-1}$; HRMS (ESI+): Calcd for $\mathrm{C}_{16} \mathrm{H}_{24} \mathrm{BO}_{3}[\mathrm{M}+\mathrm{H}]: 275.1819$, Found: 275.1819; Calcd for $\mathrm{C}_{16} \mathrm{H}_{27} \mathrm{BNO}_{3}$ [M+NH $\left.\mathrm{H}_{4}\right]$ : 292.2084, Found: 292.2091; Calcd for $\mathrm{C}_{16} \mathrm{H}_{23} \mathrm{BNaO}_{3}$ [M+Na]: 297.1638, Found: 297.1644.

\section{3-(4,4,5,5-tetramethyl-1,3,2-dioxaborolan-2-yl)cyclopentanone (2.15k):}

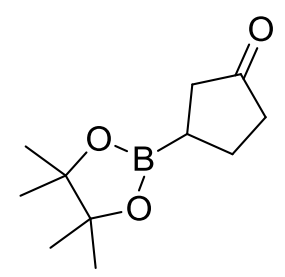

Compound 2.15k was synthesized using General Procedure 1 and purified by

flash chromatography on silica gel to afford a colorless oil; ${ }^{1} \mathrm{H}$ NMR $(500$ $\left.\mathrm{MHz}, \mathrm{CDCl}_{3}\right) \delta$ 2.34-2.17 (m, 2H), 2.16-2.04 (m, 3H), 1.88-1.77 (m, 1H), 1.69-1.55 (m, 1H), $1.23(\mathrm{~s}, 12 \mathrm{H}) ;{ }^{13} \mathrm{C}$ NMR $\left(125 \mathrm{MHz}, \mathrm{CDCl}_{3}\right) \delta 221.12,83.58,40.26,38.99$, 25.33, 24.81, 24.80, 19.65; ${ }^{11} \mathrm{~B}$ NMR (160 MHz, $\left.\mathrm{CDCl}_{3}\right): \delta 33.48$; IR (NaCl) 2978, 1742, 1385 , 1323, 1144, 968, $858 \mathrm{~cm}^{-1}$; HRMS (ESI+): Calcd for $\mathrm{C}_{11} \mathrm{H}_{20} \mathrm{BO}_{3}[\mathrm{M}+\mathrm{H}]$ : 211.1506, Found: 211.1492; Calcd for $\mathrm{C}_{11} \mathrm{H}_{23} \mathrm{BNO}_{3}$ [M+NH 4 ]: 228.1771, Found: 228.1762; Calcd for $\mathrm{C}_{11} \mathrm{H}_{19} \mathrm{BNaO}_{3}[\mathrm{M}+\mathrm{Na}]: 233.1325$, Found: 233.1313.

\section{3-(4,4,5,5-tetramethyl-1,3,2-dioxaborolan-2-yl)propanenitrile (2.15l):}

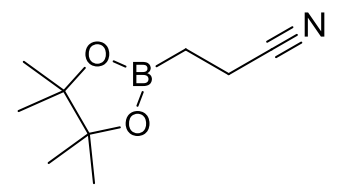

Compound 2.15I was synthesized using General Procedure 1 and purified by flash chromatography on silica gel to afford a colorless oil; ${ }^{1} \mathrm{H}$ NMR

$\left(500 \mathrm{MHz}, \mathrm{CDCl}_{3}\right) \delta 2.39(\mathrm{t}, \mathrm{J}=7.9 \mathrm{~Hz}, 2 \mathrm{H}), 1.24(\mathrm{~s}, 12 \mathrm{H}), 1.17(\mathrm{t}, \mathrm{J}=7.9 \mathrm{~Hz}, 2 \mathrm{H}) ;{ }^{13} \mathrm{C} \mathrm{NMR}$ $\left(125 \mathrm{MHz}, \mathrm{CDCl}_{3}\right) \delta 121.11,84.04,24.85,11.98,7.58 ;{ }^{11} \mathrm{~B} \mathrm{NMR}\left(160 \mathrm{MHz}, \mathrm{CDCl}_{3}\right): \delta 32.70 ;$ IR (NaCl) 2980, 2249, 1379, 1337, 1144, 968, $843 \mathrm{~cm}^{-1}$; HRMS (ESI+): Calcd for $\mathrm{C}_{9} \mathrm{H}_{20} \mathrm{BN}_{2} \mathrm{O}_{2}$ [M+NH 4 ]: 199.1618, Found: 199.1616; Calcd for $\mathrm{C}_{9} \mathrm{H}_{16} \mathrm{BNNaO}_{2}$ [M+Na]: 204.1172, Found: 204.1174. 


\section{N,N-dimethyl-3-(4,4,5,5-tetramethyl-1,3,2-dioxaborolan-2-yl)propanamide $(2.15 \mathrm{~m})$ :}

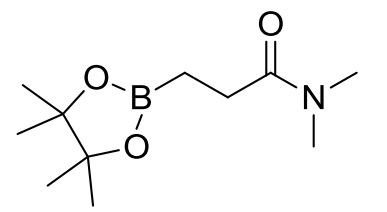

Compound 2.15m was synthesized using General Procedure 1 and purified by flash chromatography on silica gel to afford a yellow oil; ${ }^{1} \mathrm{H}$ NMR (500 MHz, $\left.\mathrm{CDCl}_{3}\right) \delta 2.96(\mathrm{~s}, 3 \mathrm{H}), 2.91(\mathrm{~s}, 3 \mathrm{H}), 2.43(\mathrm{t}, \mathrm{J}=7.4 \mathrm{~Hz}$, 2H), $1.22(\mathrm{~s}, 12 \mathrm{H}), 0.94(\mathrm{t}, \mathrm{J}=7.4 \mathrm{~Hz}, 2 \mathrm{H}) ;{ }^{13} \mathrm{C} \mathrm{NMR}\left(125 \mathrm{MHz}, \mathrm{CDCl}_{3}\right) \delta$ 174.26, 82.73, 37.10, 35.67, 28.36, 24.89, 7.07; ${ }^{11} \mathrm{~B}$ NMR (160 MHz, $\left.\mathrm{CDCl}_{3}\right): \delta 32.18$; IR (NaCl) 2976, 2932, 1647, 1375, 1327, 1148, 970, $874 \mathrm{~cm}^{-1}$; HRMS (ESI+): Calcd for $\mathrm{C}_{11} \mathrm{H}_{23} \mathrm{BNO}_{3}[\mathrm{M}+\mathrm{H}]: 228.1771$, Found: 228.1772; Calcd for $\mathrm{C}_{11} \mathrm{H}_{22} \mathrm{BNNaO}_{3}$ [M+Na]: 250.1590, Found: 250.1586 .

\section{4,4-bis(4,4,5,5-tetramethyl-1,3,2-dioxaborolan-2-yl)butan-2-one (2.15n):}

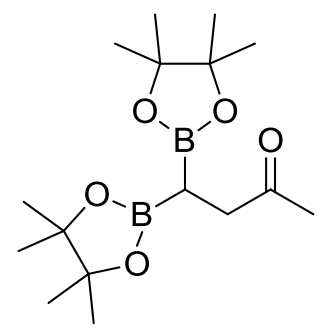

Compound 2.15n was synthesized using General Procedure 1 (with $2 \mathrm{X}$ diboron) and purified by flash chromatography on silica gel to afford colorless oil; ${ }^{1} \mathrm{H}$ NMR $\left(500 \mathrm{MHz}, \mathrm{CDCl}_{3}\right): \delta 2.72(\mathrm{~d}, \mathrm{~J}=8.1 \mathrm{~Hz}, 2 \mathrm{H}), 2.09$ (s, 3H), $1.22(\mathrm{~s}, 12 \mathrm{H}), 1.19(\mathrm{~s}, 12 \mathrm{H}), 0.95(\mathrm{t}, \mathrm{J}=7.9 \mathrm{~Hz}, 1 \mathrm{H}) ;{ }^{13} \mathrm{C}$ NMR $(125$ $\left.\mathrm{MHz}, \mathrm{CDCl}_{3}\right): \delta 209.03,83.15,40.73,29.18,24.82,24.60 ;{ }^{11} \mathrm{~B}$ NMR $\left(160 \mathrm{MHz}, \mathrm{CDCl}_{3}\right): \delta$ 32.73; IR (NaCl) 2978, 1717, 1369, 1314, 1142, 970, $853 \mathrm{~cm}^{-1}$; HRMS (ESI+): Calcd for $\mathrm{C}_{16} \mathrm{H}_{31} \mathrm{~B}_{2} \mathrm{O}_{5}[\mathrm{M}+\mathrm{H}]:$ 325.2358, Found: 325.2345; Calcd for $\mathrm{C}_{16} \mathrm{H}_{30} \mathrm{~B}_{2} \mathrm{NaO}_{5}$ [M+Na]: 347.2177, Found: 347.2163 . 
Synthesis and characterization of enantiopure mixed diboron $(R, R)-2.13($ Scheme 2.4$):^{1}$

$\left(2 R, 2^{\prime} R\right)-1,1^{\prime}-($ benzylazanediyl)bis(propan-2-ol) $(R, R)-2.17$ :

To a 1-neck round-bottomed flask was added $R$ - (+)-propylene oxide $(R)$ reaction mixture was diluted with methanol $(5 \mathrm{~mL})$ and heated to $60{ }^{\circ} \mathrm{C}$. After $8 \mathrm{~h}$, the reaction mixture was concentrated via rotary evaporator and purified by silica gel column chromatography to provide the product as a yellow oil $(1.54 \mathrm{~g}, 88 \%)$. TLC (alumina, EtOAc): $\mathrm{Rf}=0.44 .{ }^{1} \mathrm{H}$ NMR $\left(500 \mathrm{MHz}, \mathrm{CDCl}_{3}\right) \delta=7.36-7.26(\mathrm{~m}, 5 \mathrm{H}), 3.9-3.80(\mathrm{~m}, 3 \mathrm{H}), 3.50(\mathrm{~d}, J=$ $13.6 \mathrm{~Hz}, 1 \mathrm{H}), 2.78(\mathrm{~s}, 2 \mathrm{H}, \mathrm{OH}), 2.45(\mathrm{~d}, J=5.2 \mathrm{~Hz}, 2 \mathrm{H}), 2.44(\mathrm{~d}, J=7.5 \mathrm{~Hz}, 2 \mathrm{H}), 1.09(\mathrm{~d}, J=$ $6.2 \mathrm{~Hz}, 6 \mathrm{H}) ;{ }^{13} \mathrm{C} \mathrm{NMR}\left(125 \mathrm{MHz}, \mathrm{CDCl}_{3}\right) \delta=138.6,129.1,128.6,127.5,64.1,62.2,59.9,20.4$.

\section{$\left(2 R, 2^{\prime} R\right)-1,1^{\prime}$-azanediylbis(propan-2-ol) $(R, R)-2.18$ :}

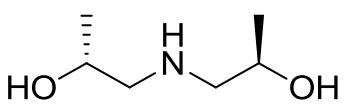

To a $25 \mathrm{ml}$ round-bottomed flask was added 10\% Pd/C (32 mg, 0.297 $\mathrm{mmol})$ and $(R, R)-2.17(1.328 \mathrm{~g}, 5.95 \mathrm{mmol})$ in methanol $(6 \mathrm{~mL})$ to give a black suspension. The reaction mixture was stirred under a hydrogen atmosphere at room temperature for $6 \mathrm{~h}$. After completion of the reaction, the suspension was filtered through a pad of celite and concentrated to give the product as light yellow oil (729 mg, 92\%). TLC (alumina, $5 \% \mathrm{MeOH} / \mathrm{EtOAc}): \mathrm{Rf}=0.30 .{ }^{1} \mathrm{H}$ NMR $\left(500 \mathrm{MHz}, \mathrm{CDCl}_{3}\right) \delta=3.84-3.78(\mathrm{~m}, 2 \mathrm{H}), 2.67(\mathrm{dd}, J=$ 12.1, 3.0 Hz, 2H), $2.49(\mathrm{dd}, J=12.1,9.0 \mathrm{~Hz}, 2 \mathrm{H}), 1.16(\mathrm{~d}, J=6.2 \mathrm{~Hz}, 6 \mathrm{H}) ;{ }^{13} \mathrm{C} \mathrm{NMR}(125 \mathrm{MHz}$, $\left.\mathrm{CDCl}_{3}\right) \delta=66.2,56.8,20.7$ 
(4R,8R)-4,8-dimethyl-2-(4,4,5,5-tetramethyl-1,3,2-dioxaborolan-2-yl)-1,3,6,2-

dioxazaborocane, $(4 R, 8 R)-2.13$ :

To a solution of bis(pinacolato)diboron $2.3(1 \mathrm{~g}, 3.94 \mathrm{mmol})$ in diethyl ether room temperature for $24 \mathrm{~h}$. The white solid was collected by filtration and washed with copious amount of diethyl ether to provide the desired product $(4 R, 8 R)-\mathbf{2 . 1 3}(660 \mathrm{mg}, 62 \%)$, which was sufficiently pure to perform the $\beta$-boration experiments. Recrystallization from acetonitrile yielded colorless single crystals suitable for X-ray diffraction analysis. ${ }^{1} \mathrm{H}$ NMR $(500 \mathrm{MHz}$, $\left.\mathrm{CD}_{3} \mathrm{CN}\right) \delta=5.14(\mathrm{~s}, \mathrm{br}, 1 \mathrm{H}), 4.11-4.04(\mathrm{~m}, 1 \mathrm{H}), 3.70-3.63(\mathrm{~m}, 1 \mathrm{H}), 3.32-3.27(\mathrm{~m}, 1 \mathrm{H}), 2.69(\mathrm{dd}$, $J=11.5,3.7 \mathrm{~Hz}, 1 \mathrm{H}), 2.28-2.22(\mathrm{~m}, 1 \mathrm{H}), 1.92-1.86(\mathrm{~m}, 1 \mathrm{H}), 1.16(\mathrm{~s}, 12 \mathrm{H}), 1.13(\mathrm{~d}, J=6.2 \mathrm{~Hz}$ $3 \mathrm{H}), 1.12(\mathrm{~d}, J=6.2 \mathrm{~Hz}, 3 \mathrm{H}) ;{ }^{13} \mathrm{C}$ NMR $\left(125 \mathrm{MHz}, \mathrm{CD}_{3} \mathrm{CN}\right) \delta=81.4,67.5,66.8,58.0,56.4$, 24.7, 24.7, 19.0, 18.3; ${ }^{11} \mathrm{~B}$ NMR (160 MHz, CD $\left.{ }_{3} \mathrm{CN}\right) \delta=35.51\left(s p^{2}-\mathrm{B}\right), 8.95\left(s p^{3}-\mathrm{B}\right) ; \mathrm{IR}(\mathrm{NaCl})$ 3074, 2971, 2929, 2883, 1368, 1251, 1114, 1024, 971, 854, $804 \mathrm{~cm}^{-1}$; HRMS (ESI+): Calcd for $\mathrm{C}_{12} \mathrm{H}_{26} \mathrm{~B}_{2} \mathrm{NO}_{4}[\mathrm{M}+\mathrm{H}]^{+}:$270.2048, Found: 270.2047.

\section{General procedure 2: re-optimized $\beta$-boration protocol (Tables 2.4 and 2.5, Scheme 2.5):}

To a $25 \mathrm{~mL} 2$ neck round bottom flask was added copper(I) chloride (7.36mg, 0.074 mmol). $\mathrm{CH}_{2} \mathrm{Cl}_{2}(0.5 \mathrm{~mL})$ was added and the suspension was stirred for $2 \mathrm{~min}$. PDIPA diboron 2.13 (240mg, $0.892 \mathrm{mmol}$ ) in $\mathrm{CH}_{2} \mathrm{Cl}_{2}(7.2 \mathrm{~mL}$ ) was added by syringe and the suspension was stirred for another $5 \mathrm{~min}$ (the solution turned brown). Cyclohexen-2-one 2.21h (71.5mg, 0.744 mmol) followed by $\mathrm{CF}_{3} \mathrm{CH}_{2} \mathrm{OH}(0.214 \mathrm{~mL}, 2.97 \mathrm{mmol})$ were added by syringe. The solution was heated to $40{ }^{\circ} \mathrm{C}$ and stirred until no starting material was detected by TLC. The reaction 
mixture was filtered through a pad of celite, concentrated and purified by silica gel chromatography.

\section{Characterization of compounds 8h-16:}

\section{1-(4,4,5,5-tetramethyl-1,3,2-dioxaborolan-2-yl)pentan-3-one (2.22b):}

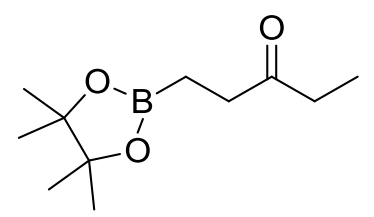

Compound 2.22b was synthesized using General Procedure 2 and purified by flash chromatography on silica gel to afford a colorless oil; ${ }^{1} \mathrm{H} \mathrm{NMR}$ $\left(500 \mathrm{MHz}, \mathrm{CDCl}_{3}\right) \delta=2.54(\mathrm{t}, J=7.2 \mathrm{~Hz}, 2 \mathrm{H}), 2.40(\mathrm{q}, J=7.4 \mathrm{~Hz}, 2 \mathrm{H})$,

$1.22(\mathrm{~s}, 12 \mathrm{H}), 1.04(\mathrm{t}, J=7.4 \mathrm{~Hz}, 3 \mathrm{H}), 0.90(\mathrm{t}, J=7.2 \mathrm{~Hz}, 2 \mathrm{H}) ;{ }^{13} \mathrm{C} \mathrm{NMR}\left(125 \mathrm{MHz}, \mathrm{CDCl}_{3}\right) \delta=$ 212.1, 83.2, 37.1, 35.4, 24.8, 8.1; ${ }^{11} \mathrm{~B}$ NMR (160 MHz, $\left.\mathrm{CDCl}_{3}\right): \delta=33.58 ; \mathrm{IR}(\mathrm{NaCl}) 2978$, 1715, 1377, 1315, 1148, 968, $837 \mathrm{~cm}^{-1}$; HRMS (ESI+): Calcd for $\mathrm{C}_{11} \mathrm{H}_{22} \mathrm{BO}_{3}[\mathrm{M}+\mathrm{H}]^{+}: 213.1662$, Found: 213.1662.

\section{1-(4,4,5,5-tetramethyl-1,3,2-dioxaborolan-2-yl)hexan-3-one (2.22c):}

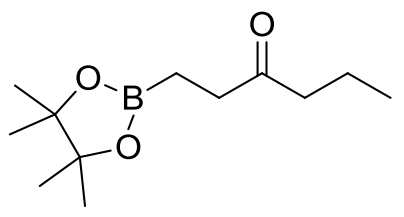

Compound 2.22c was synthesized using General Procedure 2 and purified by flash chromatography on silica gel to afford a colorless oil; ${ }^{1} \mathrm{H}$ NMR $\left(500 \mathrm{MHz}, \mathrm{CDCl}_{3}\right) \delta=2.54(\mathrm{t}, J=7.1 \mathrm{~Hz}, 2 \mathrm{H}), 2.36(\mathrm{t}, J=$ $7.3 \mathrm{~Hz}, 2 \mathrm{H}), 1.59$ (sextet, $J=7.3 \mathrm{~Hz}, 2 \mathrm{H}), 1.22(\mathrm{~s}, 12 \mathrm{H}), 0.89(\mathrm{t}, J=7.4 \mathrm{~Hz}, 5 \mathrm{H}) ;{ }^{13} \mathrm{C} \mathrm{NMR}(125$ $\left.\mathrm{MHz}, \mathrm{CDCl}_{3}\right) \delta=211.7,83.1,44.2,37.6,24.8,17.6,13.8 ;{ }^{11} \mathrm{~B} \mathrm{NMR}\left(160 \mathrm{MHz}, \mathrm{CDCl}_{3}\right): \delta=$ 33.54; IR ( $\mathrm{NaCl}) 2976,1712,1379,1315,1148,968,845 \mathrm{~cm}^{-1}$; HRMS (ESI+): Calcd for $\mathrm{C}_{12} \mathrm{H}_{24} \mathrm{BO}_{3}[\mathrm{M}+\mathrm{H}]^{+}:$227.1819, Found: 227.1805. 


\section{4-(4,4,5,5-tetramethyl-1,3,2-dioxaborolan-2-yl)pentan-2-one (2.22d):}

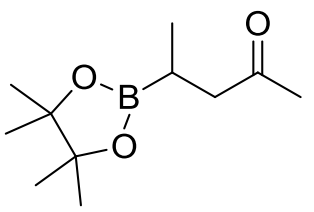

Compound 2.22d was synthesized using General Procedure 2 and purified by flash chromatography on silica gel to afford a colorless oil; ${ }^{1} \mathrm{H}$ NMR (500 $\left.\mathrm{MHz}, \mathrm{CDCl}_{3}\right) \delta=2.55-2.53(\mathrm{~m}, 2 \mathrm{H}), 2.10(\mathrm{~s}, 3 \mathrm{H}), 1.28-1.24(\mathrm{~m}, 1 \mathrm{H}), 1.22$ $(\mathrm{s}, 6 \mathrm{H}), 1.21(\mathrm{~s}, 6 \mathrm{H}), 0.94(\mathrm{~d}, J=7.5 \mathrm{~Hz}, 3 \mathrm{H}) ;{ }^{13} \mathrm{C}$ NMR $\left(125 \mathrm{MHz}, \mathrm{CDCl}_{3}\right) \delta=209.1,83.1$, 47.7, 29.8, 24.8, 24.7, 15.1; ${ }^{11} \mathrm{~B}$ NMR (160 MHz, $\left.\mathrm{CDCl}_{3}\right): \delta=33.79$; IR (NaCl) 2978, 1715, 1369, 1315, 1146, 968, $862 \mathrm{~cm}^{-1}$; HRMS (ESI+): Calcd for $\mathrm{C}_{11} \mathrm{H}_{22} \mathrm{BO}_{3}[\mathrm{M}+\mathrm{H}]^{+}:$213.1662, Found: 213.1639.

\section{5-(4,4,5,5-tetramethyl-1,3,2-dioxaborolan-2-yl)hexan-3-one (2.22e):}

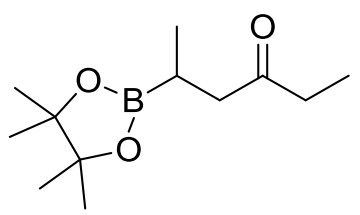

Compound 2.22e was synthesized using General Procedure 2 and purified by flash chromatography on silica gel to afford a colorless oil; ${ }^{1} \mathrm{H}$ NMR $\left(500 \mathrm{MHz}, \mathrm{CDCl}_{3}\right) \delta=2.53-2.51(\mathrm{~m}, 2 \mathrm{H}), 2.38(\mathrm{qd}, J=3.7,7.4 \mathrm{~Hz}, 2 \mathrm{H})$

1.30-1.26 (m, 1H), $1.23(\mathrm{~s}, 6 \mathrm{H}), 1.22(\mathrm{~s}, 6 \mathrm{H}), 1.04(\mathrm{t}, J=7.4 \mathrm{~Hz}, 3 \mathrm{H}), 0.95(\mathrm{~d}, J=7.5 \mathrm{~Hz}, 3 \mathrm{H})$; ${ }^{13} \mathrm{C}$ NMR $\left(125 \mathrm{MHz}, \mathrm{CDCl}_{3}\right) \delta=211.8,83.0,46.3,35.8,24.8,24.7,15.1,8.0 ;{ }^{11} \mathrm{~B}$ NMR $(160$ $\left.\mathrm{MHz}, \mathrm{CDCl}_{3}\right): \delta=33.58 ; \mathrm{IR}(\mathrm{NaCl}) 2976,2934,1713,1369,1315,1146,968,860 \mathrm{~cm}^{-1} ; \mathrm{HRMS}$ (ESI+): Calcd for $\mathrm{C}_{12} \mathrm{H}_{24} \mathrm{BO}_{3}[\mathrm{M}+\mathrm{H}]^{+}:$227.1819, Found: 227.1796.

\section{1,3-diphenyl-3-(4,4,5,5-tetramethyl-1,3,2-dioxaborolan-2-yl)propan-1-one (2.22g):}

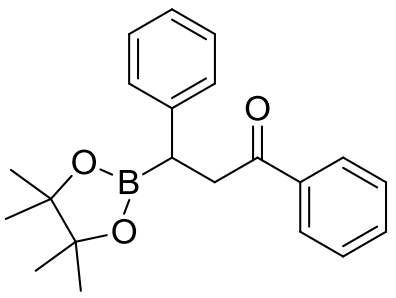

Compound 2.22g was synthesized using General Procedure 2 and purified by flash chromatography on silica gel to afford a yellow oil;

${ }^{1} \mathrm{H}$ NMR $\left(500 \mathrm{MHz}, \mathrm{CDCl}_{3}\right) \delta=7.97-7.95(\mathrm{~m}, 2 \mathrm{H}), 7.59-7.50(\mathrm{~m}, 1 \mathrm{H})$, 7.45-7.42 (m, 2H), 7.34-7.24 (m, 4H), 7.21-7.13 (m, 1H), $3.55(\mathrm{dd}, J=$

$10.9,18.3 \mathrm{~Hz}, 1 \mathrm{H}), 3.42(\mathrm{dd}, J=5.0,18.3 \mathrm{~Hz}, 1 \mathrm{H}), 2.80(\mathrm{dd}, J=5.0,10.9 \mathrm{~Hz}, 1 \mathrm{H}), 1.24(\mathrm{~s}, 6 \mathrm{H})$, 
$1.16(\mathrm{~s}, 6 \mathrm{H}) ;{ }^{13} \mathrm{C}$ NMR $\left(125 \mathrm{MHz}, \mathrm{CDCl}_{3}\right) \delta=199.8,142.0,136.9,133.0,128.6,128.6,128.5$, 128.1, 125.7, 83.5, 43.4, 27.3, 24.7, 24.6; ${ }^{11} \mathrm{~B}$ NMR $\left(160 \mathrm{MHz}, \mathrm{CDCl}_{3}\right): \delta=32.63 ; \mathrm{IR}(\mathrm{NaCl})$ 2978, 1682, 1367, 1321, 1142, 754, $698 \mathrm{~cm}^{-1}$; HRMS (ESI+): Calcd for $\mathrm{C}_{21} \mathrm{H}_{26} \mathrm{BO}_{3}[\mathrm{M}+\mathrm{H}]^{+}$: 337.1975, Found: 337.1981.

\section{3-(4,4,5,5-tetramethyl-1,3,2-dioxaborolan-2-yl)cyclohexanone (2.22h):}

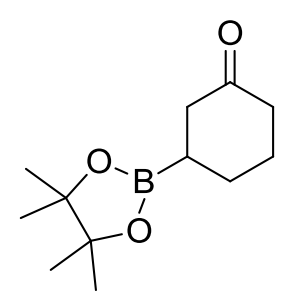

Compound 2.22h was synthesized using General Procedure $\mathbf{2}$ and purified by flash chromatography on silica gel to afford a pale yellow oil; TLC $(20 \%$ EtOAC/Hexanes): $\mathrm{Rf}=0.37 .{ }^{1} \mathrm{H}$ NMR $\left(500 \mathrm{MHz}, \mathrm{CDCl}_{3}\right) \delta=2.39-2.25(\mathrm{~m}$, $4 \mathrm{H}), 2.11-2.01(\mathrm{~m}, 1 \mathrm{H}), 1.89-1.82(\mathrm{~m}, 1 \mathrm{H}), 1.79-1.68(\mathrm{~m}, 1 \mathrm{H}), 1.67-1.59(\mathrm{~m}$,

1H), 1.49-1.40 (m, 1H), $1.22(\mathrm{~s}, 12 \mathrm{H}) ;{ }^{13} \mathrm{C} \mathrm{NMR}\left(125 \mathrm{MHz}, \mathrm{CDCl}_{3}\right) \delta=212.4,83.5,42.6,41.9$, 28.5, 26. 6, 25.1, 24.8, 24.8; ${ }^{11} \mathrm{~B}$ NMR (160 MHz, $\left.\mathrm{CDCl}_{3}\right): \delta=33.11 ; \mathrm{IR}(\mathrm{NaCl}) 2978,1711$, 1383, 1327, 1144, 980, $851 \mathrm{~cm}^{-1}$; HRMS (ESI+): Calcd for $\mathrm{C}_{12} \mathrm{H}_{22} \mathrm{BO}_{3}[\mathrm{M}+\mathrm{H}]^{+}: 225.1662$, Found: 225.1639 .

\section{4-methyl-4-(4,4,5,5-tetramethyl-1,3,2-dioxaborolan-2-yl)pentan-2-one (2.22j):}

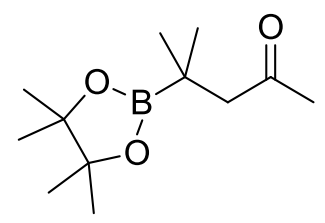

Compound 2.22j was synthesized using General Procedure $\mathbf{2}$ and purified by flash chromatography on silica gel to afford a colorless oil; ${ }^{1} \mathrm{H}$ NMR (500 $\left.\mathrm{MHz}, \mathrm{CDCl}_{3}\right) \delta=2.48(\mathrm{~s}, 2 \mathrm{H}), 2.07(\mathrm{~s}, 3 \mathrm{H}), 1.23(\mathrm{~s}, 12 \mathrm{H}), 0.91(\mathrm{~s}, 6 \mathrm{H}) ;{ }^{13} \mathrm{C}$

NMR $\left(125 \mathrm{MHz}, \mathrm{CDCl}_{3}\right) \delta=208.8,83.0,55.8,30.1,24.7 ;{ }^{11} \mathrm{~B}$ NMR $\left(160 \mathrm{MHz}, \mathrm{CDCl}_{3}\right): \delta=$ 34.10; IR (NaCl) 2976, 2934, 1715, 1367, 1308, 1140, 968, $858 \mathrm{~cm}^{-1}$; HRMS (ESI+): Calcd for $\mathrm{C}_{12} \mathrm{H}_{24} \mathrm{BO}_{3}[\mathrm{M}+\mathrm{H}]^{+}:$227.1819, Found: 227.1814. 


\section{3-methyl-4-(4,4,5,5-tetramethyl-1,3,2-dioxaborolan-2-yl)pentan-2-one (2.22k):}

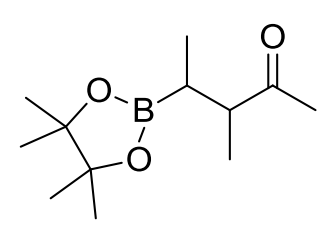

Compound 2.22k was synthesized using General Procedure 2 and purified by flash chromatography on silica gel to afford a colorless oil; ${ }^{1} \mathrm{H}$ NMR (500 $\left.\mathrm{MHz}, \mathrm{CDCl}_{3}\right) \delta=2.59(\mathrm{~m}, 1.21 \mathrm{H}), 2.14(\mathrm{~s}, 0.63 \mathrm{H}$, minor diastereomer $)$, $2.11(\mathrm{~s}, 3 \mathrm{H}$, major diastereomer), $1.26(\mathrm{~m}, 1.21 \mathrm{H}), 1.23(\mathrm{~s}, 12 \mathrm{H}$, major diastereomer), $1.21(\mathrm{~s}$, 2.52H, minor diastereomer), $1.13(\mathrm{~d}, J=7.2 \mathrm{~Hz}, 3 \mathrm{H}$, major diastereomer), 1.12 (d, $J=7.2 \mathrm{~Hz}$, $0.63 \mathrm{H}$, minor diastereomer), $0.91(\mathrm{~d}, J=7.5 \mathrm{~Hz}, 3 \mathrm{H}$, major diastereomer), 0.89 (d, $J=8.5 \mathrm{~Hz}$, 0.63H, minor diastereomer); ${ }^{13} \mathrm{C}$ NMR $\left(125 \mathrm{MHz}, \mathrm{CDCl}_{3}\right): \delta=213.1,83.1,83.0,50.1,49.8$, 28.2, 28.1, 24.8, 24.8, 15.7, 14.8, 13.0, 12.3; ${ }^{11} \mathrm{~B}$ NMR $\left(160 \mathrm{MHz}, \mathrm{CDCl}_{3}\right): \delta=33.63 ; \mathrm{IR}(\mathrm{NaCl})$ 2976, 1711, 1369, 1317, 1146, 968, $856 \mathrm{~cm}^{-1}$; HRMS (ESI+): Calcd for $\mathrm{C}_{12} \mathrm{H}_{24} \mathrm{BO}_{3}[\mathrm{M}+\mathrm{H}]^{+}$: 227.1819.

\section{1-(2-(4,4,5,5-tetramethyl-1,3,2-dioxaborolan-2-yl)cyclohexyl)ethanone (2.22l):}

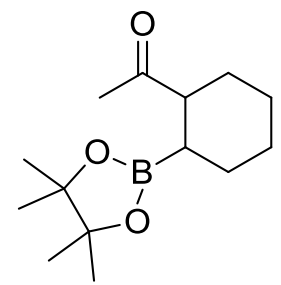

Compound 2.22l was synthesized using General Procedure 2 and purified by

flash chromatography on silica gel to afford a light yellow oil; ${ }^{1} \mathrm{H}$ NMR (500 $\left.\mathrm{MHz}_{\mathrm{CDCl}}\right): \delta=2.57(\mathrm{dt}, J=4.5,7.5 \mathrm{~Hz}, 1 \mathrm{H}$, major diastereomer$), 2.49(\mathrm{dt}$, $J=6.5,13.5 \mathrm{~Hz}, 0.1 \mathrm{H}$, minor diastereomer $), 2.12(\mathrm{~s}, 3.3 \mathrm{H}), 1.88-1.78(\mathrm{~m}$, 2.2H), 1.69-1.65 (m, 1.1H), 1.55-1.50 (m, 1.1H), 1.48-1.42 (m, 2H), 1.41-1.34 (m 2.2H), 1.29$1.26(\mathrm{~m}, 1.1 \mathrm{H}), 1.22(\mathrm{~d}, J=4.3 \mathrm{~Hz}, 13.2 \mathrm{H}) ;{ }^{13} \mathrm{C} \mathrm{NMR}\left(125 \mathrm{MHz}, \mathrm{CDCl}_{3}\right): \delta=212.1,83.2,82.8$ $53.0,52.2,29.9,27.9,27.6,27.6,26.7,26.7,26.5,25.8,25.4,25.2,25.1,24.9,24.8,24.8,24.6$, 24.6; ${ }^{11} \mathrm{~B}$ NMR $\left(160 \mathrm{MHz}, \mathrm{CDCl}_{3}\right): \delta=33.22 ; \mathrm{IR}(\mathrm{NaCl}) 2928,2855,1707,1377,1311,1146$, 970, $852 \mathrm{~cm}^{-1}$; HRMS (ESI+): Calcd for $\mathrm{C}_{14} \mathrm{H}_{26} \mathrm{BO}_{3}[\mathrm{M}+\mathrm{H}]^{+}:$253.1975, Found: 253.1993. 


\section{3-(4,4,5,5-tetramethyl-1,3,2-dioxaborolan-2-yl)pentanal (2.24):}

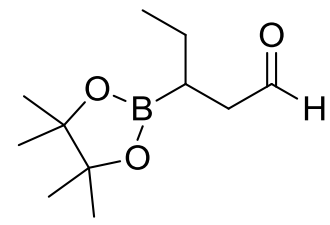

Compound 2.24 was synthesized using General Procedure 2 and purified by

flash chromatography on silica gel to afford a colorless oil; TLC (5\% EtOAc/Hexanes): $\mathrm{Rf}=0.30 .{ }^{1} \mathrm{H}$ NMR $\left(500 \mathrm{MHz}, \mathrm{CDCl}_{3}\right) \delta=9.76(\mathrm{~s}, 1 \mathrm{H})$, $2.58(\mathrm{dd}, J=7.2,18.0 \mathrm{~Hz}, 1 \mathrm{H}), 2.51(\mathrm{dd}, J=7.2,18.0 \mathrm{~Hz}, 1 \mathrm{H}), 1.53-1.46(\mathrm{~m}, 1 \mathrm{H}), 1.43-1.36(\mathrm{~m}$, 1H), 1.32-1.26 (m, 1H), $1.24(\mathrm{~s}, 6 \mathrm{H}), 1.23(\mathrm{~s}, 6 \mathrm{H}), 0.92(\mathrm{t}, J=7.4 \mathrm{~Hz}, 3 \mathrm{H}) ;{ }^{13} \mathrm{C} \mathrm{NMR}(125 \mathrm{MHz}$ $\left.\mathrm{CDCl}_{3}\right) \delta=203.0,83.3,45.6,24.9,24.7,23.6,13.3 ;{ }^{11} \mathrm{~B} \mathrm{NMR}\left(160 \mathrm{MHz}, \mathrm{CDCl}_{3}\right): \delta=33.74 ; \mathrm{IR}$ ( $\mathrm{NaCl}) 2977,1725,1368,1318,1146,968,854 \mathrm{~cm}^{-1}$; HRMS (ESI+): Calcd for $\mathrm{C}_{11} \mathrm{H}_{21} \mathrm{BNaO}_{3}$ $[\mathrm{M}+\mathrm{Na}]^{+}:$235.1481, Found: 235.1484.

\section{2-methyl-3-(4,4,5,5-tetramethyl-1,3,2-dioxaborolan-2-yl)propanal (2.25):}

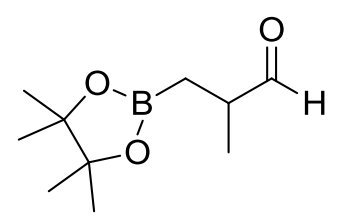

Compound 2.25 was synthesized using General Procedure 2 and purified by flash chromatography on silica gel to afford a colorless oil; TLC (5\% EtOAc/Hexanes): $\mathrm{Rf}=0.21 .{ }^{1} \mathrm{H} \mathrm{NMR}\left(400 \mathrm{MHz}, \mathrm{CDCl}_{3}\right) \delta=9.64(\mathrm{~s}, 1 \mathrm{H})$, $2.56(\mathrm{~m}, 1 \mathrm{H}), 1.25(\mathrm{~s}, 6 \mathrm{H}), 1.24(\mathrm{~s}, 6 \mathrm{H}), 1.15(\mathrm{~d}, J=7.2 \mathrm{~Hz}, 3 \mathrm{H}), 1.05(\mathrm{dd}, J=6.9,15.9 \mathrm{~Hz}, 1 \mathrm{H})$

$0.83(\mathrm{dd}, J=7.7,15.9 \mathrm{~Hz}, 1 \mathrm{H}) ;{ }^{13} \mathrm{C} \mathrm{NMR}\left(125 \mathrm{MHz}, \mathrm{CDCl}_{3}\right) \delta=205.3,83.4,42.7,24.8,15.7$;

${ }^{11}$ B NMR $\left(160 \mathrm{MHz}, \mathrm{CDCl}_{3}\right): \delta=33.38 ; \mathrm{IR}(\mathrm{NaCl}) 2979,1723,1369,1319,1147,968,852 \mathrm{~cm}^{-}$

${ }^{1}$; HRMS (ESI+): Calcd for $\mathrm{C}_{10} \mathrm{H}_{19} \mathrm{BNaO}_{3}[\mathrm{M}+\mathrm{Na}]^{+}:$221.1325, Found: 221.1311. 
$\left(\left[\operatorname{PDIPA} \mathbf{B}_{2}\right][K(\text { thf })]\right)_{2},((2.20) \text { thf })_{2}$ :

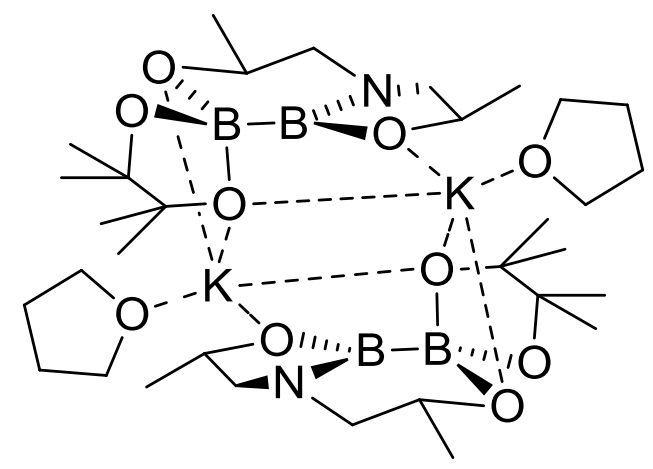

Under an atmosphere of nitrogen $\mathbf{2 . 1 3}(70 \mathrm{mg}, 260$ $\mu \mathrm{mol})$ and $\mathrm{KO}^{t} \mathrm{Bu}(41 \mathrm{mg}, 365 \mu \mathrm{mol}, 1.4$ equiv) were combined in $2 \mathrm{~mL}$ of dry THF. After 3 days, X-ray quality crystals separated, which were washed with $n$ hexane $(2 \times 2 \mathrm{~mL})$ and dried in vacuo to give $27 \mathrm{mg}(36$ $\mu$ mol, 27\%) of a colorless solid. m.p.: $>160^{\circ} \mathrm{C}$ (decomp.); ${ }^{1} \mathrm{H}$ NMR $\left(700 \mathrm{MHz}, \mathrm{THF}-\mathrm{d}_{8}\right): \delta=$ $4.43-4.38$ (m, $1 \mathrm{H}, \mathrm{OCH}(\mathrm{A})), 4.37-4.31$ (m, $\left.1 \mathrm{H}, \mathrm{OCH}\left(\mathrm{A}^{\prime}\right)\right), 4.15-4.09$ (m, $\left.1 \mathrm{H}, \mathrm{OCH}(\mathrm{B})\right)$, $3.63-3.60\left(\mathrm{~m}, 4 \mathrm{H}, \mathrm{CH}_{2} \mathrm{O}(\mathrm{THF})\right), 3.14\left(\mathrm{t}, J=8 \mathrm{~Hz}, 1 \mathrm{H}, \mathrm{CH}_{2} \mathrm{~N}(\mathrm{~A})\right), 3.09$ (t, $J=8 \mathrm{~Hz}, 1 \mathrm{H}$, $\left.\mathrm{CH}_{2} \mathrm{~N}\left(\mathrm{~A}^{\prime}\right)\right), 2.76-2.66\left(\mathrm{~m}, 2 \mathrm{H}, \mathrm{CH}_{2} \mathrm{~N}(\mathrm{~A}, \mathrm{~B})\right), 2.59-2.55\left(\mathrm{~m}, 2 \mathrm{H}, \mathrm{CH}_{2} \mathrm{~N}\left(\mathrm{~A}^{\prime}, \mathrm{B}\right)\right), 1.79-1.76$ $\left(\mathrm{m}, 4 \mathrm{H}, \mathrm{CH}_{2} \mathrm{O}(\mathrm{THF})\right), 1.30\left(\mathrm{~d}, J_{\mathrm{HH}}=6 \mathrm{~Hz}, 3 \mathrm{H}, \mathrm{CH}_{3}\left(\mathrm{~A}^{\prime}\right)\right), 1.19\left(\mathrm{~d}, J=6 \mathrm{~Hz}, 3 \mathrm{H}, \mathrm{CH}_{3}\left(\mathrm{~A}^{\prime}\right)\right)$, 1.09, 1.07, 1.06 (two signals) (s, $6 \mathrm{H}, \mathrm{CH}_{3}\left(\right.$ pin)), 1.04 (d, $J=6 \mathrm{~Hz}, 3 \mathrm{H}, \mathrm{CH}_{3}(\mathrm{~B})$ ), 0.99 (two signals) (s, $3 \mathrm{H}, \mathrm{CH}_{3}\left(\right.$ pin) ), 0.95 (s, $3 \mathrm{H}, \mathrm{CH}_{3}\left(\right.$ pin)); ${ }^{13} \mathrm{C} \mathrm{NMR}\left(175 \mathrm{MHz}, \mathrm{THF}-\mathrm{d}_{8}\right): \delta=78.5$, 78.4, 77.2, 77.0, 74.7, 74.1, 68.4, 66.1, 65.9, 58.2, 57-7, 57.4, 57.3, 27.6, 27.5, 27.3, 27.1 (two signals), 26.7 (two signals), 26.6, 24.6, 23.1, 22.6; ${ }^{11} \mathrm{~B}$ NMR (224 MHz, THF-d 8 ): $\delta=38.1$ (v br s), 5.4 (br s); Anal. Calcd for: $\mathrm{C}_{32} \mathrm{H}_{64} \mathrm{O}_{10} \mathrm{~N}_{2} \mathrm{~B}_{4} \mathrm{~K}_{2}$ : C, 50.68; H, 8.51; N, 3.67\%. Found: C, 50.84; $\mathrm{H}, 8.58 ; \mathrm{N}, 3.61 \%$.

\section{$\underline{\text { X-ray Crystallographic Analysis: }}$}

Crystals were centered on the goniometer of an Oxford Diffraction SuperNova equipped with an Eos detector and operating with $\mathrm{CuK} \alpha$ radiation $(\boldsymbol{R}, \boldsymbol{R})-\mathbf{2 . 1 3}$ or a Bruker SMART 1000 $((\mathbf{2 . 2 0}) \text { thf })_{2}$ diffractometer using MoK $\square$ radiation, respectively. The data collection routine, unit cell refinement, and data processing were carried out with the program CrysAlisPro $((R, R)-2)^{2}$ or 
SMART $^{3}{ }^{3}$ SAINT $^{4}$ and $\operatorname{SADABS}^{5}\left(((\mathbf{1 0}) \mathrm{K} \cdot \text { thf })_{2}\right)$. The structures were solved by direct methods and refined using SHELXTL NT or SHELXTL $6.14 .{ }^{6}$ The final refinement model involved anisotropic displacement parameters for all non-hydrogen atoms and a riding model for all hydrogen atoms. In the case of $(R, R)-\mathbf{2 . 1 3}$, the anisotropic displacement parameters of the pinacol group suggest disorder, but attempts to model 2-position disorder did not improve the overall model and were abandoned. In the structure of $((\mathbf{2 . 2 0}) \text { thf })_{2}$, the THF molecule is partly disordered; two positions were refined (ratio of occupancies: 54:46). Additionally, a part of the diisopropanolamine moiety is disordered (see text). The absolute configuration of $(R, R)-\mathbf{2 . 1 3}$ was established from anomalous dispersion effects (Flack $\mathrm{x}=-0.07(18) ;{ }^{7}$ Hooft P2(true) $=1.000$, $\mathrm{P} 3($ true $)=1.000, \mathrm{P} 3($ rac-twin $)=0.4 \times 1015 ; \mathrm{P} 3($ false $\left.)=0.000, \mathrm{y}=-0.05(7)^{8}\right)$.

\section{$X$-ray data for $(R, R)-2.13$ :}

$\mathrm{C}_{12} \mathrm{H}_{25} \mathrm{~B}_{2} \mathrm{NO}_{4}, \mathrm{Mr}=268.95$, crystal dimensions $0.211 \times 0.072 \times 0.066 \mathrm{~mm}^{3}$, orthorhombic, $P 2{ }_{1} 2_{1} 2_{1}, a=9.5436(2), b=11.7206(3), c=13.6397(3) \AA, V=1525.69(6) \AA^{3}, Z=4, Z^{\prime}=1, \rho_{\text {calcd }}$ $=1.171 \mathrm{~g} / \mathrm{cm}^{3}, \mu=0.673 \mathrm{~mm}^{-1}, \mathrm{CuK}_{\alpha}$ radiation $(1.5418 \AA), \mathrm{T}=100(2) \mathrm{K}, 2 \theta_{\max }=144.5^{\circ}, 9951$ reflections with 2992 unique $[\mathrm{R}(\mathrm{int})=0.0274], \mathrm{R} 1=0.0365$ (for 2852 unique data with $\mathrm{I}>$ $2 \square(\mathrm{I})), \mathrm{wR} 2=0.994$ (all data), max peak/hole $=0.246 /-0.205 \mathrm{e}^{-} / \AA^{3}$.

\section{X-ray data for 2.13:}

$\mathrm{C}_{12} \mathrm{H}_{25} \mathrm{~B}_{2} \mathrm{NO}_{4}, \mathrm{Mr}=268.95$, crystal dimensions $0.51 \times 0.24 \times 0.21 \mathrm{~mm}^{3}$, orthorhombic, $P 2_{1} 2_{1} 2_{1}$, $a=9.5091(3), b=11.8200(3), c=13.6947(4) \AA, V=1539.25(8) \AA^{3}, Z=4, Z^{\prime}=1, \rho_{\text {calcd }}=1.161$ $\mathrm{g} / \mathrm{cm}^{3}, \mu=0.082 \mathrm{~mm}^{-1}$, MoK $\alpha$ radiation $(0.71073 \AA), \mathrm{T}=120(2) \mathrm{K}, 2 \theta_{\max }=54.0^{\circ}, 17150$ reflections with 1927 unique $[R($ int $)=0.0652], R 1=0.0495$ (for 1708 unique data with $\mathrm{I}>2 \square(\mathrm{I})$ ), $\mathrm{wR} 2=0.1433$ (all data), max peak $/$ hole $=0.469 /-0.216 \mathrm{e}^{-} / \AA^{3}$. 


\section{X-ray data for $((2.20) \text { thf })_{2}$ :}

$\mathrm{C}_{16} \mathrm{H}_{32} \mathrm{~B}_{2} \mathrm{KNO}_{5}, \mathrm{Mr}=379.15$, crystal dimensions $0.42 \times 0.31 \times 0.29 \mathrm{~mm}^{3}$, triclinic, $P-1, a=$ 9.8528(3), $b=10.1429(3), c=10.9177(3) \AA, \square=86.801(1)^{\circ}, \square=83.170(1)^{\circ}, \square=69.752(1)^{\circ}, V$ $=1018.12(5) \AA^{3}, Z=2, Z^{\prime}=1, \rho_{\text {calcd }}=1.237 \mathrm{~g} / \mathrm{cm}^{3}, \mu=0.285 \mathrm{~mm}^{-1}, M_{\alpha}$ radiation $(0.71073 \AA$ ), $\mathrm{T}=120(2) \mathrm{K}, 2 \theta_{\max }=56.0^{\circ}, 13552$ reflections with 4906 unique $[\mathrm{R}(\mathrm{int})=0.0356], \mathrm{R} 1=$ 0.0378 (for 4272 unique data with $\mathrm{I}>2 \square(\mathrm{I})$ ), $\mathrm{wR} 2=0.1030$ (all data), max peak/hole $=0.327 /-$ $0.360 \mathrm{e}^{-} / \AA^{3}$.

\subsection{Synthetic procedures for Chapter 3}

\section{Preparation of allenoates:}

Allenoates were prepared following a published procedure (General Procedure 3) by Kwon, as described below. ${ }^{9}$ References for previously reported allenoates are provided in the table below. Spectral data for unreported allenoates follows.

\begin{tabular}{|l|l|l|l|l|}
\hline Substrate & $\mathbf{R}^{1}$ & $\mathbf{R}^{2}$ & $\mathbf{R}^{3}$ & Reference \\
\hline $3.26 \mathrm{a}$ & $\mathrm{H}$ & $\mathrm{H}$ & $\mathrm{Me}$ & J. Chem. Soc. $(\mathrm{C})$ 1969, 2443 \\
\hline $3.26 \mathrm{~b}$ & $\mathrm{H}$ & $\mathrm{H}$ & $\mathrm{Et}$ & Available from Sigma-Aldrich \\
\hline $3.26 \mathrm{c}$ & $\mathrm{H}$ & $\mathrm{H}$ & $\left(\mathrm{CH}_{2}\right)_{3} \mathrm{C}_{6} \mathrm{H}_{5}$ & Unknown in the literature \\
\hline $3.26 \mathrm{~d}$ & $\mathrm{Ph}$ & $\mathrm{H}$ & $\mathrm{Me}$ & Helv. Chim. Acta $1980, \mathbf{6 3}, 438$ \\
\hline $3.26 \mathrm{e}$ & $\mathrm{Ph}$ & $\mathrm{H}$ & $\mathrm{Et}$ & J. Am. Chem. Soc. 2007, 129, 1494 \\
\hline $3.26 \mathrm{f}$ & $\mathrm{Ph}$ & $\mathrm{H}$ & $\left(\mathrm{CH}_{2}\right)_{3} \mathrm{C}_{6} \mathrm{H}_{5}$ & Unknown in the literature \\
\hline $3.26 \mathrm{~g}$ & $\mathrm{Me}$ & $\mathrm{H}$ & $\mathrm{Me}$ & Helv. Chim. Acta $1980, \mathbf{6 3}, 438$ \\
\hline $3.26 \mathrm{~h}$ & $\mathrm{Me}$ & $\mathrm{H}$ & $\mathrm{Et}$ & Org. Synth. 1990, Coll. Vol. 7, 232 \\
\hline $3.26 \mathrm{i}$ & $\mathrm{Me}$ & $\mathrm{H}$ & ${ }^{i} \mathrm{Pr}$ & Unknown in the literature \\
\hline $3.26 \mathrm{j}$ & $\mathrm{Me}$ & $\mathrm{H}$ & ${ }^{t} \mathrm{Bu}$ & Unknown in the literature \\
\hline $3.26 \mathrm{k}$ & $\mathrm{Me}$ & $\mathrm{H}$ & $o-n i t r o b e n z y l$ & Unknown in the literature \\
\hline 3.261 & $\mathrm{Me}$ & $\mathrm{Me}$ & Et & Helv. Chim. Acta 1980, 63, 438 \\
\hline
\end{tabular}




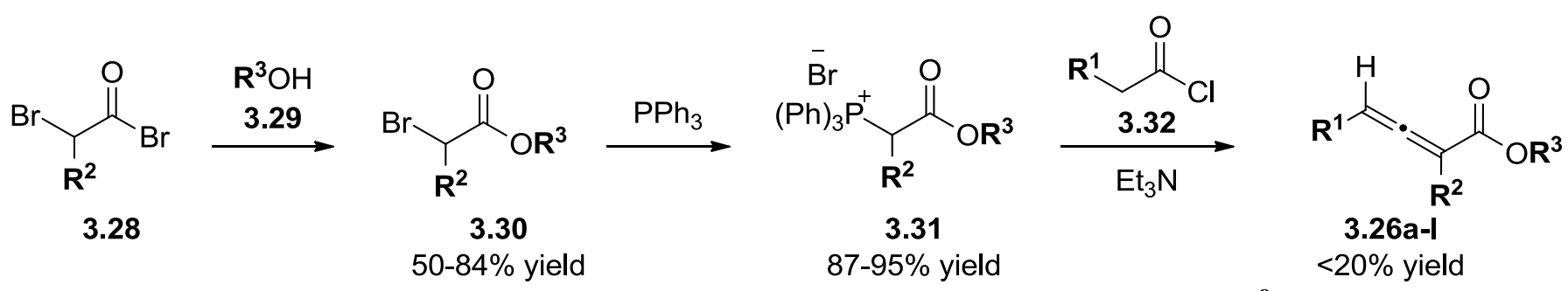

General procedure 3 for the synthesis of allenoates 3.26a-3.261 (Scheme 3.4): ${ }^{9}$

A solution of bromoacetyl bromide $\mathbf{3 . 2 8}$ (1.5 equiv) in dichloromethane was cooled to 0 ${ }^{\circ} \mathrm{C}$ in an ice water bath. Alcohol 3.29 (1 equiv) and triethylamine (1 equiv) were successively added. After stirring overnight, water was added and the organic layer was separated. The aqueous layer was extracted twice more with dichloromethane. The combined extract was washed with brine, dried over sodium sulfate and concentrated by rotary evaporation. The residue was then purified by flash chromatography on silica gel to give bromoester $\mathbf{3 . 3 0}$ (50-84\% yield). The bromoester was then dissolved in benzene and triphenylphosphine (1 equiv) was added. The resulting mixture was further stirred for 24 hours at room temperature and was then filtered and washed with hexane to give phosphonium salt 3.31 (87-95\% yield). To this resulting phosphonium salt was added a 2:1 mixture of hexanes:dichloromethane and the suspension was cooled to $0{ }^{\circ} \mathrm{C}$ in an ice-water bath. 1.1 equivalents of triethylamine were added and the mixture was stirred for 2 hours. An additional 1.1 equivalents of triethylamine were added, followed by dropwise addition of acetyl chloride 3.32. The reaction mixture was stirred overnight, allowing the ice bath to melt. The resulting mixture was poured into a fritted vacuum funnel packed with silica gel and was washed with dichloromethane several times. The combined filtrate was carefully evaporated and purified by either Kugelrohr distillation or flash chromatography on silica gel. 


\section{Characterization of unreported allenoates $(3.26 c, f, i-k)$ :}

\section{3-Phenylpropyl buta-2,3-dienoate (3.26c):}

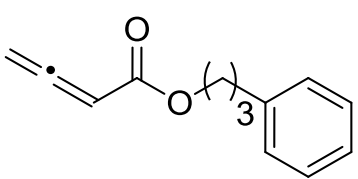

Compound 3.26c was synthesized using General Procedure $\mathbf{3}$ and purified by flash chromatography on silica gel to afford a yellow oil; ${ }^{1} \mathrm{H}$ NMR $\left(500 \mathrm{MHz}, \mathrm{CDCl}_{3}\right) \delta 7.29(\mathrm{t}, J=7.5 \mathrm{~Hz}, 2 \mathrm{H}), 7.19(\mathrm{~m}, J=7.6 \mathrm{~Hz}$,

$3 \mathrm{H}), 5.65(\mathrm{t}, J=6.5 \mathrm{~Hz}, 1 \mathrm{H}), 5.23(\mathrm{~d}, J=6.5 \mathrm{~Hz}, 2 \mathrm{H}), 4.17(\mathrm{t}, J=6.5 \mathrm{~Hz}, 2 \mathrm{H}), 2.70(\mathrm{t}, J=7.7$ $\mathrm{Hz}, 2 \mathrm{H}), 2.03-1.96(\mathrm{~m}, 2 \mathrm{H}) ;{ }^{13} \mathrm{C}$ NMR $(126 \mathrm{MHz}) \delta 215.99,165.89,141.30,128.58,128.55$, 126.15, 88.12, 79.40, 64.39, 32.20, 30.33; HRMS (APCI+): Calcd for $\mathrm{C}_{13} \mathrm{H}_{15} \mathrm{O}_{2}[\mathrm{M}+\mathrm{H}]^{+}$: 203.1072, Found 203.1080; TLC: 1:9 / EtOAc:Hexanes, $\mathrm{R}_{\mathrm{f}}$ 0.39.

\section{3-Phenylpropyl 4-phenylbuta-2,3-dienoate (3.26f):}<smiles>O=C(/C=C/c1ccccc1)O[AlH]c1ccccc1</smiles>

Compound 3.26f was synthesized using General Procedure $\mathbf{3}$ and purified by flash chromatography on silica gel to afford a yellow oil; ${ }^{1} \mathrm{H}$

NMR $\left(500 \mathrm{MHz}, \mathrm{CDCl}_{3}\right) \delta 7.48-7.13(\mathrm{~m}, 10 \mathrm{H}), 6.64(\mathrm{~d}, J=6.4 \mathrm{~Hz}, 1 \mathrm{H}), 6.03(\mathrm{~d}, J=6.4 \mathrm{~Hz}$, 1H), $4.20(\mathrm{t}, J=6.4 \mathrm{~Hz}, 2 \mathrm{H}), 2.74(\mathrm{t}, J=7.6 \mathrm{~Hz}, 2 \mathrm{H}), 2.06-1.94(\mathrm{~m}, 2 \mathrm{H})$; HRMS (APCI+): Calcd for $\mathrm{C}_{19} \mathrm{H}_{19} \mathrm{O}_{2}[\mathrm{M}+\mathrm{H}]^{+}:$279.1380, Found 279.1386; TLC: 1:9 / EtOAc:Hexanes, $\mathrm{R}_{\mathrm{f}} 0.37$.

\section{Isopropyl penta-2,3-dienoate (3.26i):}

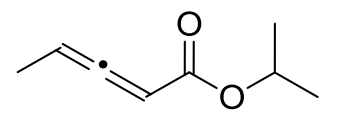

Compound 3.26i was synthesized using General Procedure $\mathbf{3}$ and purified by Kugelrohr distillation to afford a Colorless oil; ${ }^{1} \mathrm{H}$ NMR $(500 \mathrm{MHz}$, $\left.\mathrm{CDCl}_{3}\right) \delta 5.61-5.51(\mathrm{~m}, 1 \mathrm{H}), 5.11-4.99(\mathrm{~m}, 1 \mathrm{H}), 3.19(\mathrm{q}, J=2.6 \mathrm{~Hz}, 1 \mathrm{H}), 1.84-1.77(\mathrm{~m}$, $3 \mathrm{H}), 1.27-1.24(\mathrm{~m}, 6 \mathrm{H})$; HRMS (APCI+): Calcd for $\mathrm{C}_{18} \mathrm{H}_{13} \mathrm{O}_{2}[\mathrm{M}+\mathrm{H}]^{+}:$141.0910, Found 141.0909; TLC: 1:9 / EtOAc:Hexanes, $\mathrm{R}_{\mathrm{f}} 0.45$. 


\section{tert-butyl penta-2,3-dienoate (3.26j):}<smiles>CC=C=CC(=O)OC(C)(C)C</smiles>

Compound 3.26j was synthesized using General Procedure 3 and purified by Kugelrohr distillation to afford a colorless oil; ${ }^{1} \mathrm{H}$ NMR $(500 \mathrm{MHz}$, $\left.\mathrm{CDCl}_{3}\right) \delta 5.61-5.44(\mathrm{~m}, 1 \mathrm{H}), 3.14(\mathrm{q}, J=2.5 \mathrm{~Hz}, 1 \mathrm{H}), 1.87-1.72(\mathrm{~m}, 3 \mathrm{H}), 1.47(\mathrm{~d}, J=6.5 \mathrm{~Hz}$, 9H); GC/MS (EI+): Calcd for $\mathrm{C}_{9} \mathrm{H}_{14} \mathrm{O}_{2}$ : 154, Found 154; TLC: 1:9 / EtOAc:Hexanes, $\mathrm{R}_{\mathrm{f}} 0.50$.

\section{2-Nitrobenzyl penta-2,3-dienoate (3.26k):}

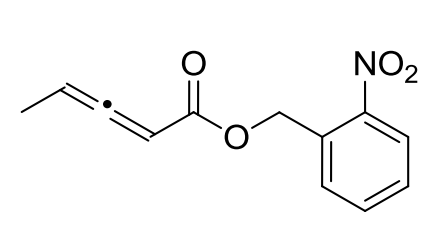

Compound 3.26k was synthesized using General Procedure $\mathbf{3}$ and purified by flash chromatography on silica gel to afford a white solid; ${ }^{1} \mathrm{H}$ NMR $\left(500 \mathrm{MHz}, \mathrm{CDCl}_{3}\right) \delta 8.12(\mathrm{t}, J=7.6 \mathrm{~Hz}, 1 \mathrm{H}), 7.69-7.58$ $(\mathrm{m}, 2 \mathrm{H}), 7.53-7.46(\mathrm{~m}, 1 \mathrm{H}), 5.59(\mathrm{~d}, J=5.6 \mathrm{~Hz}, 2 \mathrm{H}), 3.34(\mathrm{q}, J=2.5 \mathrm{~Hz}, 1 \mathrm{H}), 1.95-1.77(\mathrm{~m}$, 3H); HRMS (APCI+): Calcd for $\mathrm{C}_{12} \mathrm{H}_{12} \mathrm{NO}_{4}[\mathrm{M}+\mathrm{H}]^{+}$: 234.0761, Found 234.0764; TLC: 1:4 / EtOAc:Hexanes, $\mathrm{R}_{\mathrm{f}} 0.35$.

Procedures 4-7 for the optimization of the $\beta$-boration of ethyl-2,3-butadienoate (Table 3.1):

Procedure 4 (Entry 1): 1,3-Dimethylimidazolium-2-carboxylate (2.5 $\mathrm{mg}, 0.018 \mathrm{mmol})$ and copper(I) chloride $(1.8 \mathrm{mg}, 0.018 \mathrm{mmol})$ were added to a $10 \mathrm{~mL}, 2$-neck, round-bottomed flask. $\mathrm{ACN}(2 \mathrm{ml})$ was added and the reaction was stirred for $15 \mathrm{~min}$. Bis(pinacolato)diboron (100 mg, $0.394 \mathrm{mmol})$ in ACN (2 ml) was added, followed by ethyl 2,3-butadienoate $(0.042 \mathrm{ml}, 0.358$ mmol) and the black reaction mixture was stirred at room temperature for 2 hours then analyzed by GC. ${ }^{10}$

Procedure 5 (Entry 2): 1,3-dicyclohexylimidazolium tetrafluoroborate (5.7 mg, $0.018 \mathrm{mmol}$ ), sodium tert-butoxide $(3.4 \mathrm{mg}, 0.036 \mathrm{mmol})$ and copper(I) chloride (1.8 $\mathrm{mg}, 0.018 \mathrm{mmol})$ were 
added to a $10 \mathrm{~mL}, 2$-neck, round-bottomed flask. THF (3 ml) was added and the reaction was stirred for 2.5 hours. Bis(pinacolato)diboron $(100 \mathrm{mg}, 0.392 \mathrm{mmol})$ in THF (1 ml) was added via syringe. After 10 minutes. ethyl 2,3-butadienoate $(0.041 \mathrm{ml}, 0.357 \mathrm{mmol})$ was added and the reaction was stirred at room temperature for 2 hours then analyzed by GC. ${ }^{11}$

Procedure 6 (Entries 3-8): Copper(I) chloride (3.5 mg, $0.036 \mathrm{mmol})$ was added to a $10 \mathrm{~mL}, 2$ neck, round-bottomed flask fitted with a reflux condenser (for entries 5-6, $\mathrm{NaO}^{t} \mathrm{Bu}$ and DPEphos were also added at this time). DCM $(0.5 \mathrm{ml})$ was added and the reaction was stirred for 2 min. PDIPA diboron $(115 \mathrm{mg}, 0.428 \mathrm{mmol})$ in DCM (4 ml) was injected via syringe. After 10 minutes, ethyl 2,3-butadienoate $(0.041 \mathrm{ml}, 0.357 \mathrm{mmol})$ was added and the reaction was stirred at reflux for 2 hours then analyzed by GC (for entries 3 and 7, TFE was added directly after the allenoate).

Procedure 7 (Entries 9-18): Copper(I) chloride (3.5 mg, $0.036 \mathrm{mmol}$ ) and PDIPA diboron (115 $\mathrm{mg}, 0.428 \mathrm{mmol}$ ) were added to a $10 \mathrm{~mL}, 2$-neck, round-bottomed flask fitted with a reflux condenser. THF (4.5 ml) was added (for entry 9, DMF was used instead). After 10 minutes, ethyl 2,3-butadienoate $(0.041 \mathrm{ml}, 0.357 \mathrm{mmol})$ was added and the reaction was stirred at the indicated temperature for 2 hours then analyzed by GC. For entries 12-18, copper(I) chloride was substituted for the indicated catalyst.

\section{General procedure 8 for the $\beta$-boration of substrates 3.26a-l (Table 3.2):}

Copper(I) chloride (3.53 mg, $0.036 \mathrm{mmol}$ ) and PDIPA diboron 2.13 (115 mg, 0.428 mmol) were added to a $10 \mathrm{~mL}, 2$-neck, round-bottomed flask and purged with vacuum / nitrogen. THF $(2.5 \mathrm{ml})$ was added and the suspension was stirred for $5 \mathrm{~min}$, producing a black mixture. Ethyl 2,3-butadienoate 3.26b (40 $\mathrm{mg}, 0.357 \mathrm{mmol})$ dissolved in THF $(0.5 \mathrm{ml})$ was added, 
washing once more with $\mathrm{THF}(0.5 \mathrm{ml})$, and the reaction was stirred at room temperature and followed by TLC until the starting material was gone (typically 2-3 hours). The contents were then filtered through celite, washing with diethyl ether, and concentrated by rotary evaporation. Compounds were purified by either Kugelrohr distillation or flash chromatography on silica gel.

\section{Characterization of compounds 3.27a-l:}

methyl 3-(4,4,5,5-tetramethyl-1,3,2-dioxaborolan-2-yl)but-3-enoate (3.27a):

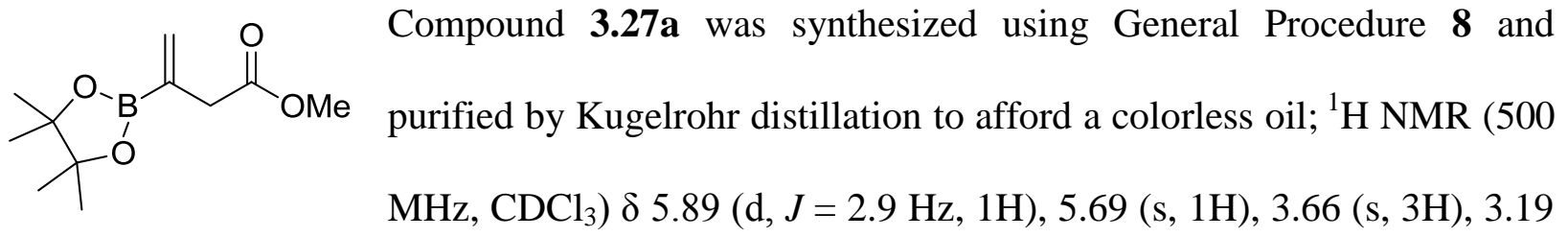

(s, 2H), $1.26(\mathrm{~d}, J=4.7 \mathrm{~Hz}, 12 \mathrm{H}) ;{ }^{13} \mathrm{C} \mathrm{NMR}(126 \mathrm{MHz}) \delta 172.75,132.02,83.89,51.81,40.62$,

24.81; ${ }^{11} \mathrm{~B}$ NMR $(160 \mathrm{MHz}) \delta$ 29.58; HRMS (ESI+): Calcd for $\mathrm{C}_{11} \mathrm{H}_{20} \mathrm{BO}_{4}[\mathrm{M}+\mathrm{H}]^{+}:$: 227.1449, Found 227.1444; Calcd for $\mathrm{C}_{11} \mathrm{H}_{23} \mathrm{BNO}_{4}\left[\mathrm{M}+\mathrm{NH}_{4}\right]^{+}$: 244.1715, Found: 244.1718; TLC: 1:9 / EtOAc:Hexanes, $\mathrm{R}_{\mathrm{f}} 0.28$.

ethyl 3-(4,4,5,5-tetramethyl-1,3,2-dioxaborolan-2-yl)but-3-enoate (3.27b):

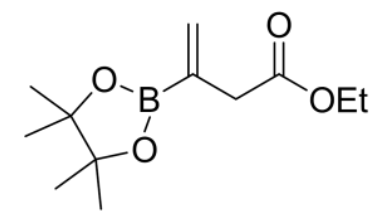

Compound 3.27b was synthesized using General Procedure 8 and purified by Kugelrohr distillation to afford a colorless oil; ${ }^{1} \mathrm{H}$ NMR $\left(500 \mathrm{MHz}, \mathrm{CDCl}_{3}\right) \delta 5.89(\mathrm{~d}, J=2.9 \mathrm{~Hz}, 1 \mathrm{H}), 5.69(\mathrm{~s}, 1 \mathrm{H}), 4.12(\mathrm{q}, J$ $=7.1 \mathrm{~Hz}, 2 \mathrm{H}), 3.17(\mathrm{~s}, 2 \mathrm{H}), 1.26(\mathrm{~s}, 12 \mathrm{H}), 1.25(\mathrm{t}, J=7.1 \mathrm{~Hz}, 3 \mathrm{H}) ;{ }^{13} \mathrm{C} \mathrm{NMR}(126 \mathrm{MHz}) \delta$ 172.35, 131.94, 83.85, 60.60, 40.84, 24.78, 14.38; ${ }^{11} \mathrm{~B}$ NMR (160 MHz) $\delta 29.57$; HRMS (ESI+): Calcd for $\mathrm{C}_{12} \mathrm{H}_{22} \mathrm{BO}_{4}[\mathrm{M}+\mathrm{H}]^{+}$: 241.1606, Found: 241.1600; Calcd for $\mathrm{C}_{12} \mathrm{H}_{21} \mathrm{BNaO}_{4}[\mathrm{M}+\mathrm{Na}]^{+}$: 263.1425, Found: 263.1435; TLC: 1:9 / EtOAc:Hexanes, $\mathrm{R}_{\mathrm{f}} 0.35$. 


\section{3-phenylpropyl 3-(4,4,5,5-tetramethyl-1,3,2-dioxaborolan-2-yl)but-3-enoate (3.27c):}

Compound 3.27c was synthesized using General Procedure 8 and

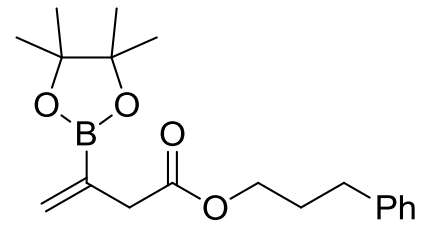
purified by flash chromatography on silica gel to afford a light yellow oil; ${ }^{1} \mathrm{H}$ NMR $\left(500 \mathrm{MHz}, \mathrm{CDCl}_{3}\right) \delta 7.30-7.26(\mathrm{~m}, 2 \mathrm{H}), 7.21-7.17$ (m, 3H), $5.92(\mathrm{~d}, J=2.9 \mathrm{~Hz}, 1 \mathrm{H}), 5.71(\mathrm{~s}, 1 \mathrm{H}), 4.10(\mathrm{t}, J=6.6 \mathrm{~Hz}, 2 \mathrm{H}), 3.19(\mathrm{~s}, 2 \mathrm{H}), 2.68(\mathrm{t}, J=$ $7.6 \mathrm{~Hz}, 2 \mathrm{H}), 1.99-1.92(\mathrm{~m}, 2 \mathrm{H}), 1.26(\mathrm{~s}, 12 \mathrm{H}) ;{ }^{13} \mathrm{C}$ NMR (126 MHz) $\delta 172.40,141.44,132.10$, $128.57,128.56,126.11,83.88,63.94,40.68,32.27,30.41,24.86 ;{ }^{11} \mathrm{~B}$ NMR $(160 \mathrm{MHz}) \delta 29.69$; HRMS (ESI+): Calcd for $\mathrm{C}_{19} \mathrm{H}_{28} \mathrm{BO}_{4}[\mathrm{M}+\mathrm{H}]^{+}$: 331.2075, Found: 331.2083; Calcd for $\mathrm{C}_{19} \mathrm{H}_{27} \mathrm{BNaO}_{4}[\mathrm{M}+\mathrm{Na}]^{+}:$353.1895, Found: 353.1917; TLC: 1:9 / EtOAc:Hexanes, $\mathrm{R}_{\mathrm{f}} 0.34$.

\section{(Z)-methyl 4-phenyl-3-(4,4,5,5-tetramethyl-1,3,2-dioxaborolan-2-yl)but-3-enoate (3.27d):}

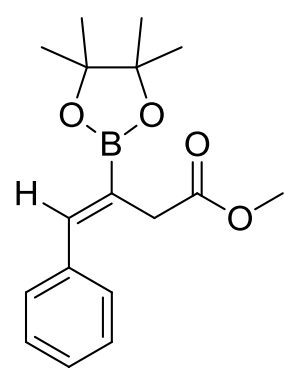

Compound 3.27d was synthesized using General Procedure 8 and purified by flash chromatography on silica gel to afford a light yellow oil; ${ }^{1} \mathrm{H}$ NMR (500 $\left.\mathrm{MHz}, \mathrm{CDCl}_{3}\right) \delta 7.41-7.26(\mathrm{~m}, 6 \mathrm{H}), 3.68(\mathrm{~s}, 3 \mathrm{H}), 3.41(\mathrm{~d}, J=1.3 \mathrm{~Hz}, 2 \mathrm{H})$, $1.30(\mathrm{~s}, 12 \mathrm{H}) ;{ }^{13} \mathrm{C}$ NMR $(126 \mathrm{MHz}) \delta 173.01,144.35,137.03,129.03$, $128.41,127.77,83.92,51.91,35.10,24.86 ;{ }^{11} \mathrm{~B}$ NMR (160 MHz) $\delta 30.19$;

HRMS (ESI+): Calcd for $\mathrm{C}_{17} \mathrm{H}_{24} \mathrm{BO}_{4}[\mathrm{M}+\mathrm{H}]^{+}$: 303.1762, Found: 303.1779; Calcd for $\mathrm{C}_{17} \mathrm{H}_{23} \mathrm{BNaO}_{4}[\mathrm{M}+\mathrm{Na}]^{+}:$325.1582, Found: 325.1596; TLC: 1:9 / EtOAc:Hexanes, $\mathrm{R}_{\mathrm{f}} 0.31$.

\section{(Z)-ethyl 4-phenyl-3-(4,4,5,5-tetramethyl-1,3,2-dioxaborolan-2-yl)but-3-enoate (3.27e):}

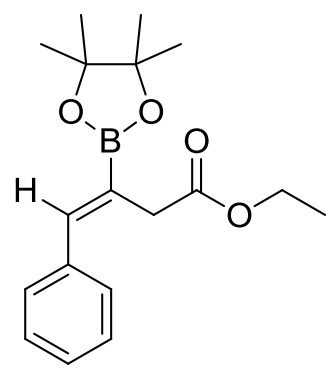

Compound 3.27e was synthesized using General Procedure 8 and purified by flash chromatography on silica gel to afford a light yellow oil; ${ }^{1} \mathrm{H}$ NMR $\left(500 \mathrm{MHz}, \mathrm{CDCl}_{3}\right) \delta 7.41-7.27(\mathrm{~m}, 6 \mathrm{H}), 4.14(\mathrm{q}, J=7.1 \mathrm{~Hz}, 2 \mathrm{H}), 3.39$ 
$(\mathrm{d}, J=1.3 \mathrm{~Hz}, 2 \mathrm{H}), 1.31(\mathrm{~s}, 12 \mathrm{H}), 1.25(\mathrm{t}, J=7.1 \mathrm{~Hz}, 3 \mathrm{H}) ;{ }^{13} \mathrm{C}$ NMR $(126 \mathrm{MHz}) \delta 174.18$ 144.28, 137.11, 129.06, 128.38, 127.72, 83.88, 60.68, 35.33, 24.89, 14.39; ${ }^{11}$ B NMR (160 MHz) $\delta$ 30.20; HRMS (ESI+): Calcd for $\mathrm{C}_{18} \mathrm{H}_{26} \mathrm{BO}_{4}[\mathrm{M}+\mathrm{H}]^{+}:$317.1924, Found: 317.1883; Calcd for $\mathrm{C}_{18} \mathrm{H}_{25} \mathrm{BNaO}_{4}[\mathrm{M}+\mathrm{Na}]^{+}:$339.1738, Found: 339.1713; TLC: 1:9 / EtOAc:Hexanes, $\mathrm{R}_{\mathrm{f}} 0.33$.

\section{(Z)-3-phenylpropyl 4-phenyl-3-(4,4,5,5-tetramethyl-1,3,2-dioxaborolan-2-yl)but-3-enoate} (3.27f):

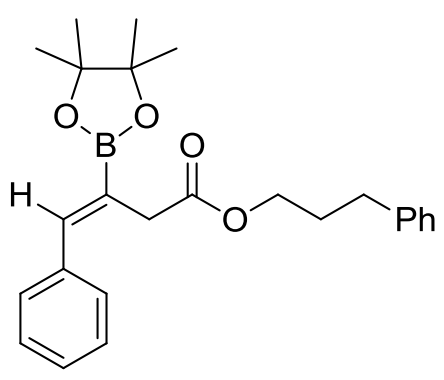

Compound 3.27f was synthesized using General Procedure 8 and purified by flash chromatography on silica gel to afford a light yellow oil; ${ }^{1} \mathrm{H}$ NMR $\left(500 \mathrm{MHz}, \mathrm{CDCl}_{3}\right) \delta 7.43-7.14(\mathrm{~m}, 11 \mathrm{H}), 4.11$ (t, $J=6.5 \mathrm{~Hz}, 2 \mathrm{H}), 3.41(\mathrm{~s}, 2 \mathrm{H}), 2.68(\mathrm{t}, J=7.7 \mathrm{~Hz}, 2 \mathrm{H}), 2.00-1.90$ (m, 2H), $1.30(\mathrm{~s}, 12 \mathrm{H}) ;{ }^{13} \mathrm{C}$ NMR (126 MHz) $\delta$ 172.64, 144.47, $141.42,137.13,129.06,128.58,128.55,128.42,127.78,126.10,83.91,63.98,35.27,32.25$, 30.43, 24.91; ${ }^{11} \mathrm{~B}$ NMR $(160 \mathrm{MHz}) \delta 30.19$; HRMS (ESI+): Calcd for $\mathrm{C}_{25} \mathrm{H}_{32} \mathrm{BO}_{4}[\mathrm{M}+\mathrm{H}]^{+}$: 407.2388, Found: 407.2416; Calcd for $\mathrm{C}_{25} \mathrm{H}_{31} \mathrm{BKO}_{4}[\mathrm{M}+\mathrm{K}]^{+}$: 445.1947, Found: 445.1961; TLC: 1:9 / EtOAc:Hexanes, $\mathrm{R}_{\mathrm{f}} 0.31$.

\section{(Z)-methyl 3-(4,4,5,5-tetramethyl-1,3,2-dioxaborolan-2-yl)pent-3-enoate (3.27g):}

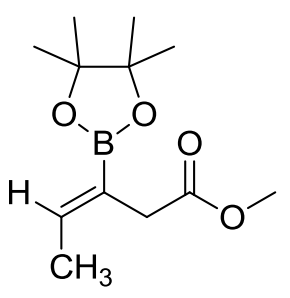

Compound 3.27g was synthesized using General Procedure 8 and purified by Kugelrohr distillation to afford a colorless oil; ${ }^{1} \mathrm{H}$ NMR $\left(500 \mathrm{MHz}, \mathrm{CDCl}_{3}\right) \delta$ $6.56(\mathrm{q}, J=6.8,1 \mathrm{H}), 3.65(\mathrm{~s}, 3 \mathrm{H}), 3.20(\mathrm{~s}, 2 \mathrm{H}), 1.73(\mathrm{~d}, J=6.8 \mathrm{~Hz}, 3 \mathrm{H}), 1.25$ (s, 12H); ${ }^{13} \mathrm{C}$ NMR (126 MHz) $\delta 172.90,143.21,83.55,51.77,33.53,24.83$, 
14.70; ${ }^{11} \mathrm{~B}$ NMR $(160 \mathrm{MHz}) \delta 30.12$; HRMS (ESI+): Calcd for $\mathrm{C}_{12} \mathrm{H}_{22} \mathrm{BO}_{4}[\mathrm{M}+\mathrm{H}]^{+}:$241.1606, Found: 241.1618; Calcd for $\mathrm{C}_{12} \mathrm{H}_{21} \mathrm{BNaO}_{4}[\mathrm{M}+\mathrm{Na}]^{+}$: 263.1425, Found: 263.1440; TLC: 1:9 / EtOAc:Hexanes, $\mathrm{R}_{\mathrm{f}} 0.33$.

(Z)-ethyl 3-(4,4,5,5-tetramethyl-1,3,2-dioxaborolan-2-yl)pent-3-enoate (3.27h):

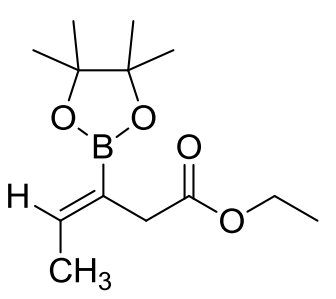

Compound 3.27h was synthesized using General Procedure 8 and purified by Kugelrohr distillation to afford a colorless oil; ${ }^{1} \mathrm{H}$ NMR $(500 \mathrm{MHz}$, $\left.\mathrm{CDCl}_{3}\right) \delta 6.56(\mathrm{q}, J=6.8 \mathrm{~Hz}, 1 \mathrm{H}), 4.10(\mathrm{q}, J=7.1 \mathrm{~Hz}, 2 \mathrm{H}), 3.18(\mathrm{~s}, 2 \mathrm{H})$, $1.73(\mathrm{t}, J=5.0 \mathrm{~Hz}, 3 \mathrm{H}), 1.25-1.22(\mathrm{~m}, 15 \mathrm{H}) ;{ }^{13} \mathrm{C} \mathrm{NMR}(126 \mathrm{MHz}) \delta$ $172.47,143.17,83.51,60.49,33.79,24.85,14.72,14.37 ;{ }^{11}$ B NMR (160 MHz) $\delta 29.98$; HRMS (ESI+): Calcd for $\mathrm{C}_{13} \mathrm{H}_{24} \mathrm{BO}_{4}[\mathrm{M}+\mathrm{H}]^{+}$: 255.1762, Found: 255.1753; Calcd for $\mathrm{C}_{13} \mathrm{H}_{23} \mathrm{BNaO}_{4}$ $[\mathrm{M}+\mathrm{Na}]^{+}:$277.1582, Found: 277.1589; TLC: 1:9 / EtOAc:Hexanes, $\mathrm{R}_{\mathrm{f}} 0.34$.

\section{(Z)-isopropyl 3-(4,4,5,5-tetramethyl-1,3,2-dioxaborolan-2-yl)pent-3-enoate (3.27i):}

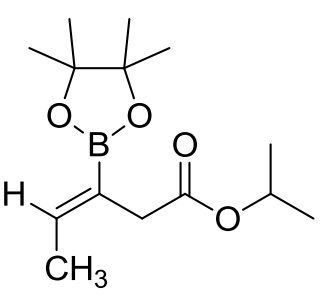

Compound 3.27i was synthesized using General Procedure 8 and purified by Kugelrohr distillation to afford a colorless oil; ${ }^{1} \mathrm{H}$ NMR $(500 \mathrm{MHz}$, $\left.\mathrm{CDCl}_{3}\right) \delta 6.58-6.51(\mathrm{~m}, 1 \mathrm{H}), 4.96(\mathrm{~m}, 1 \mathrm{H}), 3.13(\mathrm{~s}, 2 \mathrm{H}), 1.73(\mathrm{~d}, J=6.8$ $\mathrm{Hz}, 3 \mathrm{H}), 1.24(\mathrm{~s}, 12 \mathrm{H}), 1.20(\mathrm{~d}, J-6.3 \mathrm{~Hz}, 6 \mathrm{H}) ;{ }^{13} \mathrm{C} \mathrm{NMR}(126 \mathrm{MHz}) \delta$ 172.02, 143.14, 83.49, 67.66, 34.09, 24.87, 21.96, 14.72; ${ }^{11}$ B NMR (160 MHz) $\delta 30.01$; HRMS (ESI+): Calcd for $\mathrm{C}_{14} \mathrm{H}_{26} \mathrm{BO}_{4}[\mathrm{M}+\mathrm{H}]^{+}:$269.1919, Found: 269.1893; TLC: 1:9 / EtOAc:Hexanes, $\mathrm{R}_{\mathrm{f}} 0.37$. 


\section{(Z)-tert-butyl 3-(4,4,5,5-tetramethyl-1,3,2-dioxaborolan-2-yl)pent-3-enoate (3.27j):}

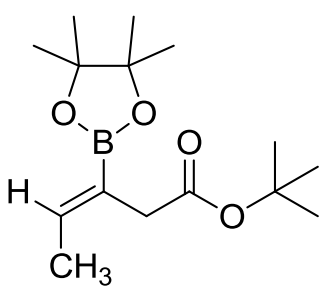

Compound 3.27j was synthesized using General Procedure 8 and purified by Kugelrohr distillation to afford a colorless oil; ${ }^{1} \mathrm{H}$ NMR $(500 \mathrm{MHz}$,

$\left.\mathrm{CDCl}_{3}\right) \delta 6.56-6.51(\mathrm{~m}, 1 \mathrm{H}), 3.09(\mathrm{~s}, 2 \mathrm{H}), 1.73(\mathrm{~d}, J=6.8 \mathrm{~Hz}, 3 \mathrm{H}), 1.42$ $(\mathrm{s}, 9 \mathrm{H}), 1.24(\mathrm{~s}, 12 \mathrm{H}) ;{ }^{13} \mathrm{C} \mathrm{NMR}(126 \mathrm{MHz}) \delta 171.73,142.73,83.36$,

80.01, 34.93, 28.14, 24.81, 14.64; ${ }^{11} \mathrm{~B}$ NMR (160 MHz) $\delta 30.05$; HRMS (ESI+): Calcd for $\mathrm{C}_{15} \mathrm{H}_{28} \mathrm{BO}_{4}[\mathrm{M}+\mathrm{H}]^{+}:$283.2075, Found: 283.2081; Calcd for $\mathrm{C}_{15} \mathrm{H}_{27} \mathrm{BNaO}_{4}[\mathrm{M}+\mathrm{Na}]^{+}:$305.1895, Found: 305.1894; TLC: 1:9 / EtOAc:Hexanes, $\mathrm{R}_{\mathrm{f}} 0.44$.

\section{(Z)-2-nitrobenzyl 3-(4,4,5,5-tetramethyl-1,3,2-dioxaborolan-2-yl)pent-3-enoate (3.27k):}

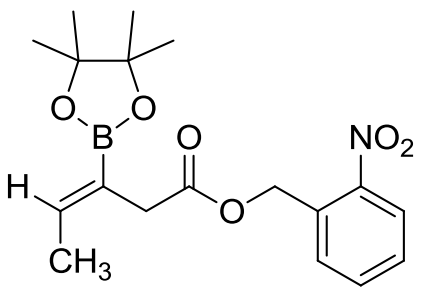

Compound 3.27k was synthesized using General Procedure 8 and purified by flash chromatography on silica gel to afford a yellow oil; ${ }^{1} \mathrm{H}$ NMR $\left(500 \mathrm{MHz}, \mathrm{CDCl}_{3}\right) \delta 8.12(\mathrm{~d}, J=8.4 \mathrm{~Hz}, 1 \mathrm{H}), 7.63(\mathrm{~d}, J=$ $3.9 \mathrm{~Hz}, 2 \mathrm{H}), 7.50-7.54(\mathrm{~m}, 1 \mathrm{H}), 6.62(\mathrm{q}, J=7.0 \mathrm{~Hz}, 1 \mathrm{H}), 5.53(\mathrm{~s}$, 2H), $3.32(\mathrm{~s}, 2 \mathrm{H}), 1.77(\mathrm{~d}, J=6.8 \mathrm{~Hz}, 3 \mathrm{H}), 1.22(\mathrm{~s}, 12 \mathrm{H}) ;{ }^{13} \mathrm{C}$ NMR $(126 \mathrm{MHz}) \delta 171.73$, $147.7 *, 144.01,133.82,128.74,128.56,125.14,83.63,62.91,33.59,24.86,14.83 ;{ }^{11} \mathrm{~B}$ NMR $(160 \mathrm{MHz}) \delta$ 29.88; HRMS (ESI+): Calcd for $\mathrm{C}_{18} \mathrm{H}_{25} \mathrm{BNO}_{6}[\mathrm{M}+\mathrm{H}]^{+}:$362.1769, Found: 362.1746; Calcd for $\mathrm{C}_{18} \mathrm{H}_{24} \mathrm{BNNaO}_{6}[\mathrm{M}+\mathrm{Na}]^{+}$: 384.1589, Found: 384.1565; TLC: 1:4 / EtOAc:Hexanes, $\mathrm{R}_{\mathrm{f}} 0.38$.

*Note: The carbon directly attached to the nitro group was not observed in the normal ${ }^{13} \mathrm{C}$ spectrum. HMBC spectroscopy identified a peak at approximately $147.7 \mathrm{ppm}$, which shows multiple bond correlation to other signals from the aromatic ring. 


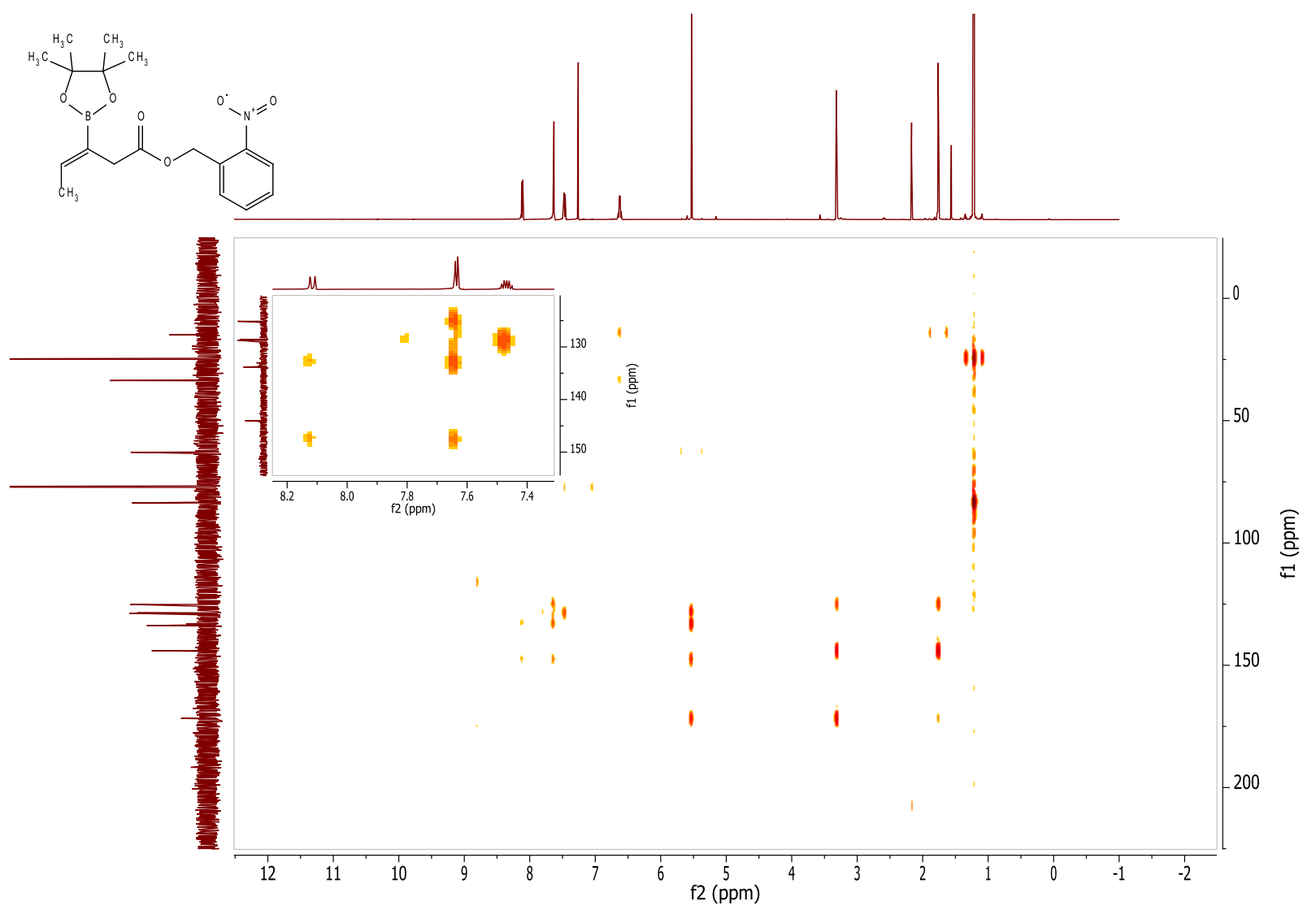

(Z)-ethyl 2-methyl-3-(4,4,5,5-tetramethyl-1,3,2-dioxaborolan-2-yl)pent-3-enoate (3.271):
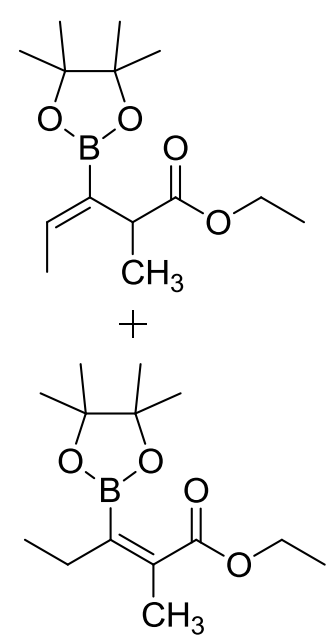

Compound 3.27l was synthesized using General Procedure 8 and purified by Kugelrohr distillation to afford a colorless oil; ${ }^{1} \mathrm{H}$ NMR $(500 \mathrm{MHz}$, $\left.\mathrm{CDCl}_{3}\right) \delta 6.45(\mathrm{q}, J=6.8 \mathrm{~Hz}, 1 \mathrm{H}), 4.22(\mathrm{q}, J=7.1 \mathrm{~Hz}, 0.5 \mathrm{H}), 4.17-4.04$ (m, 2H), $3.47(\mathrm{q}, J=7.1 \mathrm{~Hz}, 1 \mathrm{H}), 2.29-2.21(\mathrm{~m}, 0.5 \mathrm{H}), 1.80(\mathrm{~s}, 0.75 \mathrm{H})$, $1.74(\mathrm{~d}, J=6.8 \mathrm{~Hz}, 3 \mathrm{H}), 1.34$ (s, 3H), $1.30-1.19$ (m, 22H), 1.05 (t, $J=7.7$ $\mathrm{Hz}, 0.75 \mathrm{H}) ;{ }^{13} \mathrm{C}$ NMR $(126 \mathrm{MHz}) \delta 175.52,171.14,140.58,131.66,83.26$, $83.20,68.12,61.55,60.47,38.89,25.75,25.13,24.83,16.62,14.38,14.25$, 12.44, 11.77; ${ }^{11} \mathrm{~B}$ NMR (160 MHz) $\delta$ 30.05; HRMS (ESI+): Calcd for 
$\mathrm{C}_{14} \mathrm{H}_{26} \mathrm{BO}_{4}[\mathrm{M}+\mathrm{H}]^{+}:$269.1919, Found: 269.1924; Calcd for $\mathrm{C}_{14} \mathrm{H}_{25} \mathrm{BNaO}_{4}[\mathrm{M}+\mathrm{Na}]^{+}:$291.1738, Found: 291.1737; TLC: 1:9 / EtOAc:Hexanes, $\mathrm{R}_{\mathrm{f}}$ 0.34.

\section{Example of 1D NOESY for product 3.27i:}

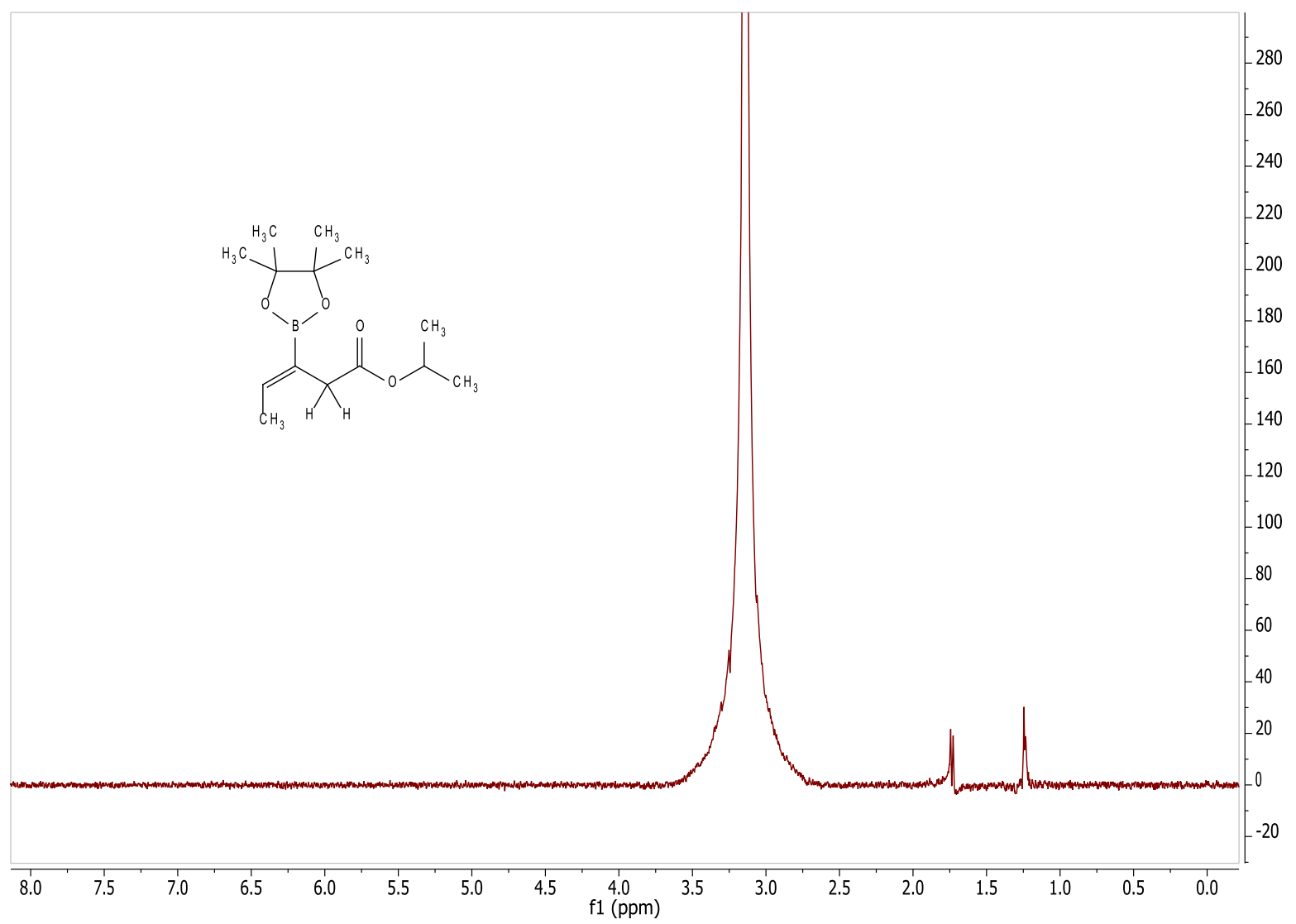

(E)-methyl 3-phenylpent-3-enoate $((E)-3.39)$ :

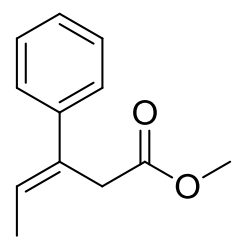

$\mathrm{PdCl}_{2}\left(\mathrm{PPh}_{3}\right)_{2}$ (4 mg, 0.05 equiv) and $\mathrm{K}_{2} \mathrm{CO}_{3}$ (28 mg, 2 equiv) were added to a 10 $\mathrm{mL}, 2$-neck, round-bottomed flask fitted with a reflux condenser and purged several times with vacuum and nitrogen. DMF $(2 \mathrm{ml})$ was added. Iodobenzene

(22 $\mu \mathrm{l}, 2$ equiv) followed by $\mathbf{3 . 2 7} \mathrm{g}$ ( $24 \mathrm{mg}, 1$ equiv) dissolved in DMF (1 ml) was added, washing with additional DMF, and the reaction was heated to $90{ }^{\circ} \mathrm{C}$ and stirred for 18 hours. The crude mixture was diluted with diethyl ether $(10 \mathrm{ml})$ and DMF was removed by washing 
with saturated $\mathrm{LiBr}(3 \times 5 \mathrm{ml})$. The organic layer was dried over $\mathrm{Na}_{2} \mathrm{SO}_{4}$, filtered, concentrated by rotary evaporation, and purified by flash chromatography on silica gel to afford $(E)-\mathbf{3 . 3 9}$ as a light yellow oil (19 mg, 100\%). Spectral data is consistent with the literature. ${ }^{12}{ }^{1} \mathrm{H}$ NMR (500 $\left.\mathrm{MHz}, \mathrm{CDCl}_{3}\right) \delta 7.43-7.18(\mathrm{~m}, 5 \mathrm{H}), 6.06(\mathrm{q}, J=6.9 \mathrm{~Hz}, 1 \mathrm{H}), 3.66(\mathrm{~s}, 3 \mathrm{H}), 3.53(\mathrm{~s}, 2 \mathrm{H}), 1.84(\mathrm{~d}$, $J=6.9 \mathrm{~Hz}, 3 \mathrm{H}) .{ }^{13} \mathrm{C}$ NMR $(126 \mathrm{MHz}) \delta 172.04,142.45,133.38,128.48,126.99,125.96,52.10$, 35.67, 14.73. TLC: 1:9 / EtOAc:Hexanes, $\mathrm{R}_{\mathrm{f}}=0.42$.

\subsection{Synthetic procedures for Chapter 4}

General procedure 9 for the optimization of the $\beta$-boration of 2-cyclohexen-1-one in water

\section{(Table 4.1):}

Bis(pinacolato)diboron (72 mg, 1.1 equiv), 2-cyclohexen-1-one (25 $\mu \mathrm{l}, 1.0$ equiv), and amine (0.02 equiv) were added to a 1 -dram, PTFE vial with a magnetic stirbar. A stock solution of dilute $\mathrm{CuCl}_{2}$ in DI water was prepared to a final concentration of $1.72 \mathrm{mM}$. From the stock solution, $1.5 \mathrm{ml}$ was added to the reaction vessel, providing 0.01 equiv $\mathrm{CuCl}_{2}$. The reaction mixture was stirred vigorously for 1 hour at room temperature. $1 \mathrm{ml}$ Ethyl acetate was added and allowed to stir for 1 minute. The layers were allowed to separate and the organic layer was analyzed by GC. Stock copper solutions were not freshly prepared each day. They showed no decrease in catalytic activity after bench top storage over several months.

General procedure 10 for the optimization of the $\beta$-boration of 3-methyl-2-cyclohexen-1one in water (Table 4.2):

Bis(pinacolato)diboron (72 mg, 1.1 equiv), 3-methyl-2-cyclohexen-1-one (29 $\mu 1,1.0$ equiv), and 4-picoline $(0.5 \mu \mathrm{l}, 0.02$ equiv or $1.27 \mu 1,0.05$ equiv) were added to a 1 -dram, PTFE vial with a magnetic stirbar. Additives were also added at this time, when used. A stock 
solution of dilute $\mathrm{Cu}$ (II) salt in DI water was prepared as before to provide 0.01 equiv $\mathrm{Cu}$ (II) per $1.5 \mathrm{ml}$. From the stock solution, $1.5 \mathrm{ml}$ was added to the reaction vessel. The reaction mixture was stirred vigorously for 1 hour at room temperature. $1 \mathrm{ml}$ Ethyl acetate was then added and allowed to stir for 1 minute. The layers were then allowed to separate and the organic layer was analyzed by GC.

General procedure 11 for the copper-catalyzed $\beta$-boration of $\alpha, \beta$-unsaturated carbonyl compounds in water 4.3a-o (Scheme 4.2):

Bis(pinacolato)diboron (144 mg, 1.1 equiv), benzyl acrylate (77 $\mu 1,1.0$ equiv), and 4picoline $(2.54 \mu \mathrm{l}, 0.05$ equiv) were added to a $5 \mathrm{ml}$ round-bottomed flask with a magnetic stirbar. From the $1.72 \mathrm{mM}$ stock solution, $3 \mathrm{ml}$ was added to the reaction vessel. The reaction mixture was stirred vigorously for 1-3 hours at room temperature, typically producing a dark red or black mixture, until the reaction was complete by TLC analysis.

\section{Procedure 12 for solid substrate 4.3f:}

Bis(pinacolato)diboron (144 mg, 1.1 equiv), chalcone (77 $\mu 1,1.0$ equiv), and 4-picoline (2.54 $\mu 1,0.05$ equiv) were added to a $5 \mathrm{ml}$ round-bottomed flask with a magnetic stirbar and washed down the edge of the flask with THF $(600 \mu \mathrm{l})$. From the $1.72 \mathrm{mM}$ stock solution, $3 \mathrm{ml}$ was added to the reaction vessel. The reaction mixture was stirred vigorously for 2 hours at room temperature, typically producing a dark red or black mixture, until the reaction was complete by TLC analysis. 


\section{Work up procedure 1:}

$2 \mathrm{ml}$ Hexanes was then added and allowed to stir for 15 minute, which produced clear or slightly colored layers. The contents were transferred to a separatory funnel, washing with hexanes. After collecting the organic layer, the aqueous layer was extracted using $2 \times 5 \mathrm{ml}$ hexanes. The combined organic extracts were then washed 5 X $5 \mathrm{ml}$ DI water, dried over sodium sulfate, filtered, and concentrated in vacuo to provide the product.

\section{Work up procedure 2:}

The products derived from cyclic ketones were not efficiently extracted into hexanes. Ethyl acetate was used as the extraction solvent $(3 \times 5 \mathrm{ml})$, and the combined organic extracts were dried over sodium sulfate, filtered, and concentrated in vacuo. The residue was then purified by flash chromatography on silica gel. Alternatively, $4.3 \mathrm{a}$ and $\mathbf{4 . 3 \mathrm { b }}$ were extracted with cyclohexanone using the procedure described above, or distilled at reduced pressure using a Kugelrohr, to provide nearly identical yields.

\section{Work up procedure 3:}

Using a slight modification of a method pioneered by Molander, ${ }^{13} 5$ equivalents of sodium perborate were added to the reaction mixture and allowed to stir until the borated product was consumed by TLC (1-2 hours). The solvent was removed by rotary evaporation followed by high vacuum overnight. The resulting white solid was re-dissolved in hot acetone. After cooling to room temperature, the solution was filtered to remove the excess insoluble $\mathrm{NaBO}_{3}$. The acetone solution was concentrated to afford the product. 


\section{Characterization of compounds 4.3a-0:}

\section{3-(4,4,5,5-tetramethyl-1,3,2-dioxaborolan-2-yl)cyclohexanone (4.3a):}

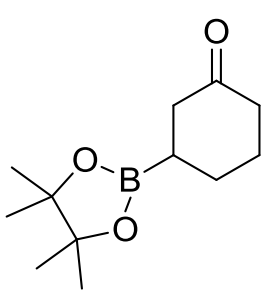

Compound 4.3a was synthesized using General Procedure 11 and purified by Work Up Procedure 2 to afford a colorless oil; ${ }^{1} \mathrm{H},{ }^{13} \mathrm{C}$, and ${ }^{11} \mathrm{~B}$ NMR spectra are consistent with the literature ${ }^{14}$; TLC: 1:4 / EtOAc:Hexanes, $\mathrm{R}_{\mathrm{f}} 0.40$.

\section{3-methyl-3-(4,4,5,5-tetramethyl-1,3,2-dioxaborolan-2-yl)cyclohexanone (4.3b):}

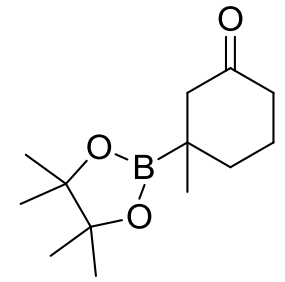

Compound 4.3b was synthesized using General Procedure 11 and purified by Work Up Procedure 2 to afford a colorless oil; ${ }^{1} \mathrm{H}$ and ${ }^{13} \mathrm{C}$ NMR spectra are consistent with the literature ${ }^{15} ;{ }^{11} \mathrm{~B}$ NMR (160 MHz) $\delta$ 34.0; TLC: 1:9 /

EtOAc:Hexanes, $\mathrm{R}_{\mathrm{f}} 0.22$.

\section{1-(4,4,5,5-tetramethyl-1,3,2-dioxaborolan-2-yl)hexan-3-one (4.3c):}

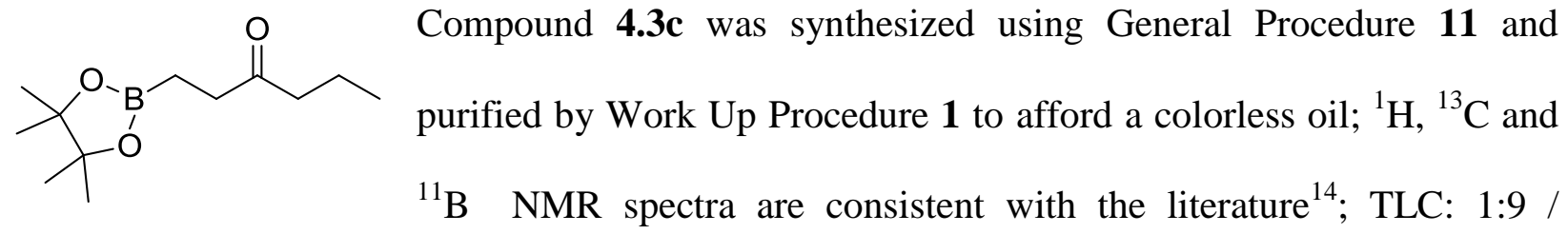

EtOAc:Hexanes, $\mathrm{R}_{\mathrm{f}} 0.31$.

\section{5-(4,4,5,5-tetramethyl-1,3,2-dioxaborolan-2-yl)hexan-3-one (4.3d):}

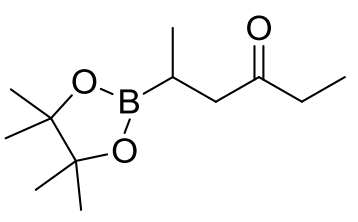

Compound 4.3d was synthesized using General Procedure 11 and purified by Work Up Procedure 1 to afford a colorless oil; ${ }^{1} \mathrm{H},{ }^{13} \mathrm{C}$, and ${ }^{11} \mathrm{~B}$ NMR spectra are consistent with the literature ${ }^{14}$; TLC: 1:9 / EtOAc:Hexanes, $\mathrm{R}_{\mathrm{f}}$

0.34 . 


\section{4-(4,4,5,5-tetramethyl-1,3,2-dioxaborolan-2-yl)nonan-2-one (4.3e):}

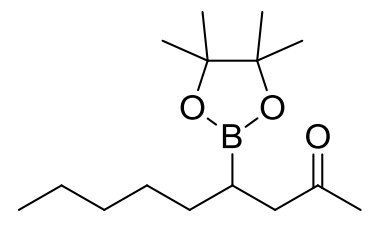

Compound 4.3e was synthesized using General Procedure 11 and purified by Work Up Procedure 1 to afford a colorless oil; ${ }^{1} \mathrm{H}$ NMR $(500 \mathrm{MHz}$,

$\left.\mathrm{CDCl}_{3}\right) \delta 2.56(\mathrm{~d}, J=7.2 \mathrm{~Hz}, 2 \mathrm{H}), 2.11(\mathrm{~s}, 3 \mathrm{H}), 1.44-1.33(\mathrm{~m}, 1 \mathrm{H}), 1.29$ - $1.20(\mathrm{~m}, 18 \mathrm{H}), 0.92-0.82(\mathrm{~m}, 3 \mathrm{H}) ;{ }^{13} \mathrm{C}$ NMR $(126 \mathrm{MHz}) \delta 209.4,83.1,46.0,32.1,30.5,29.8$, 28.7, 24.9, 24.8, 22.7, 14.2.; ${ }^{11} \mathrm{~B}$ NMR (160 MHz) $\delta 33.8$; HRMS (APCI+): Calcd for $\mathrm{C}_{15} \mathrm{H}_{30} \mathrm{BO}_{3}$ $[\mathrm{M}+\mathrm{H}]^{+}:$269.2283, Found 269.2273; TLC: 1:9 / EtOAc:Hexanes, $\mathrm{R}_{\mathrm{f}}$ 0.28.

\section{1,3-diphenyl-3-(4,4,5,5-tetramethyl-1,3,2-dioxaborolan-2-yl)propan-1-one (4.3f):}

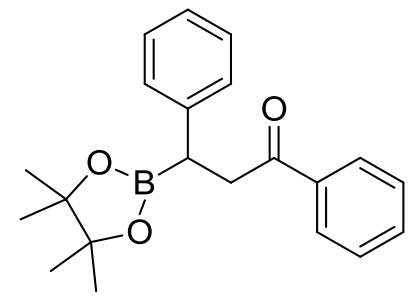

Compound 4.3f was synthesized using General Procedure 12 and purified by Work Up Procedure 1 (higher purity material is obtained when THF solvent is removed under vacuum prior to the addition of hexanes) to afford a pale yellow semi-solid; ${ }^{1} \mathrm{H},{ }^{13} \mathrm{C}$, and ${ }^{11} \mathrm{~B} \mathrm{NMR}$ spectra are consistent with the literature ${ }^{14}$; TLC: $1: 9$ / EtOAc:Hexanes, $\mathrm{R}_{\mathrm{f}} 0.42$.

\section{6-methyl-4-(4,4,5,5-tetramethyl-1,3,2-dioxaborolan-2-yl)hept-5-en-2-one (4.3g):}

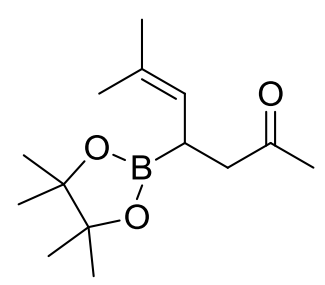

Compound 4.3g was synthesized using General Procedure 11 and purified by Work Up Procedure 1 to afford a colorless oil; ${ }^{1} \mathrm{H}$ NMR (500 MHz, $\left.\mathrm{CDCl}_{3}\right) \delta 5.06-4.91(\mathrm{~m}, 1 \mathrm{H}), 2.68-2.52(\mathrm{~m}, 2 \mathrm{H}), 2.23-2.13(\mathrm{~m}, 1 \mathrm{H})$, $2.11(\mathrm{~s}, 3 \mathrm{H}), 1.67(\mathrm{~d}, J=1.5 \mathrm{~Hz}, 3 \mathrm{H}), 1.62(\mathrm{~d}, J=1.4 \mathrm{~Hz}, 3 \mathrm{H}), 1.23(\mathrm{~s}, 6 \mathrm{H})$, $1.20(\mathrm{~s}, 6 \mathrm{H}) ;{ }^{13} \mathrm{C}$ NMR $(126 \mathrm{MHz}) \delta 209.1,132.2,123.2,83.1,46.4,29.7,26.0,24.7,24.6,18.2$;

${ }^{11} \mathrm{~B}$ NMR (160 MHz) $\delta$ 32.5; HRMS (ESI+): Calcd for $\mathrm{C}_{14} \mathrm{H}_{36} \mathrm{BO}_{3}[\mathrm{M}+\mathrm{H}]^{+}:$253.1970, Found 253.1989; TLC: 1:9 / EtOAc:Hexanes, $\mathrm{R}_{\mathrm{f}} 0.35$. 


\section{3-(4,4,5,5-tetramethyl-1,3,2-dioxaborolan-2-yl)cyclopentanone (4.3h):}

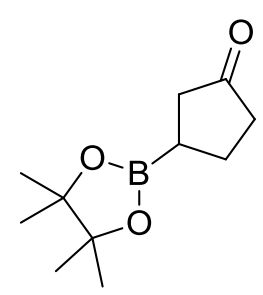

Compound 4.3h was synthesized using General Procedure 11 and purified by Work Up Procedure 2 to afford a colorless oil; ${ }^{1} \mathrm{H}$ and ${ }^{13} \mathrm{C}$ NMR spectra are consistent with the literature ${ }^{16} ;{ }^{11} \mathrm{~B}$ NMR (160 MHz) $\delta$ 33.8; TLC: 1:4 / EtOAc:Hexanes, $\mathrm{R}_{\mathrm{f}} 0.32$.

potassium trifluoro(3-oxocyclopentyl)borate (4.3i):

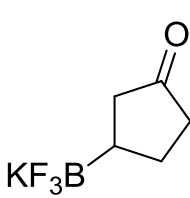

Compound 4.3i was synthesized using General Procedure 11 and purified by Work

Up Procedure 3 to afford a Pale yellow solid; ${ }^{1} \mathrm{H}$ NMR (500 MHz, acetone- $\left.d_{6}\right) \delta$ $2.04-1.98(\mathrm{~m}, 1 \mathrm{H}), 1.97-1.77(\mathrm{~m}, 4 \mathrm{H}), 1.73-1.63(\mathrm{~m}, 1 \mathrm{H}), 1.06-0.92(\mathrm{~m}$, $1 \mathrm{H}) ;{ }^{13} \mathrm{C}$ NMR $(126 \mathrm{MHz}) \delta 223.9,42.6,40.0,26.6 ;{ }^{11} \mathrm{~B}$ NMR $(160 \mathrm{MHz}) \delta 5.0 ;{ }^{19} \mathrm{~F}$ NMR (471 MHz) $\delta$-70.99; HRMS (ESI-): Calcd for $\mathrm{C}_{5} \mathrm{H}_{7} \mathrm{OBF}_{3}\left[\mathrm{M}-\mathrm{K}^{+}\right]^{-}:$151.0548, Found 151.0559.

\section{benzyl 3-(4,4,5,5-tetramethyl-1,3,2-dioxaborolan-2-yl)propanoate (4.3j):}

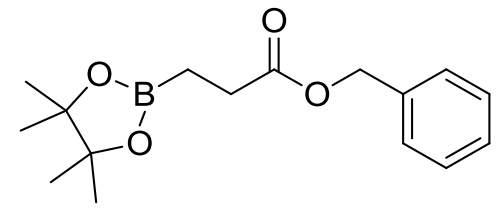

Compound 4.3j was synthesized using General Procedure 11 and purified by Work Up Procedure 1 to afford a colorless oil; ${ }^{1} \mathrm{H}$, ${ }^{13} \mathrm{C}$, and ${ }^{11} \mathrm{~B}$ NMR spectra are consistent with the literature ${ }^{16}$;

TLC: 1:9 / EtOAc:Hexanes, $\mathrm{R}_{\mathrm{f}} 0.30$.

methyl 3-(4,4,5,5-tetramethyl-1,3,2-dioxaborolan-2-yl)butanoate (4.3k):

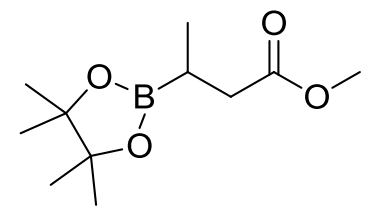

Compound 4.3k was synthesized using General Procedure 11 and purified by Work Up Procedure 1 to afford a colorless oil; ${ }^{1} \mathrm{H}$ and ${ }^{13} \mathrm{C} \mathrm{NMR}$ spectra are consistent with the literature ${ }^{17} ;{ }^{11} \mathrm{~B}$ NMR $(160 \mathrm{MHz}) \delta 33.9$;

TLC: 1:9 / EtOAc:Hexanes, $\mathrm{R}_{\mathrm{f}} 0.34$. 
ethyl 3-(4,4,5,5-tetramethyl-1,3,2-dioxaborolan-2-yl)butanoate (4.31):

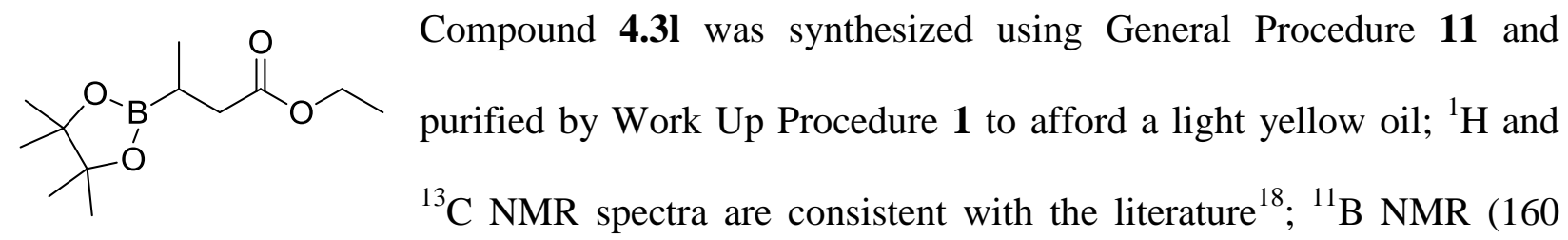

MHz) $\delta 33.8$; TLC: 1:9 / EtOAc:Hexanes, $\mathrm{R}_{\mathrm{f}} 0.39$.

methyl 2-methyl-3-(4,4,5,5-tetramethyl-1,3,2-dioxaborolan-2-yl)propanoate (4.3m):

Compound $\mathbf{4 . 3 m}$ was synthesized using General Procedure 11 and purified
spectra are consistent with the literature ${ }^{16}$; TLC: $1: 9$ / EtOAc:Hexanes, $\mathrm{R}_{\mathrm{f}}$ 0.35 .

tert-butyl 3-(4,4,5,5-tetramethyl-1,3,2-dioxaborolan-2-yl)butanoate (4.3n):

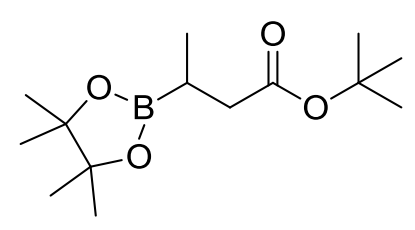

Compound 4.3n was synthesized using General Procedure 11 and the organic components were extracted with tetrachloroethylene- $d_{6}$ and analyzed by ${ }^{1} \mathrm{H}$ NMR. Spectra compared with the literature. ${ }^{19}$

potassium (4-(tert-butoxy)-4-oxobutan-2-yl)trifluoroborate (4.30):<smiles>CC([Pb])CC(=O)OC(C)(C)C</smiles>
Compound 4.3o was synthesized using General Procedure 11 and purified by Work Up Procedure 3 to afford a white solid; ${ }^{1} \mathrm{H}$ NMR $(400 \mathrm{MHz}$, acetone- $\left.d_{6}\right) \delta 2.26-2.18(\mathrm{~m}, 1 \mathrm{H}), 1.83-1.73(\mathrm{~m}, 1 \mathrm{H}), 1.40(\mathrm{~s}, 9 \mathrm{H}), 0.83-0.69(\mathrm{~m}, 4 \mathrm{H}),{ }^{13} \mathrm{C}$ NMR (126 MHz) $\delta 176.4,78.7,40.5,28.4,16.0 ;{ }^{11} \mathrm{~B}$ NMR $(160 \mathrm{MHz}) \delta 6.6 ;{ }^{19} \mathrm{~F}$ NMR $(471$ MHz) $\delta$-71.65; HRMS (ESI-): Calcd for $\mathrm{C}_{8} \mathrm{H}_{15} \mathrm{O}_{2} \mathrm{BF}_{3}\left[\mathrm{M}-\mathrm{K}^{+}\right]$: 211.1123, Found 211.1132. 
Procedure 13 for the $\beta$-boration of 1-hexen-3-one with tetra(hydroxyl)diborane (Scheme 4.3):

Tetra(hydroxy)diborane (51 mg, 1.1 equiv), 1-hexen-3-one (60 $\mu 1,1.0$ equiv), and 4picoline $(2.54 \mu \mathrm{l}, 0.05$ equiv) were added to a $5 \mathrm{ml}$ round-bottomed flask with a magnetic stirbar. $3 \mathrm{ml}$ from a stock solution of $1.72 \mathrm{mM} \mathrm{CuSO}_{4}$ in DI water was added as before to provide 0.01 equiv $\mathrm{CuSO}_{4}$. The reaction mixture was stirred vigorously for 16 hours at room temperature. Pinacol (183 mg, 3.0 equiv) was added followed by $2 \mathrm{ml}$ hexanes and the mixture was stirred for 2 hours at room temperature. The product was isolated using the same hexanes extraction procedure as previously described.

\section{${ }^{11}$ B NMR sample preparation (Figure 4.2):}

Bis(pinacolato)diboron (10 mg) was added to a 1 dram vial. For sample A, $700 \mu$ of 4picoline was added; the sample was vortexed and transferred to a quartz NMR tube. For sample B, $700 \mu \mathrm{l}$ of DI water was added; the sample was vortexed for 5 minutes (at which time the solid was not completely dissolved) and transferred to a quartz NMR tube. It was noted that the partial transfer of solid to the NMR tube or the use of nuclease-free water had no effect on the spectrum. For sample $\mathbf{C}, 700 \mu \mathrm{l}$ of DI water was added, followed by 4-picoline (3.83 $\mu 1,1$ equiv); the sample was vortexed for 5 minutes and transferred to a quartz NMR tube. 


\section{UV-Vis measurements:}

Figure 4.3. Visible region of the UV-Vis spectra of copper(II) and 4-picoline complexes.

\section{Cu : 4-picoline}

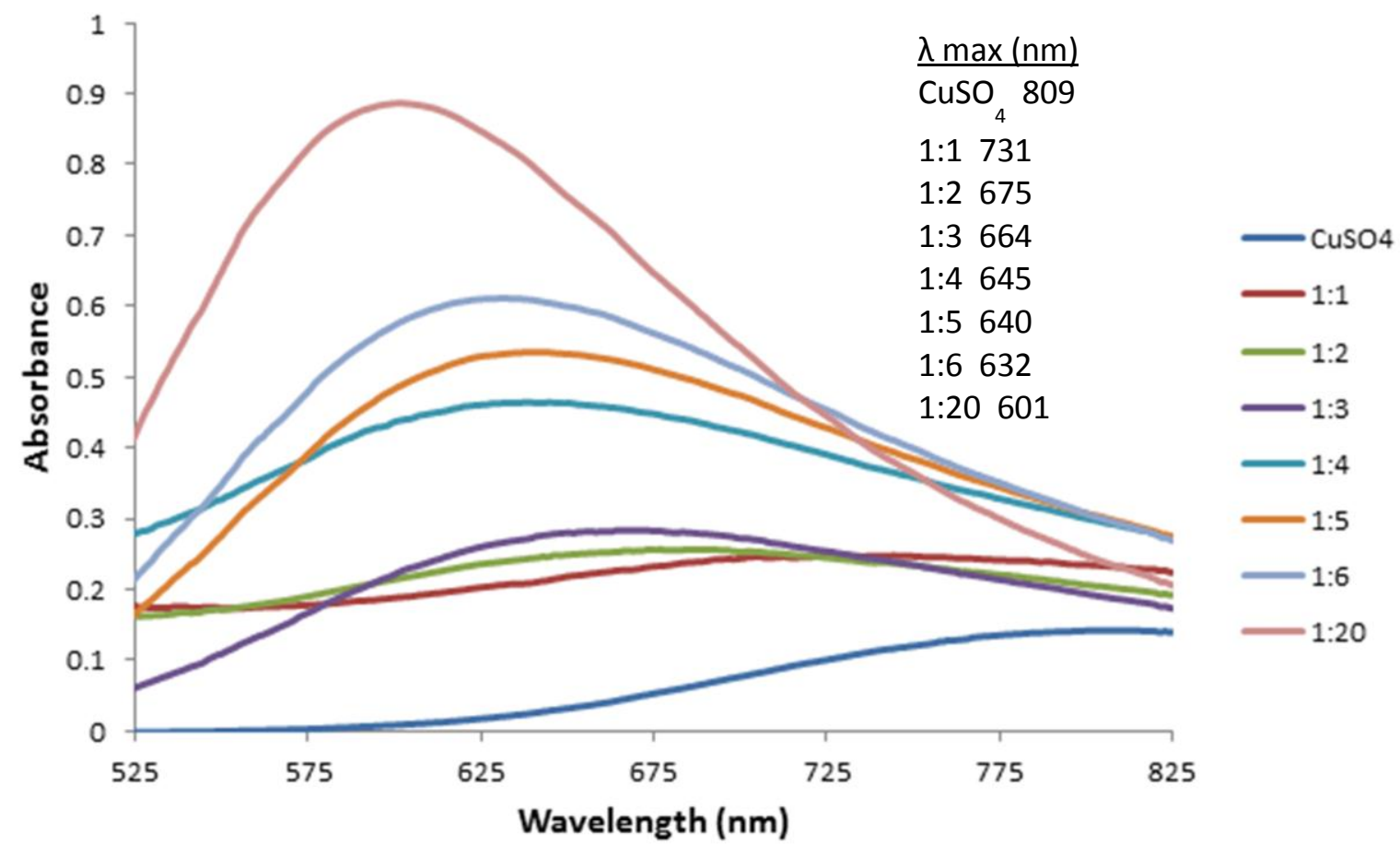

Sample preparation: A stock solution of copper sulfate $(1 \mathrm{mg} / \mathrm{ml})$ in DI water was prepared and divided into $2 \mathrm{ml}$ aliquots in 1 dram vials. An appropriate volume of 4-picoline was added and the vial was capped and vortexed for 30 seconds. A white precipitate formed and was filtered using a small gravity filter apparatus. The resulting filtrate was then analyzed by UVVis. Each sample was prepared immediately before obtaining the spectrum.

\section{General considerations for the determination of SKIE (Figures 4.4 and 4.5, Table 4.3):}

Data was obtained at $23{ }^{\circ} \mathrm{C}$ using 3-methyl-2-cyclohexen-1-one as the substrate using General Procedure 11 with the addition of $1 \mathrm{ml}$ THF to provide a homogenous solution. Each minute, $100 \mu \mathrm{l}$ aliquots were removed and quenched by addition to a 1:1 mixture of ethyl acetate 
and water (we previously determined that the aqueous $\beta$-boration reaction did not proceed in the presence of an immiscible solvent). The organic layer of each fraction was analyzed by GC. Each data point was the average of two trials. Data analysis and graphs were performed in Microsoft Excel 2010.

General procedure 14 for $\beta$-boration of chalcone using various chiral ligands (Scheme 4.5):

Pybox L1 (8 mg, 0.05 equiv) was added to a $10 \mathrm{ml}$ round-bottomed flask equipped with a magnetic stir bar. $3 \mathrm{ml}$ of the $1.72 \mathrm{mM}$ stock copper solution was added, followed by $200 \mu \mathrm{l}$ of THF, and the mixture was stirred for 10 minutes. Chalcone 4.1f (107 mg, 1.0 equiv) and bis(pinacolato)diboron (144 mg, 1.1 equiv) were added and washed down the flask with $400 \mu \mathrm{l}$ THF. The reaction was stirred at room temperature and monitored by TLC. Work Up Procedure 1 was used to isolate a mixture of organic components, which was concentrated and analyzed by ${ }^{1} \mathrm{H}$ NMR.

\section{General procedure 15 for oxidation of $\beta$-boronic ketone:}

The concentrated product generated by General Procedure 14 was dissolved in $3 \mathrm{ml}$ methanol and transferred to a $10 \mathrm{ml}$ round-bottomed flask equipped with a magnetic stir bar. Sodium perborate ( $257 \mathrm{mg}$, 5 equiv relative to chalcone) was added, followed by $3 \mathrm{ml}$ DI water, and the mixture was stirred for 2 hours at room temperature. The product was extracted using 3 X $5 \mathrm{ml}$ ethyl acetate. The combined organics were washed with brine, dried over sodium sulfate, filtered, and concentrated to provide a simple mixture that was analyzed by HPLC. 


\section{HPLC conditions:}

The sample was prepared to a final concentration of $1 \mathrm{mg} / \mathrm{ml}$ in the mobile phase solvent. After equilibration of the column using 95:5 / hexanes:isopropanol, $10 \mu \mathrm{l}$ of sample was injected and the solvent polarity was maintained at a ratio of $95: 5$ at a flow rate of $0.5 \mathrm{ml} / \mathrm{min}$. The retention times of the $(S)$ and $(R) \beta$-hydroxy ketones were 17.8 and 20.5 minutes, respectively.

Stereochemistry was tentatively assigned by comparison with the literature, ${ }^{20}$ but not confirmed due to unsuccessful stereo-induction.

\subsection{References for Chapter 5}

1. Dubois, L.; Fiaud, J.-C.; Kagan, H. B. Synthesis of Chiral Lithium Diatkoxyaminoborohydrides Tetrahedron 1995, 51, 3803-3812.

2. CrysAlisPro 171.33.41, Oxford Diffraction: Wroclaw, Poland, 2009.

3. SMART 5.049, Bruker AXS, Inc., Madison,. Wisconsin, USA, 1998

4. SAINT 6.45, Bruker AXS, Inc., Madison, Wisconsin, USA, 2003

5. Sheldrick, G. M., SADABS 2006/1, Bruker AXS, Inc., Madison, Wisconsin, USA, 2006

6. Sheldrick, G. M. A short history of SHELX Acta Crystallogr. A 2008, 64, 112-122.

7. Flack, H. D. On Enantiomorph-Polarity Estimation Acta Crystallogr. A 1983, 39, 876-881.

8. Hooft, R. W. W.; Straver, L. H.; Spek, A. L. Determination of Absolute Structure Using Bayesian Statistics on Bijvoet Differences J. Appl. Crystallogr. 2008, 41, 96-103.

9. Creech, G. S.; Kwon, O. Alcohol-Assisted Phosphine Catalysis: One-Step Syntheses of Dihydropyrones from Aldehydes and Allenoates Org. Lett. 2008, 10, 429-432.

10. Voutchkova, A. M.; Feliz, M.; Clot, E.; Eisenstein, O.; Crabtree, R. H. Imidazolium Carboxylates as Versatile and Selective N-Heterocyclic Carbene Transfer Agents: Synthesis, Mechanism, and Applications J. Am. Chem. Soc. 2007, 129, 12834-12846.

11. Laitar, D. S.; Tsui, E. Y.; Sadighi, J. P. Catalytic Diboration of Aldehydes via Insertion into the Copper-Boron Bond J. Am. Chem. Soc. 2006, 128, 11036-11037. 
12. Oku, A.; Abe, M.; Iwamoto, M. Electron Transfer Profile of Cyclopropanone Acetals in the Nonirradiated Reaction with Tetracyanoethylene, Chloranil, and Dicyanodichlorobenzoquinone J. Org. Chem. 1994, 59, 7445-7452.

13. Molander, G. A.; Ham, J. Synthesis of Functionalized Organotrifluoroborates via Halomethyltrifluoroborates Org. Lett. 2006, 8, 2031-2034.

14. Gao, M.; Thorpe, S. B.; Kleeberg, C.; Slebodnick, C.; Marder, T. B.; Santos, W. L. Structure and Reactivity of a Preactivated $\mathrm{sp}^{2}-\mathrm{sp}^{3}$ Diboron Reagent: Catalytic Regioselective Boration of

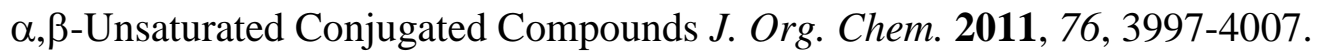

15. Mun, S.; Lee, J.-E.; Yun, J. Copper-Catalyzed $\beta$-Boration of $\alpha, \beta$-Unsaturated Carbonyl Compounds: Rate Acceleration by Alcohol Additives Org. Lett. 2006, 8, 4887-4889.

16. Gao, M.; Thorpe, S. B.; Santos, W. L. $\mathrm{sp}^{2}-\mathrm{sp}^{3}$ Hybridized Mixed Diboron: Synthesis, Characterization and Copper-Catalyzed $\beta$-Boration of $\alpha, \beta$-Unsaturated Conjugated Compounds Org. Lett. 2009, 11, 3478-3481.

17. Knott, K.; Fishovitz, J.; Thorpe, S. B.; Lee, I.; Santos, W. L. N-Terminal Peptidic Boronic Acids Selectively Inhibit Human ClpXP Org. Biomol. Chem. 2010, 8, 3451-3456.

18. Takahashi, K.; Ishiyama, T.; Miyaura, N. A Borylcopper Species Generated from Bis(pinacolato)diboron and its Additions to $\alpha, \beta$-Unsaturated Carbonyl Compounds and Terminal Alkynes J. Organomet. Chem. 2001, 625, 47-53.

19. Hirano, K.; Yorimitsu, H.; Oshima, K. Nickel-Catalyzed $\beta$-Boration of $\alpha, \beta$-Unsaturated Esters and Amides with Bis(pinacolato)diboron Org. Lett. 2007, 9, 5031-5033.

20. Sim, H.-S.; Feng, X.; Yun, J. Copper-Catalyzed Enantioselective $\beta$-Boration of Acyclic Enones Chem. Eur. J. 2009, 15, 1939-1943. 